\title{
LIMNOLOGIA DO RIO BETARI (IPORANGA-SP) E A RELAÇÃO COM O ESTADO DE CONSERVAÇÃO DE SUA BACIA HIDROGRÁFICA - SUBSÍDIOS PARA O DESENVOLVIMENTO SUSTENTÁVEL
}

Mário Donizeti Domingos

Tese apresentada à Escola de Engenharia de São Carlos, da Universidade de São Paulo, como parte dos requisitos para obtenção do título de Doutor em Ciências da Engenharia Ambiental.

ORIENTADORA: Prof ${ }^{a}$. Assoc. Maria do Carmo Calijuri

SÃO CARLOS - SP 2002 
"Os dias que esses homens passam nas montanhas são os dias que realmente vivem. Quando as cabeças se limpam de teias de aranha e o sangue corre com força pelas veias. Quando os cinco sentidos cobram vitalidade e o homem completo se torna mais sensível, e então já pode ouvir as vozes da natureza e ver as belezas que só estavam ao alcance dos mais ousados."

Reinhold Messner 
À minha esposa Luciana e aos meus filhos Isabela e Cauan. 


\section{RESUMO}

DOMINGOS, M.D. (2002). Limnologia do rio Betari (Iporanga-SP) e a relação com o estado de conservação de sua bacia hidrográfica - subsídios para o desenvolvimento sustentável. São Carlos, 2002, 272 p. Tese de Doutorado em Ciências da Engenharia Ambiental - Escola de Engenharia de São Carlos, Universidade de São Paulo.

A bacia do rio Betari, localizada em uma das poucas áreas ainda preservadas do Estado de São Paulo, apresenta características particulares quanto a sua geologia e geomorfologia (carste) e a Mata Atlântica, ainda preservada. Também é importante o fluxo de turistas que tem aumentado, provocando uma ocupação sem planejamento. Parte da bacia é ocupada pelo Parque Estadual Turístico do Alto Ribeira - PETAR. Com o objetivo de caracterizar o rio Betari e sua bacia hidrográfica, relacionar as características limnológicas do rio com o uso e ocupação do solo e determinar os impactos do turismo no bairro da Serra, para obter um diagnóstico ambiental da bacia e fornecer subsídios para seu desenvolvimento sustentável, foram feitas coletas em quatro estações do ano, em 14 pontos ao longo do rio. Nesses pontos, foram analisados o sedimento e as características hidráulicas, físicas e químicas e biológicas da água. Também foram utilizados sensoriamento remoto e geoprocessamento para integração das informações sobre a bacia hidrográfica e o corpo d'água. Foram, ainda realizadas análises estatísticas para a determinação de grupos, entre os pontos de coleta, com similaridades ou descontinuidades quanto aos dados obtidos. Um estudo dos impactos econômicos e sócio-culturais foi realizado no bairro da Serra, principal agrupamento humano na bacia. Os resultados mostram a existência de uma homogeneidade espacial dos parâmetros físicos e químicos analisados no rio. As características geológicas da bacia (carste) parecem exercer grande influência nos parâmetros hidrológicos analisados. A qualidade da água é boa, demonstrando que a ação antrópica ainda não comprometeu o sistema lótico, apesar da existência de metais pesados no sedimento, reflexo dos rejeitos das atividades minerárias presentes na área. A bacia hidrográfica, por sua vez, não apresentou grandes alterações na sua cobertura vegetal nos últimos anos. A comunidade bentônica apresentou variação temporal e espacial e, aparentemente, os fatores hidráulicos e as características do canal foram os principais determinantes destas variações. Os impactos econômicos e sócio-culturais do turismo, positivos e negativos, foram detectados sobre a população residente. Aparentemente, a comunidade Serrana passa por um período de euforia, graças aos benefícios econômicos propiciados pela atividade turística, porém a falta de planejamento pode comprometer a atividade e os ecossistemas regionais, impedindo, assim, o desenvolvimento sustentável.

PALAVRAS-CHAVE: ecologia de rios, macrofauna bentônica, impactos do turismo, rio Betari, Parque Estadual Turístico do Alto Ribeira, bacia hidrográfica 


\begin{abstract}
DOMINGOS, M.D. (2002). Limnology of the Betari River (Iporanga-SP) and the relation with the conservation state of its hydrographic basin - subsidiaries for a sustainable development. São Carlos, 2002, 272 p. Tese de Doutorado em Ciências da Engenharia Ambiental - Escola de Engenharia de São Carlos, Universidade de São Paulo.
\end{abstract}

The Betari River basin, localized in one of the few areas still preserved in the São Paulo Sate, presents particular characteristics regarding its geology and geomorphology and the Atlantic Forest, still preserved. The increasing flow of tourists is also important, provoking a plan less occupation of the area. Part of the basin is occupied by the Parque Estadual Turístico do Alto Ribeira - PETAR. With the objective of characterizing the Betari River and its hydrographic basin, relate the river's limnologic characteristics with the use and occupation of the land and determine the impact of tourism in the Serra borough, to obtain an environmental diagnostic of the basin and supply subsidiaries for its sustainable development, samples were collected in 4 seasons of the year, in 14 points throughout the river. In these points, sedimentation and hydraulic, physical, chemical and biological characteristics of the water were studied. Remote sensoring and geo-processing were also used to integrate information about the hydrographic basin and the body of water. Statistical analyses were then carried out to determine groups. A study of the economic and social-cultural impact was carried out in the Serra borough, the main human settlement in the basin. The results show an existence of spatial homogeneity in the physical and chemical parameters analyzed in the river. The geological characteristics of the basin seem to have a great influence in the hydrological parameters analyzed. The quality of the water is good, showing that the antropic action has not yet compromised the lotic system, despite the existence of heavy metals in sediment, a reflex of the rejects of mineral activities present in the area. The hydrographic basin did not present great changes in its vegetation in the last few years. The bentonic community presented temporal and special variation and, apparently, the hydraulic factors and the canal's characteristics were the main determiners of these variations. The economical and social-cultural impacts of tourism, positive or negative, were detected on the residing population. Apparently, the Serrana community passes through a euphoric period, thanks to the economical benefits brought by the tourist activity; however, the lack of planning can compromise the activity and these regional ecosystems, impeding, this way the sustainable development.

Keywords: river ecology, Betari river, watershed, bentonic community, impacts of tourism. 
SUMÁRIO

LISTA DE FIGURAS .................................................................................

LISTA DE TABELAS................................................................................

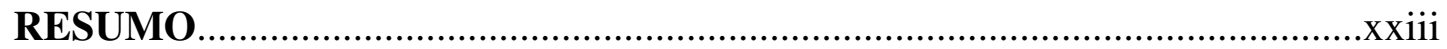

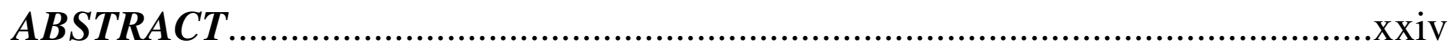

INTRODUÇÃO

REFERÊNCIAS BIBLIOGRÁFICAS............................................................

CAPÍTULO I. A ÁREA DE ESTUDO: BACIA HIDROGRÁFICA DO RIO BETARI. .004

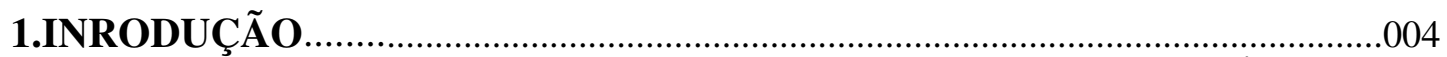

1.1. PLANEJAMENTO E GESTÃO DE BACIAS HIDROGRÁFICAS004

1.2. ESTADO DA ARTE. .009

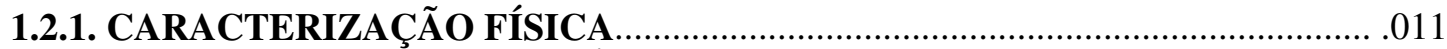

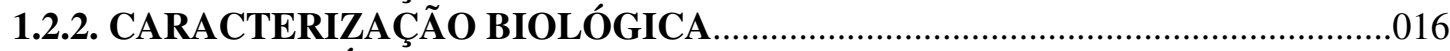

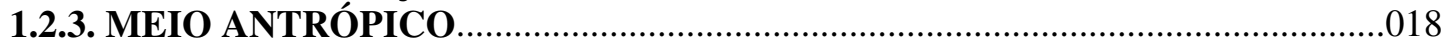

1.2.3.1. O Bairro da Serra ............................................................................

1.2.3.2. O Parque Estadual Turístico do Alto Ribeira...........................................

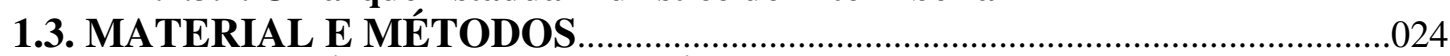

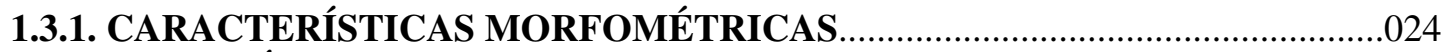

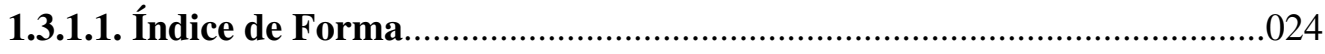

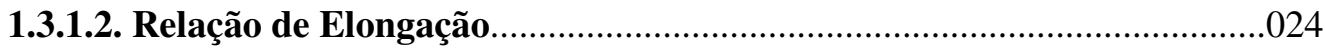

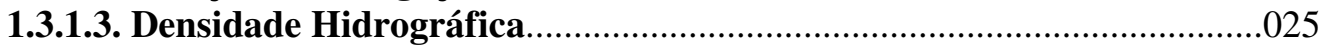

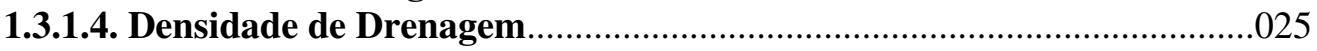

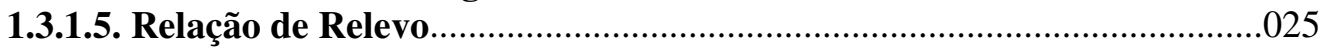

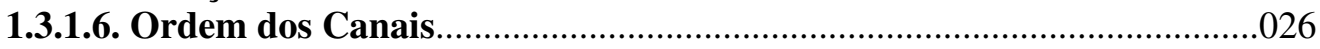

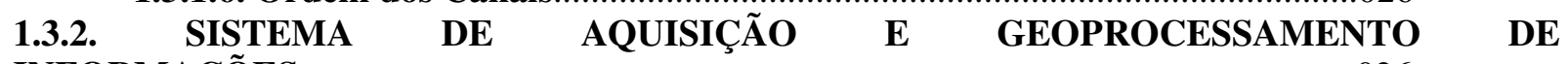

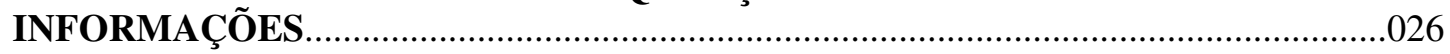

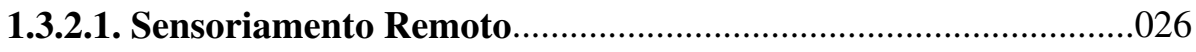

1.3.2.2. Sistema de Informações Geográficas...........................................027

1.4. RESULTADOS.

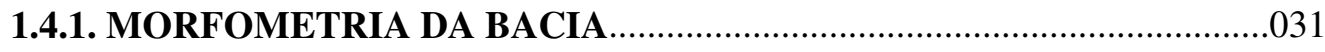

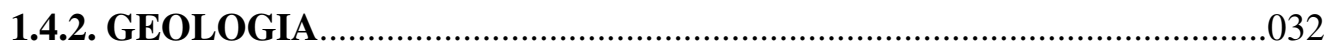

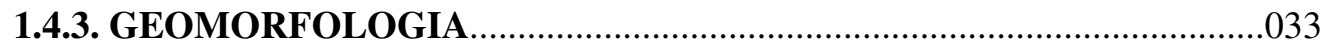

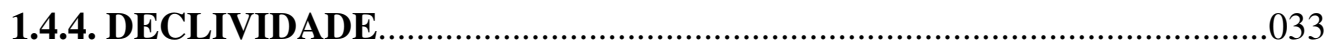

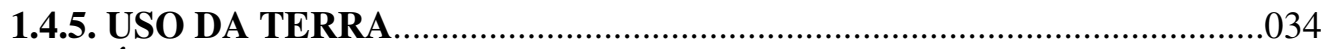

1.4.6. ÁREAS PROTEGIDAS...……………………………………………......

1.5. DISCUSS ÃO

1.6. SUMÁRIO

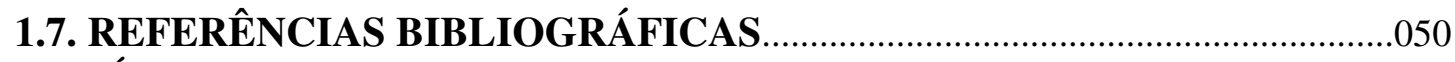

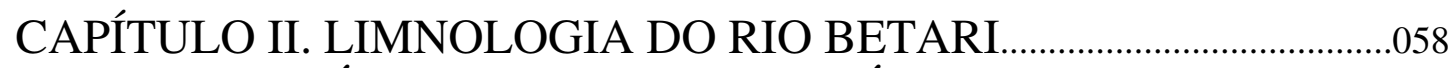

2.1. CARACTERÍSTICAS DOS SISTEMAS LÓTICOS........................................

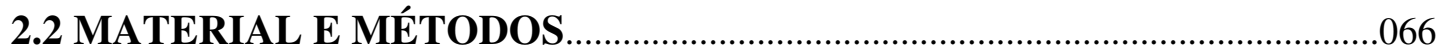

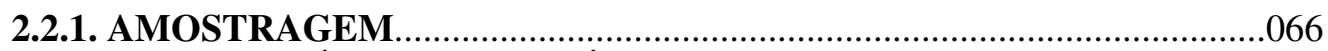

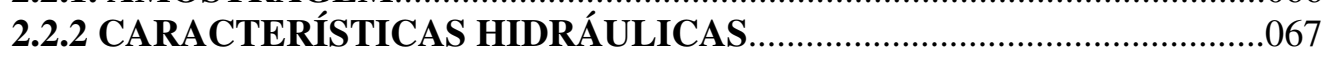

2.2.2.1. Vazão e Velocidade da Corrente...................................................667 


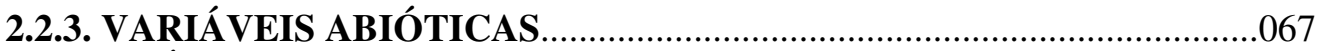

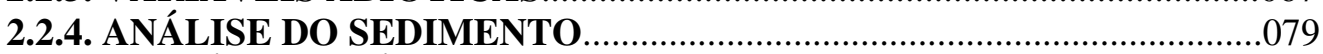

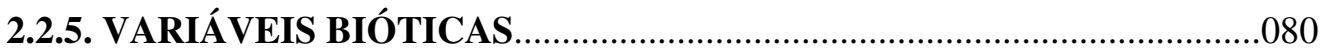

2.2.5.1. Colimetria

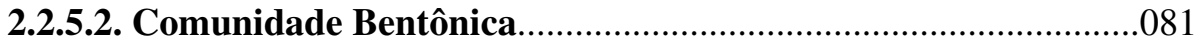

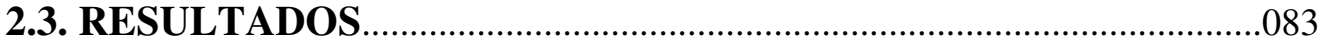

2.3.1. PRIMEIRA CAMPANHA DE AMOSTRAGEM (JANEIRO DE 2000). 083

2.3.1.1. Velocidade de Escoamento e Vazão.............................................083

2.3.1.2. Variáveis Físicas e Químicas da Água...........................................084

2.3.1.3. Análise Numérica........................................................................097

2.3.2. SEGUNDA CAMPANHA DE AMOSTRAGEM (ABRILDE 2000)........099

2.3.2.1. Velocidade de Escoamento e Vazão.............................................099

2.3.2.2. Variáveis Físicas e Químicas da Água..........................................100

2.3.2.3. Análise Numérica.......................................................................111

2.3.3. TERCEIRA CAMPANHA DE AMOSTRAGEM (JULHO DE 2000).....113

2.3.3.1. Velocidade de Escoamento e Vazão..........................................113

2.3.3.2. Variáveis Físicas e Químicas da Água..........................................114

2.3.3.3. Análise Numérica......................................................................124

2.3.4. QUARTA CAMPANHA DE AMOSTRAGEM (OUTUBRO DE 2000)..126

2.3.4.1. Velocidade de Escoamento e Vazão.............................................126

2.3.4.2. Variáveis Físicas e Químicas da Água.........................................127

2.3.4.3. Análise Numérica.....................................................................137

2.3.5. ANÁLISE SAZONAL DAS VARIÁVEIS LIMNOLÓGICAS...................139

2.3.5.1. pH, Condutividade, Alcalinidade e $\mathrm{CO}_{2}$ Total...........................139

2.3.5.2. Oxigênio dissolvido …………………………………………......141

2.3.5.3. Sólidos em suspensão orgânicos e inorgânicos..............................142

2.3.5.4. Temperatura da água .................................................................144

2.3.5.5. Demanda bioquímica de oxigênio.................................................144

2.3.5.6. Nutrientes dissolvidos e totais na água..........................................145

2.3.6. VARIÁVEIS QUÍMICAS DO SEDIMENTO ............................................

2.3.6.1. Nitrogênio e fósforo do sedimento.................................................150

2.3.6.2. Ìons do sedimento

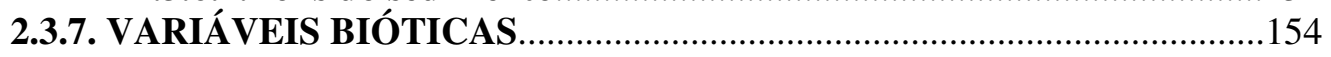

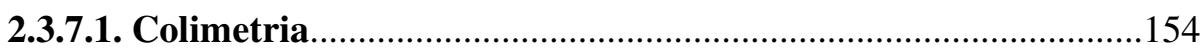

2.3.7.2. Comunidade Bentônica................................................................154

2.4. DISCUSSÃ O

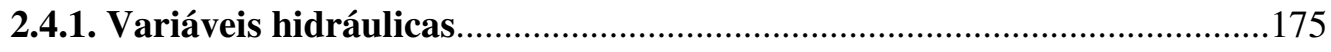

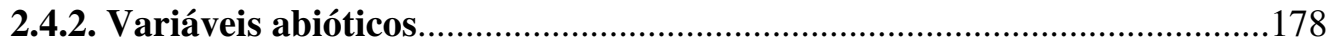

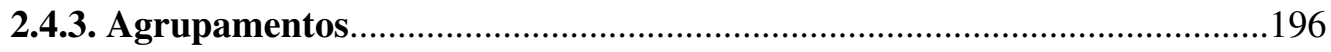

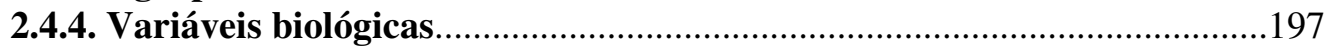

2.4.5. Sedimento

2.5. SUMÁRIO

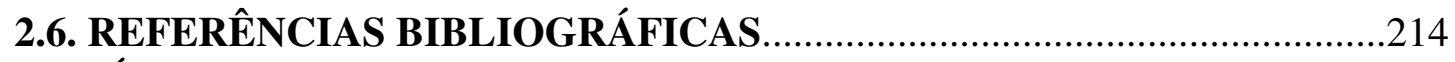

CAPÍTULO III. O TURISMO NO BAIRRO DA SERRA..............................226

3.1. TURISMO: IMPACTOS E SUSTENTABILIDADE......................................226

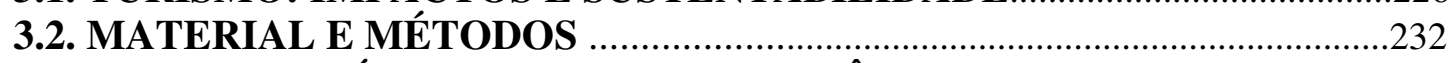

3.2.1. IMPACTOS SÓCIO-CULTURAIS E ECONÔMICOS DO TURISMO_...............232

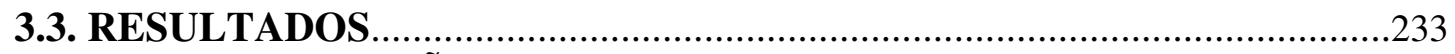

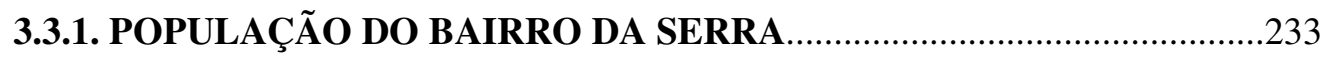




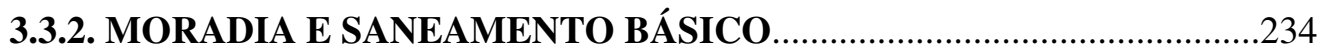

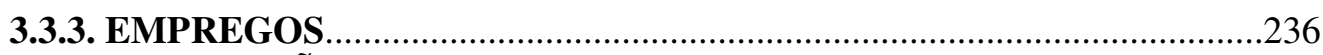

3.3.4. POPULAÇÃO RESIDENTE E TURISMO ..........................................237

3.3.5. NECESSIDADES DA POPULAÇÃO RESIDENTE...............................238

3.4. DISCUSSÃO

3.4.1 PROPOSTAS PARA O DESENVOLVIMENTO SUSTENTÁVEL DO TURISMO NO BAIRRO DA SERRA .254

3.5. SUMÁRIO. 259

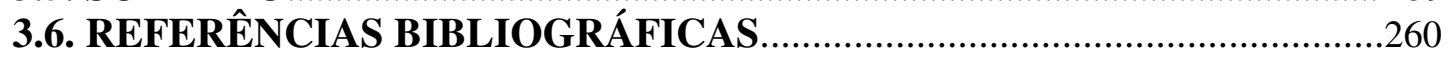

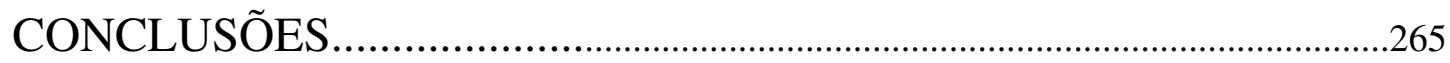

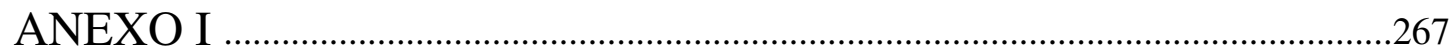




\section{LISTA DE FIGURAS}

FIGURA 1.2.1. Localização da bacia hidrográfica do rio Betari no estado de São Paulo, com destaque para área do Parque Estadual Turístico do Alto Ribeira 12

FIGURA 1.2.2. Rejeito da mina Furnas que drena para o córrego Furnas, afluente do rio Betari 13

FIGURA 1.4.1. Bacia hidrográfica do rio Betari com rede hidrográfica, pontos de coleta e minerações paralisadas. 40

FIGURA 1.4.2. Unidades lito-estratigráficas da bacia hidrográfica do rio Betari com pontos de coleta e rede hidrográfica. 41

FIGURA 1.4.3. Feições morfológicas da bacia hidrográfica do rio Betari com pontos de coleta e rede hidrográfica. 42

FIGURA 1.4.4. Declividade da bacia hidrográfica do rio Betari com pontos de coleta e rede hidrográfica. 43

FIGURA 1.4.5.1. Imagem de satélite LANDSAT TM-345 de 1986 com limites da bacia hidrográfica do rio Betari e do Parque Estadual Turístico do Alto Ribeira (PETAR) 44

FIGURA 1.4.5.2. Imagem de satélite LANDSAT TM-345 de 2000 com limites da bacia hidrográfica do rio Betari e do Parque Estadual Turístico do Alto Ribeira (PETAR) 45

FIGURA 1.4.5.3. Uso e ocupação da terra em 1986 na bacia hidrográfica do rio Betari e rede hidrográfica. .46

FIGURA 1.4.5.4. Uso e ocupação da terra em 2000 na bacia hidrográfica do rio Betari e rede hidrográfica. .47

FIGURA 1.4.6. Áreas sob proteção legal da bacia hidrográfica do rio Betari. 48

FIGURA 2.1. Relação entre tamanho do canal e mudança progressiva nos atributos funcionais e estruturais de ecossistemas lóticos. Adaptado de VANNOTE et al. (1980). (CPOM - Materia orgánica particulada grosseira $(>1 \mathrm{~mm})$. FPOM - Matéria orgânica particulada fina $(50 \mu \mathrm{m}$

$1 \mathrm{~mm})$ 
FIGURA 2.2.2. Esquema da localização dos pontos de amostragem no rio Betari, com principais afluentes .68

FIGURA 2.2.3. Ponto de coleta 1: Rio Betari (trecho de $3^{\circ}$ ordem), antes da confluência com rio Passa Vinte. .69

FIGURA 2.2.4. Ponto de coleta 2: Rio Passa Vinte (trecho de $3^{\circ}$ ordem), antes da confluência com rio Betari 69

FIGURA 2.2.5. Ponto de coleta 3: Rio Betari (trecho de $4^{\circ}$ ordem), a jusante da confluência dos rios Betari e Passa Vinte. 70

FIGURA 2.2.6. Ponto de coleta 4: Rio Betari (trecho de $4^{\circ}$ ordem), antes da ressurgência do rio Água Suja .70

FIGURA 2.2.7. Ponto de coleta 5: Rio Betari (trecho de $4^{\circ}$ ordem), a jusante do rio Água Suja e a montante do Núcleo Santana do PETAR. 71

FIGURA 2.2.8. Ponto de coleta 6: Rio Betari (trecho de $4^{\circ}$ ordem), após entrada do rio Roncador que ressurge da caverna Santana. 72

FIGURA 2.2.9. Ponto de coleta 7: Córrego Furnas (trecho de $3^{\circ}$ ordem), proveniente da extinta mineração de chumbo onde existem rejeitos de lavra ainda expostos. 73

FIGURA 2.2.10. Ponto de coleta 8: Rio Betari (trecho de $4^{\circ}$ ordem), após entrada dos córregos Furnas e Couto, e após área de influência antrópica do Núcleo Santana PETAR 74

FIGURA 2.2.11. Ponto de coleta 9: Rio Betari (trecho de $4^{\circ}$ ordem), antes do bairro da Serra....... 75

FIGURA 2.2.12. Ponto de coleta 10: Rio Betari (trecho de $4^{\circ}$ ordem), após a entrada dos córregos Seco, Ouro Grosso e Jaguatirica, no bairro da Serra. 75

FIGURA 2.2.13. Ponto de coleta 11: Rio Betari (trecho de $4^{\circ}$ ordem), no final do bairro da Serra, após a entrada de córregos menores que drenam o bairro e do rio Alambari..... .76

FIGURA 2.2.14. Ponto de coleta 12: Rio Betari (trecho de $4^{\circ}$ ordem), após entrada do córrego do Sem Fim e antes da ponte da estrada que liga Iporanga a Apiaí..... 
FIGURA 2.2.15. Ponto de coleta 13: Rio Betari (trecho de $4^{\circ}$ ordem), após a entrada do córrego do Betari, que drena o bairro do Betari e localiza-se dentro da Fazenda Betari. .77

FIGURA 2.2.16. Ponto de coleta 14: Rio Betari (trecho de $4^{\circ}$ ordem), após a entrada dos córregos do Fria e Arapongas, antes da foz no rio Ribeira de Iguape. 78

FIGURA 2.3.1.1. Variação da velocidade da corrente $\left(\mathrm{m}_{\mathrm{s}} \mathrm{s}^{-1}\right)$ ao longo do eixo longitudinal do rio Betari, no período de 16/01/00 a 18/01/00 .84

FIGURA 2.3.1.2. Variação da vazão $\left(\mathrm{m}^{3} \cdot \mathrm{s}^{-1}\right)$ ao longo do eixo longitudinal do rio Betari, no período de 16/01/00 a 18/01/00. .84

FIGURA 2.3.1.2.1.1. Variação dos valores de pH no rio Betari no período de 16/01/00 a 20/01/00. .85

FIGURA 2.3.1.2.1.2. Variação dos valores de condutividade $\left(\mu \mathrm{S} . \mathrm{cm}^{-1}\right)$ no rio Betari, no período de 16/01/00 a 20/01/00 85

FIGURA 2.3.1.2.1.3. Variação da alcalinidade (meq.L ${ }^{-1}$ ) nas estações do rio Betari, no período de 16/01/00 a 20/01/00. .86

FIGURA 2.3.1.2.1.4. Variação das concentrações de $\left(\mathrm{CO}_{2}\right)$ total $\left(\mathrm{mmol} . \mathrm{L}^{-1}\right)$ no rio Betari, no período de 16/01/00 a 20/01/00. .87

FIGURA 2.3.1.2.1.5. Variação das concentrações de $\left(\mathrm{CO}_{2}\right)$ livre $\left(\mathrm{mmol} . \mathrm{L}^{-1}\right)$ no rio Betari, no período de 16/01/00 a 20/01/00. .87

FIGURA 2.3.1.2.1.6. Variação das concentrações de $\left(\mathrm{HCO}_{3}{ }^{-}\right)\left(\mathrm{mmol} . \mathrm{L}^{-1}\right)$ no rio Betari, no período de 16/01/00 a 20/01/00 88

FIGURA 2.3.1.2.1.7. Variação das concentrações de $\left(\mathrm{CO}_{3}{ }^{2-}\right)\left(\mathrm{mmol} . \mathrm{L}^{-1}\right)$ no rio Betari, no período de 16/01/00 a 20/01/00. 88

FIGURA 2.3.1.2.2. Variação das concentrações de oxigênio dissolvido $\left(\mathrm{mg} . \mathrm{L}^{-1}\right)$ no rio Betari, no período de 16/01/00 a 20/01/00 .89

FIGURA 2.3.1.2.3.1. Variação dos valores de turbidez (UNT) no rio Betari, no período de $16 / 01 / 00$ a $20 / 01 / 00$ .90

FIGURA 2.3.1.2.3.2. Variação das concentrações de sólidos em suspensão inorgânicos (mg. $\mathrm{L}^{-1}$ ) no rio Betari, no período de 16/01/00 a 20/01/00 .90

FIGURA 2.3.1.2.3.3. Variação das concentrações de sólidos em suspensão orgânicos (mg.L $\mathrm{L}^{-1}$ ) no rio Betari, no período de 16/01/00 a 20/01/00 .91 
FIGURA 2.3.1.2.4. Variação da temperatura da água $\left({ }^{\circ} \mathrm{C}\right)$ no rio Betari, no período de $16 / 01 / 00$ a 20/01/00. .92

FIGURA 2.3.1.2.5. Variação da demanda bioquímica de oxigênio (mg.L $\mathrm{L}^{-1}$ ) no rio Betari, no período de 16/01/00 a 20/01/00. .92

FIGURA 2.3.1.2.6.1. Variação das concentrações de nitrogênio amoniacal $\left(\mu g . L^{-1}\right)$ no rio Betari, no período de $16 / 01 / 00$ a 20/01/00...... 93

FIGURA 2.3.1.2.6.2. Variação das concentrações de nitrato $\left(\mu \mathrm{g} . \mathrm{L}^{-1}\right)$ no rio Betari, no período de 16/01/00 a 20/01/00. 93

FIGURA 2.3.1.2.6.3. Variação das concentrações de nitrito (ì $\mathrm{gL}^{-1}$ ) no rio Betari, no período de 16/01/00 a 20/01/00. . .94

FIGURA 2.3.1.2.6.4. Variação das concentrações de nitrogênio orgânico total (mg.L ${ }^{-}$ $\left.{ }^{1}\right)$ no rio Betari, no período de 16/01/00 a 20/01/00. .94

FIGURA 2.3.1.2.6.5. Variação das concentrações de fosfato inorgânico (I g. $\mathrm{L}^{-1}$ ) no rio Betari, no período de 16/01/00 a 20/01/00. 95

FIGURA 2.3.1.2.6.6. Variação das concentrações de fosfato total dissolvido (i $\mathrm{gL}^{-1}$ ) no rio Betari, no período de 16/01/00 a 20/01/00. 95

FIGURA 2.3.1.2.6.7. Variação das concentrações de fósforo total (ì $g \mathrm{~L}^{-1}$ ) no rio Betari, no período de 16/01/00 a 20/01/00. 96

FIGURA 2.3.1.2.6.8. Variação das concentrações de silicato reativo (mg. $\mathrm{L}^{-1}$ ) no rio Betari, no período de 16/01/00 a 20/01/00 .96

FIGURA 2.3.1.3. Dendrograma da análise de agrupamento das medidas médias das variáveis físicas e químicas da água nas estações do rio Betari em janeiro de 2000. .98

FIGURA 2.3.2.1.1. Variação da velocidade da corrente $\left(\mathrm{m}_{\mathrm{s}} \mathrm{s}^{-1}\right)$ ao longo do eixo longitudinal do rio Betari, no período de15/04/00 a 19/04/00. .99

FIGURA 2.3.2.1.2. Variação da vazão $\left(\mathrm{m}^{3} \cdot \mathrm{s}^{-1}\right)$ ao longo do eixo longitudinal do rio Betari, no período de15/04/00 a 19/04/00. 100

FIGURA 2.3.2.2.1.1. Variação dos valores de $\mathrm{pH}$ no rio Betari no período de 15/04/00 a $19 / 04 / 00$. 101 
FIGURA 2.3.2.2.1.2. Variação dos valores de condutividade $\left(\mu \mathrm{S} . \mathrm{cm}^{-1}\right)$ no rio Betari, no período de 15/04/00 a 19/04/00. 101

FIGURA 2.3.2.2.1.3. Variação da alcalinidade (meq.L ${ }^{-1}$ ) nas estações do rio Betari, no período de 15/04/00 a 19/04/00. 102

FIGURA 2.3.2.2.1.4. Variação das concentrações de $\left(\mathrm{CO}_{2}\right)$ total $\left(\mathrm{mmol} . \mathrm{L}^{-1}\right)$ no rio Betari, no período de 15/04/00 a 19/04/00. 102

FIGURA 2.3.2.2.1.5. Variação das concentrações de $\left(\mathrm{CO}_{2}\right)$ livre $\left(\mathrm{mmol} . \mathrm{L}^{-1}\right)$ no rio Betari, no período de 15/04/00 a 19/04/00. 103

FIGURA 2.3.2.2.1.6. Variação das concentrações de $\left(\mathrm{HCO}_{3}{ }^{-}\right)\left(\mathrm{mmol} . \mathrm{L}^{-1}\right)$ no rio Betari, no período de 15/04/00 a 19/04/00 103

FIGURA 2.3.2.2.1.7. Variação das concentrações de $\left(\mathrm{CO}_{3}{ }^{2-}\right)\left(\mathrm{mmol} . \mathrm{L}^{-1}\right)$ no rio Betari, no período de 15/04/00 a 19/04/00. 104

FIGURA 2.3.2.2.2. Variação das concentrações de oxigênio dissolvido (mg. $\left.\mathrm{L}^{-1}\right)$ no rio Betari, no período de 15/04/00 a 19/04/00. 104

FIGURA 2.3.2.2.3.1. Variação das concentrações de sólidos em suspensão inorgânicos $\left(\mathrm{mg} \cdot \mathrm{L}^{-1}\right)$ no rio Betari, no período de 15/04/00 a $19 / 04 / 00$ 105

FIGURA 2.3.2.2.3.2. Variação das concentrações de sólidos em suspensão orgânicos $\left(\mathrm{mg} . \mathrm{L}^{-1}\right)$ no rio Betari, no período de 15/04/00 a $19 / 04 / 00$ 105

FIGURA 2.3.2.2.4. Variação da temperatura da água $\left({ }^{\circ} \mathrm{C}\right)$ no rio Betari, no período de $15 / 04 / 00$ a $19 / 04 / 00$ 106

FIGURA 2.3.2.2.5. Variação da demanda bioquímica de oxigênio (mg.L $\left.\mathrm{L}^{-1}\right)$ no rio Betari, no período de 15/04/00 a 19/04/00. 106

FIGURA 2.3.2.2.6.1. Variação das concentrações de nitrogênio amoniacal $\left(\mu g . L^{-1}\right)$ no rio Betari, no período de 15/04/00 a 19/04/00. 107

FIGURA 2.3.2.2.6.2. Variação das concentrações de nitrato $\left(\mu \mathrm{g} . \mathrm{L}^{-1}\right)$ no rio Betari, no período de 15/04/00 a 19/04/00 107

FIGURA 2.3.2.2.6.3. Variação das concentrações de nitrito (ì $\mathrm{gL}^{-1}$ ) no rio Betari, no período de 15/04/00 a 19/04/00. 108 
FIGURA 2.3.2.2.6.4. Variação das concentrações de nitrogênio orgânico total (mg.L'

$\left.{ }^{1}\right)$ no rio Betari, no período de 15/04/00 a 19/04/00. 108

FIGURA 2.3.2.2.6.5. Variação das concentrações de fosfato inorgânico (ì $\mathrm{gL}^{-1}$ ) no rio Betari, no período de 15/04/00 a 19/04/00. 109

FIGURA 2.3.2.2.6.6. Variação das concentrações de fosfato total dissolvido (î $\mathrm{gL}^{-1}$ ) no rio Betari, no período de 15/04/00 a 19/04/00. 109

FIGURA 2.3.2.2.6.7. Variação das concentrações de fósforo total (ì $g \mathrm{~L}^{-1}$ ) no rio Betari, no período de 15/04/00 a 19/04/00. 110

FIGURA 2.3.2.2.6.8. Variação das concentrações de silicato reativo $\left(\mathrm{mg} . \mathrm{L}^{-1}\right)$ no rio Betari, no período de 15/04/00 a 19/04/00. 110

FIGURA 2.3.2.3. Dendrograma da análise de agrupamento das medidas médias das variáveis físicas e químicas da água nas estações do rio Betari em abril de 2000.. 112

FIGURA 2.3.3.1.1. Variação da velocidade da corrente $\left(\mathrm{m}_{\mathrm{s}} \mathrm{s}^{-1}\right)$ ao longo do eixo longitudinal do rio Betari, no período de 22/07/00 a 25/07/00...... 113

FIGURA 2.3.3.1.2. Variação da vazão $\left(\mathrm{m}^{3} \cdot \mathrm{s}^{-1}\right)$ ao longo do eixo longitudinal do rio Betari, no período de 22/07/00 a 25/07/00. .113

FIGURA 2.3.3.2.1.1. Variação dos valores de $\mathrm{pH}$ no rio Betari no período de 21/07/00 a $25 / 07 / 00$. .114

FIGURA 2.3.3.2.1.2. Variação dos valores de condutividade $\left(\mu \mathrm{S} . \mathrm{cm}^{-1}\right)$ no rio Betari, no período de 21/07/00 a 25/07/00. 114

FIGURA 2.3.3.2.1.3. Variação da alcalinidade (meq. L $^{-1}$ ) nas estações do rio Betari, no período de 21/07/00 a 25/07/00. 115

FIGURA 2.3.3.2.1.4. Variação das concentrações de $\left(\mathrm{CO}_{2}\right)$ total $\left(\mathrm{mmol} . \mathrm{L}^{-1}\right)$ no rio Betari, no período de 21/07/00 a 25/07/00. 115

FIGURA 2.3.3.2.1.5. Variação das concentrações de $\left(\mathrm{CO}_{2}\right)$ ( livre $\left(\mathrm{mmol} . \mathrm{L}^{-1}\right)$ no rio Betari, no período de 21/07/00 a 25/07/00. 116

FIGURA 2.3.3.2.1.6. Variação das concentrações de $\left(\mathrm{HCO}_{3}{ }^{-}\right)\left(\mathrm{mmol} . \mathrm{L}^{-1}\right)$ no rio Betari, no período de 21/07/00 a 25/07/00. 116

FIGURA 2.3.3.2.1.7. Variação das concentrações de $\left(\mathrm{CO}_{3}{ }^{2-}\right)\left(\mathrm{mmol} . \mathrm{L}^{-1}\right)$ no rio Betari, no período de 21/07/00 a 25/07/00. 117 
FIGURA 2.3.3.2.2. Variação das concentrações de oxigênio dissolvido (mg. $\left.\mathrm{L}^{-1}\right)$ no rio Betari, no período de 21/07/00 a 25/07/00. 117

FIGURA 2.3.3.2.3.1. Variação das concentrações de sólidos em suspensão inorgânicos (mg.L ${ }^{-1}$ ) no rio Betari, no período de 21/07/00 a 25/07/00........118

FIGURA 2.3.3.2.3.2. Variação das concentrações de sólidos em suspensão orgânicos (mg. $\mathrm{L}^{-1}$ ) no rio Betari, no período de 21/07/00 a 25/07/00...........118

FIGURA 2.3.3.2.4. Variação da temperatura da água $\left({ }^{\circ} \mathrm{C}\right)$ no rio Betari, no período de $21 / 07 / 00$ a $25 / 07 / 00$. 119

FIGURA 2.3.3.2.5. Variação da demanda bioquímica de oxigênio (mg. $\mathrm{L}^{-1}$ ) no rio Betari, no período de 21/07/00 a 25/07/00. 119

FIGURA 2.3.3.2.6.1. Variação das concentrações de nitrogênio amoniacal $\left(\mu \mathrm{g} . \mathrm{L}^{-1}\right)$ no rio Betari, no período de 21/07/00 a 25/07/00. 120

FIGURA 2.3.3.2.6.2. Variação das concentrações de nitrato $\left(\mu \mathrm{g} . \mathrm{L}^{-1}\right)$ no rio Betari, no período de 21/07/00 a 25/07/00. 120

FIGURA 2.3.3.2.6.3. Variação das concentrações de nitrito (ì $\mathrm{gL}^{-1}$ ) no rio Betari, no período de 21/07/00 a 25/07/00. 121

FIGURA 2.3.3.2.6.4. Variação das concentrações de nitrogênio orgânico total (mg.L${ }^{1}$ ) no rio Betari, no período de 21/07/00 a 25/07/00. .121

FIGURA 2.3.3.2.6.5. Variação das concentrações de fosfato inorgânico (ì $\mathrm{gL}^{-1}$ ) no rio Betari, no período de 21/07/00 a 25/07/00. 122

FIGURA 2.3.3.2.6.6. Variação das concentrações de fosfato total dissolvido (ì $\mathrm{gL}^{-1}$ ) no rio Betari, no período de 21/07/00 a 25/07/00. 122

FIGURA 2.3.3.2.6.7. Variação das concentrações de fósforo total (ì $\mathrm{gL}^{-1}$ ) no rio Betari, no período de 21/07/00 a 25/07/00. 123

FIGURA 2.3.3.2.6.8. Variação das concentrações de silicato reativo (mg.L ${ }^{-1}$ ) no rio Betari, no período de 21/07/00 a 25/07/00. .123

FIGURA 2.3.3.3. Dendrograma da análise de agrupamento das medidas médias das variáveis físicas e químicas da água nas estações do rio Betari em julho de 2000 . 125

FIGURA 2.3.4.1.1. Variação da velocidade da corrente $\left(\mathrm{m}_{\mathrm{s}} \mathrm{s}^{-1}\right)$ ao longo do eixo longitudinal do rio Betari, no período de 15/10/00 a 18/10/00. 126 
FIGURA 2.3.4.1.2. Variação da vazão $\left(\mathrm{m}^{3} \cdot \mathrm{s}^{-1}\right)$ ao longo do eixo longitudinal do rio Betari, no período de 15/10/00 a 18/10/00. 127

FIGURA 2.3.4.2.1.1. Variação dos valores de $\mathrm{pH}$ no rio Betari no período de 15/10/00 a 19/10/00. 127

FIGURA 2.3.4.2.1.2. Variação dos valores de condutividade $\left(\mu{\mathrm{S} . \mathrm{cm}^{-1}}^{-1}\right)$ no rio Betari, no período de 15/10/00 a 19/10/00. 128

FIGURA 2.3.4.2.1.3. Variação da alcalinidade (meq. $\mathrm{L}^{-1}$ ) nas estações do rio Betari, no período de 15/10/00 a 19/10/00. 128

FIGURA 2.3.4.2.1.4. Variação das concentrações de $\left(\mathrm{CO}_{2}\right)$ total $\left(\mathrm{mmol} . \mathrm{L}^{-1}\right)$ no rio Betari, no período de 15/10/00 a 19/10/00. 129

FIGURA 2.3.4.2.1.5. Variação das concentrações de $\left(\mathrm{CO}_{2}\right)$ livre $\left(m m o l . L^{-1}\right)$ no rio Betari, no período de 15/10/00 a 19/10/00. 129

FIGURA 2.3.4.2.1.6. Variação das concentrações de $\left(\mathrm{HCO}_{3}{ }^{-}\right)\left(\mathrm{mmol}^{-\mathrm{L}^{-1}}\right)$ no rio Betari, no período de 15/10/00 a 19/10/00. 129

FIGURA 2.3.4.2.1.7. Variação das concentrações de $\left(\mathrm{CO}_{3}{ }^{2-}\right)\left(\mathrm{mmol} . \mathrm{L}^{-1}\right)$ no rio Betari, no período de 15/10/00 a 19/10/00. 130

FIGURA 2.3.4.2.2. Variação das concentrações de oxigênio dissolvido (mg. $\left.\mathrm{L}^{-1}\right)$ no rio Betari, no período de 15/10/00 a 19/10/00. 130

FIGURA 2.3.4.2.3.1. Variação das concentrações de sólidos em suspensão inorgânicos (mg. $\mathrm{L}^{-1}$ ) no rio Betari, no período de 15/10/00 a 19/10/00........131

FIGURA 2.3.4.2.3.2. Variação das concentrações de sólidos em suspensão orgânicos (mg.L $\mathrm{L}^{-1}$ ) no rio Betari, no período de 15/10/00 a 19/10/00..... 131

FIGURA 2.3.4.2.4. Variação dos valores de temperatura da água $\left({ }^{\circ} \mathrm{C}\right)$ no rio Betari, no período de 15/10/00 a 19/10/00. 132

FIGURA 2.3.4.2.5. Variação da demanda bioquímica de oxigênio (mg. $\mathrm{L}^{-1}$ ) no rio Betari, no período de 15/10/00 a 19/10/00. 132

FIGURA 2.3.4.2.6.1. Variação das concentrações de nitrogênio amoniacal $\left(\mu g . L^{-1}\right)$ no rio Betari, no período de 15/10/00 a 19/10/00. .133

FIGURA 2.3.4.2.6.2. Variação das concentrações de nitrato $\left(\mu \mathrm{g} . \mathrm{L}^{-1}\right)$ no rio Betari, no período de 15/10/00 a 19/10/00. 133 
FIGURA 2.3.4.2.6.3. Variação das concentrações de nitrito (ì $\mathrm{gL}^{-1}$ ) no rio Betari, no período de 15/10/00 a 19/10/00. 134

FIGURA 2.3.4.2.6.4. Variação das concentrações de nitrogênio orgânico total (mg.L$\left.{ }^{1}\right)$ no rio Betari, no período de 15/10/00 a 19/10/00 134

FIGURA 2.3.4.2.6.5. Variação das concentrações de fosfato inorgânico (ì $\mathrm{g}^{\mathrm{L}} \mathrm{L}^{-1}$ ) no rio Betari, no período de 15/10/00 a 19/10/00. 135

FIGURA 2.3.4.2.6.6. Variação das concentrações de fosfato total dissolvido (i $\mathrm{gL}^{-1}$ ) no rio Betari, no período de 15/10/00 a 19/10/00. 135

FIGURA 2.3.4.2.6.7. Variação das concentrações de fósforo total (ì $g \mathrm{~L}^{-1}$ ) no rio Betari, no período de 15/10/00 a 19/10/00. 136

FIGURA 2.3.4.2.6.8. Variação das concentrações de silicato reativo (mg.L $\left.{ }^{-1}\right)$ no rio Betari, no período de 15/10/00 a 19/10/00. 136

FIGURA 2.3.4.3. Dendrograma da análise de agrupamento das medidas médias das variáveis físicas e químicas da água nas estações do rio Betari em outubro de 2000 138

FIGURA 2.3.5.1.1. Valores médios de $\mathrm{pH}$ dos cinco dias de coleta intensiva, nos quatro períodos de estudo no rio Betari 139

FIGURA 2.3.5.1.2. Valores médios de condutividade elétrica dos cinco dias de coleta intensiva, nos quatro períodos de estudo no rio Betari 140

FIGURA 2.3.5.1.3. Valores médios de alcalinidade dos cinco dias de coleta intensiva, nos quatro períodos de estudo no rio Betari. 141

FIGURA 2.3.5.1.4. Valores médios de $\left(\mathrm{CO}_{2}\right)$ total dos cinco dias de coleta intensiva, nos quatro períodos de estudo no rio Betari. 141

FIGURA 2.3.5.2.1. Valores médios de $\mathrm{O}_{2}$ dissolvido dos cinco dias de coleta intensiva, nos quatro períodos de estudo no rio Betari 142

FIGURA 2.3.5.3.1. Valores médios de sólidos orgânicos em suspensão dos cinco dias de coleta intensiva, nos quatro períodos de estudo no rio Betari..143

FIGURA 2.3.5.3.2. Valores médios de sólidos inorgânicos em suspensão dos cinco dias de coleta intensiva, nos quatro períodos de estudo no rio Betari..143

FIGURA 2.3.5.4. Valores médios de temperatura dos cinco dias de coleta intensiva, nos quatro períodos de estudo no rio Betari. 144 
FIGURA 2.3.5.5. Valores médios de DBO dos cinco dias de coleta intensiva, nos quatro períodos de estudo no rio Betari 145

FIGURA 2.3.5.6.1. Valores médios da concentração de nitrogênio amoniacal dos cinco dias de coleta intensiva, nos quatro períodos de estudo no rio Betari....... 146

FIGURA 2.3.5.6.2. Valores médios da concentração de nitrito dos cinco dias de coleta intensiva, nos quatro períodos de estudo no rio Betari 146

FIGURA 2.3.5.6.3. Valores médios da concentração de nitrato dos cinco dias de coleta intensiva, nos quatro períodos de estudo no rio Betari. 147

FIGURA 2.3.5.6.4. Valores médios da concentração de nitrogênio orgânico dos cinco dias de coleta intensiva, nos quatro períodos de estudo no rio Betari. 147

FIGURA 2.3.5.6.5. Valores médios da concentração de fosfato inorgânico dos cinco dias de coleta intensiva, nos quatro períodos de estudo no rio Betari... 148

FIGURA 2.3.5.6.6. Valores médios da concentração de fosfato total dissolvido dos cinco dias de coleta intensiva, nos quatro períodos de estudo no rio Betari.. 148

FIGURA 2.3.5.6.7. Valores médios da concentração de fósforo total dos cinco dias de coleta intensiva, nos quatro períodos de estudo no rio Betari. 149

FIGURA 2.3.5.6.8. Valores médios da concentração de silicato reativo dos cinco dias de coleta intensiva, nos quatro períodos de estudo no rio Betari..149

FIGURA 2.3.7.1. Valores médios da concentração de coliformes fecais dos cinco dias de coleta intensiva, nos quatro períodos de estudo no rio Betari..154 


\section{LISTA DE TABELAS}

TABELA 1.2.1. Altura de chuvas $(\mathrm{mm})$ no posto pluviométrico localizado na Serra dos Motas, Iporanga - SP, durante o período amostral. As datas marcadas correspondem aos dias de amostragem. .16

TABELA 1.4.2. Unidades lito-estratigráficas da bacia hidrográfica do rio Betari..... 32

TABELA 1.4.3. Feições morfológicas na bacia hidrográfica do rio Betari....33

TABELA 1.4.4. Classes de declividade na bacia hidrográfica do rio Betari..33

TABELA 1.4.5.1. Matriz de contingência obtida a partir do cruzamento entre uso e ocupação da terra de 1986 e 2000, na bacia hidrográfica do rio Betari (os valores representam as porcentagens dos pixels) 34

TABELA 1.4.5.2. Matriz de contingência obtida a partir do cruzamento entre o uso e ocupação da terra e declividade na bacia hidrográfica do rio Betari (os valores representam as porcentagens dos pixels)...... .35

TABELA 1.4.6. Matriz de contingência obtida a partir do cruzamento entre o uso e ocupação da terra e as áreas protegidas na bacia hidrográfica do rio Betari (os valores representam as porcentagens dos pixels)..... 35

TABELA 2.2.3. Variáveis físicas e químicas da água determinadas no rio Betari. 79

TABELA 2.2.4. Métodos para analise do sedimento .80

TABELA 2.3.1.2.7. Variação das concentrações de íons na água no rio Betari na amostragem de janeiro de 2000 . .97

TABELA 2.3.2.2.7. Variação das concentrações de íons na água no rio Betari na amostragem em abril de 2000 . 111

TABELA 2.3.3.2.7. Variação das concentrações de íons na água no rio Betari na amostragem em julho de 2000. 124

TABELA 2.3.4.2.7. Variação das concentrações de íons na água no rio Betari na amostragem em outubro de 2000 . 137

TABELA 2.3.6.1.1. Variação das concentrações de nitrogênio no sedimento $(\mathrm{mg} / \mathrm{g}) \mathrm{de}$ rio Betari em janeiro, abril, julho e outubro de 2000. 150 
TABELA 2.3.6.1.2. Variação das concentrações de fósforo no sedimento (mg/g) de rio Betari em janeiro, abril, julho e outubro de 2000. 151

TABELA 2.3.6.2.1. Porcentagens de cálcio no sedimento do rio Betari em janeiro, abril, julho e outubro de 2000 152

TABELA 2.3.6.2.2. Porcentagens de magnésio no sedimento do rio Betari em janeiro, abril, julho e outubro de 2000 152

TABELA 2.3.6.2.3. Porcentagens de zinco no sedimento do rio Betari em janeiro, abril, julho e outubro de 2000 . 153

TABELA 2.3.6.2.4. Porcentagens de chumbo no sedimento do rio Betari em janeiro, abril, julho e outubro de 2000 153

TABELA 2.3.7.2.1. Taxa identificados no estudo do rio Betari. .157

TABELA 2.3.7.2.2. Densidade de organismos por unidade taxonômica e total da coleta de verão $(\mathrm{jan} / 00)$. 162

TABELA 2.3.7.2.3. Densidade de organismos por unidade taxonômica e total da coleta de outono $(\mathrm{abr} / 00)$ 163

TABELA 2.3.7.2.4. Densidade de organismos por unidade taxonômica e total da coleta de inverno (jul/00). 164

TABELA 2.3.7.2.5. Densidade de organismos por unidade taxonômica e total da coleta de primavera (out/00) 165

TABELA 2.3.7.2.6. Abundância relativa por unidade taxonômica na coleta de verão (jan/00). 166

TABELA 2.3.7.2.7. Abundância relativa por unidade taxonômica na coleta de outono $(\mathrm{abr} / 00)$ 167

TABELA 2.3.7.2.8. Abundância relativa por unidade taxonômica na coleta de inverno (jul/00) 168

TABELA 2.3.7.2.9. Abundância relativa por unidade taxonômica na coleta de primavera (out/00) 169

TABELA 2.3.7.2.10. Abundância e dominância por unidade taxonômica na coleta de verão (jan/00) 170 
TABELA 2.3.7.2.11. Abundância e dominância por unidade taxonômica na coleta de outono (abr/00). .171

TABELA 2.3.7.2.12. Abundância e dominância por unidade taxonômica na coleta de inverno (jul/00). 172

TABELA 2.3.7.2.13. Abundância e dominância por unidade taxonômica na coleta de primavera (out/00) 173

TABELA 2.3.7.2.14. Freqüência de ocorrência total das unidades taxonômicas durante o estudo. 174

TABELA 2.3.7.2.24. Número de unidades taxonômicas por ponto durante o estudo. 175

TABELA 3.1. Impactos ambientais, econômicos, sociais e culturais do turismo 230

TABELA 3.3.1.1. Local de nascimento dos moradores do bairro da Serra, por estado ou município do Vale do Ribeira. 235

TABELA 3.3.2.1. Destino do lixo produzido no bairro da Serra .235

TABELA 3.3.3.1. Ocupação principal dos moradores que trabalham no bairro da Serra. 236

TABELA 3.3.4.1. Modos de ver o turismo pelos 82 residentes entrevistados no bairro da Serra. .238

TABELA 3.3.5.1. Opinião dos entrevistados sobre o que é necessário para a melhoria das condições de vida no bairro da Serra. .239

TABELA 3.3.5.2. Locais freqüentados pela população residente e pelos turistas. .240

TABELA 3.3.5.3. Como se divertem os moradores do bairro da Serra....... 241

TABELA 3.3.5.4. Caracterização dos meios de hospedagem no bairro da Serra (dados coletados em outubro de 2000) 243

TABELA 3.4.1. Quadro resumo dos impactos do turismo no bairro da Serra. 253 


\section{INTRODUÇÃO}

Os rios apresentam duas características importantes: são sistemas abertos, com grande capacidade de recepção de informações da área que drenam, e funcionam como transportadores destas informações. Segundo NEIFF (1995), os distúrbios que ocorrem nos cursos superiores, como desflorestamento, contaminação, formação de mosaicos, erosão, mudanças no regime de escoamento e inundações, são percebidos nas partes baixas da bacia e podem ser somados aos distúrbios aí localizados.

Esses mesmos distúrbios são os maiores problemas enfrentados no manejo dos rios e não se restringem somente ao ecossistema aquático, causando impactos em maior escala, na biodiversidade regional. Assim, o desenvolvimento sustentado requer a visualização integrada dos sistemas aquático e terrestre, tendo a bacia hidrográfica como unidade fundamental, incorporando uma nova ética ambiental, que deve considerar as necessidades ecológicas e buscar promover objetivos a longo prazo, pensando nas futuras gerações (PETTS \& CALLOW, 1996).

Segundo PETTS \& CALLOW (op. cit.), o manejo dos sistemas lóticos se defronta, na atualidade, com três desafios e, para superá-los, é necessária a compreensão dos processos físicos e químicos que controlam tais ecossistemas. Esses desafios são:

- a crescente demanda de recursos aquáticos, principalmente para irrigação;

- o controle da qualidade da água com tratamento dos despejos;

- a manutenção dos recursos aquáticos e terrestres, incluindo a biodiversidade.

$\mathrm{O}$ crescimento demográfico e o da atividade turística, bem como outros usos da bacia hidrográfica, podem estar alterando a qualidade da água do rio Betari. A determinação de suas características limnológicas, espacial e temporalmente, podem indicar as modificações que estão ocorrendo nesse ecossistema que, associadas a outros dados da bacia e à inserção dos 
sistemas sociais, sua relação com o meio ambiente e com a atividade turística na região, servem de subsídios para o desenvolvimento sustentável.

O presente estudo teve como objetivos:

1. avaliar biológica, física e quimicamente o rio Betari, tanto sazonal quanto espacialmente;

2. determinar as características morfométricas da bacia hidrográfica do rio Betari;

3. determinar o uso do solo na bacia hidrográfica do rio Betari, utilizando técnicas de sensoriamento remoto;

4. relacionar as características limnológicas do rio Betari com atividades antrópicas na bacia, tais como:

- ocupação

- turismo

- despejo de efluentes domésticos

- agropecuária

- mineração (atualmente desativada, mas com rejeitos expostos);

5. determinar os impactos causados pelo turismo na população do bairro da Serra, maior aglomerado humano na bacia;

6. integrar informações obtidas com as imagens de satélite e geoprocessamento, elaborando um diagnóstico ambiental da bacia;

7. fornecer subsídios para o desenvolvimento sustentável na bacia hidrográfica do rio Betari (SP). 


\section{REFERÊNCIAS BIBLIOGRÁFICAS}

NEIFF, J. J., 1995. Gerenciamento Ambiental do Paraná: geopolítica e linhas de ação. In Análise ambiental: estratégias e ações. Eds. TaukTornisielo, S.M., et al. Centro de Estudos Ambientais da UNESP - Rio Claro. T.A. Queiroz Editor, São Paulo, p156.

PETTS, G. E. \& CALLOW, P., 1996. Fluvial hydrosystems: the physical basis. In River flows and channel forms. Eds. Petts, G. e Calow, P., Blackwell Science. Oxford, 262p. 


\section{CAPÍTULO I}

\section{A ÁREA DE ESTUDO: BACIA HIDROGRÁFICA DO RIO BETARI}

\section{INTRODUÇÃO}

\subsection{PLANEJAMENTO E GESTÃO DE BACIAS HIDROGRÁFICAS}

SACHS (1996) vê o atual modelo de desenvolvimento como um sistema de produção de riqueza, acompanhado do aumento da pobreza e exclusão social e da degradação ambiental. O que existe é incorporação predatória dos recursos naturais no fluxo de renda. A natureza se torna cada vez mais um bem de consumo, e desenvolvimento é visto como crescimento econômico. Para o autor, isso não é sinônimo de desenvolvimento.

Segundo a COMISSÃO MUNDIAL SOBRE MEIO AMBIENTE E DESENVOLVIMENTO SUSTENTADO (1991), "desenvolvimento sustentável é aquele em que são atendidas as necessidades presentes, sem comprometimento de as gerações futuras terem atendidas as suas necessidades". Esse conceito apresenta limitações impostas pelo estágio atual da tecnologia e da organização social que se impõe ao meio ambiente, e pela própria capacidade de a biosfera absorver os efeitos das atividades humanas. $O$ crescimento e desenvolvimento econômico geram mudanças nos ecossistemas. Para SACHS (op cit.), a distribuição dos homens e de suas atividades no planeta é um dos principais elementos geradores da crise sócioambiental pela qual passamos.

Atualmente, considera-se que existam disponíveis conhecimentos para planejamento, desenho e gestão dos recursos hídricos, de modo que os distúrbios ambientais possam ser reduzidos a um mínimo. Porém, a dificuldade está na aplicação do conhecimento disponível para solução dos problemas 
(BISWAS, 1988). O planejamento permite a exploração dos recursos dentro de sua capacidade de regeneração, crescimento natural e reorganização.

A visão de um sistema maior, bacia hidrográfica, é fundamental para o planejamento e gestão dos ecossistemas, pois contém os fatores ecológicos (meios físico e biológico) e humanos (meios sócio-econômico e cultural).

Os vários setores da economia usam o recurso de forma diversa (qualitativa e quantitativamente) e a demanda de um interfere na necessidade de outro, gerando uma competição pelo recurso. Ações exercidas por um setor da economia em um ponto superior da bacia podem ter implicações na sua parte inferior. A quantidade do recurso pode não ser suficiente ou a qualidade pode estar abaixo das necessidades. Desta forma, o desenvolvimento da bacia pode ser comprometido, ou seja, não é sustentável (GOLUBEV, 1988).

Para que isso não ocorra, as características do sistema devem ser mantidas. O papel da água, como fator unificador de ecossistemas através do intercâmbio de matéria e energia por seu ciclo, deve ser mantido, assim como sua capacidade de interagir com outros ciclos biogeoquímicos, por exemplo, no transporte de matéria (GOLUBEV, 1988). Portanto, o desenvolvimento deve levar em consideração esses processos e, para isso, deve contemplar a bacia como um todo. Essa abordagem deve ser levada em conta no desenvolvimento sustentado. Segundo HUFSCHMIDT e MACCAULEY (1988), o uso de bacias como unidades de planejamento mostram aos planejadores todas as facetas relevantes do uso do recurso, incluindo mudanças e impactos, fora e dentro da área de uso.

PIRES e SANTOS (1995) comentaram que, para solucionar conflitos entre usuários e dimensionar a quantidade e qualidade dos recursos que cabem a cada um, assim como suas responsabilidades sobre eles, deve-se considerar os usos múltiplos de tais recursos, integrados aos processos citados acima.

Segundo NAKAGAMI (1988), a estratégia conceitual da gestão e planejamento está estruturada em quatro unidades que interagem: água, solo, cobertura vegetal e atividades humanas. Estas unidades abrangem os 
elementos básicos constituintes da bacia: elementos naturais, representados pela geologia, pedologia, e elementos sociais, como demografia e industrialização, entre outros.

Portanto, o planejamento e gestão de bacias hidrográficas devem incorporar todos os recursos ambientais da área de drenagem e devem integrar os aspectos ambientais aos sociais, econômicos e políticos, enfatizando o ambiental, já que este tem uma capacidade limitada de suporte que deve afetar os demais (PIRES e SANTOS, 1995).

As DIRETRIZES DE PESQUISA APLICADA AO PLANEJAMENTO E GESTÃO AMBIENTAL (1994) do IBAMA/MMA, dividem os sistemas em dois, com dinâmicas distintas, para o planejamento ambiental. Um sub-sistema é composto dos fatores naturais (terra, água e ar), que devem ser tratados pelos planejadores como receptores dos efeitos causados pelos usos antrópicos, que correspondem ao segundo sub-sistema. Consideram que "o problema básico do planejamento ambiental consiste em avaliar tanto a sensibilidade dos fatores naturais que compõem a paisagem de um dado espaço aos danos causados pelos usos antrópicos, quanto a intensidade dos danos a cada um desses fatores naturais".

SOUZA (2000) entende gestão ambiental "como um conjunto de procedimentos que visam à conciliação entre desenvolvimento e qualidade ambiental". A conciliação depende da capacidade de suporte do meio ambiente e das necessidades da sociedade civil e/ou do governo. Desta forma, "o planejamento está contido no sistema de gestão, uma vez que estrutura as diretrizes a serem seguidas pelos planos de ação e pela própria gestão ambiental".

NAKAGAMI (1988) considerou que o planejamento e a gestão de bacias pode ser efetuado através de três ações:

- determinação do nível de desenvolvimento da bacia, que é compatível com a meta de conservação ambiental; 
- determinação de um nível adequado de atividades de produção e expectativas das pessoas, e das condições ambientais em áreas densamente ocupadas;

- consolidação do sistema de usos do solo, de acordo com projeto de desenvolvimento urbano e industrial.

O planejamento e gerenciamento de bacias envolve etapas que podem ser desenvolvidas separadamente ou ao mesmo tempo, dependendo dos recursos disponíveis. Para PIRES e SANTOS (1995), existem três etapas no planejamento, para se obter o zoneamento ambiental da bacia:

- diagnóstico ambiental: levantamento de todos os dados sobre o ambiente físico, biológico e social, áreas de risco e áreas de usos;

- prognóstico ambiental: projeção de possíveis condições futuras de uso e ocupação, para se determinar limites de insustentabilidade;

- integração das análises ambientais: análises políticas e econômicas do plano de manejo da bacia.

A implementação do plano de manejo pode implicar drásticas mudanças no padrão de uso do solo que, muitas vezes, tornam o processo inviável. Por outro lado, impede que a propriedade individual seja utilizada de maneira exclusivista, sem resguardar os interesses futuros, mas sim, de acordo com critérios ecológicos e econômicos estabelecidos pelo plano. É uma ferramenta útil no controle e fiscalização do solo na bacia, garantindo qualidade do meio, dentro de um padrão aceitável para populações atuais e futuras (PIRES e SANTOS, 1995).

HUFSCHMIDT e MACAULEY (1988), entretanto, observam que a implementação da abordagem holística de bacia hidrográfica apresenta o inconveniente de que, raramente, as fronteiras políticas coincidem com os limites da bacia, e o sucesso depende da coordenação entre as diferentes unidades administrativas e políticas. BOURLON e BERTHON (1998), em análise do gerenciamento de bacias na América Latina, citaram que na Europa, França, Espanha, Países Baixos e Reino Unido utilizam as bacias como 
unidade de planejamento, e estão sendo seguidos por Portugal, Grécia e Itália. A participação dos usuários pode ser deliberativa (votando orçamentos), como no caso de França, Espanha e Países Baixos, ou consultiva (dando pareceres) como na Alemanha e Reino Unido. Na América Latina, o México considera bacia como unidade de planejamento em nível nacional. O Brasil apresenta uma lei para todo território, com planejamento nacional e por bacias, e com integração entre ações setoriais, através da coordenação dos projetos dos governos, municípios e usuários. Também prevê agências de financiamento e contribuições pelo uso da água, semelhante aos sistemas de gestão da França, Espanha e Países Baixos.

No estado de São Paulo, a Política Estadual de Recursos Hídricos (Lei № 7663/91) prevê: a descentralização das ações e tomadas de decisão, adotando a bacia hidrográfica como unidade físico-territorial de planejamento e gerenciamento, e a participação dos poderes públicos (estadual e municipal) e da sociedade civil, de forma a integrar os recursos hídricos com os demais recursos naturais; as ações do poder público com as dos usuários e entidades civis; a quantidade com a qualidade das águas; e o planejado com o a ser executado. Para isso conta com o Plano Estadual de Recursos Hídricos (PERH) - que define os investimentos; o Fundo Estadual de Recursos Hídricos (FEHIDRO) - que cria suporte financeiro para projetos, serviços e obras, previstos nos Planos de Bacia e priorizados pelos Comitês de Bacias; e o Sistema Integrado de Gerenciamento de Recursos Hídricos (SIGRH) - que define a forma de participação do estado, municípios, usuários e sociedade civil na execução das ações e suas respectivas responsabilidades, também através dos colegiados decisórios, os Comitês de Bacias e o Conselho Estadual de Recursos Hídricos. O rio Betari, objeto desse estudo, pertence ao comitê da Bacia Hidrográfica do Ribeira de Iguape e Litoral Sul - CBH - BS (CRH, 2001).

Assim, este capítulo tem como principais objetivos caracterizar a bacia hidrográfica do rio Betari, determinar os usos do solo e fazer um diagnóstico da bacia, para fornecer subsídios para o desenvolvimento sustentável. 


\subsection{ESTADO DA ARTE}

A região do Alto Vale do Ribeira é uma das últimas áreas ainda não atingidas pela exploração econômica desenfreada que ocorreu no estado de São Paulo, mantendo muitas de suas características originais. Nessa região, encontra-se a maior concentração de cavernas conhecidas no Brasil, muitas de grandes dimensões e formações únicas. A região apresenta, ainda, sítios arqueológicos e paleontológicos e formações geológicas, cársticas, de grande interesse científico e cênico (GT-PETAR/CENIN, 1980 e SANCHEZ, 1984).

Nas margens do rio Betari, ocorrem inúmeras cavernas de enorme potencial científico e turístico. Sítios arqueológicos, como os estudados por DE BLASIS (1996), e paleontológicos (TRAJANO, 1979) estão presentes na sua bacia.

Parte significativa da vegetação Atlântica remanescente do estado de São Paulo encontra-se nessa área, abrigando espécies em risco de extinção. Deve-se destacar a fauna cavernícola, muito frágil e especializada, que pode desaparecer com mudanças no meio epígeo. A fauna subterrânea é especialmente sensível a alterações nos fatores abióticos do meio, como temperatura e umidade. Alterações na dinâmica trófica desses sistemas podem pôr em risco esses organismos. A distribuição restrita das populações troglóbias, suas pequenas densidades e baixa capacidade de reposição, tornam-nas muito vulneráveis a alterações ambientais (TRAJANO, 1986).

Segundo BACK e ARENAS (1989), os terrenos cársticos são mais sensíveis e respondem mais dramaticamente ao estresse, que outros tipos de terrenos. Por outro lado, essas áreas são adequadas para mineração, abastecimento de água e geração de energia, sendo, portanto, um importante recurso. Vários problemas estão relacionados à utilização desse recurso, como desmoronamentos, perda de água e solo para cavidades durante escavações, 
intrusões de água em cavidades durante perfurações, invasão de água salgada, perda de água de reservatórios depois de sua construção, grande consumo de concreto na construção de represas, solos com dificuldade para reinstalação de vegetação nativa, devido à permeabilidade da rocha matriz, e contaminação da água subterrânea pela infiltração de água com agentes contaminantes, devido à ocupação humana.

O consumo de água dessas regiões também pode trazer problemas para a população, uma vez que esta é rica em carbonatos, que podem causar a formação de cálculos.

O desmatamento que ocorre (apesar das leis ambientais de proteção), o risco de instalação de mineradoras (atualmente existem algumas desativadas, mas com resíduos de lavra expostos às intempéries) e os projetos hidroelétricos, podem comprometer uma área extremamente rica em informações ainda desconhecidas e verdadeiras relíquias científicas e culturais. Aos fatores citados acima, devem-se somar os efeitos diretos e indiretos causados pelo turismo, que podem alterar o sistema antes mesmo de estar totalmente implantado, se não for devidamente planejado.

Como visto acima, a bacia do rio Betari é muito importante e configura-se numa região extremamente delicada, do ponto de vista cultural e ambiental, para a qual se faz necessário um plano de manejo e desenvolvimento sustentado, que garanta a manutenção do sistema e suas riquezas culturais, biológicas e geológicas. A criação do parque que abrange a bacia (ainda que não a sua totalidade), garante a conservação de parte desse sistema, pois essa Unidade de Conservação não apresenta clara definição de suas fronteiras e, quando foi delimitada, áreas muito ricas em cavernas, com alta diversidade biológica e com ocorrência de espécies raras (bagre-cego, Pimelodella kronei) não foram incluídas em seus limites. Essas áreas estão em risco, devido à exploração não planejada.

Dessa forma, para gestão da bacia hidrográfica e seu monitoramento, é de grande importância a caracterização limnológica do rio Betari e a associação 
dessas características com os usos da bacia hidrográfica, principalmente com o turismo, que atualmente representa a maior atividade econômica. A verificação dos impactos sócio-culturais e econômicos do turismo é um instrumento importante para subsidiar o planejamento dessa atividade, a urbanização da região e para policiar a área de preservação.

\subsubsection{CARACTERIZAÇÃo FíSICA}

O rio Betari pertence à bacia do rio Ribeira de lguape (Figura 1.1) e se localiza em seu trecho alto, na margem esquerda. É um rio encachoeirado e de corredeiras, formado pela união dos rios Passa Vinte e Betarizinho, que têm suas origens no alto das escarpas da serra de Paranapiacaba, próximo a Apiaí. $\mathrm{O}$ rio percorre e entalha filitos e calcários, formando um longo canyon de aproximadamente $12 \mathrm{~km}$. No seu curso médio e baixo, o canyon se abre devido à erosão diferencial, formando um vale aberto mas encaixado, com morros residuais e terraços de sedimentação, tornando-se adequado à agricultura e assentamentos humanos (DE BLASIS, 1996).

O rio Betari, com aproximadamente $25 \mathrm{~km}$ de comprimento (GERHARD, 1999), atravessa o Parque Estadual Turístico do Alto Ribeira (PETAR), que foi criado em 1958. Essa região se apresenta pouco impactada, com condições bastante naturais. Ao sair do Parque, o rio Betari passa pelo bairro da Serra, que vem crescendo com 0 afluxo de turistas, sem planejamento. Posteriormente, este rio atravessa uma grande área com culturas de subsistência e pequena atividade pastoril, até desaguar no rio Ribeira de Iguape, próximo ao município de Iporanga. Nesse percurso, o Betari recebe vários afluentes, muitos deles provenientes de locais distantes, que atravessam montanhas por cavernas.

GONZALEZ e ZAVAN (1986) analisaram alguns parâmetros hidrológicos de ressurgências de dez cavernas da região e verificaram, com exceção da bacteriologia, que esses sistemas estavam dentro dos padrões de potabilidade. 
Já EYSINK et al. (1988), encontraram níveis de metais pesados acima do permitido no rio Betari e o consideraram um contribuinte importante desses metais para o rio Ribeira de lguape.

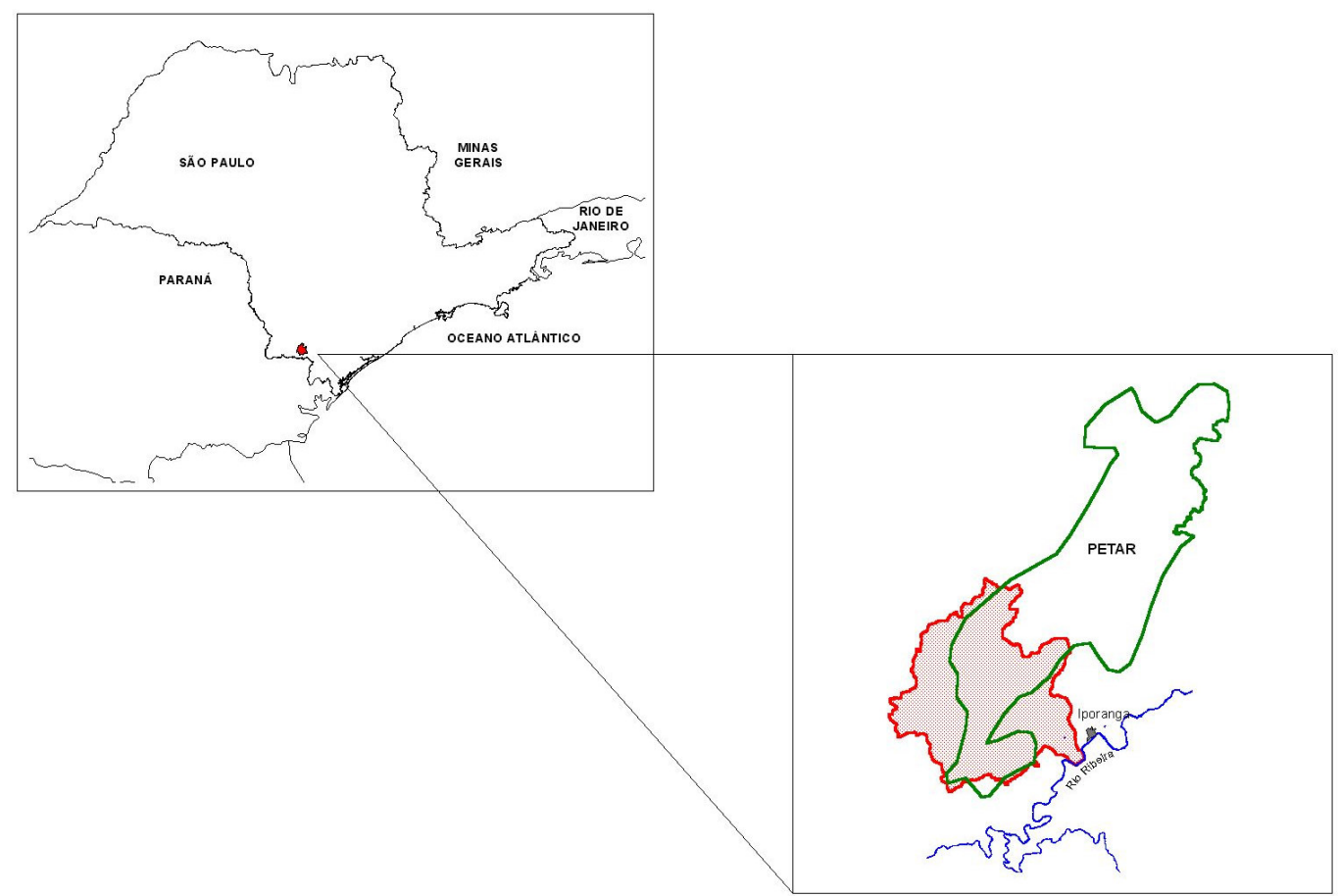

FIGURA 1.2.1 - Localização da bacia hidrográfica do rio Betari no estado de São Paulo.

HASSUI et al. (1992) estudaram a possível contaminação do rio Roncador, afluente do rio Betari e formador da caverna Santana, por efluentes da mina de Furnas que infiltram pelo pacote carbonático. Os autores (op cit.) concluiram que a infiltração de água subterrânea do córrego Furnas deverá fluir através das descontinuidades e cavidades para o rio Betari, coletor principal, sem contaminar o rio Roncador.

A bacia do rio Betari abrange os municípios de Iporanga e Apiaí. Ela apresenta um grande desnível topográfico, pois estas cidades se localizam nas cotas 100m e 1000m (acima do nível do mar), respectivamente.

Do ponto de vista geomorfológico, a bacia do rio Betari localiza-se na Província Costeira, na Serrania do Ribeira, apresentando relevo de serras 
alongadas, de topos angulosos e vertentes ravinadas, com perfis retilíneos, de inclinação maior que 15 graus, que em certos pontos sustentam planaltos isolados na porção cumeeira. A drenagem é de alta densidade, padrão paralelo pinulado e de vales fechados (IPT/PRÓ-MINÉRIO, 1981).

Segundo SANCHEZ (1984), no Alto Ribeira, o calcário aflora de forma descontínua, em uma faixa que varia de 1 a $10 \mathrm{~km}$ e está intercalada por faixas de metassedimentos detríticos (quartzitos, filitos, micaxistos, etc.), pertencentes à unidade geológica do Grupo Açungui, de idade Pré-Cambriana Superior. Também ocorrem grandes corpos graníticos intrusivos entre os metassedimentos. As faixas têm uma orientação geral NE-SW, e muitos rios correm nessa direção. A drenagem nos granitos é dendrítica e muitos rios, ao atingirem o calcário, desaparecem. Essa característica deve-se ao carste da região. Os rios desaparecem nos sumidouros que, geralmente, estão em vales cegos, e ressurgem em outros locais, ainda no calcário. Essa é atualmente a região com maior número de cavernas conhecidas no Brasil (mais de 200 catalogadas).

Além das cavernas, a região apresenta outras formas cársticas, como torres de pedra, paredões de aspecto ruiniforme e lapiás que, geralmente, estão cobertos por vegetação. Dolinas são freqüentes e captam água que também podem percorrer cavernas.

As cavernas dessa região apresentam enorme riqueza de formações, e se destacam mundialmente pelo tamanho e crescimento. Também deve-se destacar a ocorrência de abismos e cavernas com desenvolvimento vertical, sendo as maiores do país.

O relevo da região é bastante anguloso. Os vales são bem encaixados e as vertentes abruptas. Alguns canyons apresentam paredes verticais de 200 a $300 \mathrm{~m}$ de altura (SANCHEZ, 1984).

O clima é quente e úmido, sem ventos e abafado (verão), devido à grande amplitude altimétrica entre o fundo do vale e as serras. No inverno, o clima torna-se agradável sem ser rigoroso, como no alto da serra (DE BLASIS, 
1996). SETZER (1966) considerou o clima da região como do tipo Cfa (pela classificação de Köeppen), ou seja, clima úmido temperado sem estação seca definida, com temperaturas anuais ao redor de $18-19^{\circ} \mathrm{C}$. A temperatura do mês mais quente (janeiro) é superior a $22^{\circ} \mathrm{C}$, com precipitação média anual ao redor de $2000 \mathrm{~mm}$. BICHUETTE (1998) citou que o clima é Cfa nas regiões mais baixas e Cfb nas elevadas (maiores que $700 \mathrm{~m}$ ), ou seja, mesotérmico úmido, sem seca, e com a temperatura do mês mais quente (fevereiro) entre 10 e $22^{0} \mathrm{C}$.

GERHARD (1999) verificou uma precipitação média anual de $1700 \mathrm{~mm}$, analisando dados coletados na estação meteorológica da Serra dos Motas, referentes aos últimos 20 anos, e considerou o período entre os meses de outubro e março como estação chuvosa, e entre abril e setembro, quando chove no máximo $100 \mathrm{~mm}$, como período seco. O mesmo autor observou que entre março/1997 e março/1998 a precipitação anual foi a maior dos últimos 20 anos, atingindo $2114,5 \mathrm{~mm}$.

O clima da região é influenciado pela massa de ar Tropical Atlântico que, por sua vez, influencia a distribuição das chuvas no vale do rio Ribeira de Iguape, e também pela massa Polar Atlântica, provocando quedas bruscas de temperatura e chuvas fortes no verão e baixas temperaturas no inverno (SALLOUTI ALLEGRINI, 1999).

A tabela 1.2.1 mostra as alturas de chuva diárias que ocorreram no bairro da Serra, no posto pluviométrico da Serra dos Motas. Comparado às observações dos autores citados acima, o ano 2000 foi mais seco. O total acumulado em 2000 foi de $1285,55 \mathrm{~mm}$. Os meses de fevereiro $(226,48 \mathrm{~mm}) \mathrm{e}$ dezembro $(217,9 \mathrm{~mm})$ foram os que apresentaram maior precipitação. Abril foi o mês mais seco $(2,75 \mathrm{~mm})$ e marcou o início do período mais seco do ano, que se estendeu até julho. Nessa tabela também são indicadas as alturas da chuva nos dias de amostragem. As coletas de abril (outono) e de julho (inverno), foram precedidas por períodos secos. Na coleta de outubro (primavera) ocorreram precipitações no período precedente, mas nenhuma chuva significativa durante 
as coletas, e em janeiro (verão) ocorreu precipitação nos dois primeiros dias de coleta.

TABELA 121- altura de chuvas (mm) no posto pluviométrico localizado na Serra dos Motas,

Iporanga-SP, durante o periodo amostral. As datas marcadas correspondemaos dias de

amostragefPN FEV MAR ABE MAI UN UL AGO SET OUT NOV DEZ

$\begin{array}{lllllllllllll}1 & 1,2 C & 6,4 \varepsilon & 23,6 C & 0,0 & 0,0 & 0,0 & 0,1 C & 0,0 & 6,3 C & 0,0 & 0, \infty & 15, \infty\end{array}$

$\begin{array}{lllllllllllll}2 & 6,6 C & 0,0 & 1,5 C & 2,5 C & 0,5 C & 0,0 & 0,0 C & 0,0 & 29,8 C & 0,1 C & 0,0 & 0,3 C\end{array}$

$\begin{array}{lllllllllllll}3 & 1,5 C & 1,1 C & 2,2 C & 0,02 & 0,0 & 0,0 & 0,3 C & 0,3 C & 8, \pi & 0,1 C & 10,5 C & 0,0\end{array}$

$\begin{array}{lllllllllllll}4 & 0,4 C & 3,5 C & 0,0 & 0,06 & 0,0 & 0,0 & 0,9 C & 14,4 C & 0,0 & C & 0,5 C & 7,8 C\end{array}$

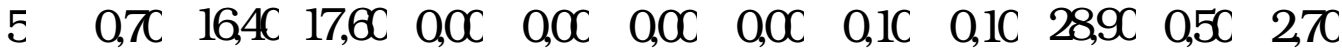

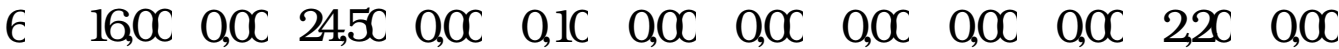

$\begin{array}{lllllllllllll}7 & 9, \infty & 0, \propto & 5, \propto & 0, \propto & 0, \propto & 0,1 C & 0, \propto & 0, \propto & 0,1 C & 0, \propto & 0,9 C & 0, \propto\end{array}$

$\begin{array}{lllllllllllll}\varepsilon & 0, \pi & 0,1 C & 3, \propto & 0,0 & 2, C & 0,0 & 0,0 & 0,01 & 0, \infty & 0,0 & 1,5 C & 0,0\end{array}$

$\begin{array}{lllllllllllll}\text { c } & 1,4 C & 0, \propto & 0, \propto & 0, \propto & 0, \propto & 0, \propto & 0, \propto & 0, \propto & 0, \propto & 0, \propto & 0, \propto & 0,0\end{array}$

$\begin{array}{lllllllllllll}1 \mathrm{C} & 0,0 & 162 C & 0,0 & 0,0 & 0,0 & 0,9 C & 0,0 & 5,1 C & 0,0 & 3,8 C & 0,0 & 0,0\end{array}$

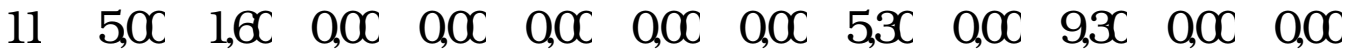

$\begin{array}{lllllllllllll}12 & 0,1 C & 11, \pi & 0,0 & 0,0 & 0,8 C & 0,0 & 0,0 & 0,0 & 28,3 C & 0,0 & 0,0 & 0,0\end{array}$

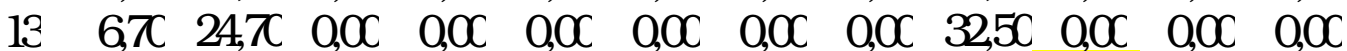

$\begin{array}{lllllllllllll}14 & 0,0 & 19, \pi & 0,0 & 0,0 & 0,0 & 0,0 & 0,0 & 0,0 & 0,0 & 0,0 & 21,9 C & 6,5 C\end{array}$

$\begin{array}{lllllllllllll}15 & 2,3 C & 23,0 & 0,0 & 0,1 C & 0,0 & 0,0 & 0,1 C & 0,0 & 0,8 C & 0,1 C & 0,0 & 36,9\end{array}$

16 $\begin{array}{llllllllllll}11,8 C & 0,3 C & 0,5 C & 0,0 & 0,0 & 0,0 & 6,1 C & 0,3 C & 0,0 & 0,1 C & 2 \propto & 23, \propto\end{array}$

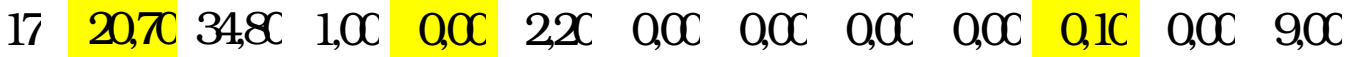

$\begin{array}{lllllllllllll}18 & 2,6 C & 4,4 C & 0,1 C & 0,1 C & 0,0 & 21,8 C & 0,01 & 3,1 C & 14,0 C & 0,5 C & 9,2 C & 0,0 C\end{array}$

$\begin{array}{lllllllllllll}1 \mathrm{C} & 1,4 C & 0,3 C & 1,8 C & 0,0 & 2,0 & 12, \pi & 0,0 & 0,0 & 0,0 & 0,0 & 45,4 C & 0,1 C\end{array}$

$\begin{array}{lllllllllllll}2 C & 1, \propto & 0,2 C & 4, \propto & 0, \propto & 0,0 & 0,1 C & 0,0 & 0,0 & 0,0 & 6,0 & 0,4 C & 0,0\end{array}$

$\begin{array}{lllllllllllll}21 & 0,1 C & 0,0 & 0,0 & 0, \propto & 0,0 & 19, \pi & 0,0 & 0,1 C & 0,0 & 0,1 C & 9, \pi & 0,0\end{array}$

$\begin{array}{lllllllllllll}22 & 0, \propto & 0,0 & 0,5 C & 0, \propto & 0,0 & 0,0 & 0,0 & 0,0 & 0,0 & 0,1 C & 31, \pi & 0,0\end{array}$

$\begin{array}{lllllllllllll}2^{2} & 0,1 C & 5,3 C & 5,9 & 0, \propto & 0,0 & 0,1 C & 20,5 C & 0,0 & 0,1 C & 0,0 & 0,0 C & 0,0\end{array}$

$\begin{array}{lllllllllllll}24 & 0,0 & 25,2 C & 0,3 C & 0,0 & 0,0 & 0,0 & 0,0 & 0,0 & 0,0 & 3,3 C & 0,0 & 0,0\end{array}$

$\begin{array}{lllllllllllll}25 & 0,0 & 1,4 C & 0,1 C & 0,0 & 0,0 & 0,0 & 0,0 & 0,0 & 0,8 C & 30,9 C & 28, \pi & 15,3 C\end{array}$

$\begin{array}{lllllllllllll}26 & 9,5 C & 0,0 & 0,0 & 0,0 & 0,0 & 0,0 & 0,0 & 0,0 & 0,0 & 0,1 C & 18, \propto c & 0,0\end{array}$

$\begin{array}{lllllllllllll}21 & 4,5 C & 0,0 & 0,0 & 0,0 & 0,0 & 11,3 C & 0,0 & 52,0 & 0,3 C & 0,0 & 0,06 & 0,3 C\end{array}$

$\begin{array}{lllllllllllll}2 \varepsilon & 0,0 & 0,1 C & 0,0 & 0,0 & 0,1 C & 0,0 & 0,0 & 34,0 & 0,1 C & 15,5 C & 0,0 & 0,0\end{array}$

$\begin{array}{lllllllllllll}2 & 0,0 & 30,0 & 3, \pi & 0,0 & 0,1 C & 0,0 & 0,0 & 0,1 C & 0, \infty & 9,1 C & 0,1 C & 39,3 C\end{array}$

$\begin{array}{llllllllllll}3 C & 0,0 & 1,5 C & 0,0 & 0,0 & 0,9 & 0,0 & 0,0 & 0, \infty & 3, \propto & 0,4 C & 27, \pi\end{array}$

$\begin{array}{llllllll}31 & 0.0 \mathrm{C} & 1.9 \mathrm{C} & 0.1 \mathrm{C} & 0.0 \mathrm{C} & 0.3 \mathrm{C} & 0.0 \mathrm{C} & 34,0 \mathrm{C}\end{array}$

TOTAL 103,9C22648987C 27. $8.5 \mathrm{C} \quad 67,6 \mathrm{C} 28,01$ 115,11121,9C111,1C183,6C217,9

Total acumulado no ano $200 \mathrm{C} 1285,5 \mathrm{bm}$ 


\subsubsection{CARACTERIZAÇÃO BIOLÓGICA}

A região do Vale do Alto Rio Ribeira de Iguape localiza-se em uma área de transição entre o Domínio Tropical Atlântico e o Domínio dos Planaltos de Araucárias (AB'SABER, 1977). É uma das últimas reservas florestais do estado de São Paulo, constituída de mata subtropical úmida perenifólia (HUECK, 1972). Segundo o IBGE (1991), a cobertura vegetal na região superior da bacia é classificada como Floresta Ombrófila Higrófila Densa Submontana. A grande maioria das árvores são latifoliadas, com raízes pouco profundas e bases dilatadas. Apresentam de 25 a $30 \mathrm{~m}$ de altura, com grande quantidade de lianas, epífitas e samambaias. A área apresenta grande biodiversidade e é rica em madeiras de lei (GT-PETAR/CENIN, 1980).

Além da mata primária, a cobertura vegetal possui formações secundárias (capoeiras e capoeirões) originadas por atividades antrópicas. Segundo SALLOUTI ALLEGRINI (1999), nas matas primárias ocorrem canelas (Ocotea ssp e Nectandra spp), cedros (Cedrela fissilis), figueiras (Ficus spp), jatobás (Hymenaeae courbari), bucuvas (Virola oleifera), cajaranas (Cabralea canjerana), aricuranas (Hyeronima alchornioides), palmiteiros (Euterpe edulis), principalmente nas áreas mais íngremes, entre outras. Nas matas secundárias estão presentes nataieiros (Tibouchinia pulchra), paus-jacarés (Piptadenia gonoacantha), embaúbas (Cecropia spp), capororocas ( Rapanea ferruginea), caqueras (Senna multijuga), goiabeiras (Psidium guajava), tucaneiras (Cytharexyllum myrianthum) e guapuruvus (Schizolobium parahyba).

Estudo realizado por GODOY et al. (1998) mostrou que a sucessão nas florestas secundárias sobre calcário é substancialmente diferente da que ocorre sobre solos originados de rochas ígneas ou metamórficas do Complexo Cristalino Brasileiro, mais ácidos.

Na região média do vale, encontra-se a última grande reserva florestal nativa de São Paulo, formando o continuum ecológico de Paranapiacaba, com mais de 120.000 ha, abrangendo as seguintes unidades de conservação: 
- PARQUE ESTADUAL TURISTICO DO ALTO RIBEIRA (PETAR)

- PARQUE ESTADUAL INTERVALES

- PARQUE ESTADUAL CARLOS BOTELHO

- PARQUE ESTADUAL JACUPIRANGA

- APA SERRA DO MAR

- ESTAÇÃO ECOLÓGICA XITUÉ

Segundo a SECRETARIA DO MEIO AMBIENTE DO ESTADO DE SÃO PAULO (1999), a fauna da região, composta por habitantes da Mata Atlântica, também é rica, sendo que várias espécies são endêmicas e outras correm perigo de extinção, como o mono-carvoeiro (Brachyteles arachnoides), a jacutinga (Pipile jacutinga), a onça pintada (Pantera onca) e a onça parda (Puma concolor). Deve-se destacar a fauna cavernícola, representada por organismos com adaptações morfo-fisio e etológicas para ocupar o ambiente hipógeo.

$\mathrm{Na}$ bacia do rio Betari foi registrada a ocorrência de espécies troglomórficas e troglóbias. MARACCHIOLO (1994) encontrou espécies troglóbias do gênero Aegla (Decapoda, Anomura) nos rios das cavernas Santana e Areias. Pimelodella kronei, um bagre troglóbio, também foi encontrado nesta última caverna (DESSEN et al., 1980 e TRAJANO, 1987). Outras espécies troglóbias ou troglomórficas, como da classe Diplopoda (centopéias), Grylloidea (grilos), Opiliones (opiliões), Amphipoda, todas artrópodes, já foram também identificadas (DESSEN et al., 1980, TRAJANO, 1987 e TRAJANO e GNASPINI-NETTO, 1990).

\subsubsection{MEIO ANTRÓPICO}

A ocupação da região data de, pelo menos, 6000 anos, quando grupos de coletores/caçadores habitavam o Médio e Alto Vale do Ribeira. Os europeus, quando chegaram à região estuarino-lagunar da Baixada do Ribeira, no início do século XVI, encontraram índios Guainases e Carijós, e iniciaram a ocupação 
do Vale do Ribeira. Diversos núcleos de mineração de ouro de aluvião se instalaram na região e o escoamento ocorria pela cidade de Registro. No século XVIII, foi instalado um arraial, onde mais tarde seria estabelecido o núcleo Iporanga, e a intensa circulação de garimpeiros entre os núcleos Apiaí, Iporanga e Iguape originou outros pontos de parada. Com o declínio da mineração, deu-se início ao desenvolvimento da agricultura de subsistência em posses de domínio familiar (MARINHO, 1992).

Em 1939 foi aberta a estrada Iporanga - Apiaí, que deu novo impulso à região, através da extração de ouro e minério de chumbo, zinco e prata. Neste período, iniciou-se o turismo nas cavernas e, em 1958, foi criado o parque do Alto Ribeira, mais tarde transformado no PETAR. Novamente, a mineração foi interrompida e teve início outro choque econômico, que originou especulação e concentração fundiária, com a expropriação de trabalhadores rurais, principalmente a partir da década de 70 . Neste período, surgiram atividades agro-pecuárias extensivas que descaracterizaram grandes áreas, inclusive serranas (MARINHO, op cit.).

$\mathrm{Na}$ década de 80 , quando medidas de proteção se intensificaram com a instalação do PETAR, os desmatamentos foram proibidos mas, por outro lado, criaram-se conflitos sociais, uma vez que não foram oferecidas alternativas. A especulação imobiliária intensificou-se e o comércio de posses tornou-se fonte de renda. Muitos habitantes tornaram-se palmiteiros, e a abertura de trilhas contribuiu muito para a descaracterização da vegetação primária (MARINHO, op cit.). Atualmente, um novo ciclo econômico se intensifica - o do turismo.

Região tradicionalmente com vocação minerária, o vale do Alto Ribeira sofreu muitos impactos, principalmente a contaminação de suas águas, devido ao tratamento do minério. Também danos físicos às cavernas e desflorestamentos foram freqüentes (GT-PETAR/CENIN,1980). Atualmente, essas atividades são mínimas, mas muitos rejeitos de minerações que estão expostos ao tempo acabam atingindo os rios pela drenagem na bacia. 
A agricultura local é de subsistência, em pequenas áreas. Existem atividades pecuárias, mas elas não são significativas. A inclinação do terreno torna à área propícia a erosão, fato que deve ser observado.

Hoje, o turismo é a atividade que traz o maior risco para região do rio Betari. O crescimento dessa atividade sem planejamento tem levado à construção de pousadas sem estrutura de saneamento básico, e é freqüente o despejo de resíduos líquidos a céu aberto ou diretamente nos córregos e rios. Da mesma forma, o vandalismo leva à destruição do patrimônio espeleológico. Esse efeito é contraditório, pois o turismo, ao que tudo indica, é a forma mais adequada de desenvolvimento econômico-regional de maneira sustentável.

\subsubsection{O Bairro Da Serra}

O bairro da Serra é o maior aglomerado humano na bacia e é onde a maioria dos turistas se hospedam. Como em outros destinos, o turismo tem gerado impactos positivos e negativos. O impacto econômico positivo é que parte da população do bairro obtém ou complementa a renda familiar graças à atividade turística. Isso tem levado alguns moradores a vislumbrarem uma fonte de renda a mais ou serem donos de seu próprio negócio, construindo quartos (pousadas), alugando quintais para campistas ou quartos para hóspedes. Segundo ROSSI (1996), 35,33\% dos turistas que visitaram o Núcleo Santana do PETAR em 1996, hospedaram-se no bairro da Serra, e outros 30,43\% acamparam no próprio núcleo. Nesse bairro, $29,23 \%$ se hospedaram em casas particulares, 30,76\% em uma das três pousadas de pessoas do próprio bairro e $35,39 \%$ em outras duas pousadas, cujos proprietários não são pessoas residentes no bairro. Em 1998, 24.100 turistas visitaram o Núcleo Santana (SECRETARIA DO MEIO AMBIENTE DO ESTADO DE SÃO PAULO, 1999), o que mostra o volume de pessoas que se hospedaram no bairro da Serra.

Por outro lado, ambientalmente, o impacto é negativo, pois esse crescimento econômico está ocorrendo sem planejamento e tem como 
conseqüências desmatamento, erosão, descaracterização cultural e poluição dos corpos d'água.

Segundo DE BLASIS (1996), essa área apresentava originalmente um padrão de ocupação disperso, com pouca visibilidade entre as casas, separadas por roças, pomares e capoeiras altas. Esse padrão de assentamento era devido ao estilo de vida tradicional dos moradores da região. Os núcleos familiares apresentavam controle sobre as parcelas em que baseavam sua subsistência. Atualmente, o padrão de ocupação já apresenta características de núcleos urbanos, com maior adensamento de construções.

O aumento demográfico e da área construída deve-se ao crescimento vegetativo, ao retorno de parentes que tentaram oportunidades em centros maiores, migração de pessoas das redondezas e as casas de turistas, que permanecem por grande parte do ano desocupadas (DE BLASIS, op. cit.). Esse crescimento gerou um núcleo de urbanização com praça, iluminação, posto de saúde, escola, ponto de ônibus e onde se concentram $53 \%$ das casas do Bairro da Serra. Outro foco de adensamento ocorre um quilometro acima deste núcleo, com $25 \%$ das casas na margem direita do rio Betari, e um terceiro foco na outra margem, com $9 \%$ das casas. Cabe ressaltar que DE BLASIS obteve esses dados em 1994 e hoje a situação é outra, com esses adensamentos mais populosos e maior área construída.

Em 1998, a situação se modificou ainda mais, devido a problemas com área de demarcação do Parque Estadual Turístico do Alto Ribeira (PETAR), que faz limite com o bairro da Serra. Muitas áreas embargadas voltaram a ser construídas, numa tentativa de oportunismo por parte de algumas pessoas, devido a problemas administrativos, que continuam até hoje.

\subsubsection{O Parque Estadual Turístico Do Alto Ribeira (PETAR)}

Em 1958 foi criado o PETAR, com objetivo de proteger o patrimônio espeleológico e a fauna e flora da Mata Atlântica. Com 35.712 ha, ele engloba 
áreas dos municípios de Apiaí e Iporanga em um perímetro de $180 \mathrm{~km}$. Na região do PETAR está a maior concentração de cavernas do Brasil, sendo que 30 estão destinadas à visitação turística. Durante 25 anos o parque ficou abandonado, quando em 1983 foi efetivamente implantado, como conseqüência da mobilização da Sociedade Brasileira de Espeleologia, pesquisadores, ambientalistas e apoio da imprensa. Nessa época, nada estava regularizado ou desapropriado e 200 famílias estavam instaladas no interior do parque, incluindo comunidades tradicionais e invasores recentes. Foram determinados os limites do parque e $80 \%$ de sua área era coberto por requerimentos e concessões de lavras, com 12 lavras em ação e cavernas sendo destruídas pela atividade minerária. A visitação turística era descontrolada e predatória (LINO, 1999). O Núcleo Caboclos, onde existia uma sede do Instituto Geográfico e Geológico, foi a sede administrativa do parque após sua criação (BONDUKI, 1997).

Entre 1985 e 1988, tiveram andamento os processos de regulamentação fundiária, implantação de núcleos de visitação pública e ações de fiscalização articuladas junto à Polícia Florestal e de Mananciais (SECRETARIA DO MEIO AMBIENTE DO ESTADO DE SÃO PAULO, 1999). Em 1989 foi inaugurado o Núcleo Santana e teve início a visitação pública regularizada. Em 1990/91 o crescimento do ecoturismo tornou o parque um atrativo potencial e a procura aumentou. A cobrança de ingressos no Núcleo Santana foi iniciada em 1992 (BONDUKI, 1997).

No período compreendido entre 1995 e 1999, a administração do Parque foi transferida para Apiaí. Foram implantadas bases de fiscalização nos Núcleos Caboclos e Casa de Pedra, e implantado o Núcleo Ouro Grosso, com centro para eventos (salas para exposições, apresentações e reuniões) e alojamento para 40 pessoas, além do Museu de Cultura Tradicional, com monjolo e casa de farinha. A regularização fundiária foi priorizada (BONDUKI, 1997; SECRETARIA DO MEIO AMBIENTE DO ESTADO DE SÃO PAULO, 1999). 
Segundo LINO (1999), 15.000 ha estão regularizados e o restante, em processo de regularização. Ocorreu a suspensão de requerimentos de alvarás minerários, fechamento de lavras irregulares e embargo de mineração remanescente. Hoje, existe uma proposta de redelimitação das fronteiras do parque para excluir a área ocupada pela comunidade tradicional (bairro da Serra), incorporando novas áreas. Três Núcleos de visitação estão implantados com infra-estrutura de recepção e monitoramento, recebendo entre 30 e 40 mil turistas/ano.

Atualmente, a extração de palmito, pressão por parte de mineradoras no entorno do parque, desmatamentos e grilagem, além da caça, são problemas enfrentados no PETAR, sendo que no bairro da Serra, com exceção da mineração, todos têm sido constatados por parte da fiscalização (SECRETARIA DO MEIO AMBIENTE DO ESTADO DE SÃO PAULO, 1999). 


\subsection{MATERIAL E MÉTODOS}

\subsubsection{CARACTERÍSTICAS MORFOMÉTRICAS}

A partir de base cartográfica digital (IBGE, escala 1:50.000), foram calculadas a área da bacia do rio Betari, o comprimento do curso principal e o perímetro (acompanhando os limites de cada sub-bacia, através de cotas altimétricas), além dos demais dados para o cálculo dos índices morfométricos.

\subsubsection{1. Índice de Forma}

Relaciona o perímetro da bacia com sua área. Foi determinado pela expressão:

$$
\mathrm{K}=\mathrm{P} /(2 \pi \mathrm{A})
$$

onde:

$$
\begin{aligned}
& K=\text { índice de forma } \\
& P=\text { perímetro da bacia } \\
& A=\text { área da bacia }
\end{aligned}
$$

\subsubsection{Relação de Elongação}

Correlaciona o diâmetro de um círculo de mesma área que a bacia considerada, e o maior comprimento dela, sendo este medido paralelamente à linha principal de drenagem. É expressa pela seguinte fórmula:

$$
\mathrm{Re}=\mathrm{d} / \mathrm{l}
$$

onde:

$$
\text { Re = relação de elongação }
$$


$\mathrm{d}=$ diâmetro do circulo de área igual à da bacia

$\mathrm{I}$ = maior comprimento em $\mathrm{Km}$

\subsubsection{Densidade Hidrográfica}

É a relação entre o número de rios e a área da bacia hidrográfica, e compara a quantidade de cursos de água existentes em uma área de tamanho padrão. É expresso em número de canais/ $/ \mathrm{Km}^{2}$, e obtido pela expressão:

$$
\mathrm{Dh}=\mathrm{N} / \mathrm{A}
$$

onde:

$\mathrm{Dh}=$ densidade hidrográfica

$\mathrm{N}$ = número total de rios ou cursos d'agua

$\mathrm{A}=$ área da bacia considerada

\subsubsection{Densidade de Drenagem}

Segundo VILLELA \& MATTOS (1975), a densidade de drenagem $\left(\mathrm{Km} / \mathrm{Km}^{2}\right)$ é um indicador do grau de desenvolvimento de um sistema de drenagem da bacia. Foi obtido pela expressão:

$D d=L / A$

onde:

$\mathrm{Dd}=$ densidade de drenagem

$\mathrm{L}=$ comprimento total dos cursos $d^{\prime}$ água da bacia

$A=$ área da bacia considerada.

\subsubsection{Relação de Relevo}

Relaciona o relevo total da bacia (diferença halométrica entre o ponto mais alto e o ponto mais baixo) e sua maior dimensão. Foi obtido pela fórmula: 
$\mathrm{Rr}=$ gradiente $\mathrm{da}$ bacia/l

onde:

$\mathrm{Rr}=$ relação de relevo em $\mathrm{m} / \mathrm{Km}$

gradiente da bacia = diferença entre a maior e menor altitude da bacia em metros

I = comprimento máximo medido paralelamente ao canal principal em $\mathrm{Km}$.

\subsubsection{Ordem dos Canais}

A ordem dos rios reflete o grau de ramificação dos cursos d'água ou a hierarquia da bacia hidrográfica. A partir das nascentes, são atribuídos números aos rios, e aqueles que não têm tributários recebem o número 1. A junção de dois rios de mesma ordem forma um canal de ordem imediatamente superior, ou seja, a junção de dois rios de ordem $n$ forma um rio de ordem $n+1$.

\subsubsection{SISTEMA DE AQUISIÇÃO E GEOPROCESSAMENTO DE INFORMAÇÕES}

Segundo CAUBET e FRANK (1993), uma questão conceitual muito importante no planejamento ambiental é o significado da intervenção sócioeconômica sobre o sistema natural, que estão interligados pelo uso do solo. A visualização e interpretação da interação entre o meio sócio-econômico e natural podem ser feitas por processos de sensoriamento remoto e sistema de informação geográfica. 


\subsubsection{Sensoriamento Remoto}

A avaliação de recursos hídricos de uma região pode ser feita através dos componentes do ciclo hidrológico e de suas relações, tanto quantitativa, como qualitativamente. Desta forma, pode-se avaliar taxas de movimentação, quantidade e qualidade da água dentro de cada subsistema do ciclo hidrológico. Esses processos variam no tempo e espaço e o sensoriamento remoto permite estender informações pontuais para um contexto mais amplo. O sensoriamento remoto também pode ser aplicado na análise e monitoramento do uso da terra e de processos geomorfológicos (NOVO, 1988).

As imagens de satélite LANDSAT 5, sensor TM (Thematic Mapper), foram fornecidas pelo INPE (Instituto Nacional de Pesquisas Espaciais de São José dos Campos) e serviram para caracterização dos usos do solo e da rede hidrológica.

\subsubsection{Sistema de Informações Geográficas - SIG}

O SIG fornece um meio de integração, superpondo mapas de dados diversos e das mais variadas fontes, criando uma nova coleção de dados regionais (GRINER, 1993).

Segundo FERRARI (1997), o SIG traz como benefício o fornecimento de melhores e novas informações, e permite a tomada de decisões de caráter estratégico como planejamento, gerenciamento e alocação de recursos. Isto é possível graças à agilidade na geração de informações para tomada de decisões, planejamento e monitoramento, por permitir maior capacidade de manipulação de informações, através de análise espacial, modelagem e simulação, já que se trata de um mecanismo para integrar, visualizar e resumir informações. Assim, auxilia na elaboração e no monitoramento de políticas de desenvolvimento. 
O SIG é muito utilizado no manejo e análise de usos da água. Segundo JURACEK e KENNY (1993), os benefícios são: base de dados para manejo; fácil acesso aos dados; acesso a conjunto de dados simultaneamente; resultados mais consistentes e reprodutíveis, comparado a métodos manuais; visualização de efeitos em amplos espaços; capacidade de facilitar e aumentar a análise de procedimentos tomados; e previsão de novas aplicações onde previamente era impossível serem feitas.

Para caracterização da região em seus aspectos físicos (Declividade, Geologia e Geomorfologia), biológicos e de uso humano, foi utilizada uma base cartográfica digital (IBGE, escala 1:50.000) fornecida pelo PPMA/SP (Projeto de Preservação da Mata Atlântica no Estado de São Paulo).

Os dados topográficos da base cartográfica digital foram transformados em Modelo Numérico de Terreno, utilizando o programa ArcView 3D, versão 3.1, a partir do qual foi obtido o mapa de declividade. Foram consideradas 5 classes: 0 a $10 \%, 10$ a 20\%, 20 a $30 \%, 30$ a $50 \%$ e superior a $50 \%$.

O mapa geológico foi produzido a partir das folhas Iporanga (SG.22-X-BV-2) (CPRM, 1974a), Apiaí (SG.22-X-B-V-1) (CPRM, 1974b), Araçaíba (SG.22X-B-II-3) (CPRM, 1974c) e Mina do Espírito Santo (SG.22-X-B-II-4) (CPRM, 1974d), todas em escala 1:50.000 do Projeto SUDELPA. Foram identificadas 9 classes de unidades lito-estratigráficas: Cenozóico - Quaternário Holoceno (aluviões em geral); Cenozóico - Quaternário Holoceno (sedimentos coluviais); Eo-Paleozóico - Intrusivas Graníticas (granitos, quartzomonzitos e granodioritos); Mesozóico - Jurássico-Cretáceo Intrusivas Básicas (complexo gábrico); Pleistoceno - Formação Pariquera-Açu (conglomerados semiconsolidados, areias e argilas); Pré-Cambriano Superior - Grupo Açungui Não Diferenciado (calcários epimetamórficos); Pré-Cambriano Superior - Grupo Açungui Não Diferenciado (metaconglomerados polimíticos); Pré-Cambriano Superior - Grupo Açungui Não Diferenciado (metassedimentos siltico-argilosos, incluindo metassiltitos, ardósias, quartzo-sericita-xisto, filitos e epiquartzitos subordinados); e Pré-Cambriano Superior - Grupo Açungui Não Diferenciado 
(quartzitos e epiquartzitos). Também foram extraídas destes mapas as minas abandonadas e seus respectivos minérios.

As feições morfológicas da região foram obtidas das folhas Iporanga (SG.22-X-B-V-2) (CPRM, 1974e), Apiaí (SG.22-X-B-V-1) (CPRM, 1974f), Araçaíba (SG.22-X-B-II-3) (CPRM, 1974g) e Mina do Espírito Santo (SG.22-XB-II-4) (CPRM, 1974h), todos em escala 1:50.000 do mesmo projeto. As 12 feições morfológicas encontradas foram: áreas calcárias de relevo cárstico, coluviões de pé de encosta, cristas e espigões em metassedimentos siltico/argiloso (Grupo Açungui), cristas e espigões em metassedimentos siltico/arenoso (Grupo Açungui), cristas quartzíticas (Grupo Açungui), dolinas, esporões do Complexo Gábrico, rocha sã aflorante, sedimentos fluviais recentes do baixo terraço, sedimentos pleistocênicos do alto terraço, superfície de cimeira (nível 800-900m) e vertentes do Planalto.

Os mapas geológico e geomorfológico foram digitalizados no programa ArcView, versão 3.2, onde foram calculadas as áreas das diversas unidades lito-estratigráficas e feições morfológicas.

Os mapas de uso e ocupação da terra foram produzidos a partir da interpretação visual de imagens de satélite LANDSAT TM-345 de setembro de 1986 e outubro de 2000, fornecidas pelo INPE (Instituto Nacional de Pesquisas Espaciais). O georeferenciamento em sistemas de referência vetorial destas imagens foi elaborado no programa ERDAS versão 8.3, e a digitalização foi feita no programa ArcView, versão 3.2. Foram estabelecidas três classes: vegetação natural - abrange as formações florestais incluindo mata e capoeira; adensamentos populacionais - abrange as áreas com agrupamento de edificações; e atividades agropecuárias - engloba áreas ocupadas pela agricultura ou pecuária. Para uma melhor distinção das classes "adensamentos populacionais" e "atividades agropecuárias", foram consultadas fotos aéreas (1:35.000) de 2000, concedidas pelo PPMA/SP (Projeto de Preservação da Mata Atlântica no Estado de São Paulo). 
A partir desses mapas, foram calculadas as áreas ocupadas pelas três classes. Os dados de uso e ocupação da terra foram relacionados, a fim de verificar a evolução no período de 1986 e 2000, através do programa IDRISI, versão 2.0, obtendo-se uma matriz de contingência. Nesta tabela, as imagens são correlacionadas pixel a pixel, indicando se a classe de uso permaneceu a mesma, modificou-se e em qual classe transformou-se. A fim de verificar a adequação do uso e ocupação atual, os dados deste mapa foram relacionados com a declividade, obtendo-se uma nova matriz de contingência.

Para a elaboração do mapa de áreas protegidas, foi aplicada a legislação incidente na área, CÓDIGO FLORESTAL, Lei ㄲo 4771, de 15 de setembro de 1965, e considerada a área do Parque Estadual Turístico Alto Ribeira (PETAR). Os critérios utilizados foram:

- de 30 (trinta) metros para os cursos d' água de menos de 10 (dez) metros de largura;

- nas nascentes, ainda que intermitentes, e nos chamados "olhos d' água", qualquer que seja a sua situação topográfica, num raio mínimo de 50 (cinqüenta) metros de largura;

- igual à metade da largura dos corpos d'água que meçam de 100 (cem) a 200 (duzentos) metros;

- no topo de morros, montes, montanhas, em áreas delimitadas a partir da curva de nível correspondente a 2/3 (dois terços) da altura mínima da elevação em relação à base;

- nas linhas cumeadas, em área delimitada a partir da curva de nível correspondente a (dois terços) da altura, em relação à base, do pico mais baixo da cumeada, fixando-se a curva de nível para cada segmento da linha de cumeada equivalente a 1.000 (mil) metros;

- nas encostas ou partes destas, com declividade superior a $45^{\circ}$, equivalente a $100 \%$ na linha de maior declive. 
Com os dados do mapa de áreas protegidas e de uso e ocupação da terra de 2000 , foi obtida a matriz de contingência no programa IDRISI, versão 2.0, com o intuito de verificar a adequação do uso das terras frente à legislação. 


\subsection{RESULTADOS}

\subsubsection{MORFOMETRIA DA BACIA}

A bacia do rio Betari engloba uma área de $216,734 \mathrm{Km}^{2}$, com $87,532 \mathrm{Km}$ de perímetro e 473 cursos d'água, que somam $520 \mathrm{Km}$ de curso. O rio Betari é de quarta ordem, sendo que em sua cabeceira ocorrem rios de terceira ordem, devido à riqueza em cursos d'água da bacia (figura 1.4.1).

O índice de forma encontrado foi de 1,66. Este índice compara a forma da bacia à um círculo de mesma área. Quanto maior o coeficiente, mais irregular é a bacia, ou quanto mais próximo de 1 for o índice, mais circular e mais sujeita a enchentes é a bacia (VILLELA \& MATTOS, 1975).

VILLELA \& MATTOS (op cit.) encontraram para a bacia do ribeirão do Lobo o valor de 1,47 e a consideraram pouco sujeita a enchentes. A bacia do rio Betari apresentou um valor maior, sendo ainda menos sujeita a enchentes.

Outro índice que está relacionado à circularidade da bacia é a relação de elongação. Na bacia do rio Betari foi encontrado um valor de 0,88 . Quanto mais próximo da unidade, mais circular é a bacia e mais sujeita a enchentes. LAGE FILHO (1996) encontrou valores que variavam de 0,60 a 0,89 em sub-bacias da bacia hidrográfica do ribeirão das Antas, em Poços de Caldas, Minas Gerais, e as considerou mediamente ou pouco circulares.

A relação de relevo é um indicativo da relação entre a declividade da bacia e seu comprimento. Valores elevados indicam declividade acentuada, enquanto valores menores indicam um relevo mais suavizado. Segundo VILLELA \& MATTOS (op cit.), a declividade determina a velocidade do escoamento superficial, afeta o tempo para a água da chuva concentrar-se no leito fluvial, sua infiltração e a suscetibilidade para erosão dos solos. A relação de relevo encontrada foi de $45,81 \mathrm{~m} / \mathrm{Km}$. Este valor é bem superior aos 
encontrados por LAGE FILHO (1996), e demonstram que a bacia possui declividade acentuada.

LAGE FILHO (1996) verificou que as sub-bacias da bacia hidrográfica do Ribeirão das Antas apresentaram densidades hidrográficas que variaram de 1,22 a 1,37 canais $/ \mathrm{Km}^{2}$. A bacia hidrográfica do rio Betari apresentou uma densidade hidrográfica de 2,2 canais $/ \mathrm{Km}^{2}$, e uma densidade de drenagem de $2,4 \mathrm{Km} / \mathrm{Km}^{2}$, o que mostra que a bacia é relativamente bem drenada. Segundo VILLELA e MATOS (1975), bacias com densidade de drenagem da ordem de $0,5 \mathrm{Km} / \mathrm{Km}^{2}$ são pobres em drenagem, e uma bacia excepcionalmente bem drenada apresentaria um valor de $3,5 \mathrm{Km} / \mathrm{Km}^{2}$.

\subsubsection{Geologia}

A tabela 1.4.2. mostra as unidades lito-estratigráficas da bacia hidrográfica do rio Betari, onde predominam as unidades Pré-Cambriano Superior - Grupo Açungui Não Diferenciado (calcários epimetamórficos), 40,08\%, e Pré-Cambriano Superior - Grupo Açungui Não Diferenciado (metassedimentos siltico-argilosos, incluindo metassiltitos, ardósias, quartzosericita-xisto, filitos e epiquartzitos subordinados), 47,44\%. Na figura 1.4.2., estão representadas a distribuição das unidades na bacia.

TABELA 1.4.2. Unidades lito-estratigráficas da bacia hidrográfica do rio Betari.

\begin{tabular}{ll}
\hline Classes & (Área) \% \\
Cenozóico - Quaternário Holoceno (aluviões em geral) & 0,63 \\
Cenozóico - Quaternário Holoceno (sedimentos coluviais) & 0,21 \\
Eo-Paleozóico - Intrusivas Graníticas (granitos, quartzomonzitos e granodioritos) & 0,20 \\
Mesozóico - Jurássico-Cretáceo Intrusivas Básicas (complexo gábrico) & 1,08 \\
Pleistoceno - Formação Pariquera-Açu (conglomerados semi-consolidados, areias e argilas) & 0,05 \\
Pré-Cambriano Superior - Grupo Açungui Não Diferenciado (calcários epimetamórficos) & 40,08 \\
Pré-Cambriano Superior - Grupo Açungui Não Diferenciado (metaconglomerados polimíticos) & 0,08 \\
Pré-Cambriano Superior - Grupo Açungui Não Diferenciado (metassedimentos siltico-argilosos, 47,44 \\
incluindo metassiltitos, ardósias, quartzo-sericita-xisto, filitos e epiquartzitos subordinados) \\
Pré-Cambriano Superior - Grupo Açungui Não Diferenciado (quartzitos e epiquartzitos) & 10,23 \\
Total & 100,00 \\
\hline
\end{tabular}




\subsubsection{Geomorfologia}

As áreas correspondentes às diversas feições morfológicas estão descritas na tabela 1.4.3. Como pode ser observado, predominam na bacia hidrográfica do rio Betari áreas calcárias de relevo cárstico $(38,42 \%)$ e cristas e espigões em metassedimentos siltico/arenoso (Grupo Açungui), 35,27\%. Na figura 1.4.3. estão representadas a distribuição das feições na bacia.

TABELA 1.4.3. Feições morfológicas na bacia hidrográfica do rio Betari.

\begin{tabular}{ll}
\hline Classes & (Área) \% \\
áreas calcárias de relevo cárstico & 38,42 \\
coluviões de pé de encosta & 0,96 \\
cristas e espigões em metassedimentos siltico/argiloso Grupo Açungui) & 9,71 \\
cristas e espigões em metassedimentos siltico/arenoso (Grupo Açungui) & 35,27 \\
cristas quartzíticas (Grupo Açungui) & 9,99 \\
dolinas & 2,42 \\
esporões do Complexo Gábrico & 0,51 \\
rocha sã aflorante & 0,54 \\
sedimentos fluviais recentes do baixo terraço & 0,76 \\
sedimentos pleistocênicos do alto terraço & 0,23 \\
superfície de cimeira (nível 800-900m) & 0,88 \\
vertentes do planalto & 0,32 \\
total & 100,00 \\
\hline
\end{tabular}

\subsubsection{Declividade}

O relevo da área é bastante acidentado (figura 1.4.4), sendo que $60,4 \%$ se encontra em declividade superior a $30 \%$ (tabela 1.4.4).

TABELA 1.4.4. Classes de declividade na bacia hidrográfica do rio Betari.

\begin{tabular}{ll}
\hline Classes & Total \\
$0-10 \%$ & 12,56 \\
$10-20 \%$ & 10,82 \\
$20-30 \%$ & 16,21 \\
$30-50 \%$ & 34,66 \\
$>50 \%$ & 25,74 \\
Total & 100,00 \\
\hline
\end{tabular}




\subsubsection{Uso da terra}

As imagens obtidas pelo satélite LANDSAT - TM 345, referentes a setembro de 1986 e outubro de 2000, podem ser observadas nas figuras 1.4.5.1 e 1.4.5.2, respectivamente. A situação do uso e conservação da terra, nos dois períodos, pode ser observada nas figuras 1.4.5.3 e 1.4.5.4. Os mapas gerados pela interpretação visual das imagens de satélite, georreferenciadas e digitalizadas, mostraram que, em setembro de 1986, a bacia do rio Betari possuía $4,58 \%$ de sua área antropizada e, em outubro de 2000 , essa área passou para $5,70 \%$, um aumento de $1,12 \%$. Ao mesmo tempo, houve um decréscimo da área de vegetação natural de 95,42\% para 94,30\%. Estes percentuais podem ser observados na matriz de contingência (tabela 1.4.5.1), onde os totais das duas datas estão representados como total de 1986 e total de 2000.

A tabela 1.4.5.1 mostra a dinâmica da ocupação do solo nesse período. Os adensamentos populacionais tiveram um aumento, decorrente do desmatamento de vegetação natural e da ocupação por edificações de áreas com atividades agropecuárias. Ao mesmo tempo, parte dos adensamentos foram transformados em atividades agropecuárias ou foram abandonados, permitindo uma regeneração da vegetação natural.

A maior parte da área ocupada por atividades agropecuárias manteve-se como tal $(3,74 \%)$, e o que contribuiu para o seu aumento foi a supressão da vegetação natural $(1,67 \%)$. 
TABELA 1.4.5.1. Matriz de contingência obtida a partir do cruzamento entre uso e ocupação da terra de 1986 e 2000, na bacia hidrográfica do rio Betari (os valores representam as porcentagens dos pixels).

\begin{tabular}{lllll}
\hline $1986 \backslash 2000$ & $\begin{array}{l}\text { adensamentos } \\
\text { populacionais }\end{array}$ & $\begin{array}{l}\text { atividades } \\
\text { agropecuárias }\end{array}$ & $\begin{array}{l}\text { vegetação } \\
\text { natural }\end{array}$ & Total de 2000 \\
$\begin{array}{l}\text { adensamentos } \\
\text { populacionais }\end{array}$ & 0,11 & 0,06 & 0,06 & 0,23 \\
atividades agropecuárias & 0,07 & 3,74 & 1,67 & 5,47 \\
vegetação natural & 0,02 & 0,59 & 93,69 & 94,30 \\
Total de 1986 & 0,20 & 4,38 & 95,42 & 100,00 \\
\hline
\end{tabular}

De forma geral, o uso da terra na área de estudo está adequado em relação à declividade. Dos 5,70\% de uso antrópico (atividades agropecuárias e adensamentos populacionais), 2,97\% encontra-se entre 0 e $30 \%, 1,59 \%$ entre 30 a $50 \%$ e $1,14 \%$ acima de $50 \%$ (tabela 1.4.5.2).

TABELA 1.4.5.2. Matriz de contingência obtida a partir do cruzamento entre o uso e ocupação da terra (outubro/2000) e a declividade na bacia hidrográfica do rio Betari (os valores representam as porcentagens dos pixels).

\begin{tabular}{lllll}
\hline Classes & $\begin{array}{l}\text { adensamentos } \\
\text { populacionais }\end{array}$ & $\begin{array}{l}\text { atividades } \\
\text { agropecuárias }\end{array}$ & vegetação natural & Total \\
\hline $0-10 \%$ & 0,10 & 1,18 & 11,28 & 12,56 \\
$10-20 \%$ & 0,04 & 0,74 & 10,04 & 10,82 \\
$20-30 \%$ & 0,03 & 0,88 & 15,31 & 16,21 \\
$30-50 \%$ & 0,05 & 1,54 & 33,08 & 34,66 \\
$>50 \%$ & 0,01 & 1,13 & 24,60 & 25,74 \\
\hline Total & 0,23 & 5,47 & 94,30 & 100,00 \\
\hline
\end{tabular}

\subsection{6. Áreas protegidas}

A figura 1.4.6. mostra áreas com algum tipo de proteção legal na bacia hidrográfica do rio Betari. Ocorrem na bacia áreas de preservação permanentes, como $30 \mathrm{~m}$ da margem de rios e $50 \mathrm{~m}$ de lagos ou nascentes, topos de morro, montes e montanhas e áreas com declividade superior a 100\%. Parte da bacia é ocupada pelo PETAR. Como pode ser observado na matriz de contingência (tabela 1.4.6), 68,19\% da área de estudo encontra-se sob 
proteção legal, dos quais $0,14 \%$ estão ocupados por adensamentos populacionais e $2,72 \%$, por atividades agropecuárias.

TABELA 1.4.6. Matriz de contingência obtida a partir do cruzamento entre o uso e ocupação da terra (outubro/2000) e as áreas protegidas na bacia hidrográfica do rio Betari (os valores representam as porcentagens dos pixels).

\begin{tabular}{lllll}
\hline Classes & adensamentos & atividades & vegetação & Total \\
& populacionais & agropecuárias & natural & \\
áreas sem proteção legal & 0,09 & 2,76 & 28,96 & 31,81 \\
áreas protegidas & 0,14 & 2,72 & 65,34 & 68,19 \\
Total & 0,23 & 5,47 & 94,30 & 100,00
\end{tabular}

\subsection{DISCUSSÃO}

O aumento da área antropizada nesses 14 anos, na bacia hidrográfica do rio Betari, pode ser considerado pequeno, quando comparado a outras áreas do Estado de São Paulo. PRADO (1999) encontrou diminuição de 50\% da vegetação natural e aumento de $13 \%$ e $5,5 \%$ de cultivo de cana e da área urbana, respectivamente, no trecho médio da bacia hidrográfica do rio Pardo, entre 1985 e 1997.

No Estado de São Paulo, o cerrado foi praticamente dizimado, devido à urbanização e à formação de agroecossistemas, e o restante é praticamente o que se encontra nas unidades de conservação. Em 1962, havia cerca de 143.700 ha de cerradão, 1.384 .450 ha de cerrado e 309.000 ha de campo cerrado (CHIARINI \& COELHO, 1972). Entre 1990 e 1992, a cobertura vegetal era composta de 73.202 ha de cerradão, 208.586 ha de cerrado e 1.834 ha de campo cerrado (INSTITUTO FLORESTAL, 1993). Em 30 anos, houve uma redução de 49,1\% de cerradão, $85,0 \%$ de cerrado e $99,4 \%$ de campo cerrado.

Este contraste da bacia hidrográfica do rio Betari com outras regiões do Estado se dá por sua inadequação à agricultura, devido ao relevo acidentado, dificuldade de acesso e à vocação minerária da região, que se encontra paralisada, e porque a maior parte da bacia se encontra protegida por algum 
tipo de instrumento legal (áreas de preservação permanente como margem de rios, topos de morro ou declividade superior a 100\%, e o PETAR).

Em outras regiões do Estado, políticas públicas incentivaram a ocupação humana de forma veloz e intensa, provocando a supressão da vegetação natural. GUILLAUMON (1989) e SHIDA (2000) verificaram que, na região de Ribeirão Preto, os incentivos fiscais à silvicultura na década de setenta, foram responsáveis pela maior parte do desmatamento do cerrado na região.

No entanto, apesar de poucas áreas ocupadas, ocorre uso inadequado em algumas regiões da bacia. Mais de $60 \%$ da área de estudo compreende terrenos com declividade onde a ocupação é crítica, uma vez que são suscetíveis a erosão e deslocamento de blocos (INSTITUTO GEOLÓGICO, 1993). Segundo o INSTITUTO GEOLÓGICO (op cit.), a classe compreendida entre 30 e 47\% corresponde ao limite para operação e veículos tracionados, e para o corte raso de madeira sem projeto de exploração sustentado. $\mathrm{Na}$ bacia hidrográfica do rio Betari, cerca de um quarto da área ocupada por atividades agropecuárias e um quarto dos adensamentos populacionais estão nesta classe. Deve-se ressaltar que a agricultura praticada na região não é mecanizada, mas de pequenas roças.

Já VIEIRA et.al.(1988) consideraram fortemente suscetíveis à erosão, terrenos com declividade superior a $20 \%$, dependendo também das condições físicas do solo. Nesse caso, $2,42 \%$ das atividades agropecuárias e $0,08 \%$ dos adensamentos populacionais localizam-se em áreas críticas; $0,1 \%$ dos adensamentos e 1,13\% das atividades agropecuárias encontram-se em declividades superiores a $50 \%$, muito fortemente suscetíveis a erosões, onde o uso agrícola não é recomendado, sob risco de serem totalmente erodidas em poucos anos.

A dinâmica observada no uso da terra pode estar associada a processos sociais e legais. Fluxo de moradores para a região foi evidenciado nas entrevistas feitas no bairro da Serra (Capítulo 2). Cerca de $20 \%$ dos moradores que vivem no bairro migraram de outras cidades e estados, vivendo com 
parentes ou em terrenos próprios. Isso, aliado à construção de pousadas ou quartos para alojamento de turistas, colaborou para o aumento dos adensamentos, e parte de áreas agrícolas e de vegetação natural foi convertida em adensamentos populacionais. Durante as entrevistas, foi citada a evasão de pessoas do bairro, mas esta questão não fazia parte do questionário. Já a regularização fundiária do parque, pode ter permitido a recuperação de algumas áreas; mesmo assim, cerca de $60 \%$ da área ocupada por adensamentos populacionais se encontra em regiões com algum tipo de proteção legal.

A área de vegetação natural perdida nesses 14 anos $(1,12 \%)$ foi transformada em área de uso agropecuário (1,09\%) e somente $0,03 \%$ em adensamentos urbanos. Isso demonstra que a produção agropecuária pode ter aumentado, indicando a melhoria das condições econômicas da região, porém como visto acima, as áreas que podem ser utilizadas para essa finalidade são poucas, devido à declividade da bacia e dos trechos protegidos.

Uma particularidade da bacia hidrográfica do rio Betari é o predomínio do relevo cárstico. Cerca de $17 \%$ da superfície terrestre é coberta por rochas carbonáticas, cujo tipo predominante é o calcário, onde o carste se desenvolve. O calcário apresenta em sua constituição mais de $50 \%$ de carbonato de cálcio e está localizado, em sua maior parte, no hemisfério norte. Apesar da pequena extensão, aproximadamente $25 \%$ da população mundial utiliza o aquífero de áreas cársticas (FORD e WILLIANS, 1989).

O desenvolvimento do carste ocorre devido à solubilidade da rocha calcária. $\mathrm{O}$ carbonato de cálcio $\left(\mathrm{CaCO}_{3}\right)$ reage com o ácido carbônico $\left(\mathrm{H}_{2} \mathrm{CO}_{3}\right)$, produzindo o íon cálcio $\left(\mathrm{Ca}^{2+}\right)$ e bicarbonato $\left(\mathrm{HCO}_{3}{ }^{-}\right)$solúvel. O processo pode ocorrer em água parada ou em movimento, mas é afetado pela temperatura e pela concentração de gás carbônico. Regiões tropicais, onde temperaturas maiores favorecem a dissolução do gás carbônico na água e com cobertura florestal, que fornece $\mathrm{CO}_{2}$ e outros ácidos orgânicos, devido à decomposição da matéria orgânica, aliado a elevadas precipitações, apresentam condições ideais para desenvolvimento do carste (GILLIESON, 1996). 
O maciço rochoso é solubilizado, tanto externamente, originando o epicarste, que fica exposto e sujeito aos processos meteorológicos, quanto internamente, formando o endocarste. No primeiro caso, são formadas dolinas, uvalas, paredões e torres de pedra, canyons, lapiás, pontes e arcos de pedras, vales fechados, dentre outros. O endocarste é caracterizado pelas cavernas. As drenagens superficiais podem desaparecer em sumidouros, que podem evoluir para grandes galerias, canyons, vales fechados (LABEGALINI, 1996).

No mundo todo, o carste vem sendo explorado para extração de calcário. A retirada de água e modificações na superfície de drenagem, geradas por irrigação ou represamento, têm diminuído o suprimento de água no carste. $\mathrm{O}$ desmatamento altera o fluxo e qualidade da água que penetra na rocha calcária. A erosão tem soterrado dolinas e uvalas (GILLIESON, 1996).

Desta forma, o turismo deve ser visto como atividade vocacional da bacia hidrográfica do rio Betari. Se executado de forma planejada, minimizando os impactos negativos e maximizando os positivos, é uma das poucas atividades que podem ser desenvolvidas nessas áreas críticas, aproveitando as características físicas como o relevo acidentado, o carste, e biológicas como a enorme diversidade da flora e a fauna, como atrativos. 


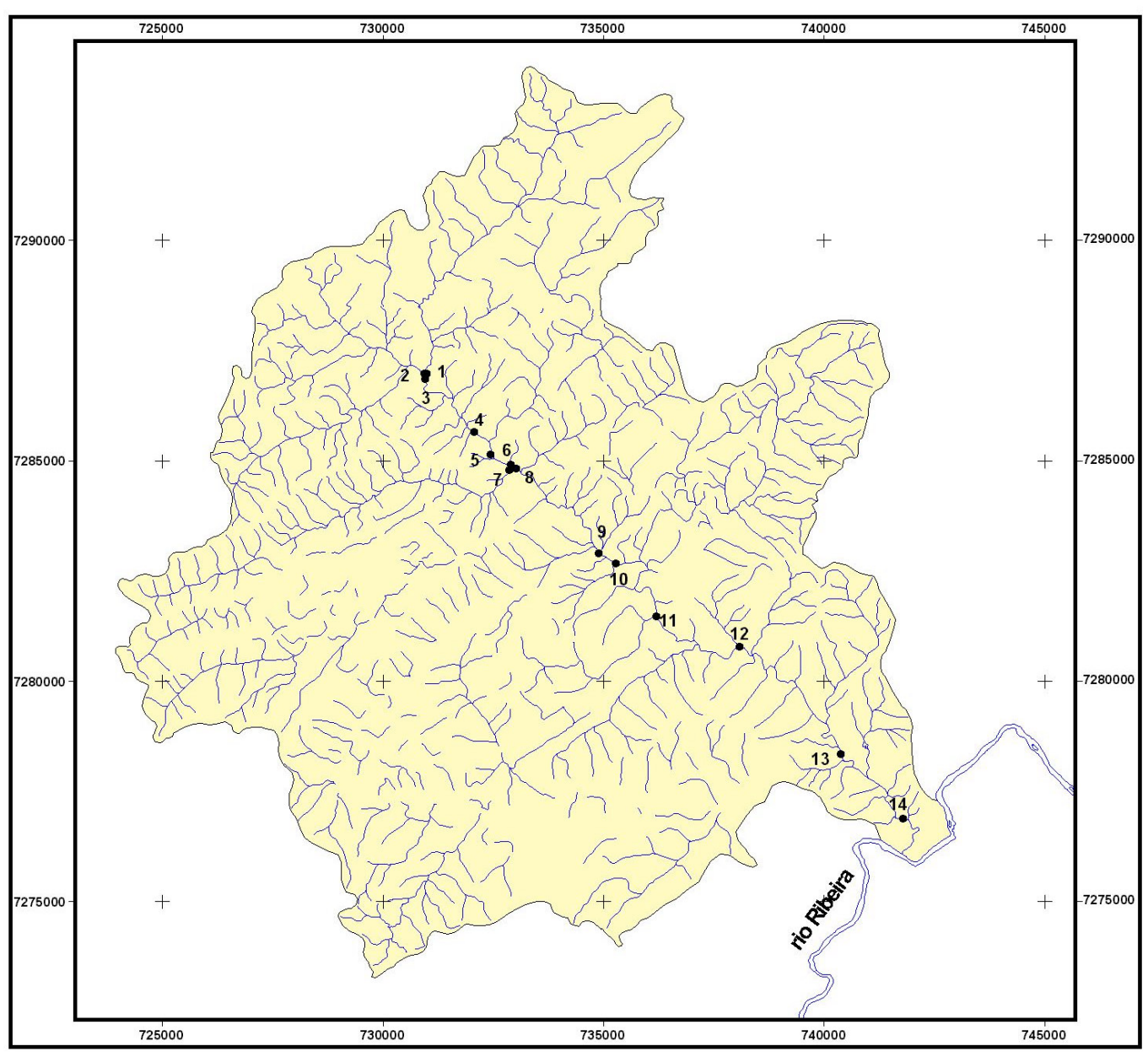

\begin{tabular}{|l|}
\hline Legenda \\
pontos de cole ta \\
rios \\
$\square$ área de estudo
\end{tabular}

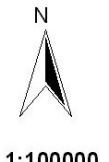

$1: 100000$

Fonte: IBGE escala 1:50.000

Figura 2.2.1. Bacia hidrográfica do rio Betari com rede hidrográfica e pontos de coleta. 


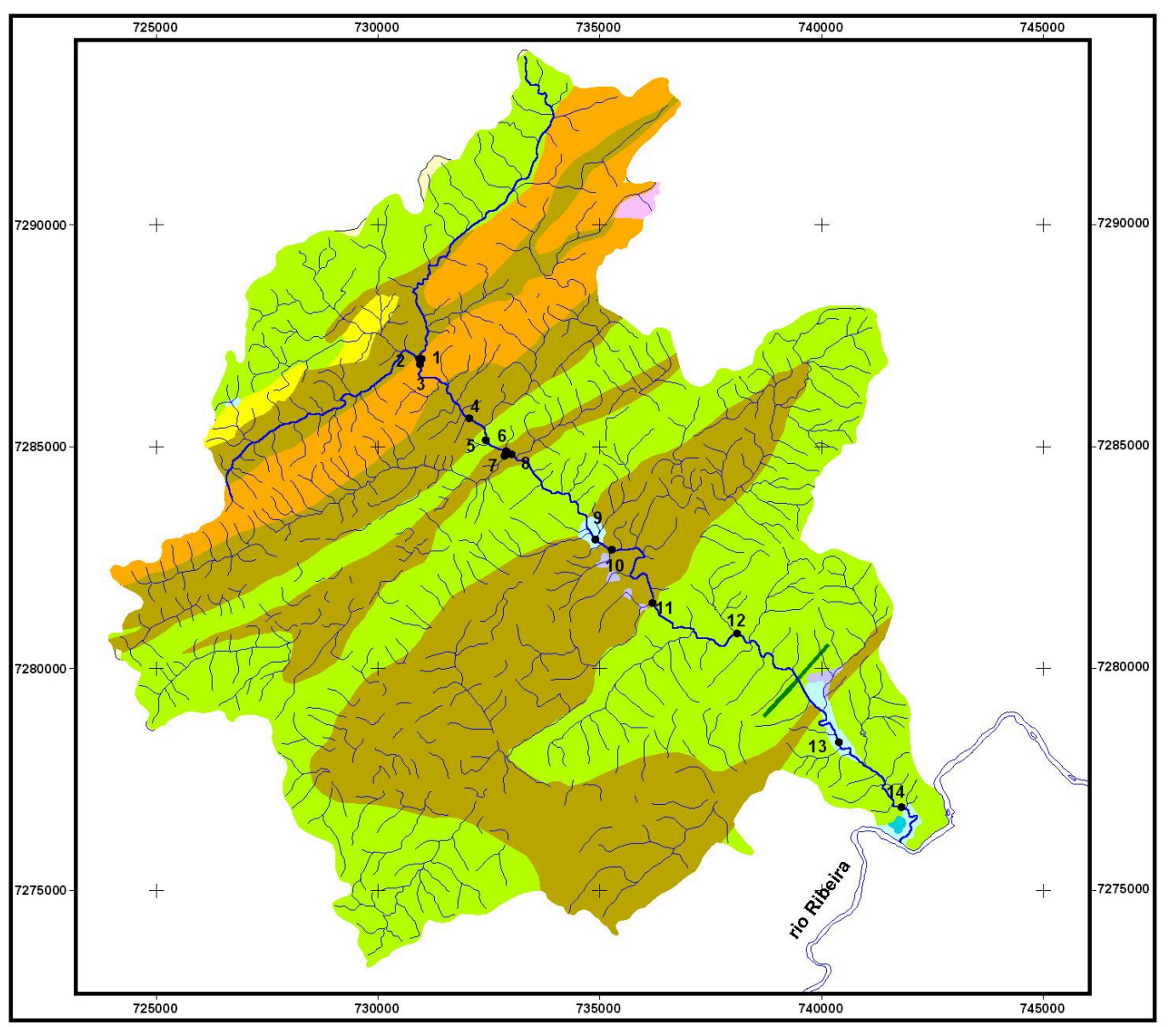

Legend

Cenozóico - Quaternário Holoceno (aluviõess em geral)

Cenozóico - Quaternário Holocento (sedimentos colnviais)

Pleistoceno - Formação Pariquera-Açu
(conglomerados semi-consolidados

cias $\mathrm{e}$ argilas

Eo-Palezoioic - Intrusivas Graniticas

Mesozóico - Jurássico-Cr
Básicas (complexo gabric

Pré-Canbriano Superior - Grupo Acungui

Năo Diferenciado (calcários epinetanónóficos)

Pré Canbriano Sup erior - Grupo Açungui

Nao Diferenciado (hetaconglom erados polimiticos

Pré-Cambriano Superior - Grupo Açungui
Não Diferenciado (netassedinentos silticoIncluindo metassilititos, ard b́sias, quartzo-sericita-xisto,

filitos e epiquartzitos sub ordinados

Pré-Cambriano Sup erior-Grupo Açungui
Năo Diferenciado (quartzitos e epiquartzitos

$\checkmark$ área sem classificaçã

$\checkmark$ rio

$N_{\text {rio Betari }}$

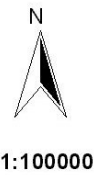

Fonte: IBGE escala 1:50.000 CPRM, $1974(a, b, c, d)$

Figura 1.4.2. Unidades lito-estratigráficas da bacia hidrográfica do rio Betari com pontos de coleta e rede hidrográfica. 


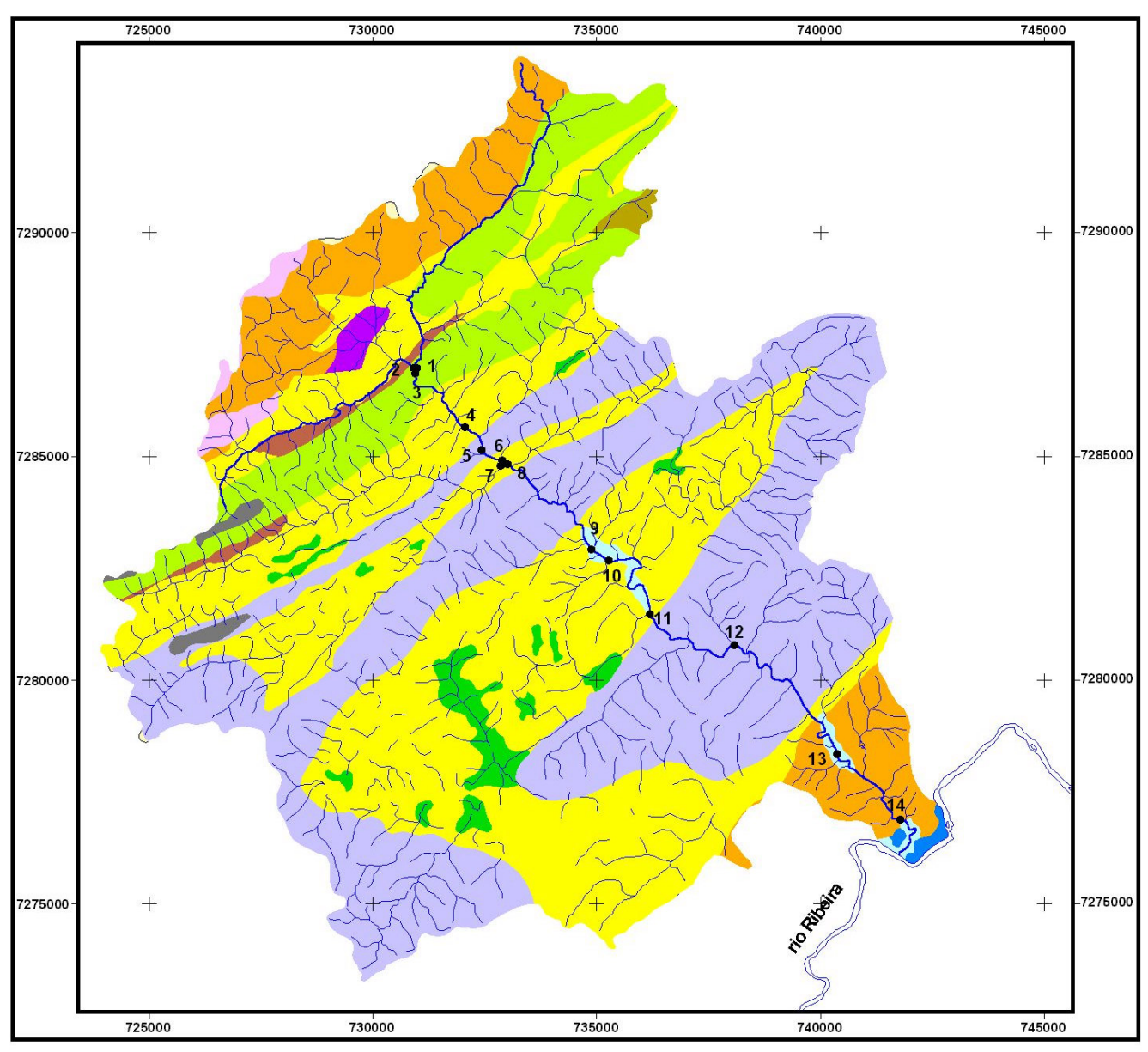

\section{Legenda}

Vertentes do Planalto

Cristas e espigões em metassedim entos

siltico/arenoso (Grupo Açungui)

Cristas quartzíticas (Grupo Açungui)

Cristas e espigões em metassedimentos

siltico/argiloso Grupo Açungui)

Superficie de cim eira (nivel 800-900m)

Rocha sã aflorante

Áreas calcárias de relevo cárstico

Dolinas

ões do Complexo Gábrico

Sedimentos fluviais recentes do baixo terraço

Sedimentos pleistocênicos do alto terraço

Coluvióes de pé de encosta

$\square$ área sem classificação

$\checkmark$ rios

$\sim$ rio Betari

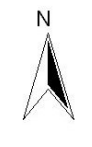

$1: 100000$

Fonte: IBGE escala 1:50.000

CPRM, $1974(e, f, g, h)$

Figura 1.4.3. Feições morfológicas da bacia hidrográfica do rio Betari com pontos de coleta $e$ rede hidrográfica. 


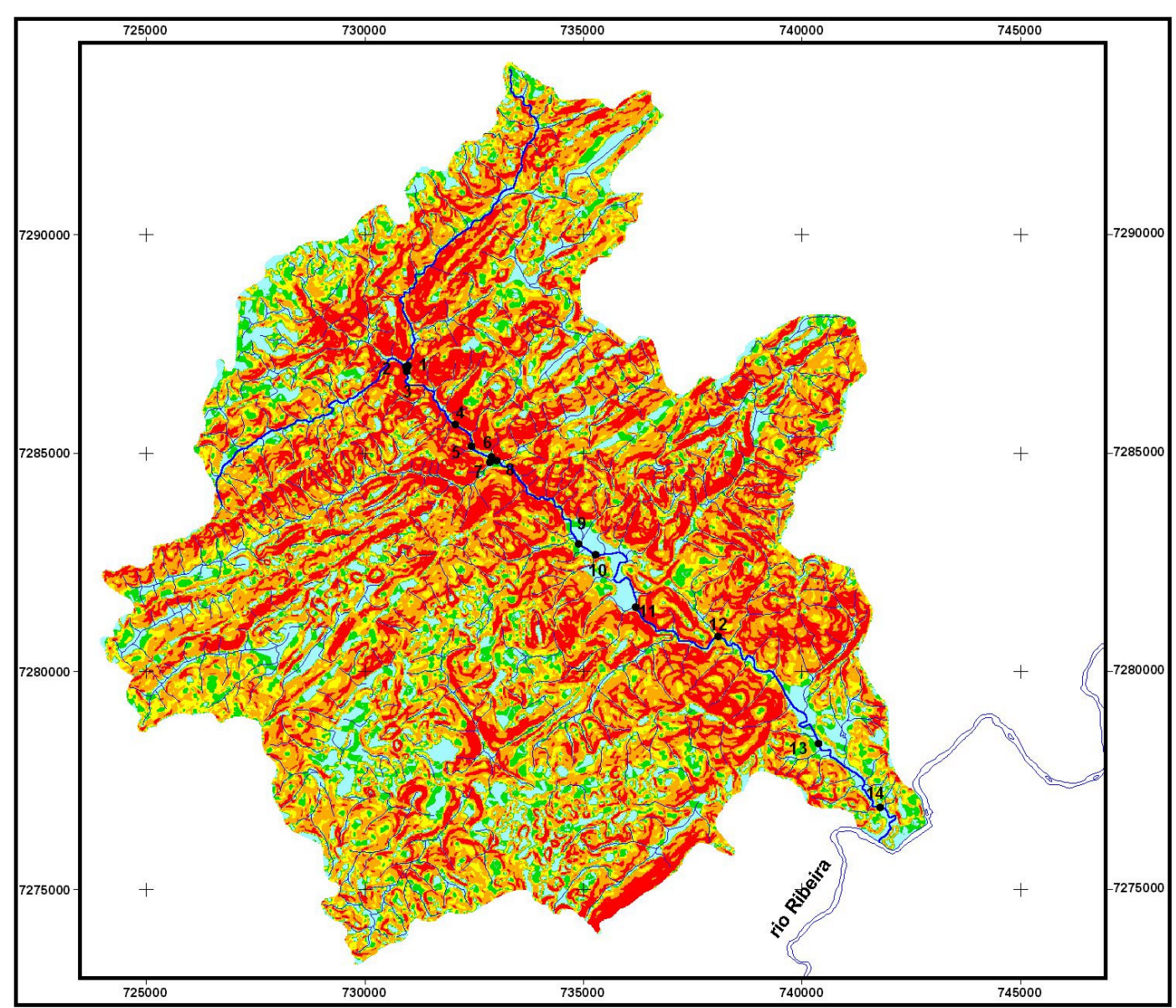

\section{Legenda \\ 0 a $10 \%$ \\ 10 a $20 \%$ \\ 20 a $30 \%$ \\ 30 a $50 \%$ \\ superior a $50 \%$ \\ $\widehat{N \text { rios }}$ \\ $\widehat{N}_{\text {rio Betari }}$}

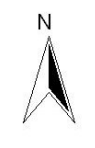

1:100000

Fonte: IBGE escala 1:50.000

Figura 1.4.4. Declividade da bacia hidrográfica do rio Betari com pontos de coleta $e$ rede hidrográfica. 


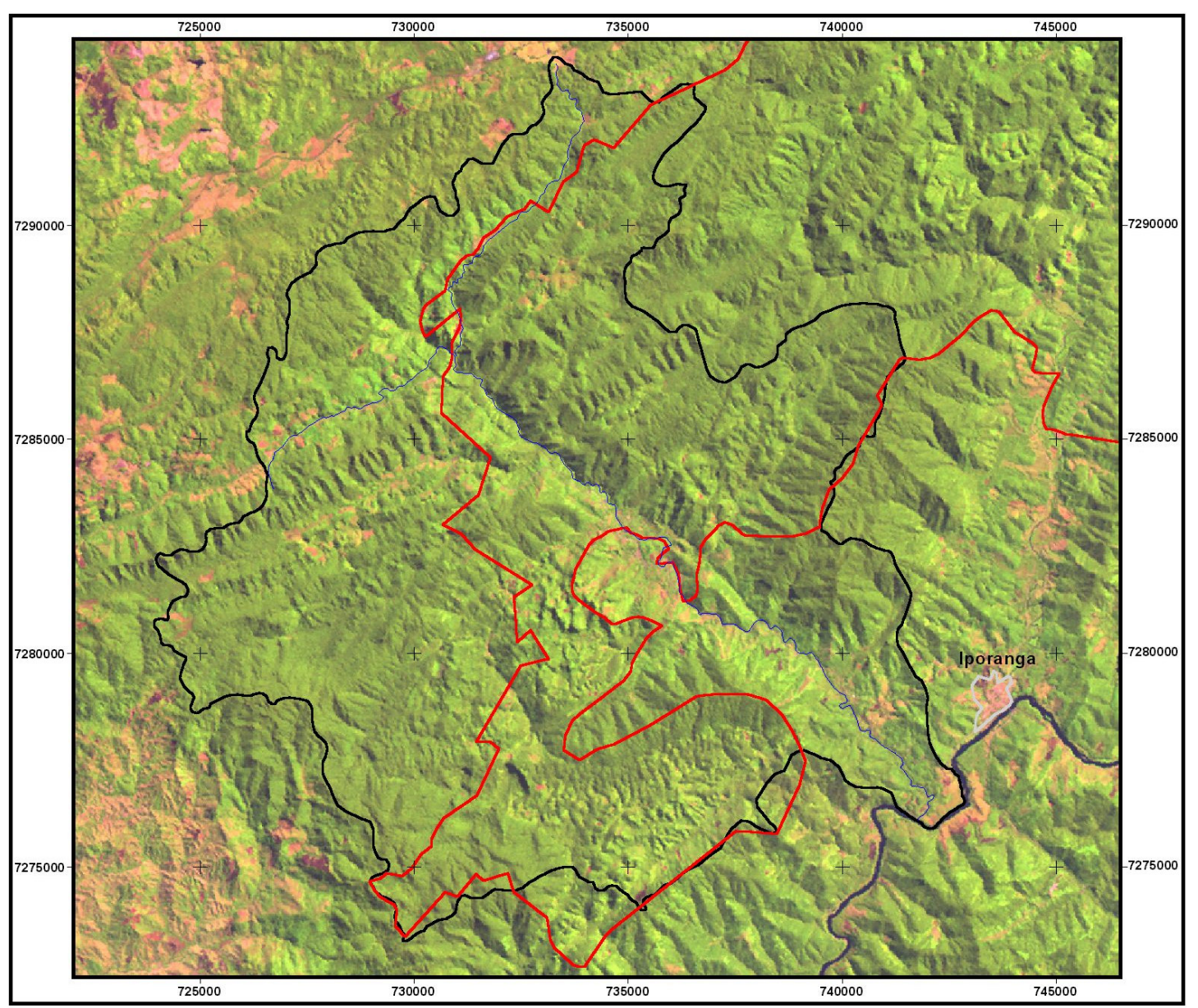

\section{Legenda}

$\square$ limite do Parque Estadual do Alto Ribeira (1)

limite da cidade de Iporanga (2)

$\square$ limite da bacia hidrográfica do

$$
\text { rio Betari }
$$

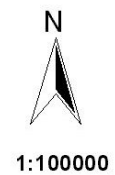

Fonte: (1) SMA, 1998

(2) IBGE escala 1:50.000

Figura 1.4.51. Imagem de Satélite LANDSAT TM-345 de $1986 \mathrm{com}$ limites da bacia hidrográfica do Betari e do Parque Estadual Turístico Alto Ribeira (PETAR). 


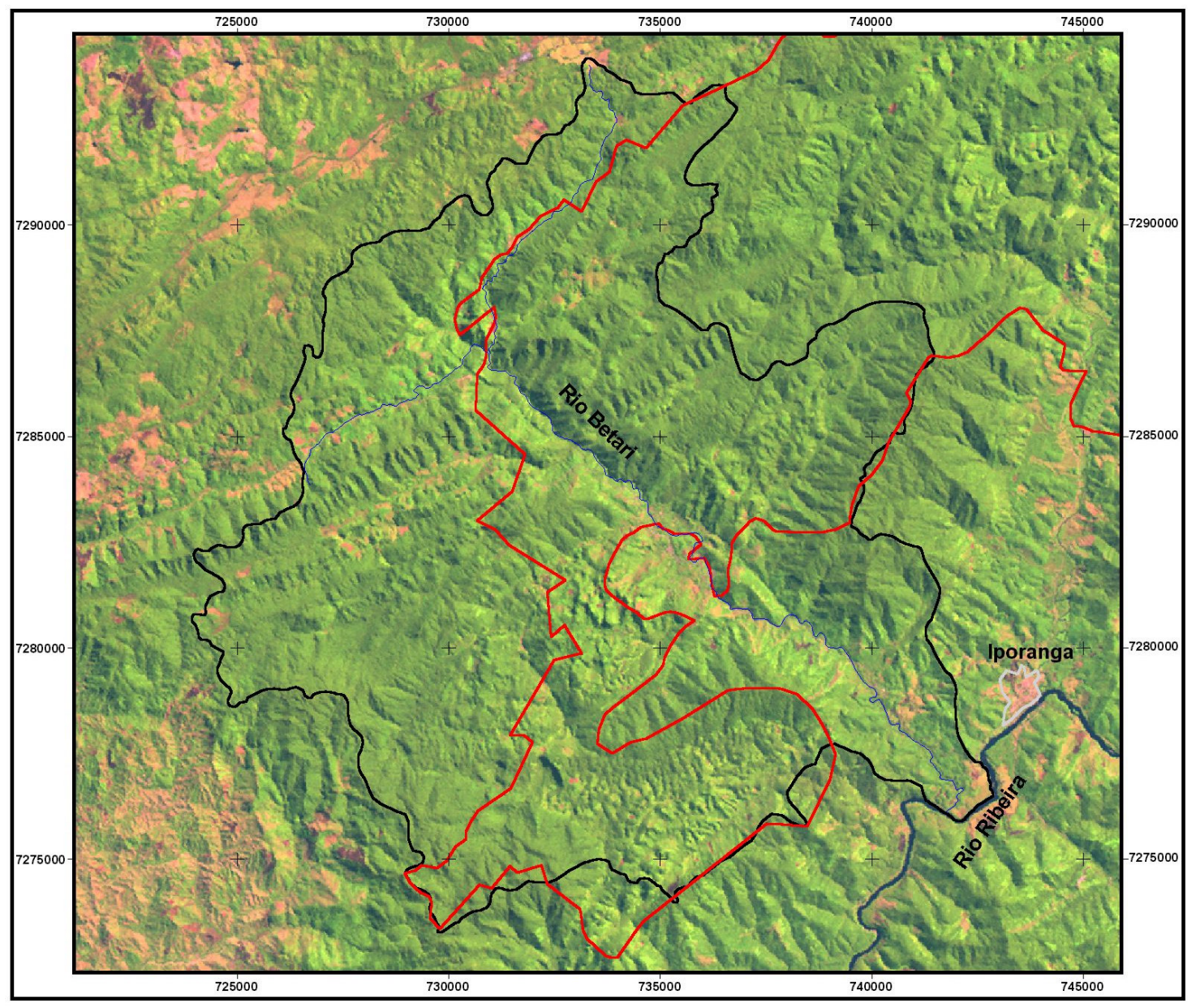

\section{Legenda}

$\square$ limite do Parque Estadual

do Alto Ribeira (1)

limite da cidade de Iporanga (2)

$\square$ limite da bacia hidrográfica do

$$
\text { rio Betari }
$$

$\triangle \operatorname{rios}(2)$

Figura 1.4.5.2. Imagem de Satélite LANDSAT TM-345 de 2000 com limites da bacia hidrográfica do Betari e do Parque Estadual Turístico Alto Ribeira (PETAR). 


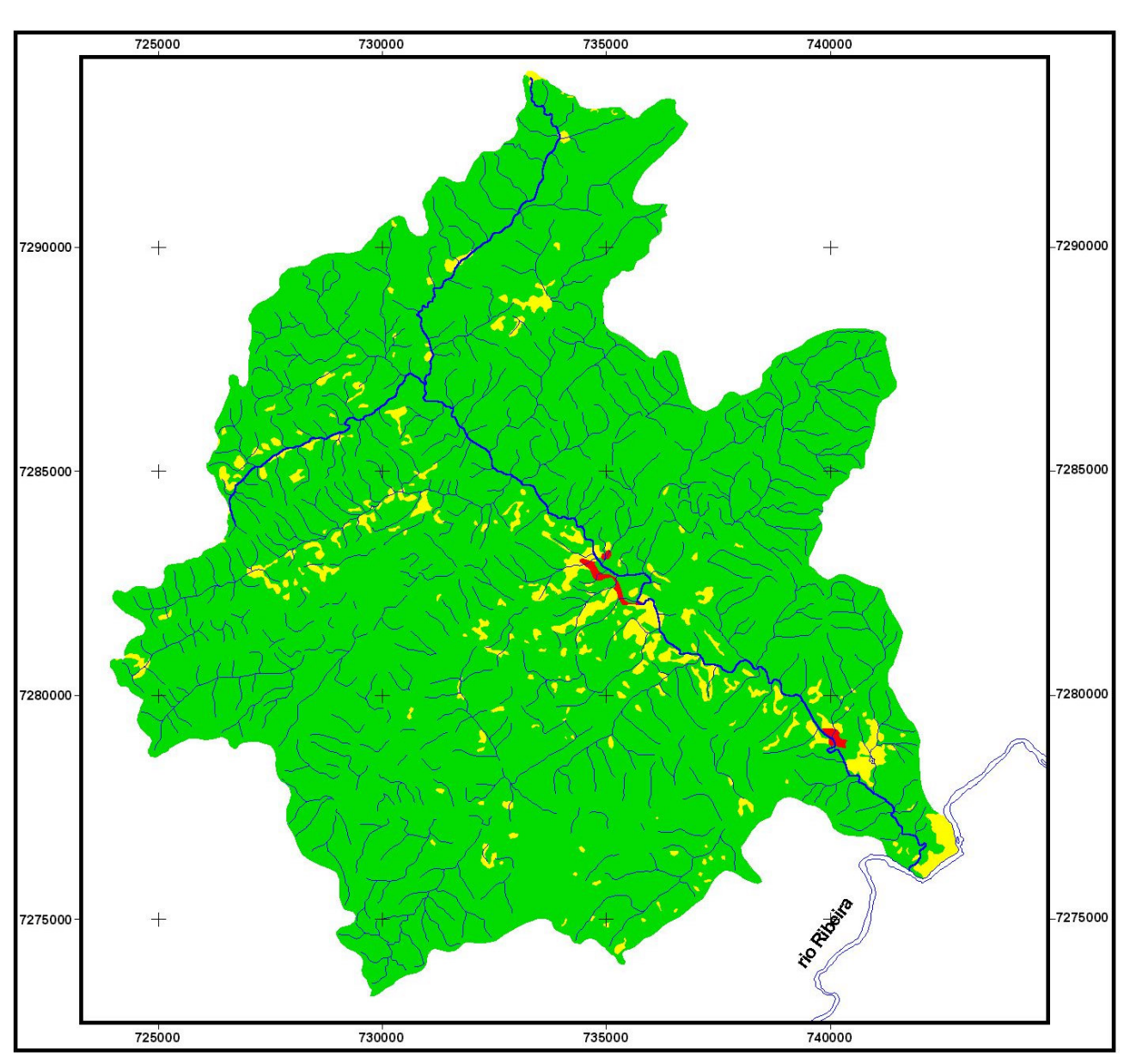

\section{Legenda \\ atividades agropecuárias \\ adensam en tos populacionais \\ vegetação natural \\ $\wedge$ rios

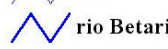

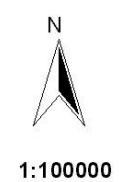

Fonte: IBGE escala 1:50.000

INPE, 1986

Figura 1.4.5.3. Uso e ocupação da terra em 1986 na bacia hidrográfica do rio Betari e rede hidrográfica. 


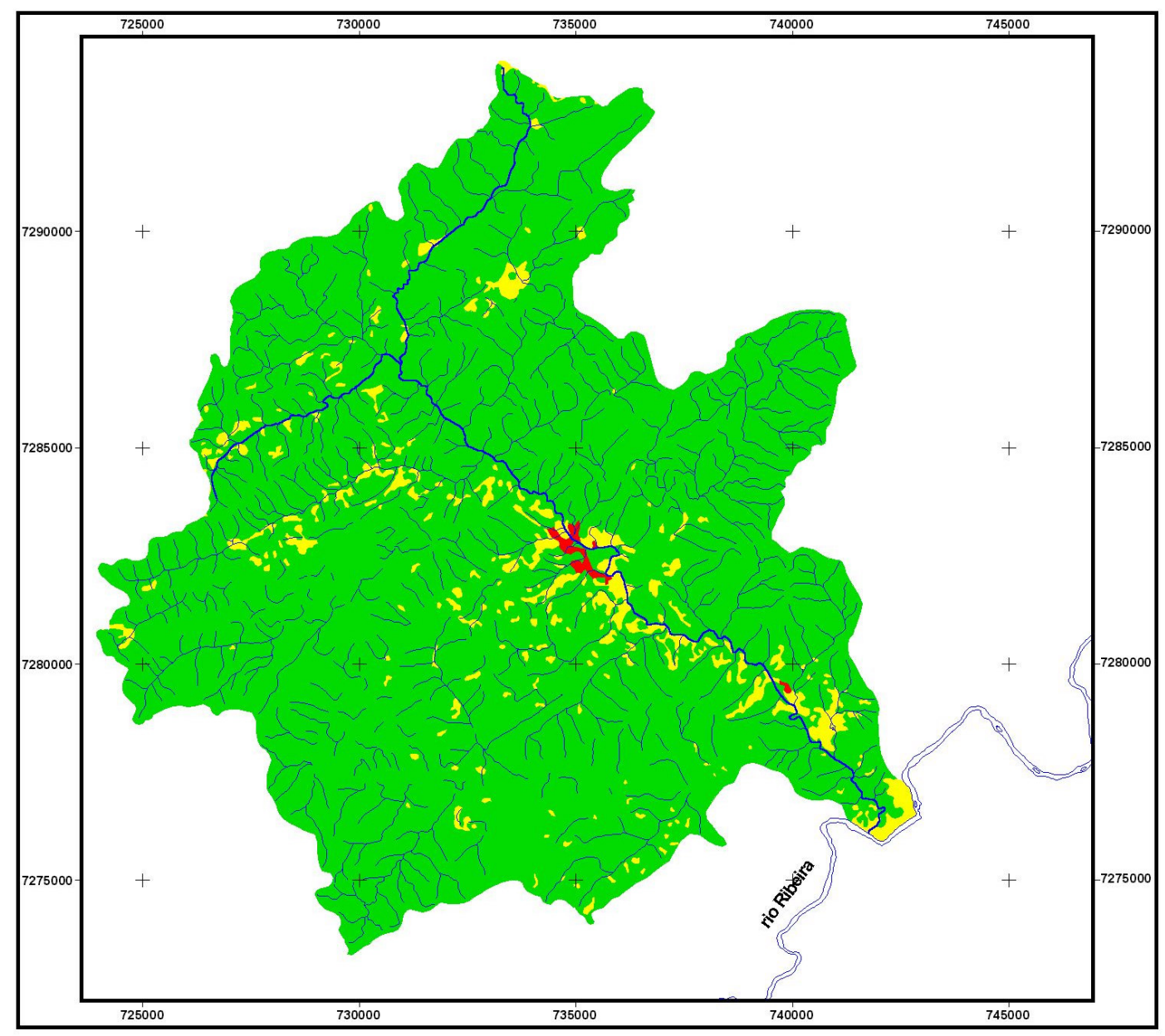

47

Legenda

atividades agropecuárias

adensam en tos populacionais

vegetação natural

$\wedge$ rios

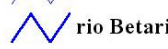

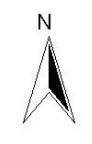

1:100000

Fonte: IBGE escala 1:50.000

INPE, 2000

Figura 1.4.5.4. Uso e ocupação da terra em 2000 na bacia hidrográfica do rio Betari e rede hidrográfica. 


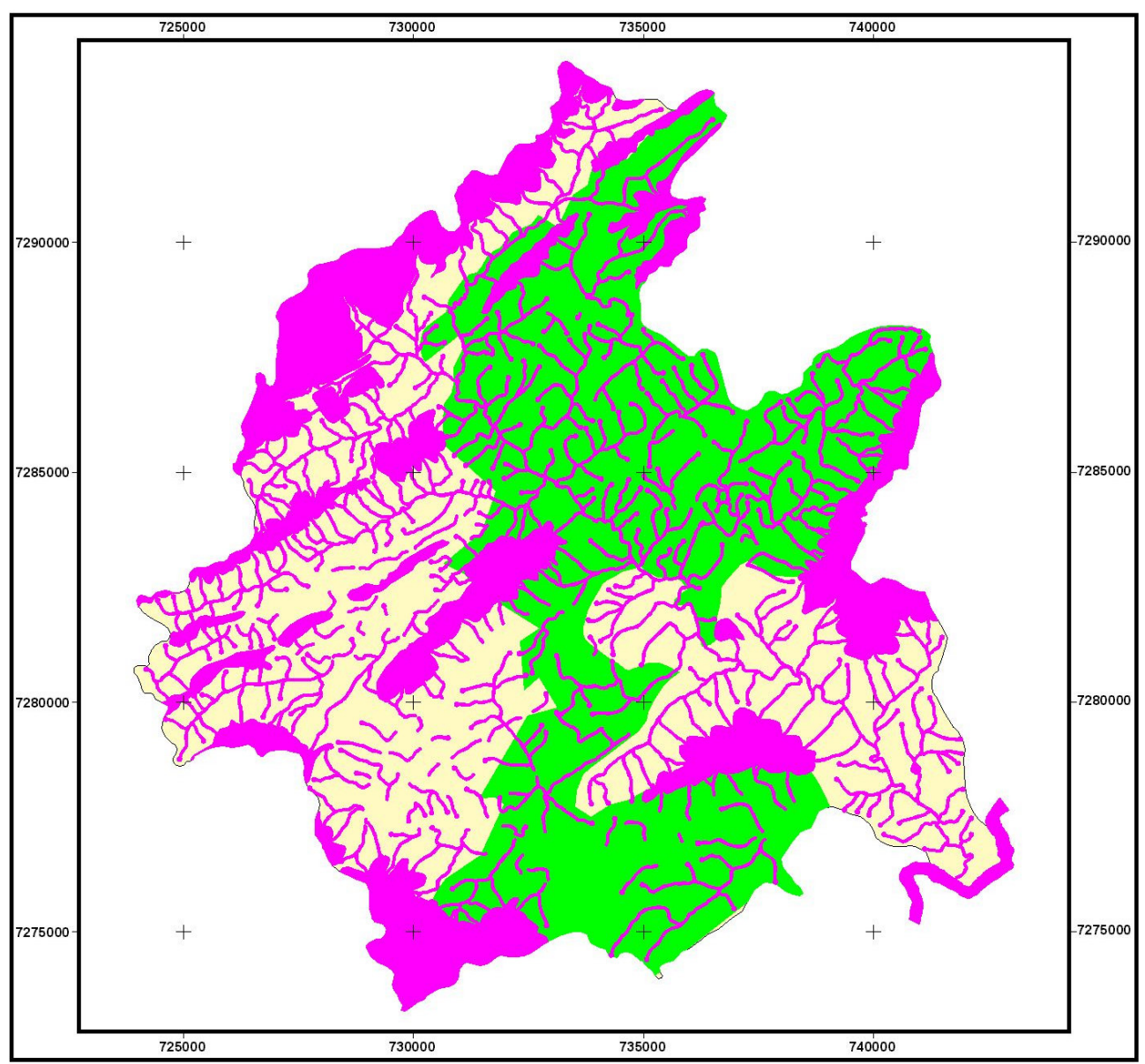

Legenda

- áreas de preservação permanente

(30m de rio, metade da largura de rio

entre 100 e $200 \mathrm{~m}, 50 \mathrm{~m}$ de lagos e nascentes,

topos de morros, montes e montanhas,
linhas de cumeadas, declividade superior a 100\%)

Parque Estadual Turistico do Alto Ribeira (PETAR)

$\square$ área sem proteção legal

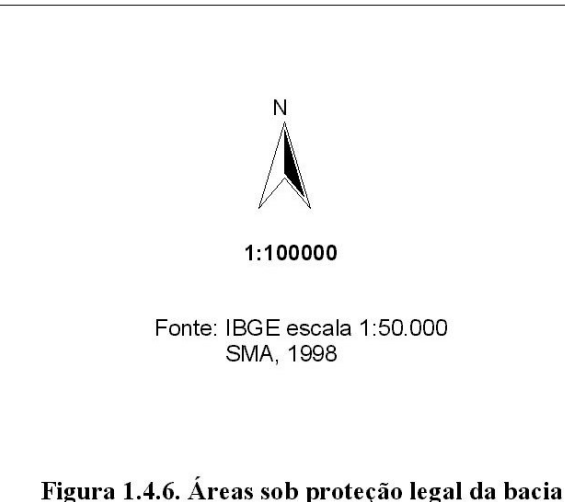
hidrográfica do rio Betari. 


\subsection{SUMÁRIO}

A Bacia hidrográfica do rio Betari possui as seguintes características morfométricas:

- Área-216,734 $\mathrm{Km}^{2}$;

- Perímetro - 87, 532 Km;

- $\quad$ Índice de Forma - 1,66;

- Relação de Elongação - 0,88;

- Relação de Relevo - 45,81 m/Km;

- Densidade de Drenagem - 2,2 canais $/ \mathrm{Km}^{2}$;

- Número de Cursos de Água - 473;

- Ordem do rio Betari - $4^{\mathrm{a} .}$ ordem.

Geologicamente, predominam metassedimentos síltico-argilodos e calcários epimetamórficos, e geomorfologicamente, o relevo cárstico e cristas e espigões. O aumento da área antropizada na bacia nos últimos 14 anos foi pequeno, provavelmente, devido às características do relevo e ao fato de que grande área da bacia se encontra sob algum tipo de proteção legal. Mesmo assim, áreas de preservação permanente e do parque são ocupadas. 


\subsection{REFERÊNCIAS BIBLIOGRÁFICAS}

AB'SABER, A. N., 1977 Os domínios morfológicos na América do Sul. Geomorfologia, 12: $23 \mathrm{p}$.

BACK, W. \& ARENAS, A. D., 1989. Karst terrains: resources and problems. Nature \& Resources, special issue, $19-23$ p.

BICHUETTE, M.E., 1998. Distribuição e biologia de gastrópodes de água doce, gênero Potamolithus, no Vale do Alto Ribeira, São Paulo (Mollusca: Gastropoda: Hydrobiidae).Dissertação de mestrado, Universidade de São Paulo, 91 p.

BISWAS, A. K., 1988. Sustainable water development for developing countries. In Expert Group Workshop on Lake/River Basin Approach to Environmentaly Sound Management of Water Resources, Otsu e Nagoya, Japão, 29 p.

BONDUKI, M. I., 1997. O turismo como agente transformador do Bairro da Serra - Iporanga - SP. Trabalho de Conclusão de Curso, ECA - USP, p. 77.

BOURLON, N. \& BERTHON, D., 1998. Desenvolvimento sustentável e gerenciamento das bacias hidrográficas na América Latina. $\mathbf{A}$ água em revista (CPRM), vol. 10, p. 16-22.

CAUBET, C. G. \& FRANK, B., 1993. Manejo ambiental em bacia hidrográfica: o caso do rio Benedito (Projeto Itajaí I). Das reflexões teóricas às necessidades concretas. Fundação Água Viva, Florianópolis, $51 \mathrm{p}$.

CHIARINI, J.V. \& COELHO, A.G.S. 1972. Cobertura vegetal e natural e áreas reflorestadas no Estado de São Paulo. Boletim do Instituto Agronômico de Campinas, 193, 28p+il. 
CÓDIGO FLORESTAL, Lei ㄲo 4771, de 15 de setembro de 1965.

COMISSÃO MUNDIAL SOBRE MEIO AMBIENTE E DESENVOLVIMENTO SUSTENTADO, 1991. Nosso futuro comum. Ed. Fundação Getúlio Vargas, $2^{\circ}$ edição, Rio de Janeiro, 430 p.

CPRM - COMPANHIA DE PESQUISA DE RECURSOS MINERAIS, 1974(a).

Mapa Geológico. Folha SG.22-X-B-V-2-Iporanga. Mapa №7. Projeto SUDELPA, vol. II, anexo III, parte I. São Paulo.

CPRM - COMPANHIA DE PESQUISA DE RECURSOS MINERAIS, 1974(b).

Mapa Geológico. Folha SG.22-X-B-V-1-Apiaí.Mapa oㅡ6. Projeto SUDELPA, vol. II, anexo III, parte I. São Paulo.

CPRM - COMPANHIA DE PESQUISA DE RECURSOS MINERAIS, 1974(c).

Mapa Geológico. Folha SG.22-X-B-II-3-Araçaíba. Mapa № 4. Projeto SUDELPA, vol. II, anexo III, parte I. São Paulo.

CPRM - COMPANHIA DE PESQUISA DE RECURSOS MINERAIS, 1974(d).

Mapa Geológico. Folha SG.22-X-B-II-4-Mina do Espirito Santo. Mapa no 5. Projeto SUDELPA, vol. II, anexo III, parte I. São Paulo.

CPRM - COMPANHIA DE PESQUISA DE RECURSOS MINERAIS, 1974(e).

Mapa Geomorfológico. Folha SG.22-X-B-V-2-Iporanga. Mapa №7.

Projeto SUDELPA, vol. XIII, anexo VIII, parte I. São Paulo.

CPRM - COMPANHIA DE PESQUISA DE RECURSOS MINERAIS, 1974(f).

Mapa Geomorfológico. Folha SG.22-X-B-V-1-Apiaí. Mapa oㅡ 6. Projeto SUDELPA, vol. XIII, anexo VIII, parte I. São Paulo.

CPRM - COMPANHIA DE PESQUISA DE RECURSOS MINERAIS, 1974(g).

Mapa Geomorfológico. Folha SG.22-X-B-II-3-Araçaíba. Mapa no 4 .

Projeto SUDELPA, vol. XIII, anexo VIII, parte I. São Paulo.

CPRM - COMPANHIA DE PESQUISA DE RECURSOS MINERAIS, 1974(h).

Mapa Geomorfológico. Folha SG.22-X-B-II-4-Mina do Espirito Santo.

Mapa no 5. Projeto SUDELPA, vol. XIII, anexo VIII, parte I. São Paulo. 
CRH - CONSELHO DE RECURSOS HÍDRICOS, 2001. O Conselho Estadual de Recursos Hídricos - CRH e o SIGRH no estado de São Paulo. URL: http://www.sigrh.sp.gov.br/cgi-bin/sigrh/apresentacao/CRH/ SIGRHESTRUTURA.HTML. 11/06/2001.

DE BLASIS, P. A. D., 1996. Bairro da Serra em três tempos: arqueologia, uso do espaço regional e continuidade cultural no médio vale do Ribeira. Tese de Doutoramento, Universidade de São Paulo, Faculdade de Filosofia , Letras e Ciências Humanas, 166p.

DESSEN, E. M. B., ESTON, V. R., SILVA, M. S., TEMPERINIBECK, M. T. \& TRAJANO, E., 1980. Levantamento preliminar da fauna de cavernas de algumas regiões do Brasil. Ciência e Cultura. V 32,n 6, p 714 - 725.

DIRETRIZES DEPESQUISA APLICADA AO PLANEJAMENTO E GESTÃo AMBIENTAL, 1994. Ministério do Meio Ambiente, dos Recursos Hídricos e da Amazônia Legal, Instituto Brasileiro do Meio Ambiente e dos Recursos Naturais Renováveis (MMA/IBAMA), Brasília, 101 p.

EYSINK, G. G., PÁDUA. H. B., PIVA-BERTOLETTI, S. A. E., MARTINS, M. C., PEREIRA, D. N. \& ROBERTO, S., 1988. Metais pesados no vale do Ribeira e em Iguape-Cananéia. Ambiente. V 2, n 1, p 6 - 13.

FERRARI, R., 1997. Viagem ao SIG: planejamento estratégico, viabilização, implantação e gerenciamento de sistemas de informação geográfica. Editora Sagres, Curitiba, $174 \mathrm{p}$.

FORD, D.C. \& WILLIANS, P.W., 1989. Karst geomorphology and hydrology. London. Uniwin Hyman, $601 \mathrm{p}$.

GERHARD, P., 1999. Ecologia de populações e comportamento de quatro espécies de bagres Heptapterinae (Teleostei: Siluriformes) em riachos da Alto Vale do rio Ribeira (Iporanga, São Paulo). Dissertação de mestrado, Universidade de São Paulo, 116 p. 
GILLIESON, D.S., 1996. Caves: processes, development and managemente. Oxford, Blackwell Publisher, $324 \mathrm{p}$.

GODOY, J.R.L., METZGER, J.P. \& AIDAR, M.P.M., (1998). Estrutura e composição específica do estrato arbóreo de três estádios sucessionais de Mata Atlântica sobre calcário no PETAR, Iporanga, SP. In Resumos do IV Simpósio de Iniciação Científica da USP, Vol. 1, out/nov., p. 56.

GOLUBEV, G. N., 1988. Sustainable management of water resources: a basin approach. In Expert Group Workshop on Lake/River Basin Approach to Environmentally Sound management

GONZALES, E. L. \& ZAVAN, S. S., 1986. Análises físico-químicas e bacteriológicas em águas provenientes de algumas cavernas do Alto Ribeira, SP. Espeleo-tema. V 15, p 43 - 52.

GRINER, A. J., 1993. Development of a water supply protection model in a GIS. Water Res. Bull. V 29,n 6, p 965 - 971.

GT-PETAR/CENIN - CENTRO INTERDISCIPLINAR DE PESQUISAS, 1980. Alto Vale do Ribeira: A necessidade de preservação. Sociedade Brasileira de Espeleologia, $8 \mathrm{p}$.

GUILLAUMON, J.R. 1989. A crise energética e a destruição da cobertura vegetal natural na região de Ribeirão Preto, no período de 1962 a 1984. In: III Congresso Brasileiro de Defesa do Meio Ambiente. Anais Volume 2. Universidade Federal do Rio de Janeiro, Rio de Janeiro. pp. 762-790.

HASSUI, Y., COPPEDÊ JUNIOR, A ., CAETANO, A .C. \& SANCHEZ, L.H., 1992. Aspectos geológico-estruturais da área de Furnas (Município de Iporanga, SP) e o problema do fluxo de efluentes. In Hasui, Y. e Mioto, J. A . (Coord), Geologia Estrutural Aplicada, São Paulo: Associação Brasileira de Geologia e Engenharia: Votorantim, p. 399 - 410. 
HUECK, K., 1972. As florestas da América do Sul. Ed. Polígono, São Paulo, $466 \mathrm{p}$.

HUFSCHMIDT, M.M. \& MACAULEY, D.S., 1988. Water resources management in a River/Lake basin context: A conceptual framework with examples from developing countries. In Expert Group Workshop on River/Lake basin approach to environmentally sound management of water resources, Japão, 40 p.

IBGE, 1991. Classificação da vegetação brasileira, adaptada a um sistema universal. Rio de Janeiro. 124 p.

INSTITUTO GEOLÓGICO. 1993. Subsídio do meio-físico-geológico ao planejamento do município de Campinas (SP). Relatório de integração Vol. I. Secretaria do Meio Ambiente, São Paulo. 74pp.

INSTITUTO FLORESTAL 1993. Inventário florestal do Estado de São Paulo. Secretaria do Meio Ambiente, São Paulo. 199 pp.

IPT/PRÓ-MINÉRIO, 1981. Mapa geomorfológico do estado de São Paulo. São Paulo.

JURACEK, K. E. \& KENNY, J. F., 1993. Management and analysis of water-use data using a geographic information system. Water Res. Bull. V 29, n 6, p 973 - 979.

LABEGALINI, J.A., 1996. Levantamento dos impactos das atividades antrópicas em regiões cársticas - Estudo de caso: Proposta de mínimo impacto para implantação de infra-estrutura turística na Gruta do Lago Azul - Serra da Bodoquena (município de Bonito-MS). Dissertação de Mestrado. Escola de Engenharia de São Carlos - USP, São Carlos, 185 p.

LAGE FILHO, A.L., 1996. Características ecológicas e limnológicas da bacia hidrográficas do Riberirão das Antas, no período de menores 
preciptações (Poços de Caldas - MG). Dissertação de Mestrado. Escola de Engenharia de São Carlos, USP, São Carlos, 192 p.

LINO, C.F., 1999. Conservação e desenvolvimento sustentável na Reserva da Biosfera da Mata Atlântica: o caso do Parque Estadual Turístico do Alto Ribeira - PETAR. In Reunión Internacional para promoción del desarrollo sostenible en los países africanos de lengua oficial portuguesa (PALOP) mediante la cooperación internacional. Sesimbra, 1998. Documentos de Trabajo, n0 28, p. 48-52.

MARACCHIOLO, N., 1994. Estuda da biologia de Aegla ssp cavernícolas do vale do Alto Ribeira, São Paulo (Crustacea: Anomura: Aeglidae). Dissertação de mestrado. Instituto de Biociências, Universidade de São Paulo.

MARINHO, M. C., 1992. Contribuição à geomorfologia cárstica do Vale do Betari, Iporanga - Apiaí, São Paulo. Trabalho de graduação, Depto. de Geografia, Universidade de São Paulo, 73 p.

NAKAGAMI, K., 1988. A strategic concept of river/lake basin management and planning. In Expert Group Workshop on Lake/River Basin Approach to Environmentaly Sound Management of Water Resources, Otsu e Nagoya, Japão, 32 p.

NOVO, E. M. L. M. 1988. Sensoriamento remoto: princípios e aplicações. Editora Edgard Blucher Ltda, São Paulo, 2º edição, 308 p.

PRADO, R.B., 1999. Influência do uso e ocupação do solo na qualidade da água: Estodo no médio rio Pardo - SP (período de 1985 a 1997). Dissertação de mestrado. Escola de Engenharia de São Carlos, USP, São Carlos, p. 209.

PIRES, J. S. R. \& SANTOS, J. E., 1995. Bacias hidrográficas: integração entre meio ambiente e desenvolvimento. Ciência Hoje, V 19, n 110, p 40 - 45.

ROSSI, P.R., 1996. O estudo da demanda real no Núcleo Santana (Parque Estadual Turístico Alto Ribeira. Identificação das possíveis causas 
para o aparecimento do fluxo do turismo não operacionalizado. Trabalho de Conclusão de Curso. Faculdade Ibero-Americana de Ciências Humanas. São Paulo, 192 p.

SACHS, I., 1996. Desenvolvimento sustentável. IBAMA - Instituto Brasileiro do Meio Ambiente e Recursos Naturais Renováveis, Brasília, Editora IBAMA/MMA, $24 \mathrm{p}$.

SALLOUTI ALLEGRINI, C.Q., 1999. Gestão do programa de uso público no Parque Estadual Turístico do Alto Ribeira - PETAR: Um estudo de caso de implantação de sistema de cobrança de ingressos e serviços. Dissertação de mestrado, Universidade de São Paulo, 179 p.

SANCHEZ, L. E., 1984. Cavernas e paisagem cárstica do Alto Vale Ribeira/SP: uma proposta de tombamento. Espeleo-tema, 14: 9 - 24.

SECRETARIA DE ESTADO DO MEIO AMBIENTE, 1998. Atlas das Unidades de Conservação do Estado de São Paulo. CPLA/SMA.

SECRETARIA DO MEIO AMBIENTE DO ESTAdO DE SÃO PAULO. 1999. Documentos básicos para o plano de manejo: Parque Estadual Turístico do Alto Ribeira. Sistematização preliminar de informações, fevereiro/1999, $99 \mathrm{p}$.

SETZER, J., 1966. Atlas climático e ecológico do Estado de São Paulo. Comissão interestadual da Bacia do Paraná - Uruguai, São Paulo, 61 p.

SHIDA, C.N. (2000). Levantamento da distribuição espacial e temporal dos elementos da paisagem e de seus determinantes, na região dos municípios Luiz Antônio e Santa Rita do passa Quatro (SP), como subsídio ao planejamento ambiental. Dissertação (Mestrado). Instituto de Biociências, Universidade de São Paulo. 114p.

SOUZA, M.P., 2000. Instrumentos de gestão ambiental: Fundamentos e prática. Editora Riani Costa, São Carlos, SP, 112 p. 
TRAJANO, E., 1979. Estudo paleontológico do Abismo do Fóssil. Espeleotema , 12: 09 - 12.

TRAJANO, E., 1986. Vulnerabilidade dos troglóbios à perturbações ambientais. Espeleo-tema, 15: 19 - 24.

TRAJANO, E., 1987. Fauna cavernícola brasileira: composição e caracterização preliminar. Rev. Bras. Biol., 3(8): 533- 561.

TRAJANO, E. \& GNASPINI-NETTO, P, 1990. Composição da fauna cavernícola brasileira, com uma análise preliminar da distribuição dos táxons. Revista Bras. Zool. 7(3): $383-407$.

VIEIRA, L.S., SANTOS, P.C.T. \& VIEIRA, M.N. (1988). Solos: propriedade, classificação e manejo. MEC/ABEAS, Brasília, 154 p.

VILLELA, S.M. \& MATTOS, A ., 1975. Hidrologia aplicada. McGraw-Hill, Rio de Janeiro, p. 245. 


\section{CAPÍTULO II}

\section{LIMNOLOGIA DO RIO BETARI}

\subsection{CARACTERÍSTICAS DOS SISTEMAS LÓTICOS}

No ciclo hidrológico, as moléculas de água, ao assimilarem energia, são transportadas para a atmosfera, contendo energia potencial. Quando ocorre a precipitação, parte dessa energia é rapidamente dissipada e o restante será dissipado após contato com o solo. Os fluxos superficiais, que podem ser efêmeros, intermitentes ou perenes, quando alimentados pelo lençol freático, continuam a dissipar energia cinética, parte como turbulência e parte no trabalho de transporte.

O transporte horizontal é o fator mais importante nos sistemas lóticos e depende da disponibilidade de energia. O fluxo de água provoca a deformação do eixo vertical para algumas variáveis ambientais freqüentes nos sistemas lênticos, tornando-as praticamente horizontais (MARGALEF, 1983).

$\mathrm{O}$ arraste contínuo de partículas e material é um aspecto importante no estudo dos rios (BEAUMONT, 1975). Numa ação erosiva, a água levanta e transporta materiais do leito, que podem ser mantidos em suspensão pela turbulência, dependendo de seus pesos. A sedimentação é constante e as partículas se distribuem no leito (as mais pesadas na área de maior capacidade de transporte e as mais leves nas áreas de menor energia). Segundo MARGALEF (1983), os materiais dissolvidos, como matéria orgânica e fósforo, são os que percorrem maior distância. A deposição diferencial de partículas de diferentes tamanhos gera uma variação de tipos "fundos" (BROOKES, 1996), que irão contribuir na organização das comunidades do ecossistema.

Grande parte do material transportado é proveniente da bacia de drenagem e o seu aporte depende das características geológicas, 
geomorfológicas, da comunidade vegetal instalada, da ocupação humana e do clima (BEAUMONT, op cit.). A precipitação nas diferentes regiões da bacia conduz, sobre e sob a superfície do solo, as "informações" para o corpo d'água. A interação também existe com a atmosfera e uma forma de analisar os processos que ocorrem nesse ecossistema é imaginar uma célula de água que se desloca ao longo de um canal. À medida que percorre esse canal, ela troca "informações", energia e matéria, com a área adjacente. Segundo MARGALEF (1983), os rios são sistemas de evacuação que convergem para um número cada vez menor de canais e se estabilizam física, química e biologicamente rio abaixo. As informações recebidas variam no tempo, em função das características climáticas, principalmente, e no espaço, longitudinalmente.

SCHUMM (1977) observou modificações nas propriedades do canal, da região da cabeceira para jusante, que influenciam a estrutura das comunidades e os processos desse ecossistema. Essas modificações diminuem o diâmetro do material do fundo e a quantidade de areia; já a profundidade do canal, velocidade média do fluxo, largura do canal e volume relativo de material aluvional depositado, aumentam com a ampliação da área de drenagem.

A teoria do continuum fluvial de VANNOTE et al. (1980), divide os rios em regiões, de acordo com características geomorfológicas (Figura 2.1). A região próxima às nascentes é influenciada pela vegetação marginal, que restringe a produção primária aquática, devido ao sombreamento, e contribui com material orgânico, portanto, alóctone. Dessa forma, predominam processos de decomposição e a relação P/R é menor que 1. O substrato é composto de cascalho e pedras. As variações sazonais de temperatura são baixas e a diversidade também. Nessa região, predominam organismos bentônicos coletores e trituradores, que se alimentam do material alóctone.

A região média do rio é transicional. A taxa de sedimentação é igual à de remoção de matéria e nutrientes do substrato, pois o canal é mais homogêneo. $A$ variação sazonal da temperatura é significativa $e$, aliada à variabilidade de substratos, permite o aumento da diversidade. A produção primária autóctone 
passa a ser tão importante quanto a alóctone. O leito é ampliado e a comunidade bentônica se modifica, dominando coletores e pastadores.

A terceira região é caracterizada por águas mais profundas, com fluxo reduzido, que permite a deposição de silte e argila, predominando organismos bentônicos coletores e, nesta região, o plâncton pode-se desenvolver. As variações de temperatura são menores e a luminosidade maior. Esses fatores colaboram para a baixa diversidade de organismos bentônicos. Segundo os autores, a ineficiência nos processos de transformação de energia que ocorrem a montante é capitalizada a jusante.

STATZNER e HIGLER (1985) apontaram várias dúvidas na teoria de VANNOTE et al (1980) e sugerem revisão e exclusão de alguns aspectos da teoria. Um deles é o fato de os aspectos físicos não exibirem um gradiente contínuo e integrado, ao contrário do que sugerem os autores da teoria, podendo existir variações que dependem do clima, da litologia e geomorfologia da bacia. Também questionaram a relação entre variabilidade de fatores ambientais e diversidade, que justifica a maior diversidade na porção média do rio. Para STATZNER e HIGLER (op cit.), nessa região não ocorre maior variabilidade de fatores ambientais para justificar a diversidade bentônica mais alta, mas sim, a transição entre a região alta e baixa do rio, o que permite a ocorrência de superposição de comunidades, uma com predomínio de insetos e outra com predomínio de crustáceos e moluscos. Outro aspecto que deve ser observado é a contínua reposição de espécies com as mesmas funções ecológicas, propiciando maior utilização da energia disponível. Segundo os autores, isso só pode ser aplicado para zonas geográficas onde fatores abióticos variam de forma marcante sazonalmente, e não apresenta correspondência nas regiões equatoriais, nas quais a reposição pode não ser imediata. 


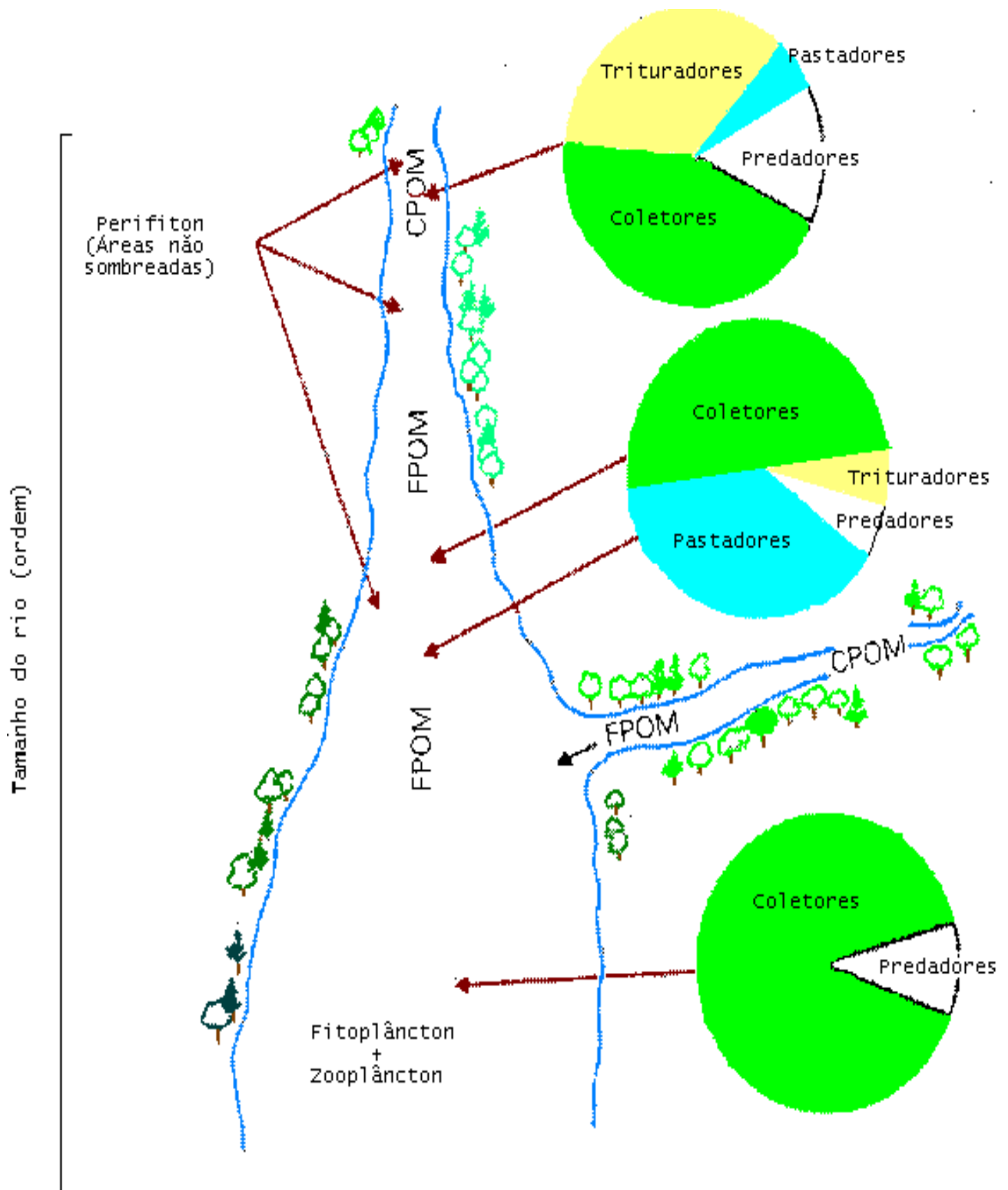

Largura relativa do canal

FIGURA 2.1- Relação entre tamanho do canal e mudança progressiva nos atributos funcionais e estruturais de ecossistemas lóticos. Adaptado de VANNOTE et al. (1980).(CPOM - Matéria orgânica particulada grosseira $(>1 \mathrm{~mm})$. FPOM - Matéria orgânica particulada fina $(50 \mu \mathrm{m}-$ $1 \mathrm{~mm}))$ 
STATZNER e HIGLER (1986) associaram a distribuição espacial dos invertebrados bentônicos em rios de várias latitudes, com as características hidráulicas do rio, como velocidade da corrente, rugosidade do canal, profundidade, declividade e raio hidráulico. Observaram que a variabilidade das características hidráulicas determinam a zonação dos organismos bentônicos. Por outro lado, citaram que os rios com abruptas mudanças de declividade e de cabeceiras podem não apresentar um padrão de zonação faunístico.

A aplicação da teoria do continuum fluvial deve ser feita com cuidado nos sistemas aquáticos tropicais, sujeitos a padrões climáticos e de cobertura vegetal diferentes das bacias de regiões temperadas, e como STATZER e HIGLER (1985) apontaram, os autores da teoria não levaram em consideração que na atualidade poucos rios se encontram em condições naturais, sem sofrer alterações antropogênicas.

Uma das alterações antrópicas mais freqüentes no gradiente longitudinal dos sistemas lóticos é a construção de reservatórios. WARD e STANFORD (1983) propuseram a teoria da Descontinuidade Serial para explicar mudanças no padrão longitudinal esperado, baseados nas modificações geradas a jusante do reservatório, e definiram dois parâmetros importantes: a distância da descontinuidade, que é o intervalo medido em unidades de comprimento, até onde ocorre mudança no padrão longitudinal; e intensidade, que é a mudança da variável medida após o represamento, ou seja, a diferença entre o sistema antes e depois do represamento. Posteriormente, essa teoria foi estendida para outros distúrbios que podem gerar uma descontinuidade, como poluição, entrada de tributários e autodepuração, e outros processos que ocorrem na bacia hidrográfica e refletem no corpo d'água (SABATER et al., 1989).

As variações temporais podem ser facilmente observadas no estudo de rios, como variações de temperatura, alteração na vazão e velocidade de corrente, no transporte de materiais e na comunidade biológica, que variam, principalmente, de acordo com os fatores climáticos regionais. NECCHI et al. (2000) observaram variações sazonais de temperatura, nitrogênio total, $\mathrm{pH}$ e 
DQO em rios da bacia do Alto São Francisco. OLIVEIRA e CALHEIROS (1998) verificaram aumento de $70 \%$ nas descargas de nutrientes e sólidos em suspensão no período de enchente/cheia, na bacia do rio Taquari, pertencente à bacia do Alto Paraguai.

Outra causa de variação temporal são as cheias. JUNK et al. (1989) sugeriram que uma das principais funções de força, em rios com amplas planícies de inundação, são os pulsos de cheias. Nesse caso, a biomassa animal presente no rio dependeria da produção das planícies de inundação, e não do material transportado das regiões superiores, gerando, inclusive, comunidades diferentes.

A estrutura organizacional longitudinal foi associada à temporal por WARD e STANFORD (1995), ao relacionarem o conceito de descontinuidade serial com os pulsos de enchentes, que modificam e heterogeneidade térmica, a estabilidade do canal, a diversidade de espécies, a conectividade entre corpos d'água e entre os corpos de água e a vegetação ciliar, e na relação CPOM/FPOM (matéria orgânica particulada grossa e matéria orgânica particulada fina, respectivamente), quando os represamentos são impostos em rios com planícies de inundação.

Essas teorias devem ser aplicadas com cautela, pois nem todos os sistemas possuem vegetação marginal próximo às nascentes, como muitos rios europeus (STATZNER e HIGLER, 1985), e nem todos os rios sofrem cheias significativas. Devem ser consideradas as diferentes latitudes e longitudes onde o sistema fluvial se insere. Não se aplicam, da mesma forma, a sistemas fluviais com significativa ação antrópica.

As atividades antrópicas se refletem na qualidade da água. $O$ desmatamento da bacia favorece a entrada de nutrientes e partículas. Estas diminuem a penetração de luz no sistema e provocam o assoreamento. $O$ aporte de material pode levar à homogeneização do substrato e dos tipos de fundo, provocando alterações na comunidade bentônica. Aportes em grande 
quantidade, além dos efeitos citados acima, podem provocar enchentes, devido a modificações do canal (GORE, 1996).

CAMARGO et al. (1996), estudando rios do litoral sul do estado de São Paulo, observaram que as características limnológicas são influenciadas, a princípio, pela fisiografia da região, porém, quando ocorrem aportes de efluentes orgânicos, a poluição passa a ser o fator determinante das características, como oxigênio dissolvido, fósforo total, fósforo e nitrogênio inorgânico dissolvido.

SÉ (1992), verificou que a qualidade da água do rio Monjolinho (São Carlos-SP) é influenciada por fatores internos, como tipo de substrato e comunidade biológica em trânsito, ou fixada em determinados trechos. Os fatores externos considerados no estudo foram: entrada de águas subterrâneas e/ou afluentes nos vários trechos, caracteres geomorfológicos, declividade, efeitos antrópicos, como despejos pontuais de águas residuárias, e presença de barragens. $O$ autor determinou subáreas na bacia, cujas drenagens determinavam trechos no rio com variáveis ambientais diferentes, correspondendo aos diferentes níveis de ocupação e a mecanismos ecológicos de autodepuração, estes dependentes do estado dos ecossistemas terrestres adjacentes, se primitivos ou em regeneração, e/ou do leito do rio, como aeração por turbulência, sedimentação, absorção biológica e adsorção química, dentre outros.

Na microbacia do ribeirão Canchim (São Carlos-SP), PRIMAVESI et al. (2000) estudaram a qualidade da água em função da ocupação por atividade pecuária. Os autores concluíram que, devido ao despejo de esgotos domésticos, as áreas de ocupação humana no interior das fazendas geravam impactos maiores que as áreas com atividade agro-pastoril.

A impermeabilização da bacia, a homogeneização e retificação de canais também modificam as características hidrológicas do rio, podendo causar enchentes. O aumento da vazão altera o transporte de material orgânico e de organismos que constantemente recolonizam a região a jusante. 
Descarga de poluentes orgânicos, de esgotos domésticos, e químicos, efluentes industriais, também provocam profundas modificações nas características ambientais e, conseqüentemente, na estrutura da comunidade. Os padrões de qualidade da água são, também, alterados para uso humano.

PORTO (1991) afirma que os padrões de qualidade da água especificam concentrações e limites para parâmetros que possam interferir na manutenção do ecossistema aquático e na saúde humana, e são utilizados para regular e controlar os níveis de qualidade a serem mantidos em um corpo d'água, de acordo com o uso a que se destina. A Resolução CONAMA nº 20, de 18/06/86, determina nove classes de usos para os corpos de água doce, salobra e salinas, e estabelece limites para os parâmetros nas várias classes. Já o Decreto ํo 8468, de 08 de setembro de 1976 classifica, segundo os usos preponderantes, as águas interiores do Estado de São Paulo, em quatro classes:

Classe I - destinada ao abastecimento doméstico sem tratamento prévio ou com simples desinfecção;

- Classe II - destinada ao abastecimento doméstico após tratamento convencional, à irrigação e a recreação de contato primário;

- $\quad$ Classe III - destinada ao abastecimento doméstico após tratamento convencional, à preservação de peixes em geral e de outros elementos da fauna e da flora, e à dessedentação de animais;

Classe IV - destinada ao abastecimento doméstico após tratamento avançado, ou a navegação, à harmonia paisagística, ao abastecimento industrial, à irrigação e a usos menos exigentes.

O Decreto no 10755 de 22 de novembro de 1977, que dispõe dos corpos d'água receptores na classificação prevista no decreto citado acima, enquadra o rios da bacia do Ribeira de Iguape na Classe I. 
Assim, este capítulo tem como principais objetivos caracterizar o rio Betari biológica, física e quimicamente, espacial e temporalmente, e relacionar essas características limnológicas com as atividades antrópicas na bacia.

\subsection{MATERIAL E MÉTODOS APLICADOS NO ESTUDO DO RIO BETARI}

\subsubsection{AMOSTRAGEM}

As atividades antrópicas causam efeitos nos ecossistemas de forma contínua e dinâmica e, da mesma forma, o sistema responde a essas interferências e aos processos naturais a que está sujeito. Assim, é necessária a análise e monitoramento das características ambientais, associando às variações sazonais, principalmente, as relacionadas à precipitação e temperatura. Como o sistema não recebe essas informações e nem responde de forma homogênea no seu eixo longitudinal, um grande número de pontos de amostragem é necessário.

As coletas foram realizadas em janeiro (verão), abril (outono), julho (inverno) e outubro (primavera). As coletas de água foram feitas durante 5 dias seguidos nos meses de amostragem, e algumas nos períodos que coincidiram com épocas de maior fluxo de turistas (julho e outubro). Os organismos bentônicos, coliformes, DBO e sedimentos para análise foram coletados uma vez por período de amostragem. Durante o período de coleta, foram feitas as entrevistas com os moradores do bairro da Serra (Capítulo 3).

Quatorze pontos de coleta foram estabelecidos no rio Betari, considerando aspectos que pudessem influenciar a qualidade da água, como a montante e a jusante dos principais afluentes e áreas com atividades antrópicas. 
A figura 1.4.1 mostra os pontos de coleta ao longo do rio Betari e a figura 2.2.2 representa esquematicamente o rio Betari, as estações de coleta, os afluentes e locais onde estes se originam. As figuras 2.2.3 até 2.2.16 descrevem os pontos de amostragem no rio Betari.

\subsubsection{CARACTERÍSTICAS HIDRÁULICAS}

\subsubsection{Vazão e Velocidade da Corrente}

A vazão, velocidade da água na secção transversal do rio, é um dado muito importante, pois está relacionado diretamente com a capacidade de transporte do rio, com a erosão fluvial e com o transporte de matéria orgânica e organismos.

Em cada período de coleta, foram determinadas as velocidades de escoamento, utilizando um molinete Valleport, e calculadas as vazões, através da soma das velocidades médias de escoamento, em cada secção transversal, multiplicada pela área de cada subsecção (WISLER \& BRATER, 1964), para cada ponto de coleta.

\subsubsection{VARIÁVEIS ABIÓTICAS}

Os parâmetros hidrológicos dos sistemas lóticos são controlados pelas características da bacia hidrográfica e variações climáticas. A interpretação destes dados é fundamental para compreensão dos processos que ocorrem nesses sistemas. A tabela 2.2.3 apresenta as variáveis físicas e químicas determinadas no rio Betari, assim como o método utilizado. 


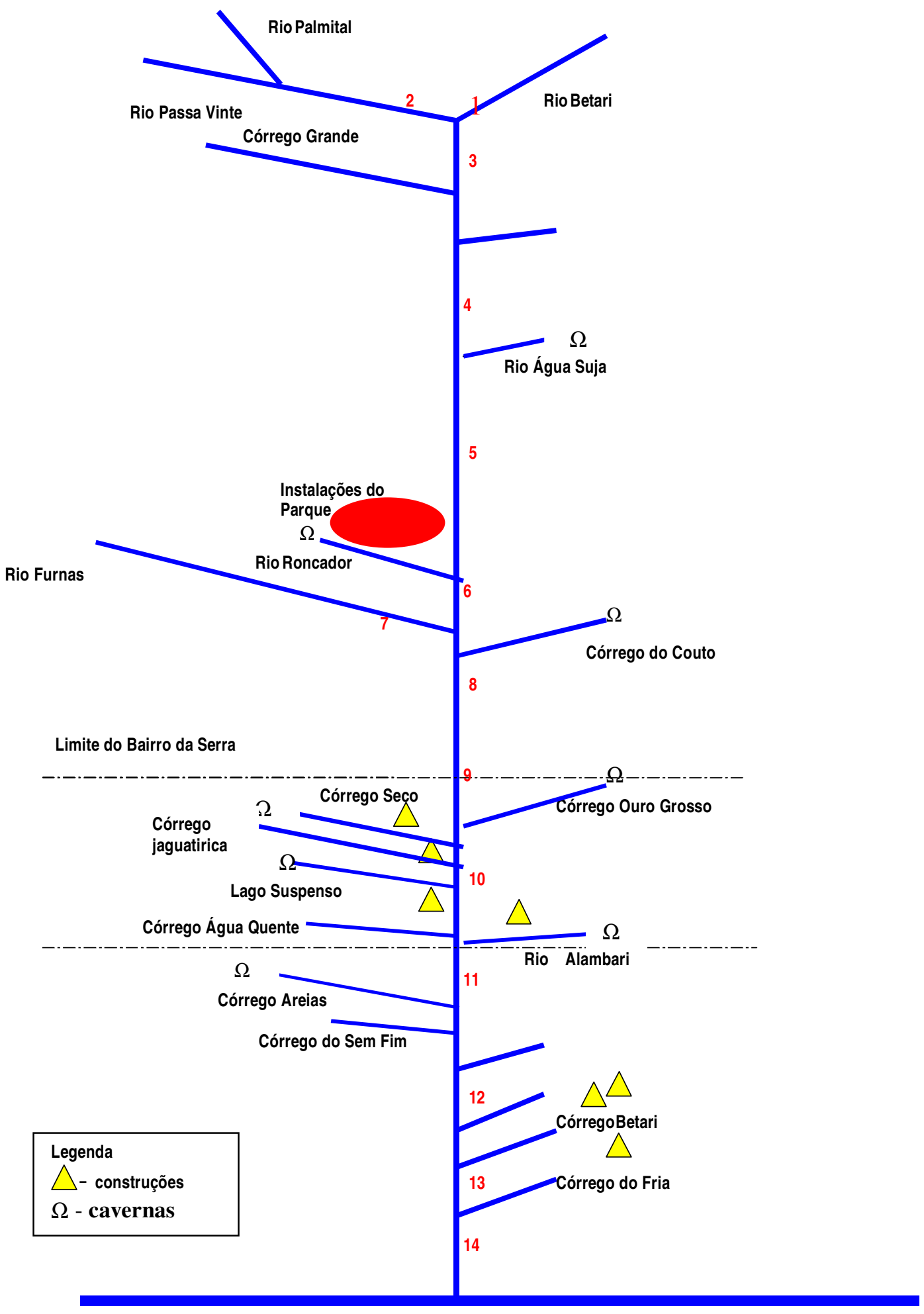

FIGURA 2.2.2 - Esquema da localização dos pontos de amostragem no rio Betari, com principais afluentes. 
TABELA 2.2.3 - Variáveis físicas e químicas da água determinadas no rio Betari

\begin{tabular}{|c|c|c|c|}
\hline Variável & Unidade & Técnica & Referência Bibliográfica \\
\hline Condutividade elétrica & is. $\mathrm{cm}^{-1}$ & Eletrodo & * \\
\hline $\begin{array}{l}\text { (amostras em triplicatas) } \\
\text { Oxigênio dissolvido }\end{array}$ & $m g \cdot L^{-1}$ & Eletrodo & * \\
\hline $\begin{array}{l}\text { (amostras em triplicata) } \\
\text { Temperatura }\end{array}$ & Mg.L & $\begin{array}{l}\text { HORIBA U-10 } \\
\text { Eletrodo }\end{array}$ & * \\
\hline $\begin{array}{c}\text { Temperatura } \\
\text { (amostras em triplicata) }\end{array}$ & ${ }^{\circ} \mathrm{C}$ & $\begin{array}{l}\text { Eletrodo } \\
\text { HORIBA U-10 }\end{array}$ & \\
\hline $\begin{array}{c}\text { pH } \\
\text { (amostras em triplicata) }\end{array}$ & * & $\begin{array}{l}\text { Eletrodo } \\
\text { HORIBA U-10 }\end{array}$ & * \\
\hline $\begin{array}{l}\text { Alcalinidade } \\
\text { Total, será utilizada para o cálculo de }\end{array}$ & $\mathrm{mg} \cdot \mathrm{L}^{-1}$ & $\begin{array}{l}\text { Titulação } \\
\text { potenciométrica }\end{array}$ & $\begin{array}{c}\text { GOLTERMAN et al. (1978) Formas } \\
\text { de carbono: }\end{array}$ \\
\hline $\mathrm{CO}_{2}, \mathrm{HCO}_{3}^{-} \mathrm{e} \mathrm{CO}_{3}^{-2}$ & $\mathrm{CaCO}_{3}$ & & MACKERETH et al. (1978) \\
\hline $\begin{array}{l}\text { Sólidos em suspensão (totais, } \\
\text { orgânicos e inorgânicos) } \\
\text { Nutrientes dissolvidos }\end{array}$ & $\mathrm{mg} \cdot \mathrm{L}^{-1}$ & Gravimetria & TEIXEIRA et al. (1965) \\
\hline Nitrogênio amoniacal & і̀ $q . L^{-1}$ & Espectrofotometria & KOROLEFF (1976) \\
\hline Nitrito & i g. $\mathrm{L}^{-1}$ & Espectrofotometria & MACKERETH et al. (1978) \\
\hline Nitrato & ì g. $\mathrm{L}^{-1}$ & Espectrofotometria & MACKERETH et al. (1978) \\
\hline Fosfato total & i g. $L^{-1}$ & Espectrofotometria & STRICKLAND \& PARSONS (1960) \\
\hline Fosfato inorgânico & $\mu \mathrm{g} \cdot \mathrm{L}^{-1}$ & Espectrofotometria & STRICKLAND \& PARSONS (1960) \\
\hline Silicato reativo & $m g \cdot L^{-1}$ & Espectrofotometria & GOLTERMAN et al. (1978) \\
\hline \multicolumn{4}{|l|}{ Nutrientes totais } \\
\hline Fósforo total & ug. $\mathrm{L}^{-1}$ & Espectrofotometria & APHA; AWWA; WEF (1995) \\
\hline Nitrogênio orgânico total (kjeldhal) & $m g . L^{-1}$ & Titulometria & APHA; AWWA; WEF (1995) \\
\hline $\begin{array}{l}\text { Demanda Bioquímica de Oxigênio } \\
\text { (DBO) }\end{array}$ & $\mathrm{mg} \mathrm{O}_{2} \mathrm{~L}^{-1}$ & titulometria & APHA; AWWA; WEF (1995) \\
\hline $\begin{array}{l}\text { Íons (cálcio, magnésio, chumbo, zinco, } \\
\text { sódio) }\end{array}$ & $\mu g \cdot L^{-1}$ & $\begin{array}{l}\text { Espectrofotometria } \\
\text { de Absorção } \\
\text { Atômica }\end{array}$ & APHA; AWWA; WEF (1995) \\
\hline
\end{tabular}

\subsubsection{ANÁLISE DO SEDIMENTO}

$\mathrm{Na}$ interface sedimento-água, ocorrem inúmeros processos que influenciam as características hidrológicas do sistema, como a precipitação de íons ou liberação de nutrientes. De acordo com as condições redox ou da presença de compostos orgânicos, esses íons e/ou nutrientes podem não estar disponíveis para comunidade. 
Amostras do sedimento foram coletadas em apenas um dia de cada período de estudo e acondicionadas em sacos plásticos para congelamento e posterior análise em laboratório. A tabela 2.2.4 mostra as variáveis químicas determinadas no sedimento do rio Betari, assim como os métodos utilizados.

TABELA 2.2. 4 - Métodos para análise do sedimento

\begin{tabular}{llll}
\hline Variável & Unidade & Técnica & $\begin{array}{l}\text { Referência } \\
\text { Bibliográfica }\end{array}$ \\
\hline Fósforo total & $\mu \mathrm{g} \cdot \mathrm{g}^{-1}$ & Incineração & Andersen, 1976 \\
\hline $\begin{array}{l}\text { Nitrogênio } \\
\text { orgânico (kjeldhal) }\end{array}$ & $\%$ & Titulometria & $\begin{array}{l}\text { APHA;AWWA; } \\
\text { WEF, 1995 }\end{array}$ \\
\hline $\begin{array}{l}\text { İons (cálcio, } \\
\text { chumbo, zinco, } \\
\text { magnésio, }\end{array}$ & $\mu \mathrm{g} \cdot \mathrm{g}^{-1}$ & $\begin{array}{l}\text { Espectrofotometria } \\
\text { de Absorção }\end{array}$ & APHA;AWWA; \\
& & Atômica & WEF, 1995 \\
\hline
\end{tabular}

\subsubsection{VARIÁVEIS BIÓTICAS}

\subsubsection{Colimetria}

Águas residuárias podem contaminar águas utilizadas para abastecimento ou recreação e, desta forma, conter agentes patogênicos, tornando-se um veículo de transmissão de doenças.

O número mais provável de coliformes totais e fecais em $100 \mathrm{~mL}$ de água foi determinado pelo método enzimático desenvolvido pela Idexx Environmental Products, Colilert, aprovado pela EPA, Environmental Protection Agency, dos Estados Unidos. 


\subsubsection{Comunidade Bentônica}

\subsection{Análise qualitativa}

Os organismos bentônicos foram coletados em apenas um dia de cada período de amostragem, com amostrador de Surber, para posterior identificação e contagem. Em cada ponto de coleta foram feitas duas amostragens, escolhendo-se áreas com cascalho, para padronizar as amostras. A identificação dos organismos bentônicos foi feita utilizando os trabalhos de: ANGRISANO, 1995, DOMINGUEZ et al. (1992), EDMONDSON (1959), FIORENTIN e CORSEVIL (1994), FONTOURA (1985), FROEHLICH (1984), HILSENHOFF (1991), MACCAFFERTY (1981), MERRITT e CUMMINS (1996).

\subsection{Análise quantitativa}

A análise da estrutura da comunidade de macroinvertebrados bentônicos foi feita sob o aspecto da abundância relativa, freqüência de ocorrência e diversidade. Para análise dos taxa abudantes e dominates, utilizou-se o critério descrito por LÔBO e LEIGHTON (1986). Foram consideradas abundantes aquelas espécies cuja ocorrência numérica é maior do que o valor médio do número total de organismos dos taxa presentes na amostra; e dominantes, aquelas espécies cuja ocorrência numérica supera $50 \%$ do número total de organismos da amostra.

Adotou-se o critério de BRANCO (1991), para análise da freqüência, que foi expressa em percentagem, como sendo a relação entre ocorrência dos diferentes taxa e o número total de amostras. Os taxa são considerados freqüentes quando a freqüência $F>50 \%$, comuns quando $10 \%<F<50 \%$ e raros quando $F<10 \%$. Para o cálculo da freqüência utilizou-se a seguinte fórmula: 
$\mathrm{F}=(\mathrm{Pa} / \mathrm{P}) .100$

onde,

$\mathrm{Pa}=$ número de amostras em que o taxon "a" esteve presente.

$\mathrm{P}=$ número total de amostras analisadas.

A análise numérica permite comparar dados de rios ou estações de coleta diferentes, ou ainda, medir sua descontinuidade.

Para cada conjunto de dados físicos e químicos (divididos por coleta), foram realizadas análises de agrupamento, visando obter dendrogramas de similaridade entre as estações de coleta. Segundo VALENTIN (1995), as análises de agrupamento reúnem objetos, por reconhecer entre eles um grau de similaridade. Posteriormente, foram realizadas análises discriminantes, visando identificar que variáveis influenciaram a formação dos grupos. De acordo com VALENTIN (op cit), a ordenação é o conjunto de técnicas pelas quais as amostras são ordenadas em função de um grande número de critérios. A ordenação consiste em posicionar estas amostras ao longo de um eixo representativo. Portanto, as amostras são posicionadas em relação a um ou mais eixos, de tal maneira que suas posições relativas aos eixos, e entre eles, proporcionem o máximo de informação sobre suas semelhanças ecológicas. 


\subsection{RESULTADOS}

\subsubsection{PRIMEIRA CAMPANHA DE AMOSTRAGEM (JANEIRO DE 2000)}

\subsubsection{Velocidade de escoamento e vazão}

A velocidade de escoamento e a vazão são diretamente influenciadas por características da bacia hidrográfica (área, declividade, material parental, entre outros) e pela ocorrência de chuvas. Esses parâmetros distinguem os ecossistemas lóticos dos demais ecossistemas aquáticos.

O rio Betari, nas amostragens realizadas em janeiro de 2000, exibiu velocidades elevadas de corrente com o máximo de $1,38 \mathrm{~m} . \mathrm{s}^{-1}$, na estação 10, dia 16/01/00; os menores valores de velocidade ocorreram nas estações do alto curso e os maiores, nas do médio para o baixo curso. Os elevados valores de velocidade que ocorrem nas estações 9 e 10 podem ter sido uma resposta a obras de prevenção de enchentes, que alteraram o canal original do rio (figura 2.3.1.1). Os valores de vazão nesse mesmo período, apresentados na figura 2.3.1.2, representam uma resposta à quantidade de chuvas que ocorreram na bacia, nos dois primeiros dias de amostragem; os valores mais elevados ocorreram no dia 17/01/00, assim como ocorreu com a velocidade da corrente, salvo algumas exceções. Nesse período amostral, só foram obtidos dados em três dias de coleta, devido à quebra do aparelho. 


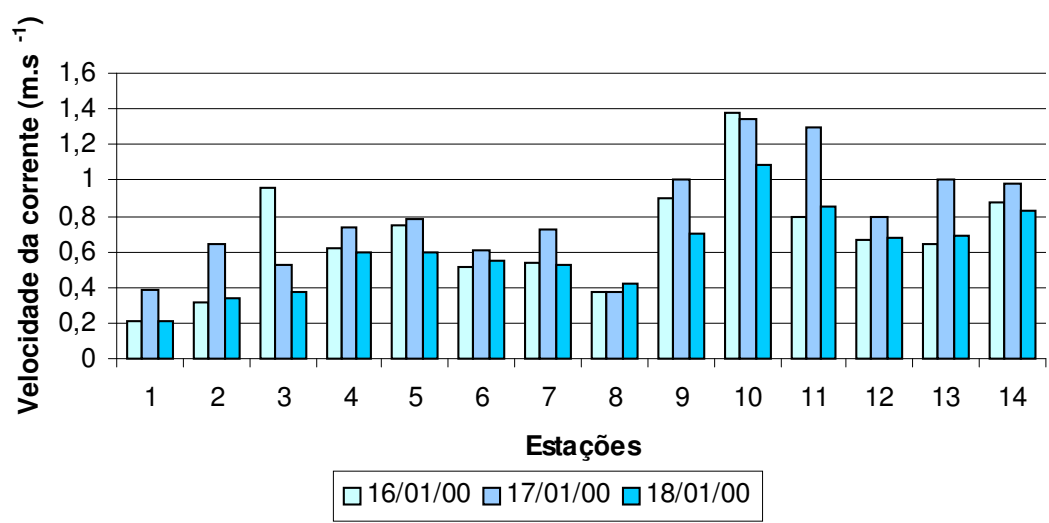

FIGURA 2.3.1.1- Variação da velocidade da corrente $\left(\mathrm{m} . \mathrm{s}^{-1}\right)$ ao longo do eixo longitudinal do rio Betari, no período de 16/01/00 a 18/01/00

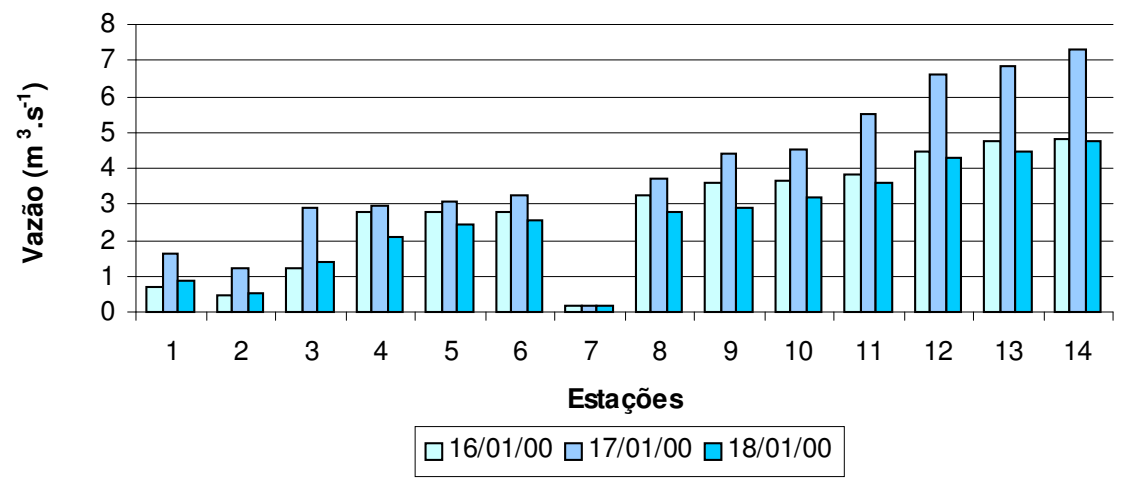

FIGURA 2.3.1.2 - Variação da vazão $\left(\mathrm{m}^{3} \cdot \mathrm{s}^{-1}\right)$ ao longo do eixo longitudinal do rio Betari, no período de 16/01/00 a 18/01/00.

\subsubsection{Variáveis físicas e químicas da água}

\subsubsection{1- $\mathrm{pH}$, condutividade, alcalinidade e formas de carbono}

As águas do rio Betari apresentaram valores de $\mathrm{pH}$ alcalinos. As estações que apresentaram valores de $\mathrm{pH}$ mais baixos (inferiores a 8,0) foram as do alto curso (estações 1, 2 e 3). Excluindo-se as estações 1 e 2, os valores mais elevados de pH no período ocorreram no dia 20/01/00 (figura 2.3.1.2.1.1). Os valores de condutividade 
(uS. $\left.\mathrm{cm}^{-1}\right)$, apresentados na figura 2.3.1.2.1.2, mostram uma diferenciação entre a estação 7 (córrego Furnas), onde ocorreram os valores mais elevados, e as estações do rio Betari; nas estações de 1 até 5 , os valores de condutividade foram inferiores. No dia 17/01/00, ocorreram os menores valores de condutividade do período, em todas as estações.

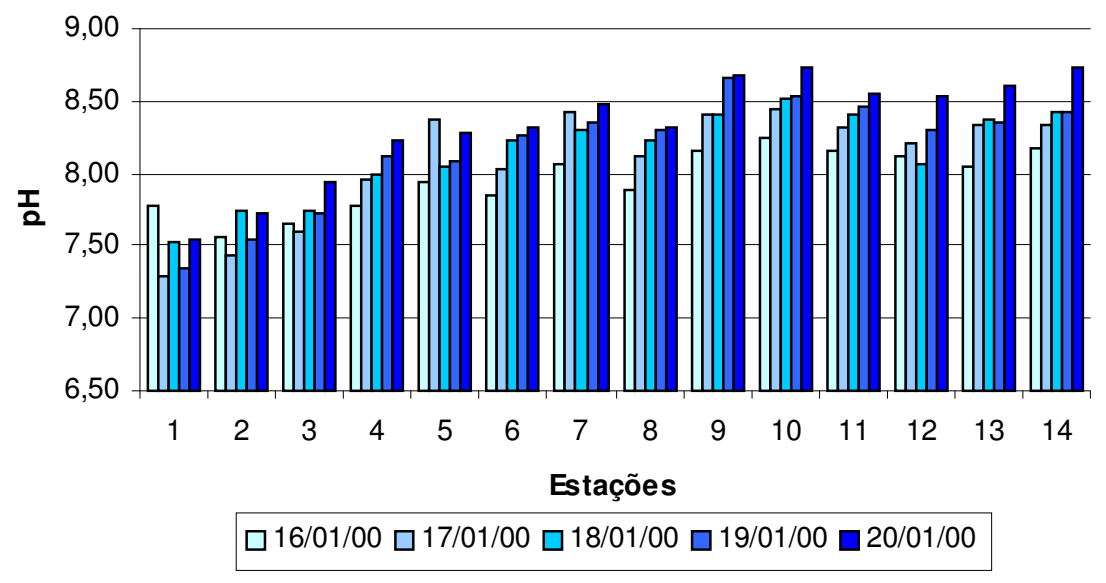

FIGURA 2.3.1.2.1.1 - Variação dos valores de pH no rio Betari, no período de 16/01/00 a 20/01/00.

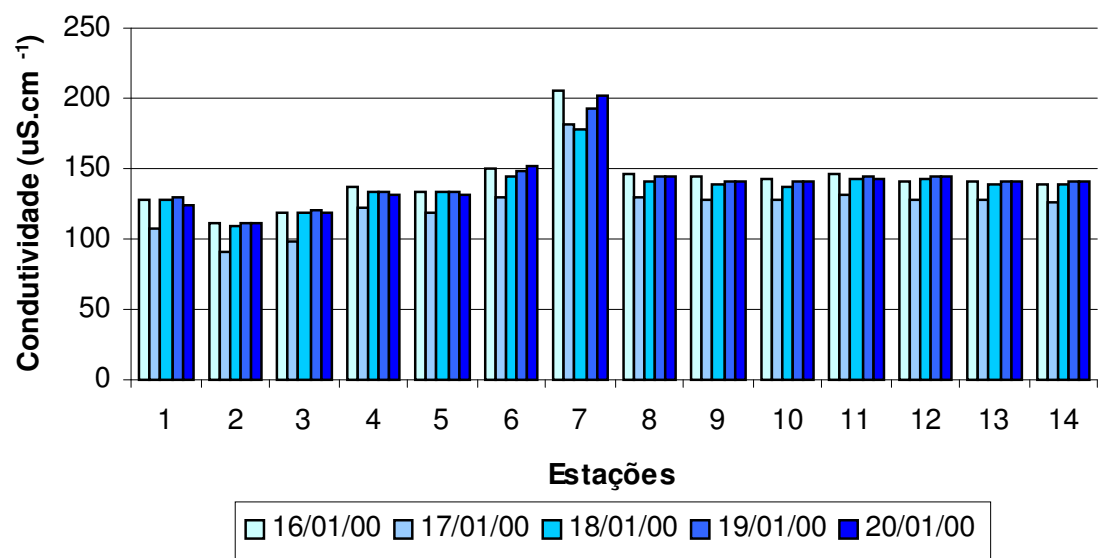

FIGURA 2.3.1.2.1.2 - Variação dos valores de condutividade (uS.cm ${ }^{-1}$ ) no rio Betari, no período de 16/01/00 a 20/01/00. 
$\mathrm{Na}$ figura 2.3.1.2.1.3, pode-se observar que os valores de alcalinidade (meq. $\mathrm{L}^{-1}$ ) seguiram o padrão da condutividade. O córrego Furnas destacou-se do rio Betari, e as estações 2 e 3 apresentaram os menores valores de alcalinidade. Nas formas de carbono (figuras 2.3.1.2.1.4 até 2.3.1.2.1.7), destacou-se a predominância do $\mathrm{HCO}_{3}{ }^{2-}$.

As altas condutividades e o teor alcalino das águas do rio Betari, em destaque o córrego Furnas, são reflexo das características geológicas da bacia hidrográfica que, como já dito anteriormente, caracteriza-se por uma área cárstica.

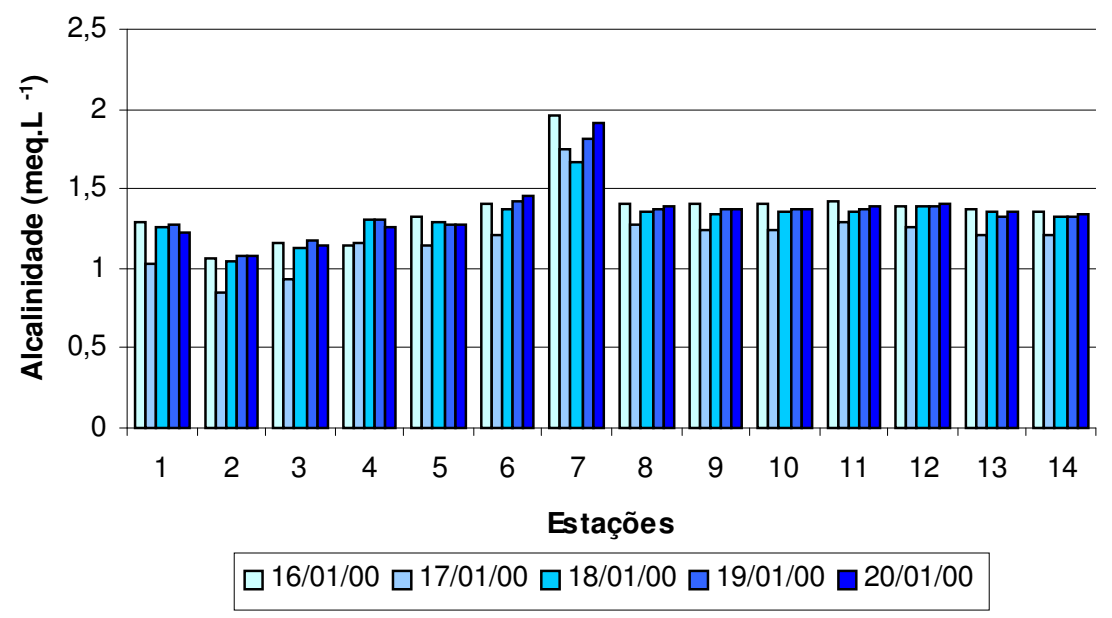

FIGURA 2.3.1.2.1.3 - Variação da alcalinidade (meq. $\mathrm{L}^{-1}$ ) nas estações do rio Betari, no período de 16/01/00 a 20/01/00. 


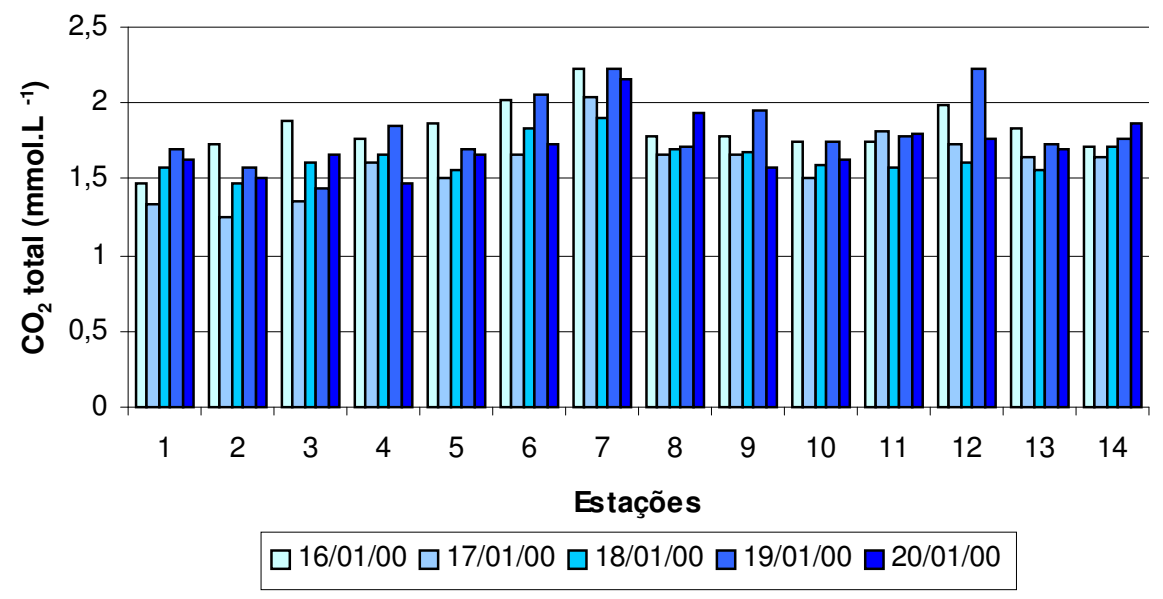

FIGURA 2.3.1.2.1.4 - Variação das concentrações de $\left(\mathrm{CO}_{2}\right)$ total $\left(\mathrm{mmol} . \mathrm{L}^{-1}\right)$ no rio Betari, no período de 16/01/00 a 20/01/00.

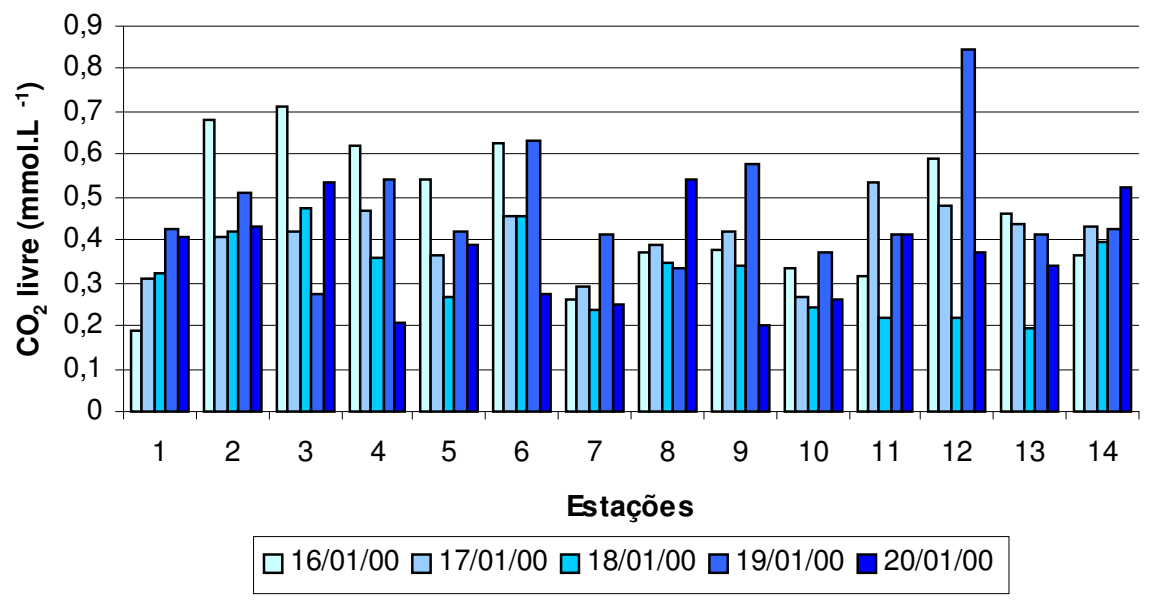

FIGURA 2.3.1.2.1.5 - Variação das concentrações de $\left(\mathrm{CO}_{2}\right)$ livre $\left(\mathrm{mmol} . \mathrm{L}^{-1}\right)$ no rio Betari, no período de16/01/00 a 20/01/00. 


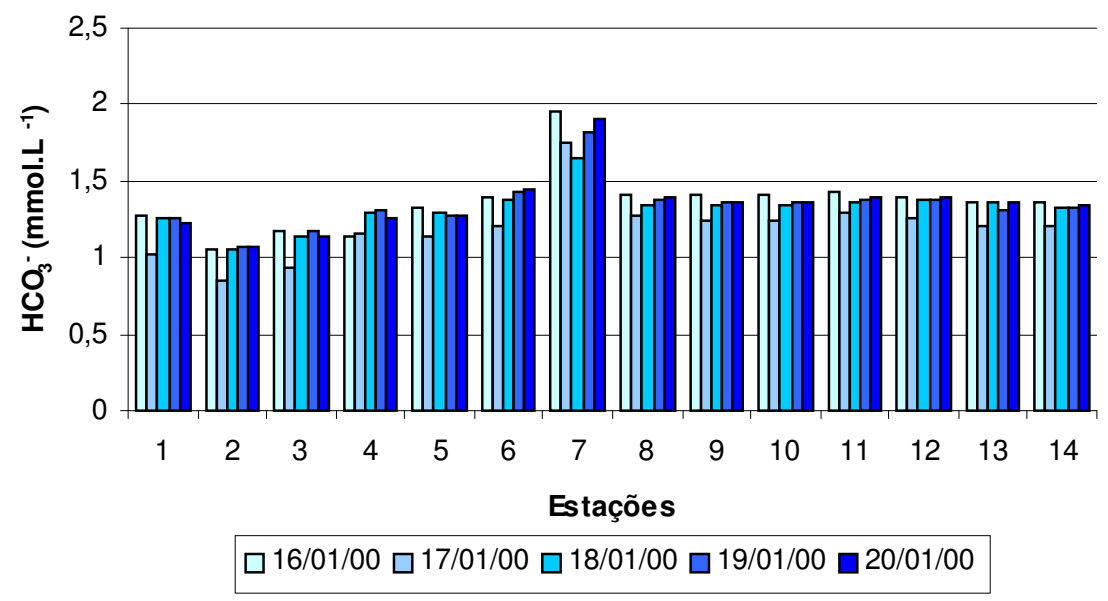

FIGURA 2.3.1.2.1.6 - Variação das concentrações de $\left(\mathrm{HCO}_{3}{ }^{-}\right)\left(\mathrm{mmol} . \mathrm{L}^{-1}\right)$ no rio Betari, no período de 16/01/00 a 20/01/00.

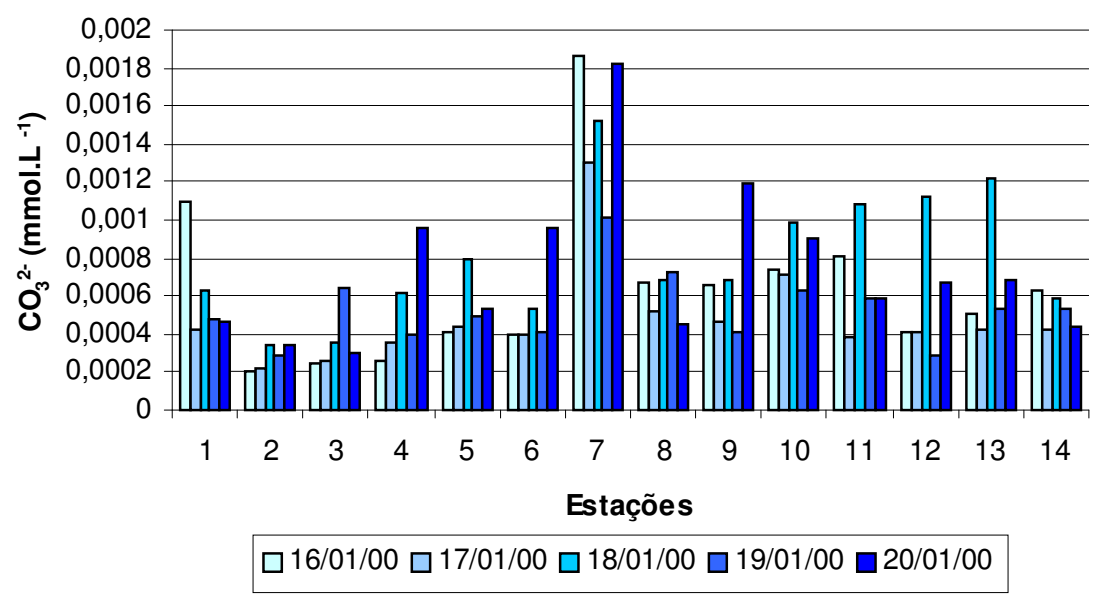

FIGURA 2.3.1.2.1.7- Variação das concentrações de $\left(\mathrm{CO}_{3}{ }^{2-}\right)\left(\mathrm{mmol} . \mathrm{L}^{-1}\right)$ no rio Betari, no período de16/01/00 a 20/01/00. 


\subsection{Oxigênio dissolvido}

O rio Betari, no período de amostragem em janeiro de 2000, apresentou água bem oxigenada. As concentrações de oxigênio dissolvido foram superiores a 8,0 mg.. $\mathrm{L}^{-1}$ (figura 2.3.1.2.2).

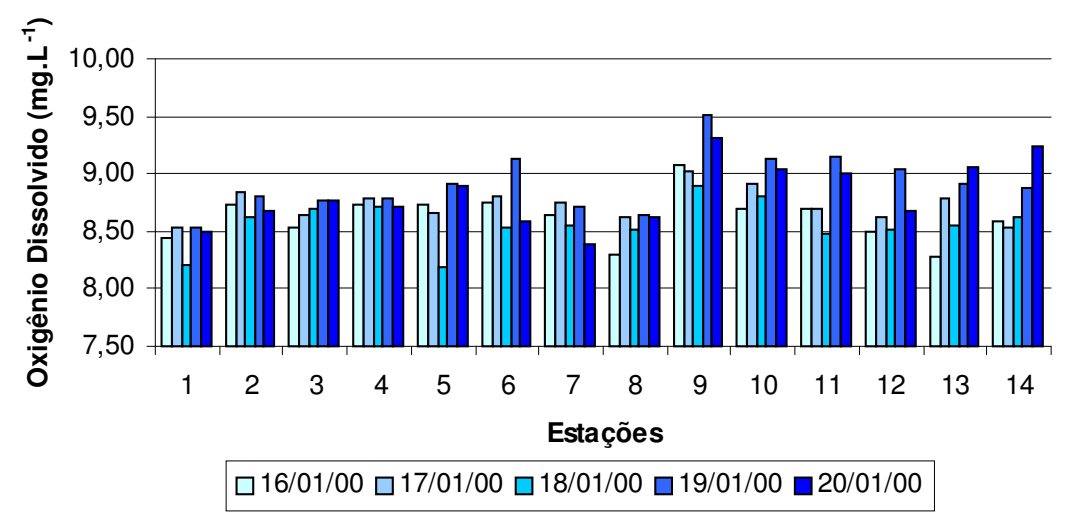

FIGURA 2.3.3.1.2.2. Variação das concentrações de oxigênio dissolvido $\left(\mathrm{mg} \cdot \mathrm{L}^{-1}\right)$ no rio Betari, no período de 16/01/00 a 20/01/00.

\subsection{Turbidez , sólidos em suspensão orgânicos e inorgânicos.}

Os valores de turbidez (figura 2.3.1.2.3.1) e as concentrações de sólidos em suspensão (figuras 2.3.1.2.3.2 e 2.3.1.2.3.3) oscilaram durante o período de amostragem, em função das chuvas. Os maiores valores do segundo dia de coleta relacionaram-se às chuvas ocorridas neste dia. Os valores mais elevados nas estações do baixo curso comprovam que essa região é mais suscetível à acumulação de materiais da bacia hidrográfica. 


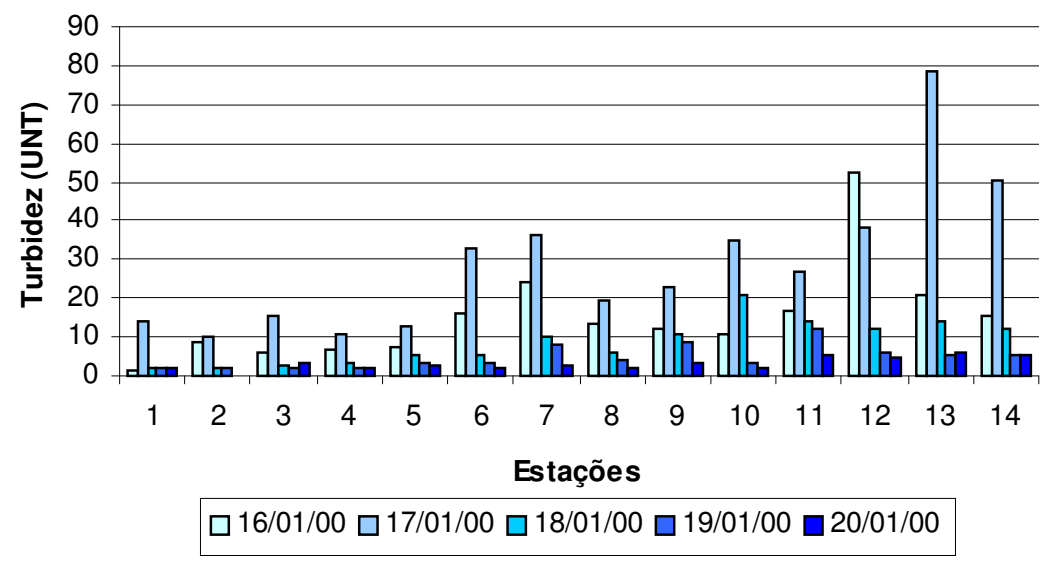

FIGURA 2.3.1.2.3.1- Variação dos valores de turbidez (UNT) no rio Betari, no período de $16 / 01 / 00$ a $20 / 01 / 00$.

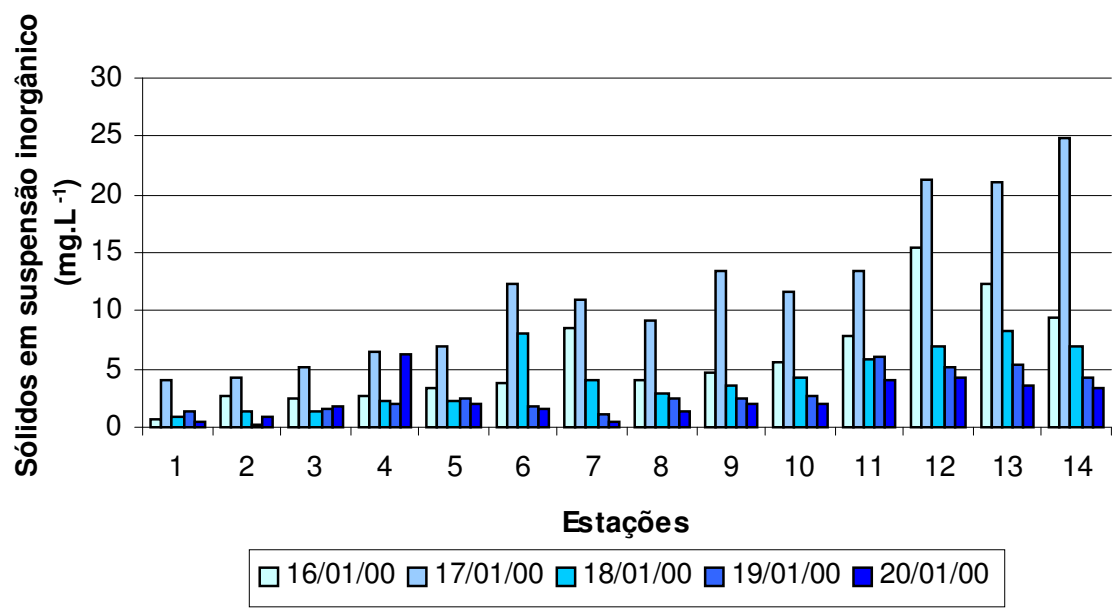

FIGURA 2.3.1.2.3.2 - Variação das concentrações de sólidos em suspensão inorgânicos (mg.L' $\left.{ }^{1}\right)$ no rio Betari, no período de 16/01/00 a 20/01/00. 


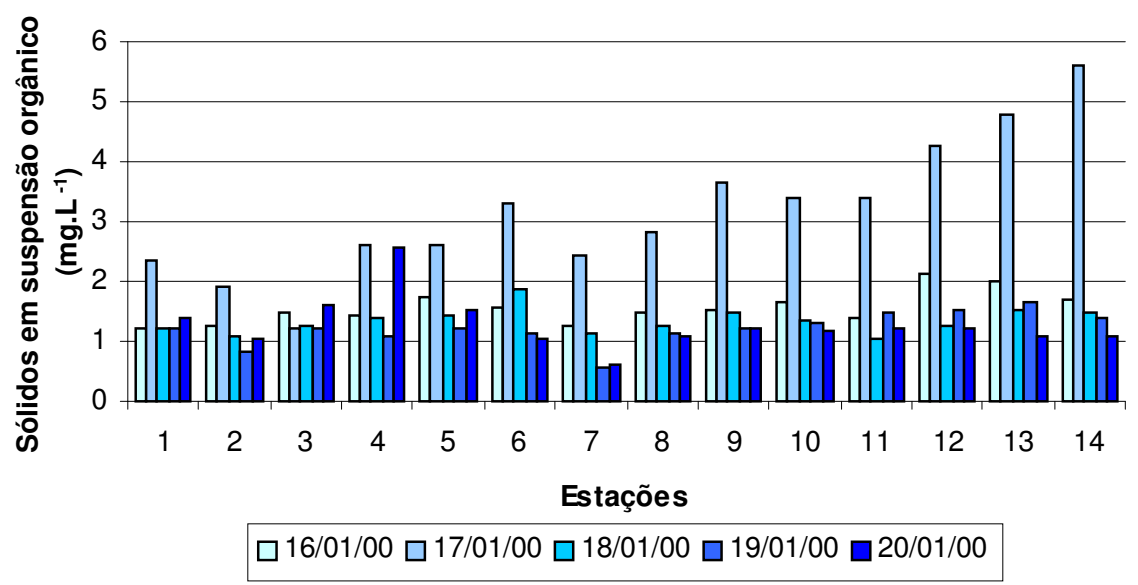

FIGURA 2.3.1.2.3.3 - Variação das concentrações de sólidos em suspensão orgânicos (mg. $\left.\mathrm{L}^{-1}\right)$ no rio Betari, no período de 16/01/00 a 20/01/00.

\subsubsection{4 - Temperatura da Água}

A temperatura da água $\left({ }^{\circ} \mathrm{C}\right)$ varia em função do sombreamento do canal na estação de amostragem e do horário de coleta. Como as coletas não foram realizadas simultaneamente, o padrão de distribuição das temperaturas ao longo do perfil longitudinal do rio Betari (valores mais elevados no baixo curso) foi função da variação dos horários de amostragem. Deve-se também considerar que, em muitos trechos do baixo curso, a vegetação ciliar é insuficiente para sombrear o canal (figura 2.3.1.2.4). 


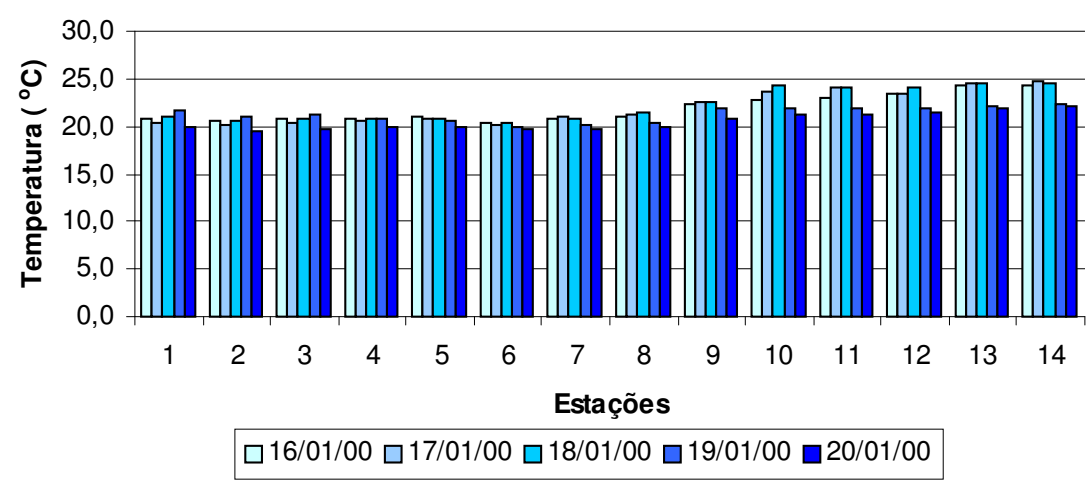

FIGURA 2.3.1.2.4 - Variação da temperatura da água $\left({ }^{\circ} \mathrm{C}\right)$ no rio Betari, no período de 16/01/00 a $20 / 01 / 00$.

\subsection{Demanda Bioquímica de Oxigênio}

O rio Betari apresentou baixos valores de demanda bioquímica de oxigênio. Somente na estação 14 , a DBO foi superior a 1,00 mg. $\mathrm{L}^{-1}$.

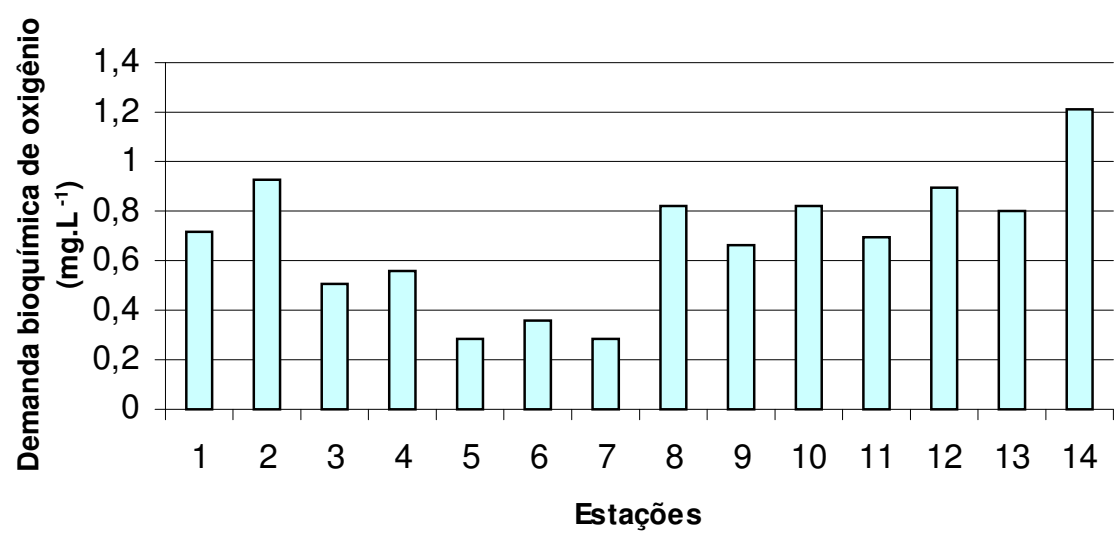

Figura 2.3.1.2.5 - Variação da demanda bioquímica de oxigênio $\left(\mathrm{mg} . \mathrm{L}^{-1}\right)$ no rio Betari em 20/01/00.

\subsection{Nutrientes dissolvidos e totais na água}

As concentrações das formas nitrogenadas - nitrogênio amoniacal, nitrato, 
nitrito e nitrogênio orgânico total - no rio Betari, estão apresentadas nas figuras 2.3.1.2.6.1 até 2.3.1.2.6.4. Entre as formas nitrogenadas, ocorreu o predomínio de nitrogênio orgânico total e nitrato. A distribuição longitudinal das formas nitrogenadas ao longo do rio não seguiram padrão definido.

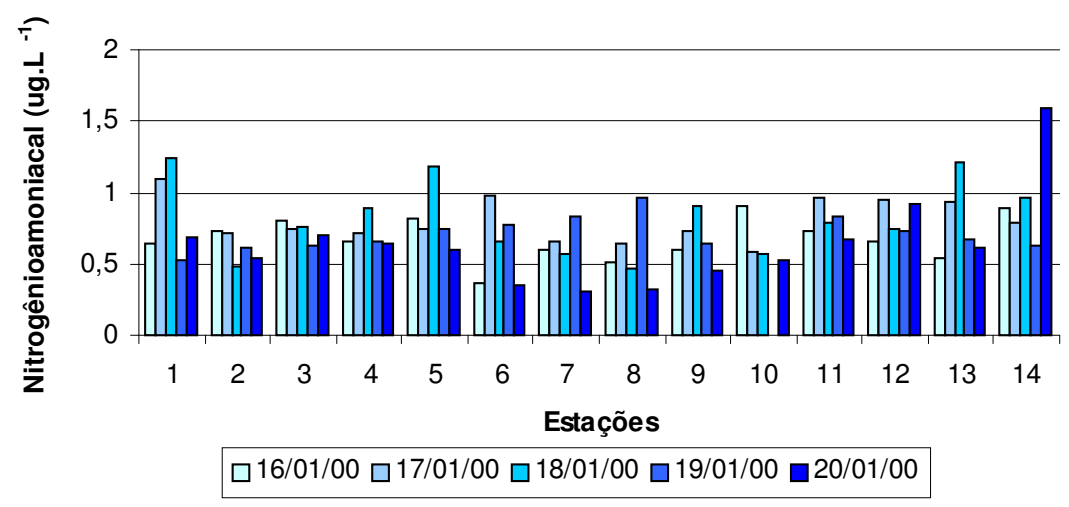

Figura 2.3.1.2.6.1 - Variação das concentrações de nitrogênio amoniacal (ug. $\mathrm{L}^{-1}$ ) no rio Betari, no período de 16/01/00 a 20/01/00.

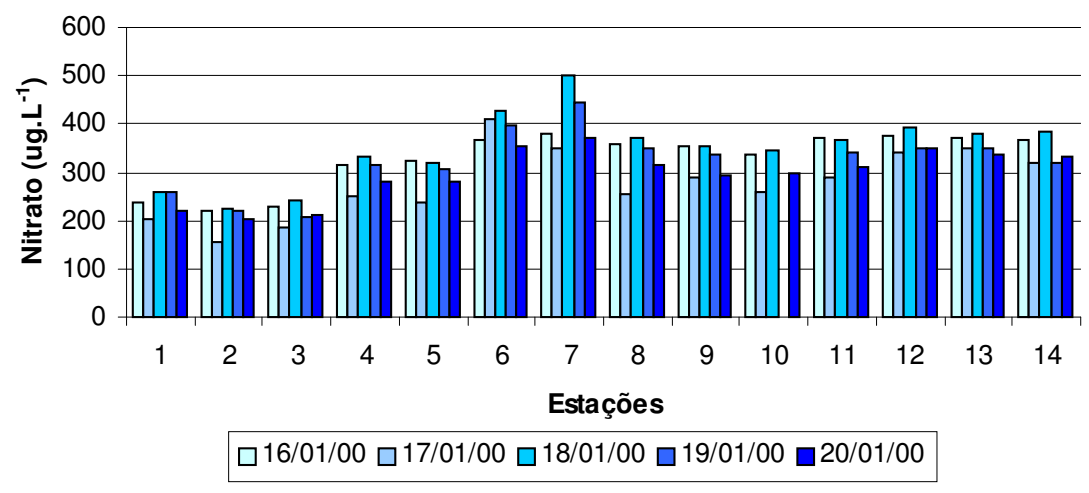

FIGURA 2.3.1.2.6.2 - Variação das concentrações de nitrato (ug. $\mathrm{L}^{-1}$ ) no rio Betari, no período de 16/01/00 a 20/01/00. 


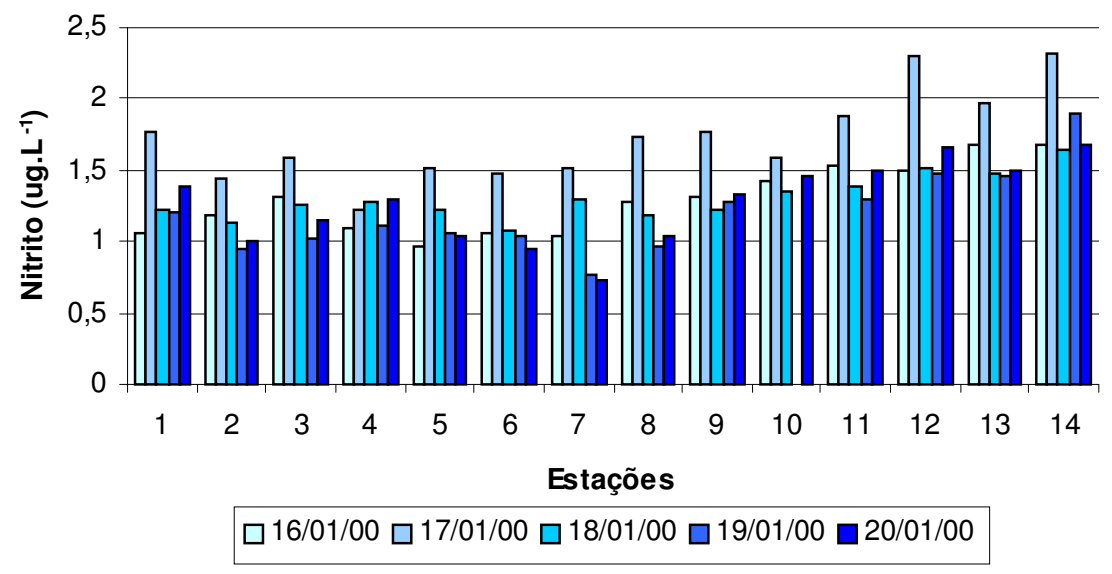

FIGURA 2.3.1.2.6.3 - Variação das concentrações de nitrito (ug. $\left.L^{-1}\right)$ no rio Betari, no período de 16/01/00 a 20/01/00.

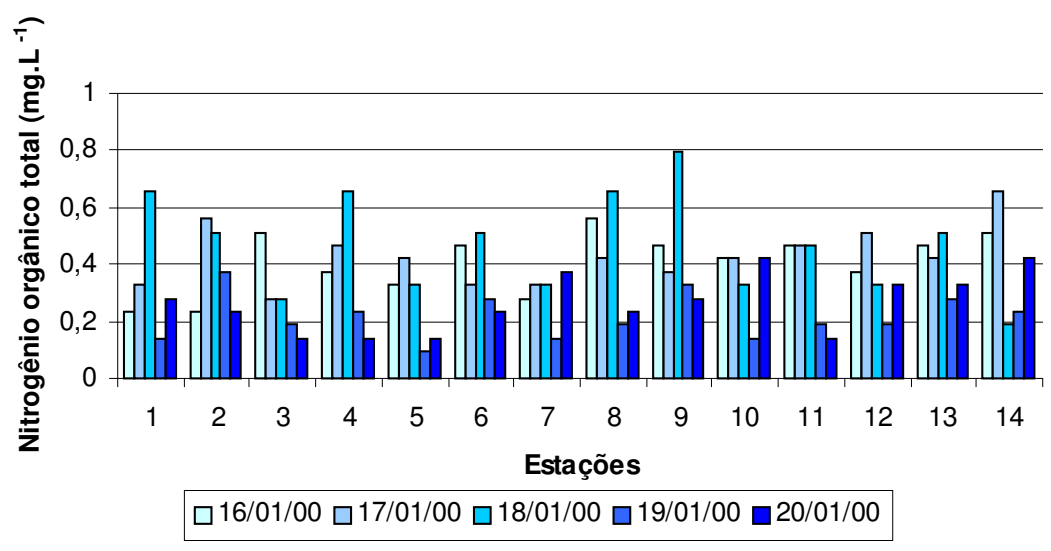

FIGURA 2.3.1.2.6.4 - Variação das concentrações de nitrogênio orgânico total (mg. $\mathrm{L}^{-1}$ ) no rio Betari, no período de 16/01/00 a 20/01/00.

Da mesma maneira que para as formas de nitrogênio, as de fósforo não demonstraram uma distribuição uniforme ao longo do perfil longitudinal do rio Betari. É possível observar maiores concentrações nos dois primeiros dias de amostragem, 
provavelmente devido ao carreamento de materiais pela chuva (figuras 2.3.1.2.6.5 até 2.3.1.2.6.7).

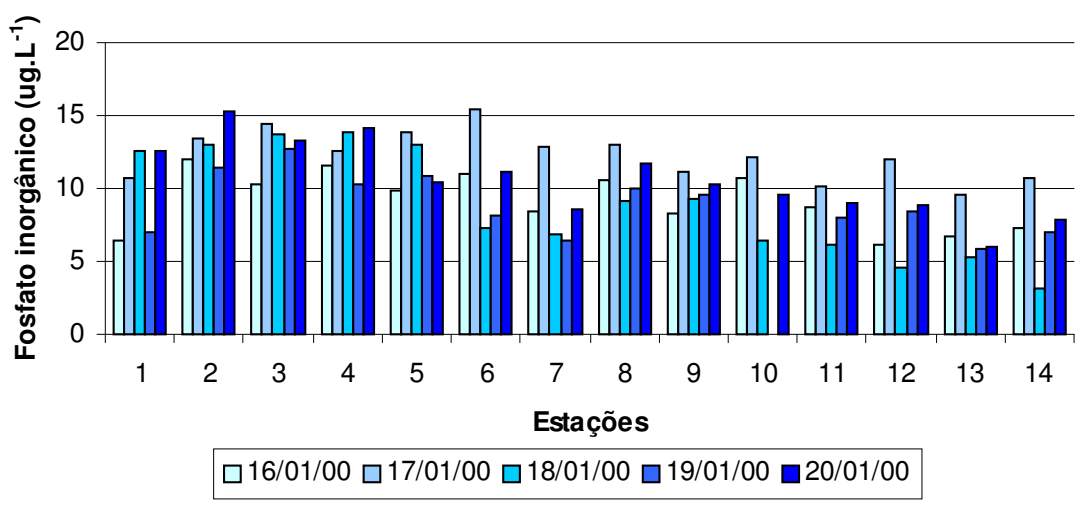

FIGURA 2.3.1.2.6.5 - Variação das concentrações de fosfato inorgânico (ug. $\mathrm{L}^{-1}$ ) no rio Betari, no período de 16/01/00 a 20/01/00.

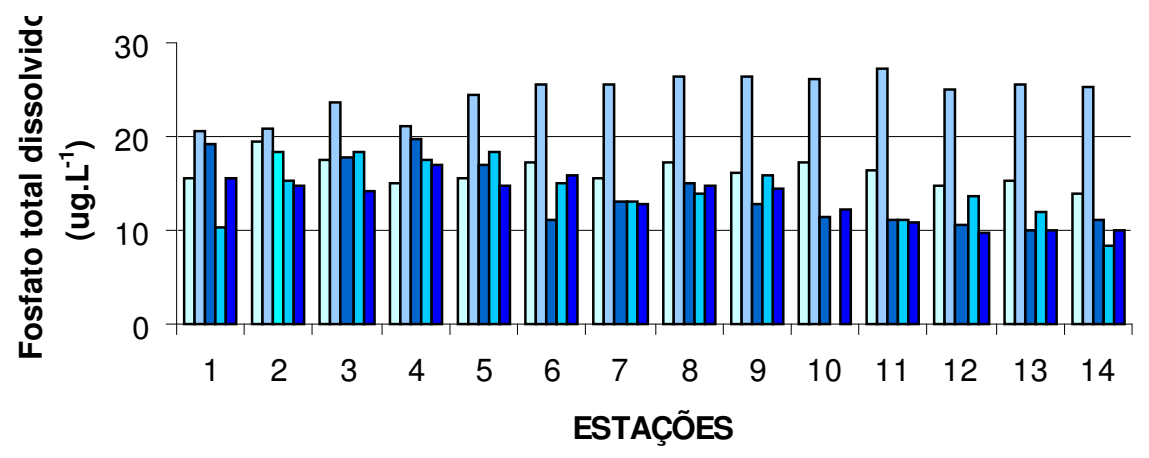

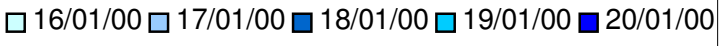

FIGURA 2.3.1.2.6.6 - Variação das concentrações de fosfato total dissolvido (ug. $\mathrm{L}^{-1}$ ) no rio Betari, no período de 16/01/00 a 20/01/00. 


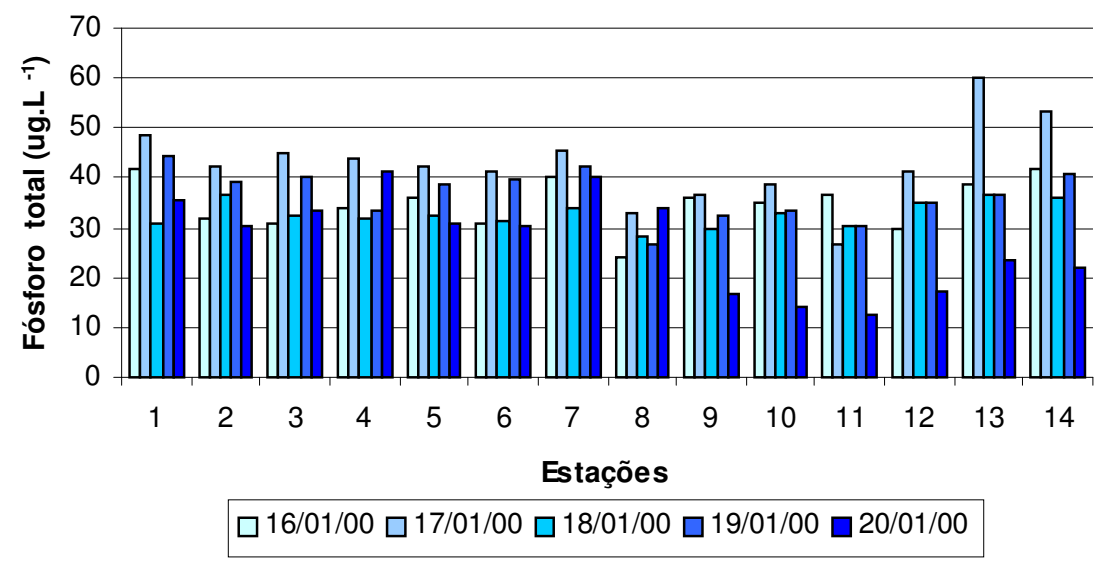

FIGURA 2.3.1.2.6.7 - Variação das concentrações de fósforo total (ug. $\mathrm{L}^{-1}$ ) no rio Betari, no período de 16/01/00 a 20/01/00.

As concentrações de silicato reativo (figura 2.3.1.2.6.8) foram superiores na porção superior do rio Betari. As menores concentrações foram observadas no segundo dia de amostragem, quando registraram-se as maiores intensidades de chuvas.

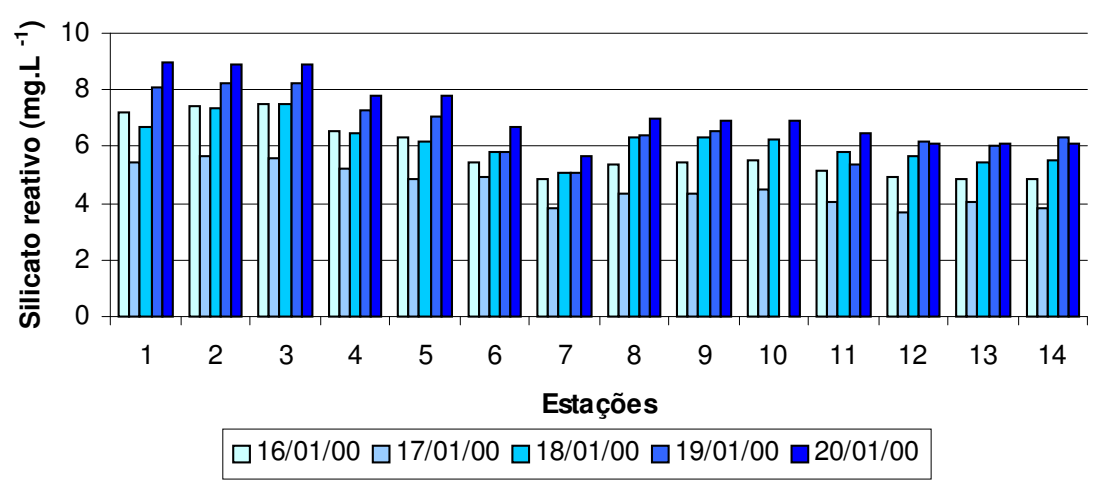

FIGURA 2.3.1.2.6.8 - Variação das concentrações de silicato reativo (mg. $\mathrm{L}^{-1}$ ) no rio 
Betari, no período de 16/01/00 a 20/01/00.

\subsubsection{7. Íons Dissolvidos na Água}

As amostras de íons cálcio, sódio e magnésio apresentaram-se acima do limite de deteç̧ão dos métodos utilizados (15 mg.L $\mathrm{L}^{-1} ; 2 \mathrm{mg} . \mathrm{L}^{-1}$; e $2 \mathrm{mg} . \mathrm{L}^{-1}$ respectivamente). Quanto as concentrações de chumbo na água, foram detectadas somente nas estações de 7 à $9\left(0,011 \mathrm{mg} . \mathrm{L}^{-1} ; 0,02 \mathrm{mg} . \mathrm{L}^{-1}\right.$ e $0,002 \mathrm{mg} . \mathrm{L}^{-1}$, respectivamente). O zinco ocorreu em todos pontos de amostragem, mas foi elevado no ponto 7 (tabela 2.3.1.2.7).

TABELA 2.3.1.2.7 - Variação das concentrações de íons na água no rio Betari na amostragem de janeiro de 2000.

\begin{tabular}{lcccccccccccccc}
\hline Estações & 1 & 2 & 3 & 4 & 5 & 6 & 7 & 8 & 9 & 10 & 11 & 12 & 13 & 14 \\
\hline $\mathrm{Zn}\left(\mathrm{mg} \cdot \mathrm{L}^{-1}\right)$ & 0,01 & 0,01 & 0,01 & 0,01 & 0,01 & 0,01 & 0,28 & 0,05 & 0,02 & 0,02 & 0,02 & 0,01 & 0,03 & 0,02 \\
$\mathrm{~Pb}\left(\mathrm{mg} \cdot \mathrm{L}^{-1}\right)$ & $*$ & $*$ & $*$ & $*$ & $*$ & $*$ & 0,01 & 0,02 & 0,02 & $*$ & $*$ & $*$ & $*$ & $*$ \\
$\mathrm{Ca}\left(\mathrm{mg} \cdot \mathrm{L}^{-1}\right)$ & $>15$ & $>15$ & $>15$ & $>15$ & $>15$ & $>15$ & $>15$ & $>15$ & $>15$ & $>15$ & $>15$ & $>15$ & $>15$ & $>15$ \\
$\mathrm{Na}\left(\mathrm{mg} \cdot \mathrm{L}^{-1}\right)$ & $>2$ & $>2$ & $>2$ & $>2$ & $>2$ & $>2$ & $>2$ & $>2$ & $>2$ & $>2$ & $>2$ & $>2$ & $>2$ & $>2$ \\
$\mathrm{Mg}\left(\mathrm{mg} \cdot \mathrm{L}^{-1}\right)$ & $>2$ & $>2$ & $>2$ & $>2$ & $>2$ & $>2$ & $>2$ & $>2$ & $>2$ & $>2$ & $>2$ & $>2$ & $>2$ & $>2$ \\
\hline
\end{tabular}

\subsubsection{Análise numérica}

A análise de agrupamento realizada com a média do conjunto de dados físicos e químicos da água, obtidos na coleta de janeiro de 2000, reuniu as estações de amostragem em grupos ao longo do perfil longitudinal: estações 1 , 2, 3, 4 e 5 (grupo 1); estações 6, 8, 9 e 10 (grupo 2); estação 7 (grupo 3); e estações 11, 12, 13, 14 (grupo 4) - figura 2.3.1.3. Porém, a análise discriminante realizada (utilizando os grupos formados) evidenciou a 
inexistência de diferenças estatisticamente significativas (intervalo de confiança de $95 \%$ ) entre os grupos formados pela análise de cluster.

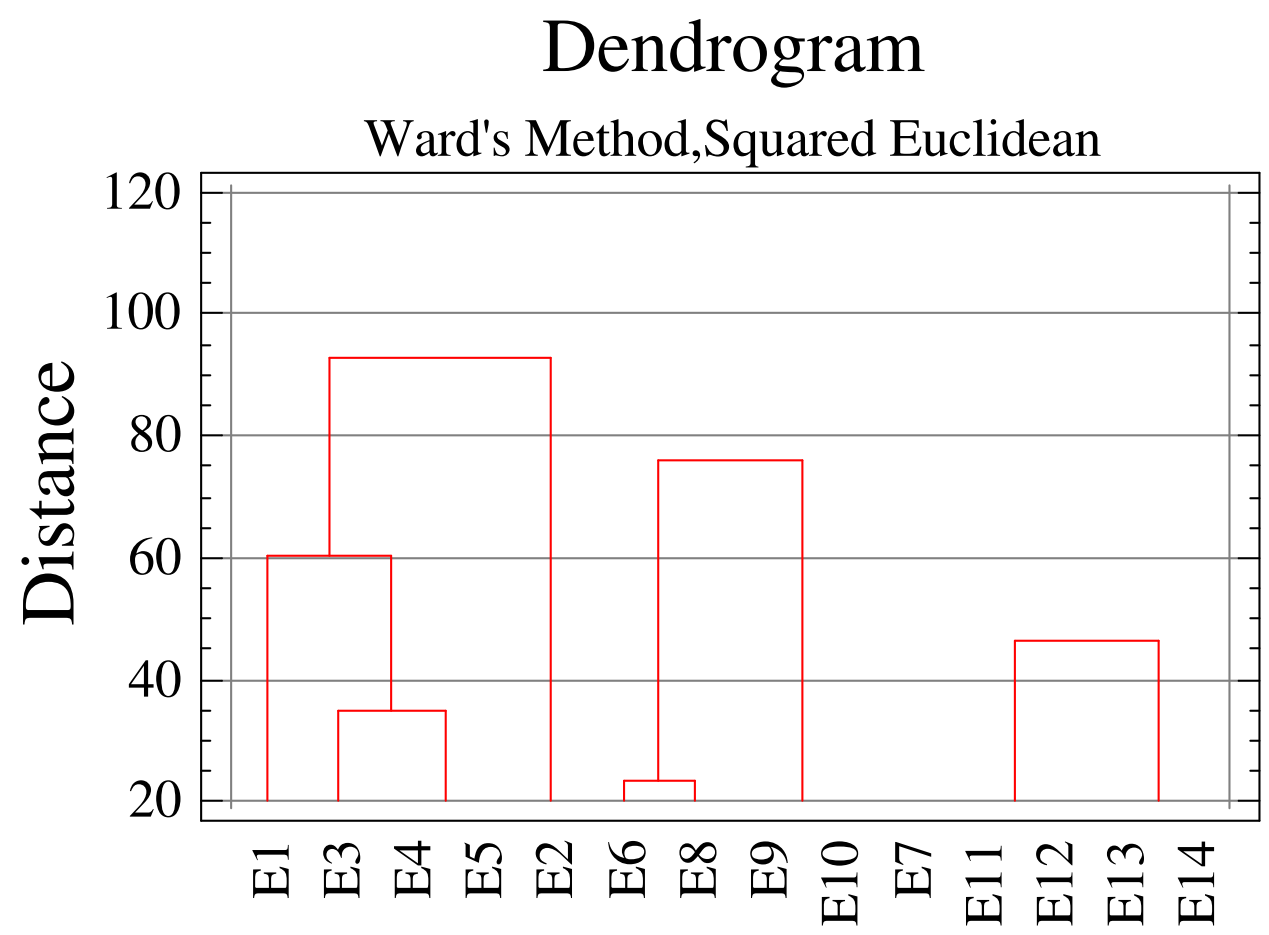

FIGURA 2.3.1.3 - Dendograma da análise de agrupamento das médias das variáveis físicas e químicas da água nas estações do rio Betari em janeiro de 2000. 


\subsubsection{SEGUNDA CAMPANHA DE AMOSTRAGEM (ABRIL DE 2000)}

\subsubsection{Velocidade de escoamento e vazão}

No segundo período de amostragem, em abril de 2000, a velocidade da corrente foi mais elevada nas estações localizadas no médio e baixo curso do rio Betari, com velocidades abaixo de $0,20 \mathrm{~m} \cdot \mathrm{s}^{-1}$ na estação 1 , e acima de 0,80 $\mathrm{m} . \mathrm{s}^{-1}$ na estação 11 (figura 2.3.2.1.1). As vazões (figura 2.3.2.1.2) variaram de $0,35 \mathrm{~m}^{3} \cdot \mathrm{s}^{-1}$ na estação 2 , até $4,24 \mathrm{~m}^{3} \cdot \mathrm{s}^{-1}$ na estação 14 .

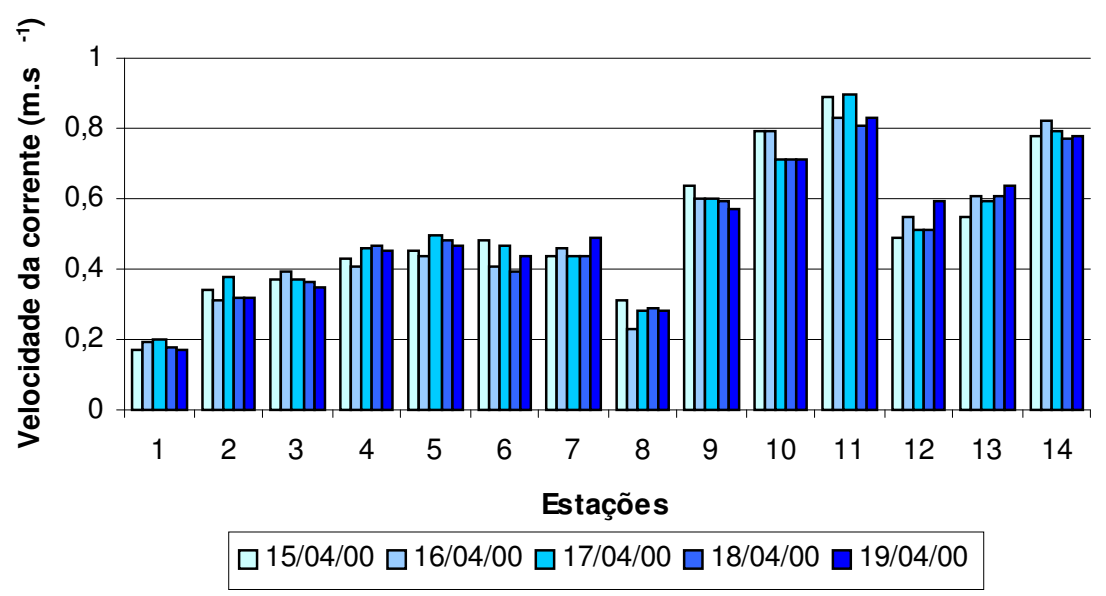

FIGURA 2.3.2.1.1- Variação da velocidade da corrente $\left(\mathrm{m}^{-1} \mathrm{~s}^{-1}\right)$ ao longo do eixo longitudinal do rio Betari, no período de 15/04/00 a 19/04/00. 


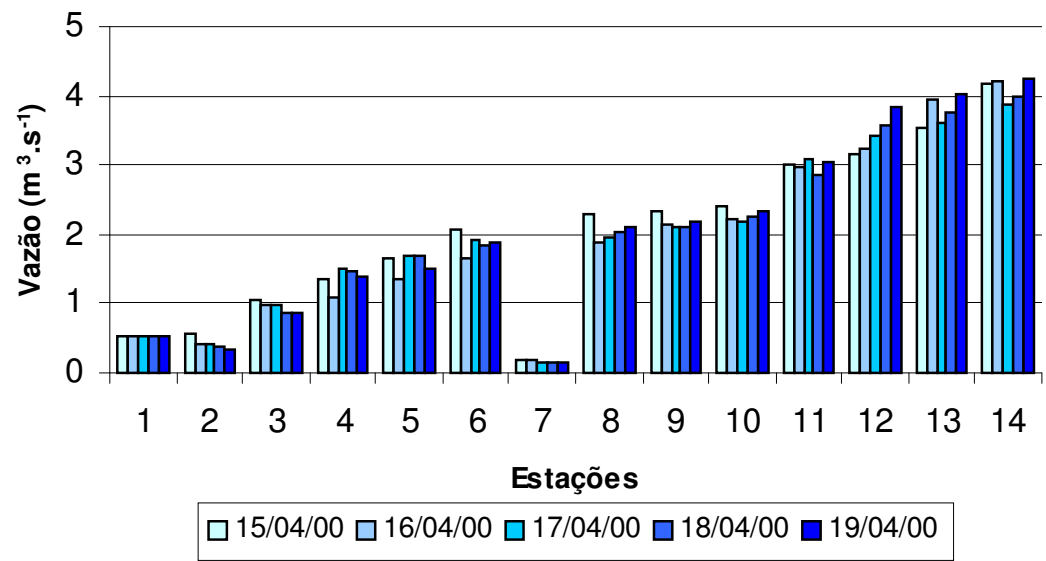

FIGURA 2.3.2.1.2- Variação da vazão $\left(\mathrm{m}^{3} \cdot \mathrm{s}^{-1}\right)$ ao longo do eixo longitudinal do rio Betari, no período de 15/04/00 a 19/04/00.

\subsubsection{Variáveis físicas e químicas da água.}

\subsubsection{1. $\mathrm{pH}$, condutividade, alcalinidade e formas de carbono.}

Os valores de $\mathrm{pH}$ do rio Betari foram alcalinos na campanha de amostragem de abril de 2000 (figura 2.3.2.2.1.1), variando entre 7,05 na estação 1, e 8,75 na estação 14. Os valores de pH foram acompanhados dos valores de condutividade elevados (figura 2.3.2.2.1.2), entre 131 uS.cm ${ }^{-1}$ na estação 1, e 195,3 uS.cm ${ }^{-1}$ na estação 7. Tanto para os valores de $\mathrm{pH}$, como para os de alcalinidade, as estações do alto curso apresentaram valores inferiores aos das estações do médio e baixo curso. 


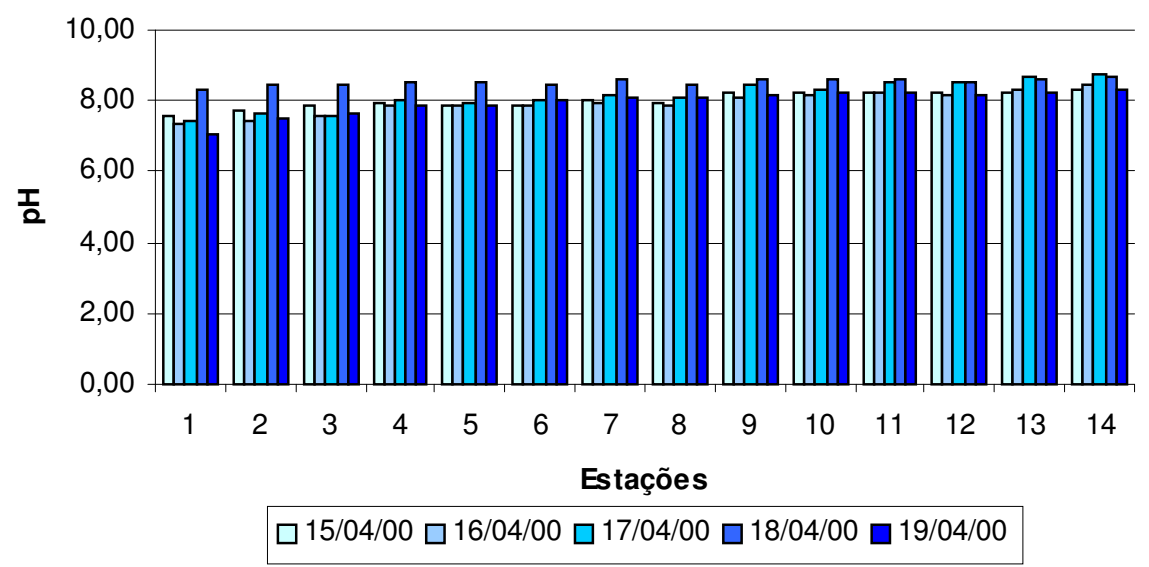

FIGURA 2.3.2.2.1.1 - Variação dos valores de pH no rio Betari, no período de 15/04/00 a $19 / 04 / 00$.

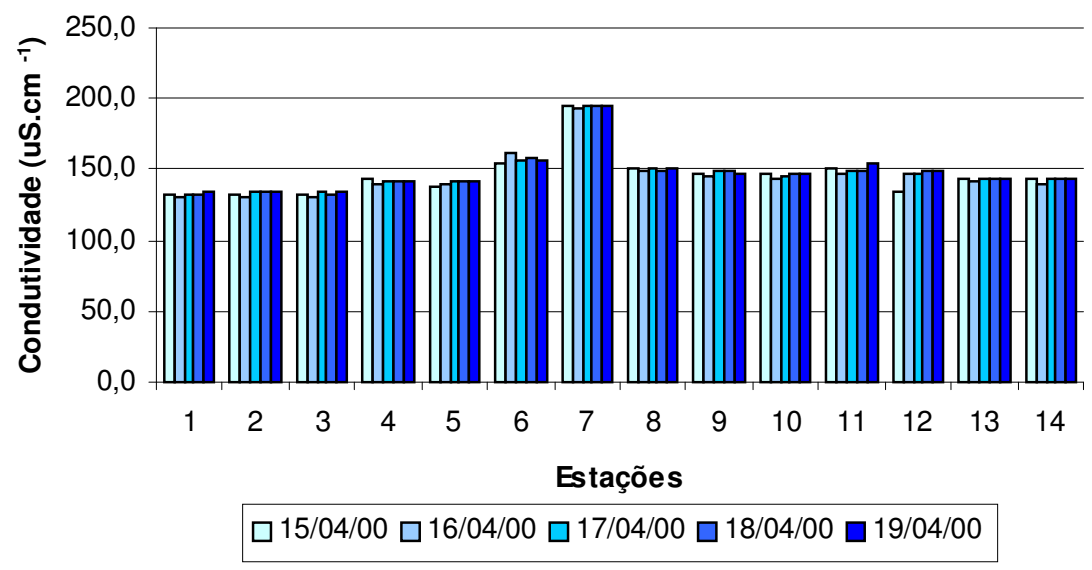

FIGURA 2.3.2.2.1.2 - Variação dos valores de condutividade $\left(\right.$ US. $\left.\mathrm{cm}^{-1}\right)$ no rio Betari, no período de 15/04/00 a 19/04/00.

Com valores de $\mathrm{pH}$ alcalinos e altas condutividades, a alcalinidade das águas do rio Betari em abril de 2000 também foi elevada, variando entre 1,33 meq. $L^{-1}$ na estação 1 , e 1,94 meq. $L^{-1}$ na estação 7 (figura 2.3.2.2.1.3). As formas de carbono apresentadas nas figuras 2.3.2..2.1.4 até 2.3.2.2.1.7 estão representadas, predominantemente, pelo bicarbonato. A alcalinidade e as concentrações de $\mathrm{HCO}_{3}{ }^{-}$foram inferiores nas estações do alto curso. 


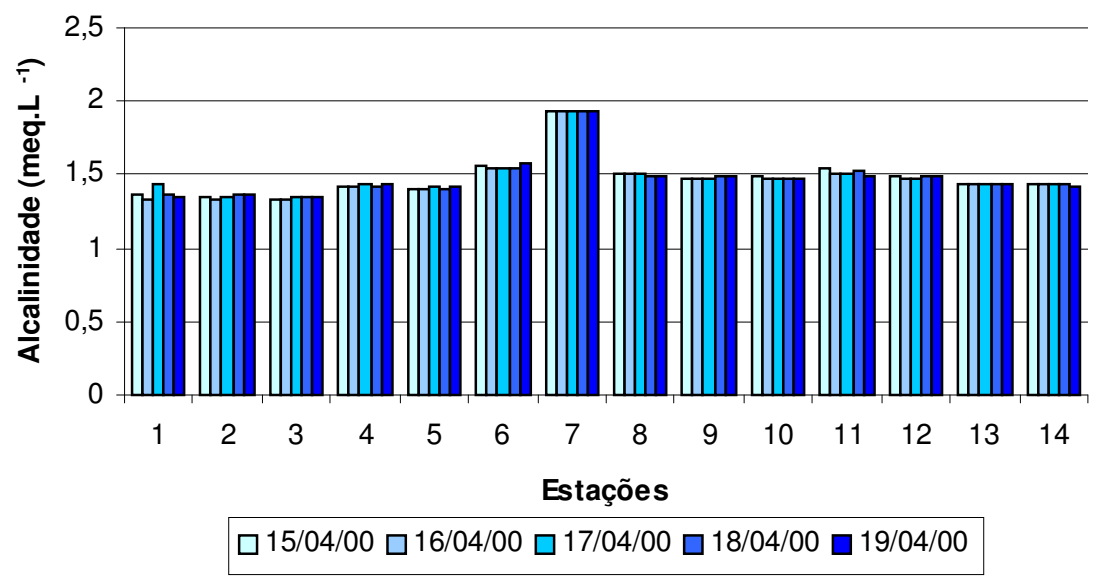

FIGURA 2.3.2.2.1.3 - Variação da alcalinidade (meq. L $^{-1}$ ) no rio Betari, no período de $15 / 04 / 00$ a $19 / 04 / 00$.

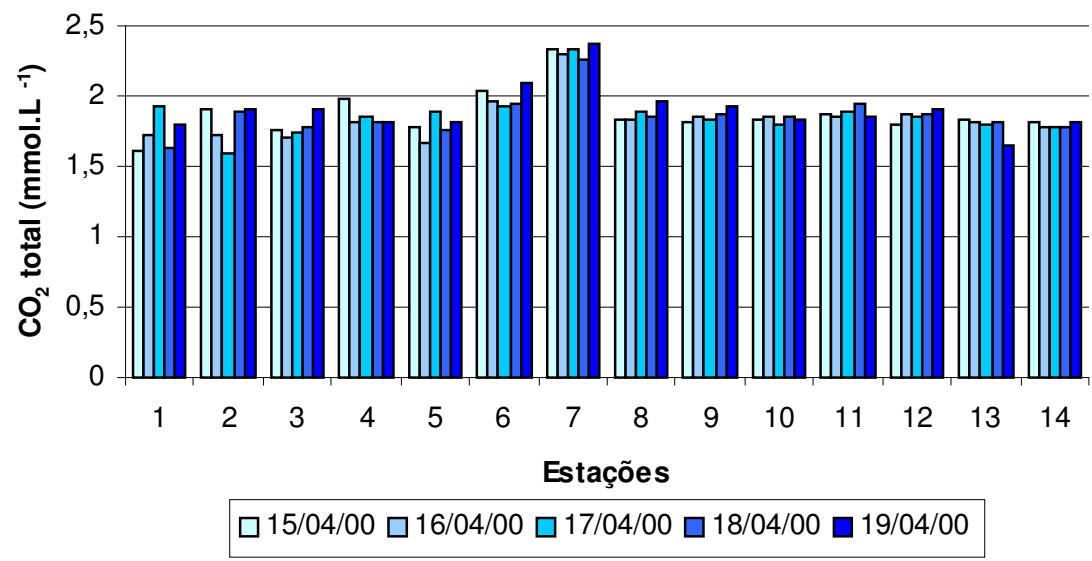

FIGURA 2.3.2.2.1.4- Variação das concentrações de $\left(\mathrm{CO}_{2}\right)$ total $\left(\mathrm{mmol} \cdot \mathrm{L}^{-1}\right)$ no rio Betari, no período de 15/04/00 a 19/04/00. 


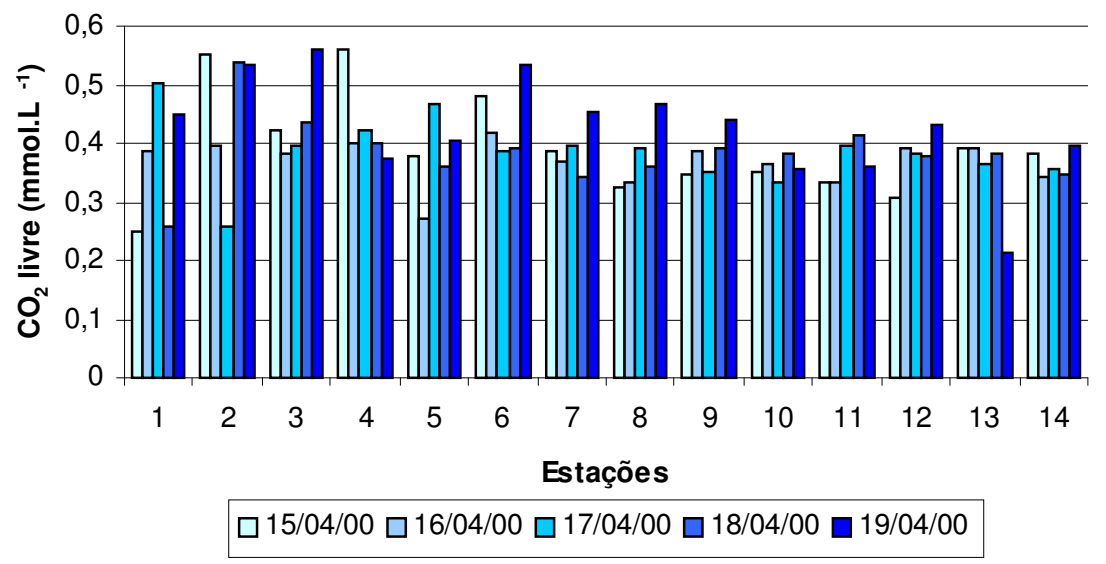

FIGURA 2.3.2.2.1.5- Variação das concentrações de $\left(\mathrm{CO}_{2}\right)$ livre $\left(\mathrm{mmol} . \mathrm{L}^{-1}\right)$ no rio Betari, no período de 15/04/00 a 19/04/00.

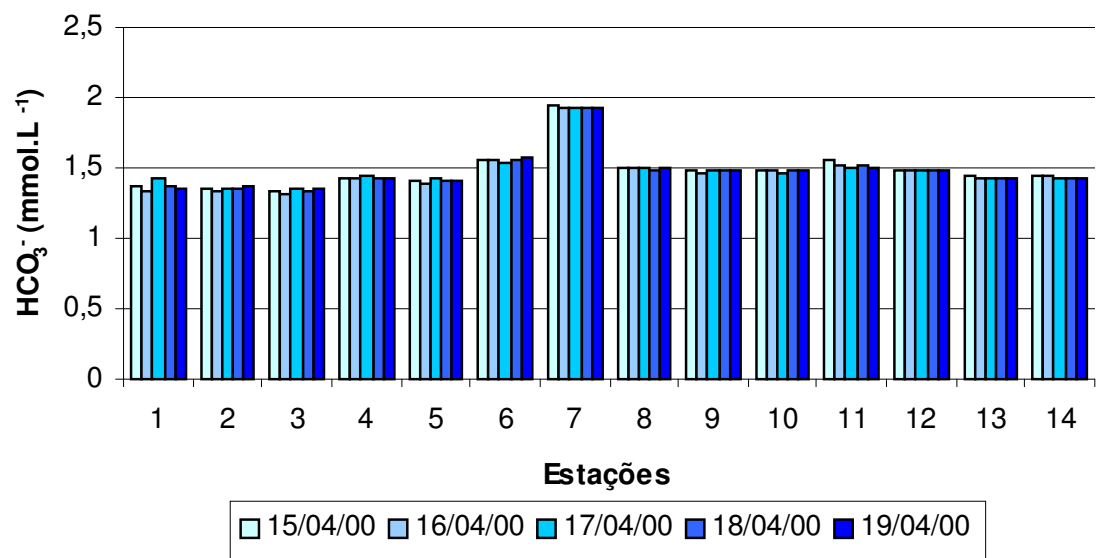

FIGURA 2.3.2.2.1.6 - Variação das concentrações de $\left(\mathrm{HCO}_{3}^{-}\right)\left(\mathrm{mmol}^{-1} \mathrm{~L}^{-1}\right)$ no rio Betari, no período de 15/04/00 a 19/04/00. 


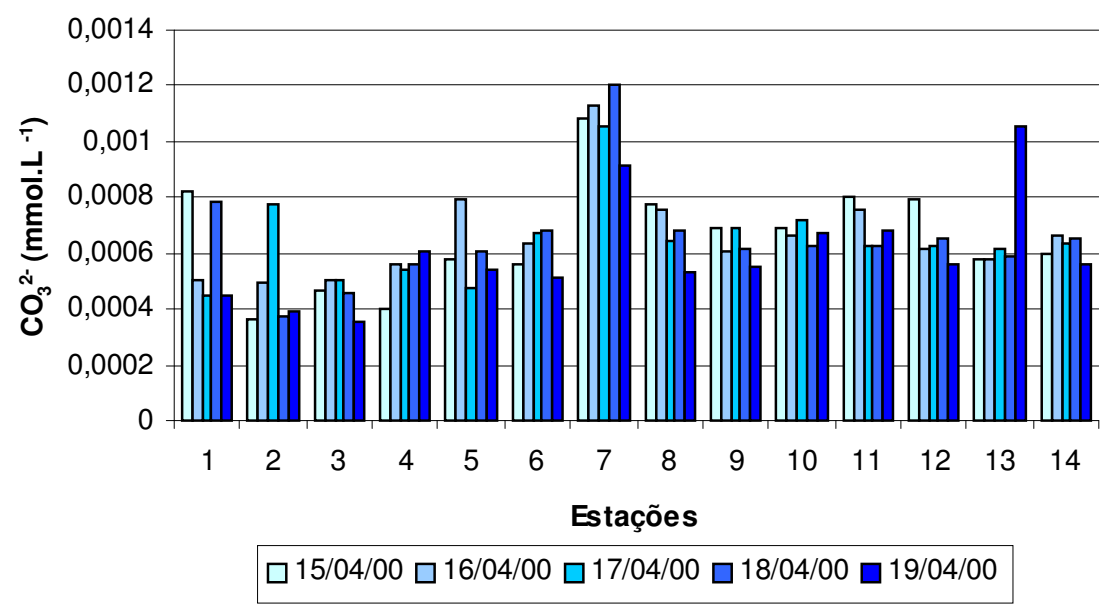

FIGURA 2.3.2.2.1.7 - Variação das concentrações de $\left(\mathrm{CO}_{3}^{-}\right)\left(\mathrm{mmol}^{-L^{-1}}\right)$ no rio Betari, no período de 15/04/00 a 19/04/00

\subsection{Oxigênio dissolvido}

$\mathrm{Na}$ época de estudo, as concentrações de oxigênio dissolvido foram elevadas ao longo de todo o curso do rio Betari. Elas estiveram acima de 8,20 mg. $\mathrm{L}^{-1}$ (figura 2.3.2.2.2).

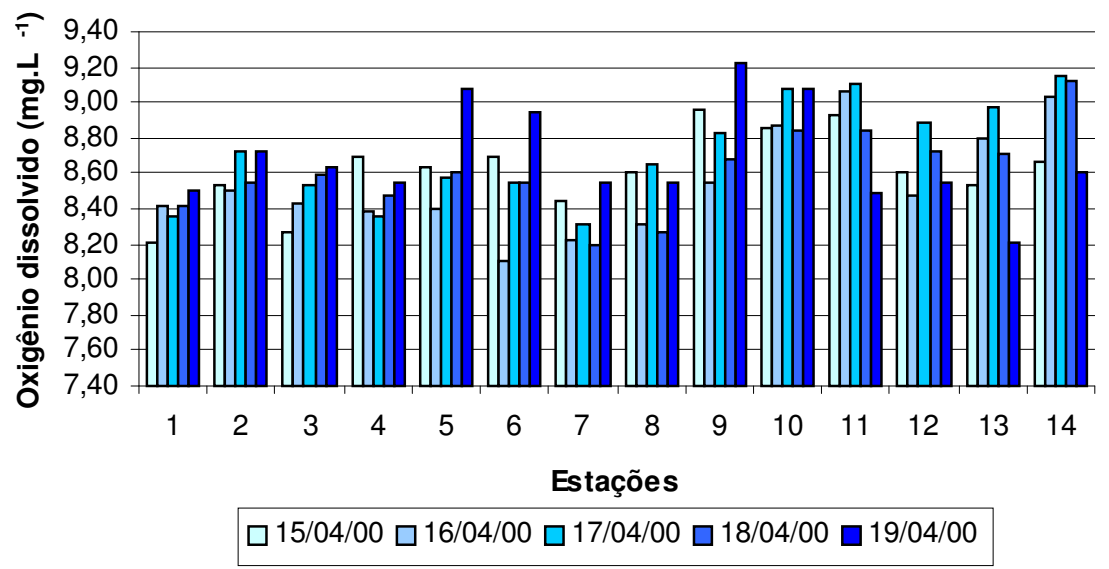

FIGURA 2.3.2.2.2 - Variação das concentrações de oxigênio dissolvido $\left(\mathrm{mg}^{\mathrm{L}} \mathrm{L}^{-1}\right)$ no rio Betari, no período de 15/04/00 a 19/04/00. 


\subsection{Turbidez, sólidos em suspensão orgânicos e inorgânicos.}

Os valores de turbidez, em abril de 2000, ficaram abaixo do limite de detecção devido, principalmente, à ausência de chuvas. As máximas concentrações de sólidos em suspensão inorgânico e orgânico, foram respectivamente, $5,60 \mathrm{mg} \cdot \mathrm{L}^{-1}$ e $1,38 \mathrm{mg} \cdot \mathrm{L}^{-1}$, observadas na estação 4 (Figuras 2.3.2.2.3.1 e 2.3.2.2.3.2, respectivamente).

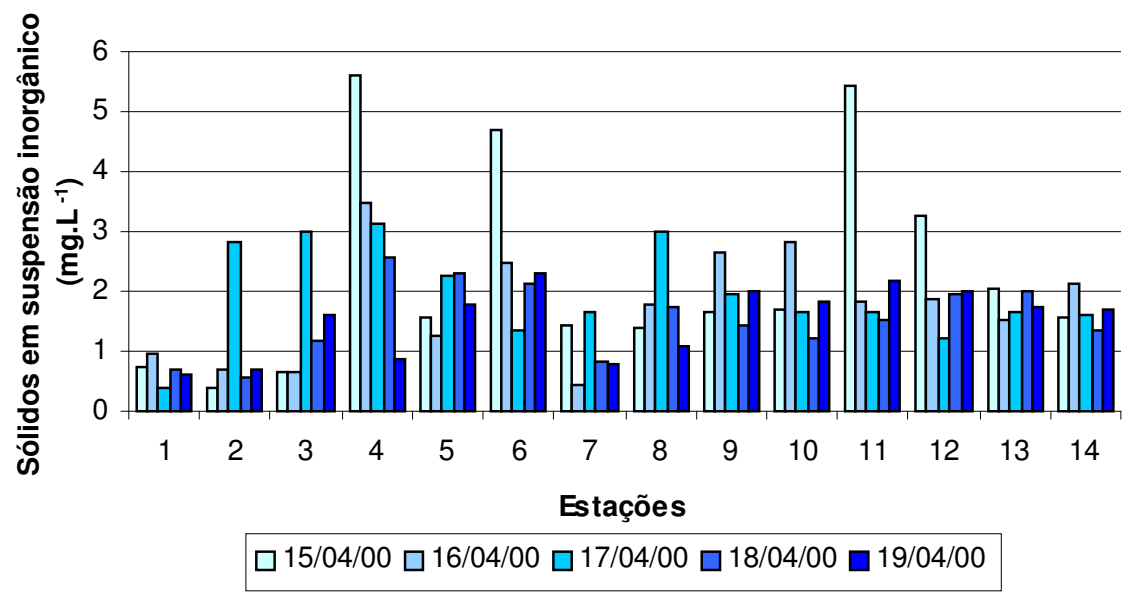

FIGURA 2.3.2.2.3.1- Variação das concentrações de sólidos em suspensão inorgânicos $\left(\mathrm{mg}^{\mathrm{L}} \mathrm{L}^{-1}\right)$ no rio Betari, no período de 15/04/00 a 19/04/00.

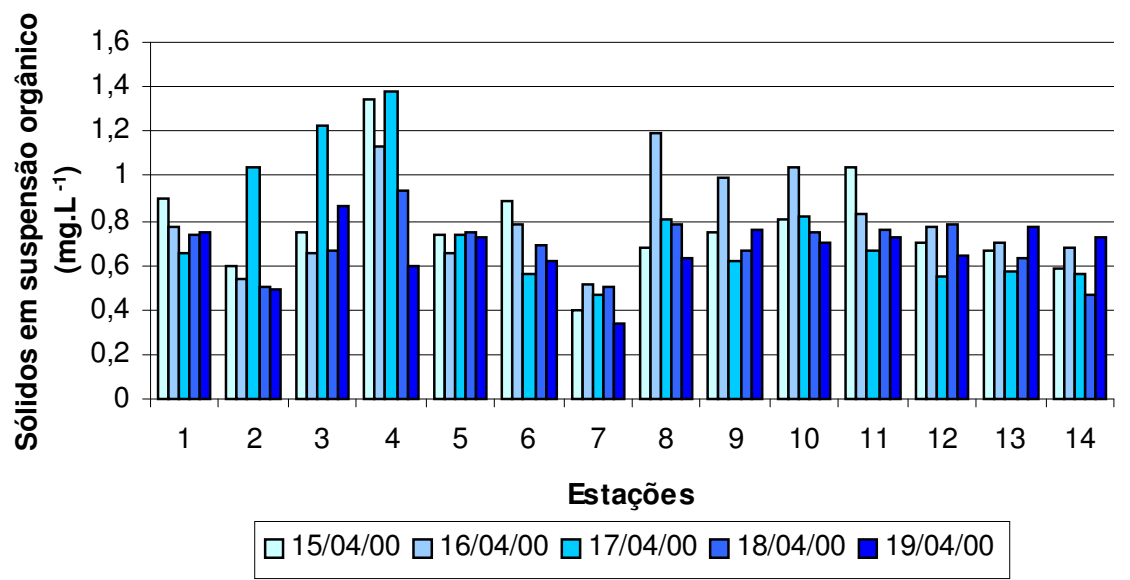

FIGURA 2.3.2.2.3.2- Variação das concentrações de sólidos em suspensão orgânicos $\left(\mathrm{mg}^{-1} \mathrm{~L}^{-1}\right)$ no rio Betari, no período de 15/04/00 a 19/04/00. 


\subsection{Temperatura da água}

Os valores de temperatura da água no rio Betari, entre 15/04/00 e $19 / 04 / 00$, ficaram na faixa de $19^{\circ} \mathrm{C}$ nas estações de 1 a 8 , e na faixa dos $20^{\circ} \mathrm{C}$ nas estações de 9 a 14 (figura 2.3.2..2.4)

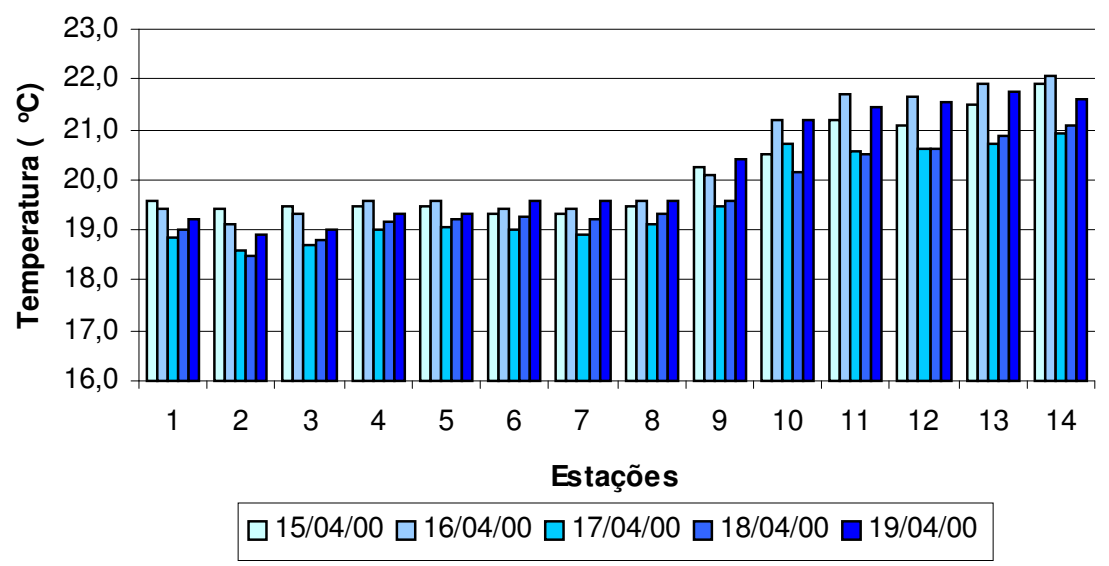

FIGURA 2.3.2.2.4 - Valores de temperatura da água $\left({ }^{\circ} \mathrm{C}\right)$ no rio Betari, no período de $15 / 04 / 00$ a $19 / 04 / 00$.

\subsection{Demanda Bioquímica de Oxigênio}

A demanda bioquímica de oxigênio foi baixa em todas as estações ao longo do rio Betari, em abril de 2000. Somente na estação 9 a DBO ficou acima de $1 \mathrm{mg}^{-\mathrm{L}^{-1}}$ (figura 2.3.2.2.5).

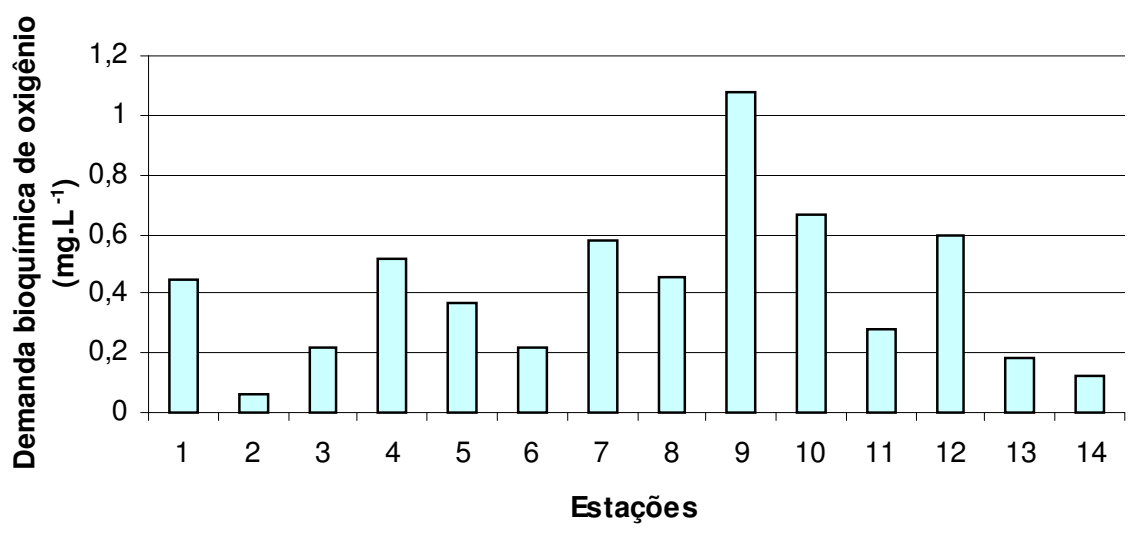

FIGURA 2.3.2.2.5 - Variação da demanda bioquímica de oxigênio $\left(\mathrm{mg}^{\mathrm{L}} \mathrm{L}^{-1}\right)$ no rio Betari no dia 19/04/00. 


\subsection{Nutrientes dissolvidos e totais na água}

As figuras 2.3.2.2.5.1 até 2.3.2.2.6.4 apresentam as concentrações das formas de nitrogênio (nitrogênio amoniacal, nitrato, nitrito, nitrogênio orgânico total), em abril de 2000. O nitrogênio orgânico foi predominante no rio Betari neste período, seguido do nitrato, que variou de $213,94 \mu \mathrm{g} \cdot \mathrm{L}^{-1}$ no ponto 3 , até $375,06 \mu \mathrm{g} \cdot \mathrm{L}^{-1}$ no ponto 8 . Não foi observado um padrão na distribuição das formas de nitrogênio ao longo do rio Betari.

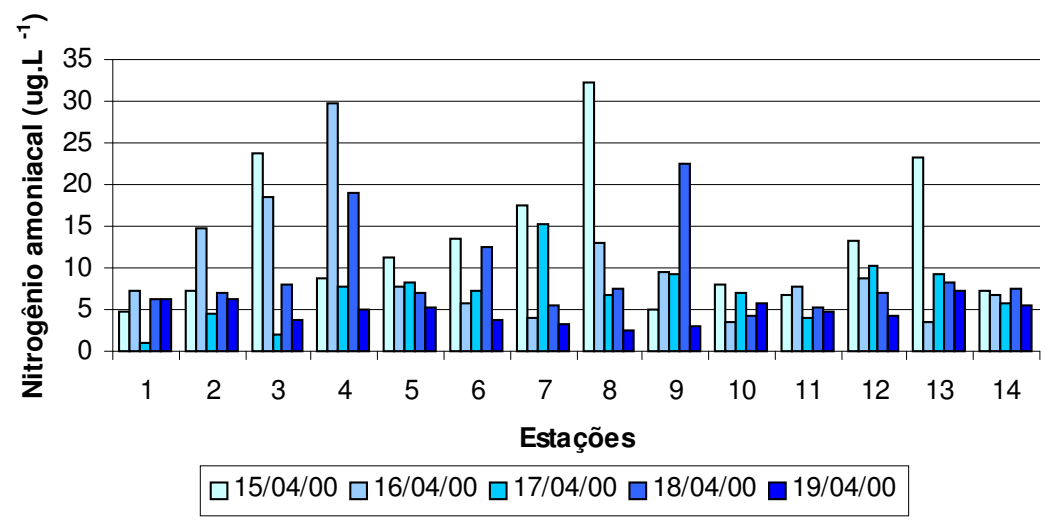

FIGURA 2.3.2.2.6.1 - Variação das concentrações de nitrogênio amoniacal (ug. $\mathrm{L}^{-1}$ ) no rio Betari, no período de 15/04/00 a 19/04/00.

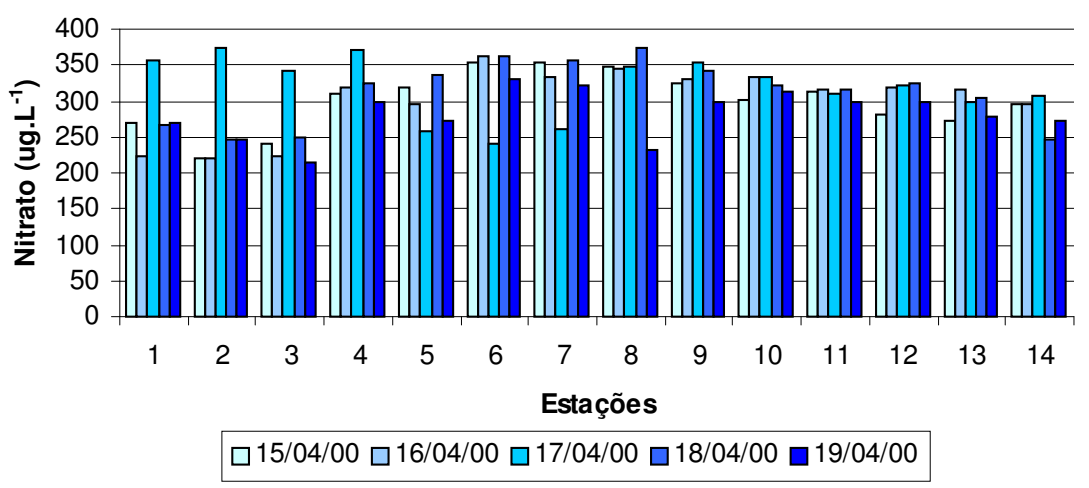


FIGURA 2.3.2.2.6.2 - Variação das concentrações de nitrato (ug. $\mathrm{L}^{-1}$ ) no rio Betari, no período de 15/04/00 a 19/04/00.

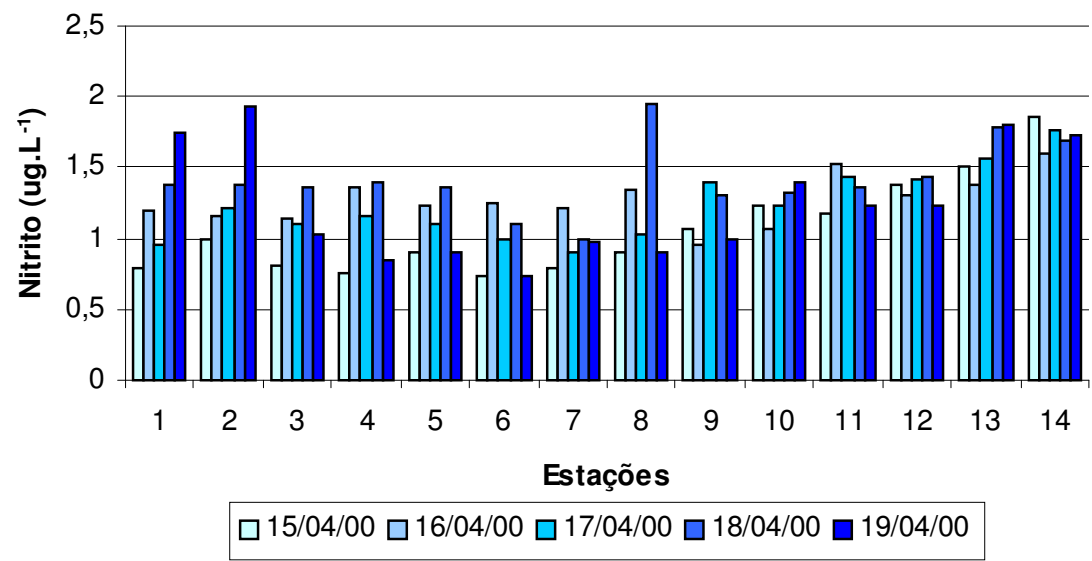

FIGURA 2.3.2.2.6.3 - Variação das concentrações de nitrito (ug. $\mathrm{L}^{-1}$ ) no rio Betari, no período de 15/04/00 a 19/04/00.

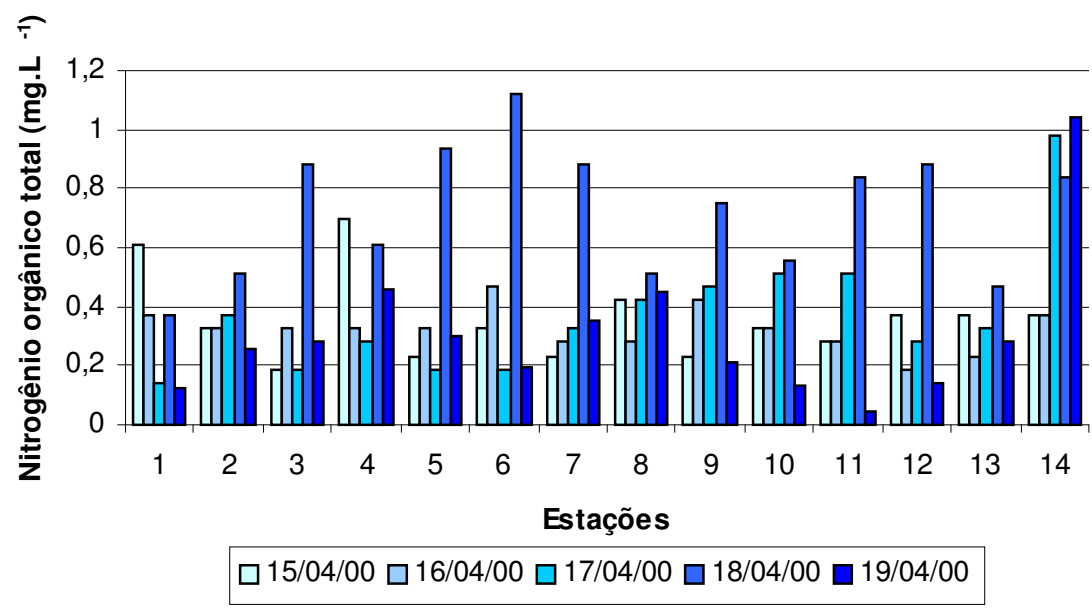

FIGURA 2.3.2.2.6.4 - Variação das concentrações de nitrogênio orgânico total $\left(\mathrm{mg}^{\mathrm{L}} \mathrm{L}^{-1}\right)$ no rio Betari, no período de 15/04/00 a 19/04/00.

As concentrações de fosfato inorgânico e fosfato total dissolvido foram mais elevadas nas estações do alto curso do rio Betari, em abril de 2000 (figuras 2.3.2.2.6.5 até 2.3.2.2.6 .7). O fosfato inorgânico, fosfato total dissolvido e fósforo total variaram de $4,98 \mu \mathrm{g} \cdot \mathrm{L}^{-1}$ a $18,79 \mu \mathrm{g} \cdot \mathrm{L}^{-1}, 9,61 \mu \mathrm{g} \cdot \mathrm{L}^{-1}$ a $23,71 \mu \mathrm{g} \cdot \mathrm{L}^{-1}$ e $14,41 \mu \mathrm{g} \cdot \mathrm{L}^{-1}$ a $54,44 \mu \mathrm{g} \cdot \mathrm{L}^{-1}$, respectivamente. 


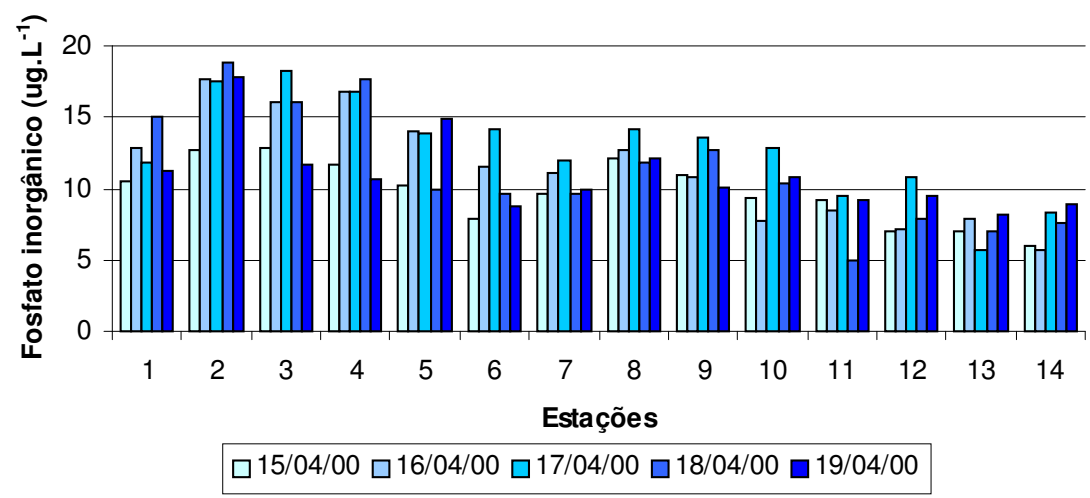

Figura 2.3.2.2.6.5 - Variação das concentrações de fosfato inorgânico (ug. $\mathrm{L}^{-1}$ ) no rio Betari, no período de 15/04/00 a 19/04/00.

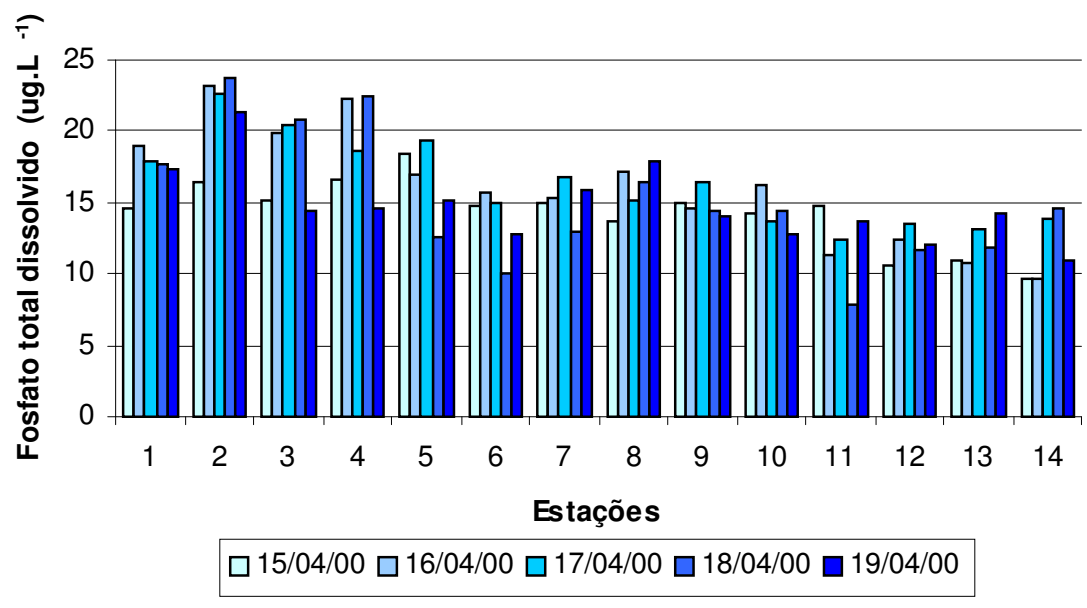

FIGURA 2.3.2.2.6.6 - Variação das concentrações de fosfato total dissolvido (ug. $\mathrm{L}^{-1}$ ) no rio Betari, no período de 15/04/00 a 19/04/00. 


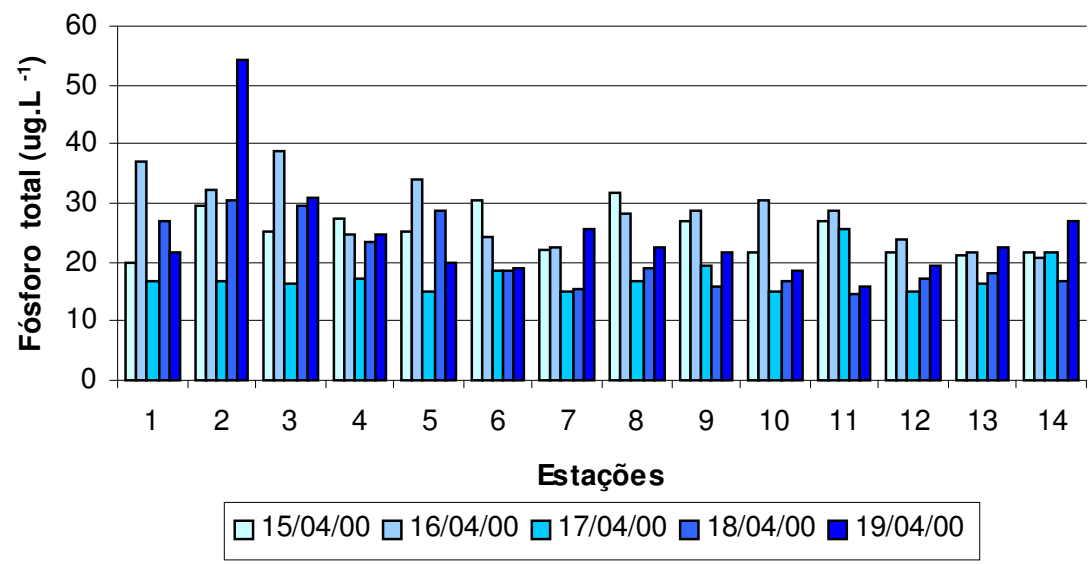

FIGURA 2.3.2.2.6.7 - Variação das concentrações de fósforo total (ug. $\mathrm{L}^{-1}$ ) no rio Betari, no período de 15/04/00 a 19/04/00.

As concentrações de silicato reativo mostraram-se elevadas ao longo de todo rio Betari, durante os cinco dias de amostragem (figura 2.3.2.2.6.8), com destaque para as estações do alto curso, como a estação 3, onde foi constatado o valor de $10,80 \mathrm{mg} \cdot \mathrm{L}^{-1}$. A menor concentração de silicatos, nesse período, ocorreu no ponto $8\left(3,23 \mathrm{mg} \cdot \mathrm{L}^{-1}\right)$.

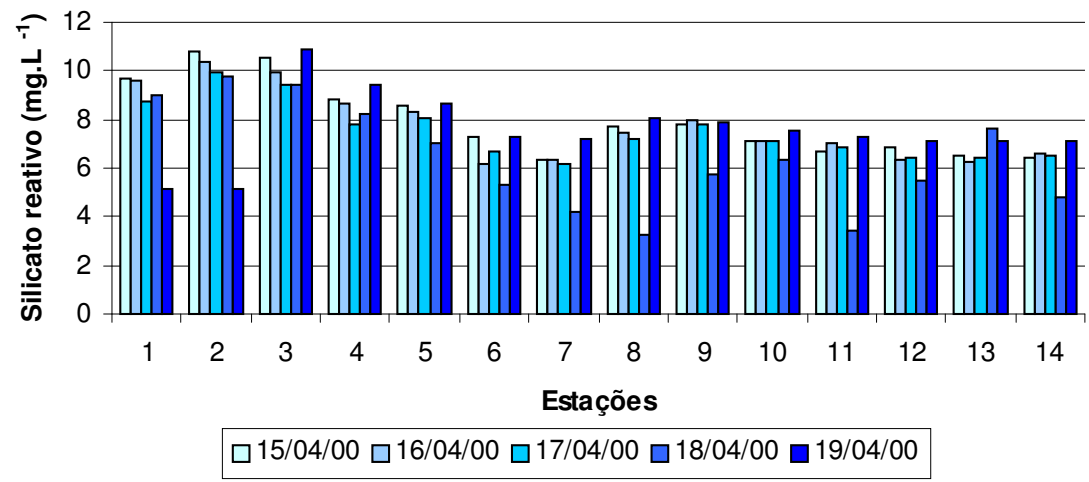

FIGURA 2.3.2.2.6.8 - Variação das concentrações de silicato reativo (mg. $\mathrm{L}^{-1}$ ) no rio Betari, no período de 15/04/00 a 19/04/00. 


\subsubsection{7. Íons Dissolvidos na Água}

As amostras de íons cálcio, sódio e magnésio apresentaram-se acima do limite de detecção dos métodos utilizados (15 mg.L $\mathrm{L}^{-1} ; 2 \mathrm{mg} \cdot \mathrm{L}^{-1}$; e $2 \mathrm{mg} \cdot \mathrm{L}^{-1}$ respectivamente). A presença de chumbo não foi detectada em nenhuma das amostras. As concentrações dos íons podem ser observadas na tabela 2.3.2.2.7. As maiores concentrações ocorreram no rio Furnas e nas estações do curso médio do rio Betari.

TABELA 2.3.2.2.7 - Variação das concentrações de íons totais na água no rio Betari na amostragem de abril de 2000.

\begin{tabular}{lcccccccccccccc}
\hline Estações & 1 & 2 & 3 & 4 & 5 & 6 & 7 & 8 & 9 & 10 & 11 & 12 & 13 & 14 \\
\hline $\mathrm{Zn}\left(\mathrm{mg} \cdot \mathrm{L}^{-1}\right)$ & 0,01 & 0,01 & 0,01 & 0,01 & 0,01 & 0,01 & 0,17 & 0,02 & 0,02 & 0,02 & 0,01 & 0,02 & 0,03 & 0,01 \\
$\mathrm{~Pb}\left(\mathrm{mg} \cdot \mathrm{L}^{-1}\right)$ & $*$ & $*$ & $*$ & $*$ & $*$ & $*$ & $*$ & $*$ & $*$ & $*$ & $*$ & $*$ & $*$ & $*$ \\
$\mathrm{Ca}\left(\mathrm{mg} \cdot \mathrm{L}^{-1}\right)$ & $>15$ & $>15$ & $>15$ & $>15$ & $>15$ & $>15$ & $>15$ & $>15$ & $>15$ & $>15$ & $>15$ & $>15$ & $>15$ & $>15$ \\
$\mathrm{Na}\left(\mathrm{mg} \cdot \mathrm{L}^{-1}\right)$ & $>2$ & $>2$ & $>2$ & $>2$ & $>2$ & $>2$ & $>2$ & $>2$ & $>2$ & $>2$ & $>2$ & $>2$ & $>2$ & $>2$ \\
$\mathrm{Mg}\left(\mathrm{mg} \cdot \mathrm{L}^{-1}\right)$ & $>2$ & $>2$ & $>2$ & $>2$ & $>2$ & $>2$ & $>2$ & $>2$ & $>2$ & $>2$ & $>2$ & $>2$ & $>2$ & $>2$ \\
\hline * abaixo do limite de detecção
\end{tabular}

\subsubsection{Análise numérica}

A análise de agrupamento realizada com a média do conjunto de dados físicos e químicos da água obtido na coleta de abril de 2000, reuniu as estações de amostragem em grupos no perfil longitudinal: estações 1, 2 e 3 (grupo 1); estações 4, 5, 6, 8 e 9 (grupo 2); estação 7 (grupo 3); e estações 10, 11, 12, 13 e 14 (grupo 4) - figura 2.3.2.3. Porém, a análise discriminante realizada (utilizando os grupos formados) evidenciou a inexistência de diferenças estatisticamente significativas (intervalo de confiança de 95\%) entre os grupos formados pela análise de cluster. 


\subsubsection{TERCEIRA CAMPANHA DE AMOSTRAGEM (JULHO DE 2000)}

\subsubsection{Velocidade de escoamento e vazão}

Em julho de 2000, os valores de velocidade da corrente não foram uniformes ao longo do eixo longitudinal do rio Betari. A estação que apresentou menores valores de velocidade de corrente foi a 1, enquanto que os maiores ocorreram na estação 11 (figura 2.3.3.1.1). Os valores de vazão (figura 2.3.3.1.2) aumentaram no terceiro dia de amostragem, em função das precipitações. A vazão apresentou tendência de aumento no contínuo do rio.

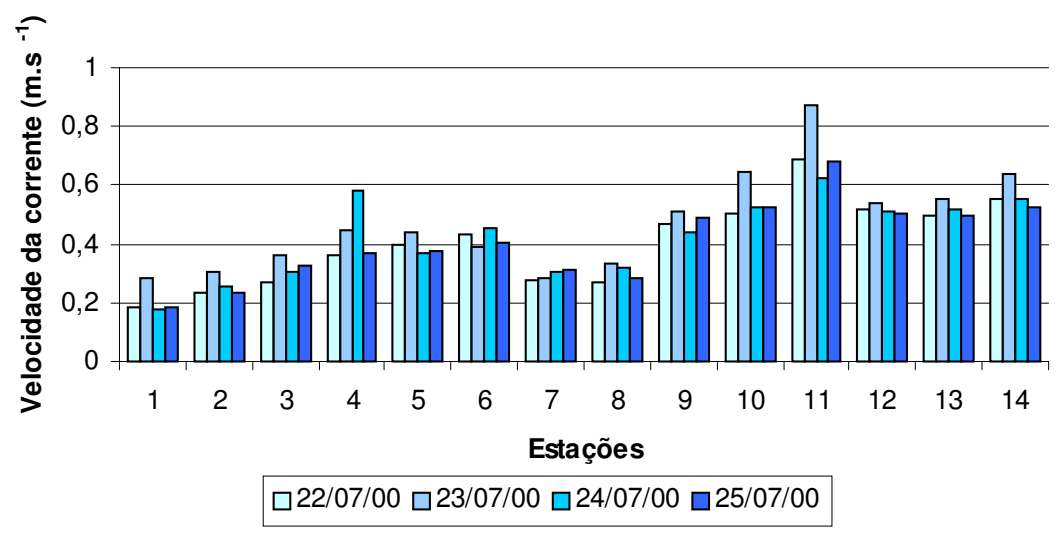

FIGURA 2.3.3.1.1 - Variação da velocidade da corrente $\left(\mathrm{m}^{-1} \mathrm{~s}^{-1}\right)$ no perfil longitudinal do rio Betari, no período de 22/07/00 a 25/07/00. 


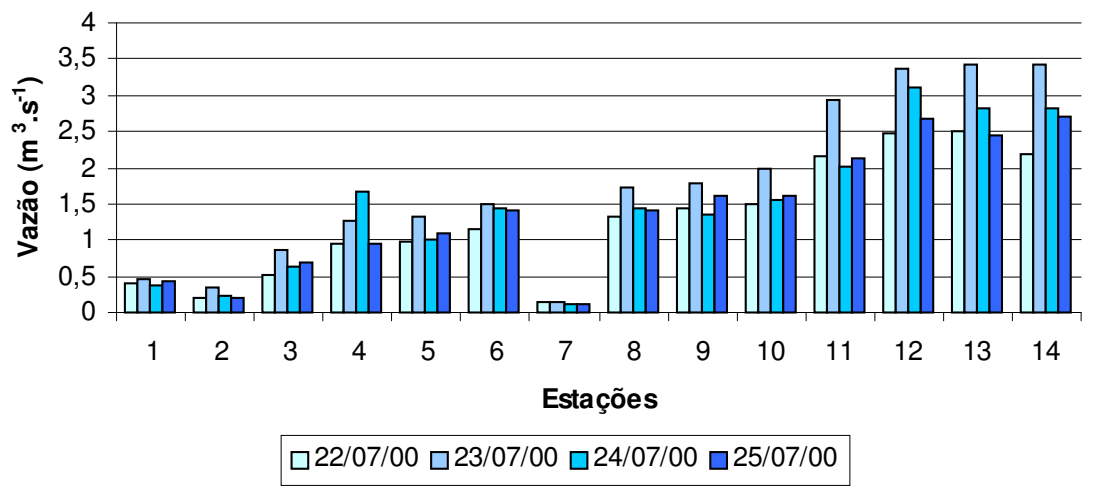

FIGURA 2.3.3.1.2 - Variação da vazão $\left(\mathrm{m}^{3} \cdot \mathrm{s}^{-1}\right)$ no perfil longitudinal do rio Betari, no período de $22 / 07 / 00$ a $25 / 07 / 00$

\subsubsection{Variáveis físicas e químicas da água}

\subsubsection{1. $\mathrm{pH}$, condutividade, alcalinidade e formas de carbono.}

Os valores de $\mathrm{pH}$, observados em julho de 2000, foram alcalinos com o menor valor de 7,47 na estação 1, e o maior de 8,76, na estação 11 (figura 2.3.3.2.1.1). Os valores de condutividade ficaram entre 137 uS.cm ${ }^{-1}$ na estação 3, e 206 uS.cm ${ }^{-1}$ na estação 7 (córrego Furnas) - figura 2.3.3.2.1.2. 


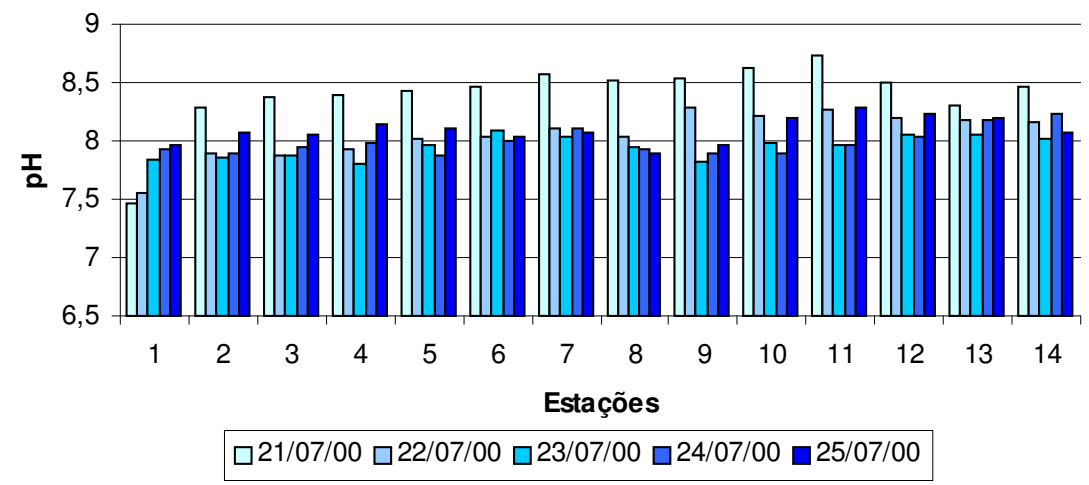

FIGURA 2.3.3.2.1.1 - Variação dos valores de pH no rio Betari, no período de 21/07/00 a 25/07/00.

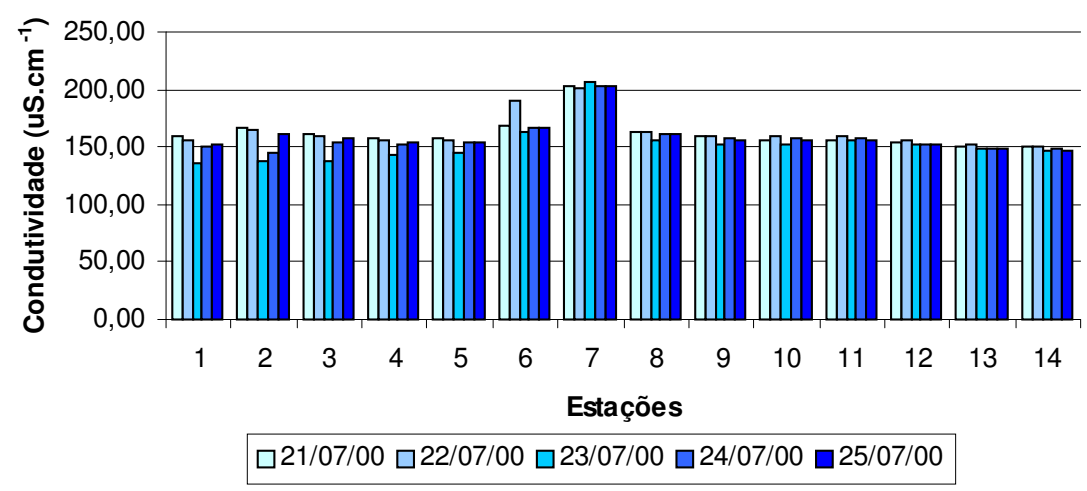

FIGURA 2.3.3.2.1.2- Variação dos valores de condutividade $\left(\mathrm{uS} . \mathrm{cm}^{-1}\right)$ no rio Betari, no período de 21/07/00 a 25/07/00.

A alcalinidade oscilou entre 1,17 meq. $\mathrm{L}^{-1}$ na estação 1 , e 1,97 meq. $1^{-1}$ na estação 7 (figura 2.3.3.2.1.3). As formas de carbono apresentaram, assim como os valores de $\mathrm{pH}$, pequenas oscilações no eixo longitudinal (excluindo-se a estação 7). As concentrações de $\mathrm{CO}_{2}$ total, $\mathrm{CO}_{2}$ livre, $\mathrm{HCO}_{3}{ }^{-}$e $\mathrm{CO}_{3}{ }^{2-}$ estão apresentadas nas figuras 2.3.3.2.1.4 até 2.3.3.2.1.7, respectivamente. 


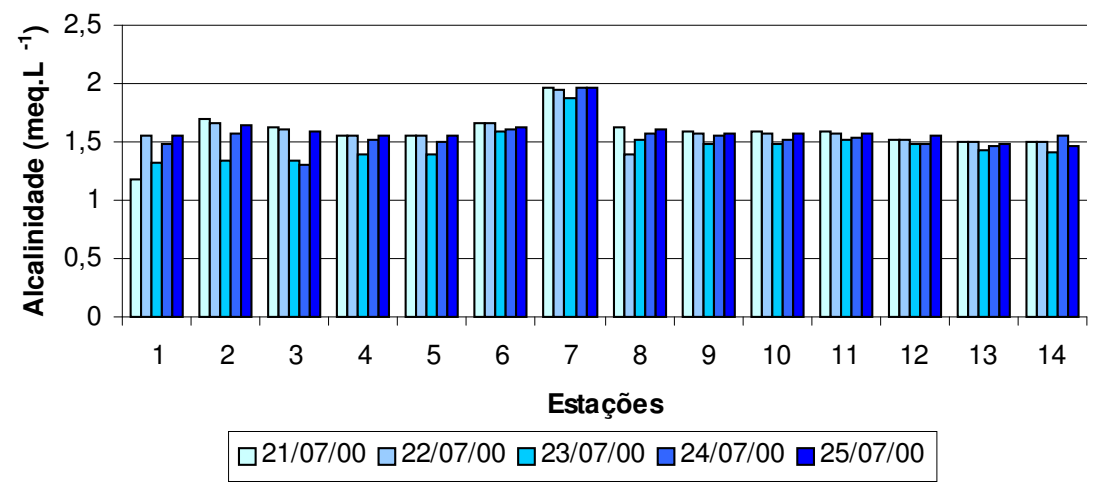

FIGURA 2.3.3.2.1.3 - Variação da alcalinidade (meq.L $L^{-1}$ ) no rio Betari, no período de 21/07/00 a $25 / 07 / 00$.

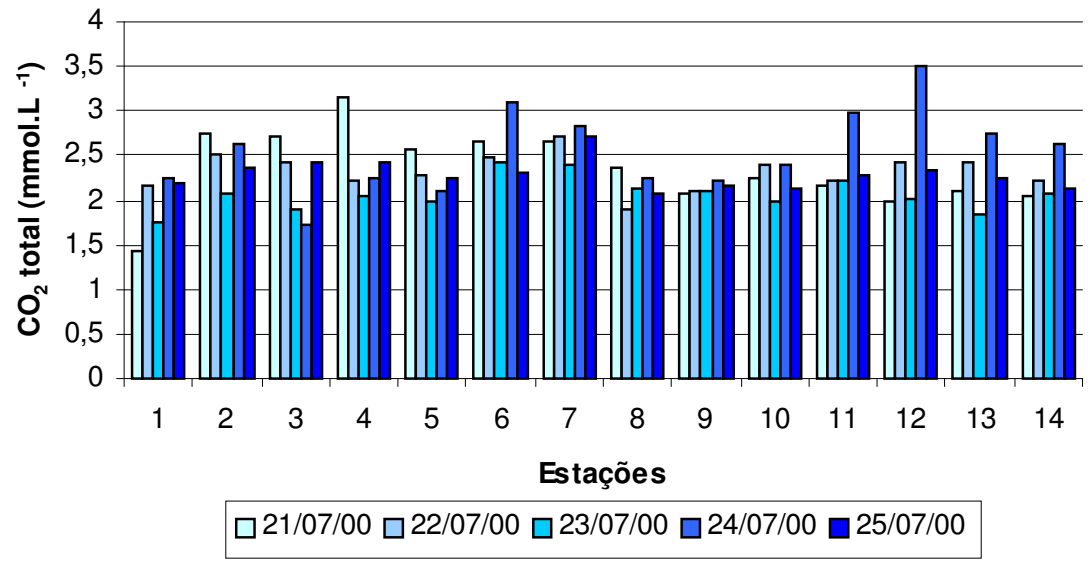

FIGURA 2.3.3.2.1.4 - Variação das concentrações de $\left(\mathrm{CO}_{2}\right)$ total $\left(\mathrm{mmol} . \mathrm{L}^{-1}\right)$ no rio Betari no período de 21/07/00 a 25/07/00. 


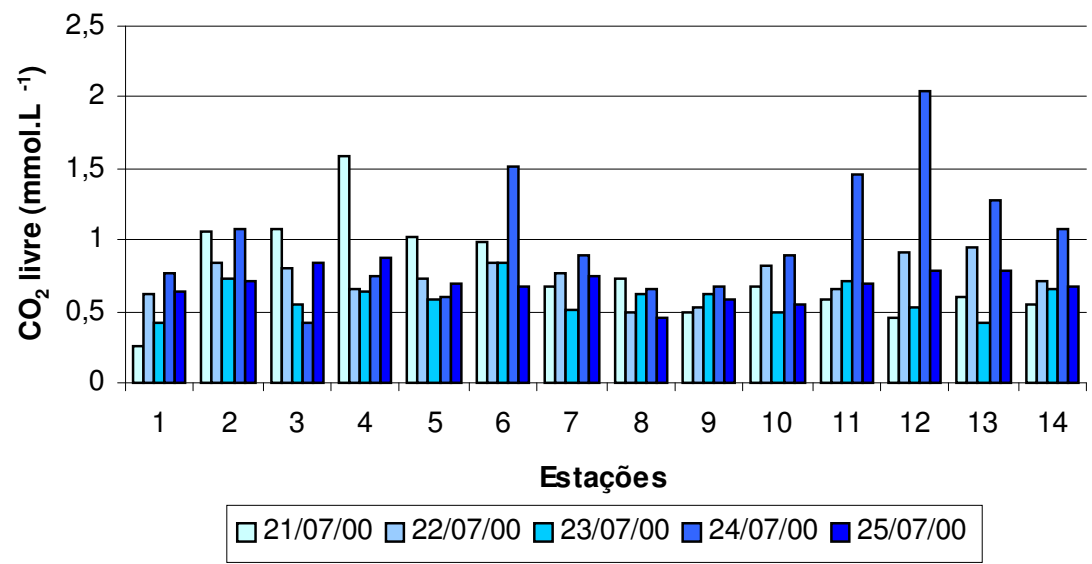

FIGURA 2.3.3.2.1.5 - Variação das concentrações de $\left(\mathrm{CO}_{2}\right)$ livre $\left(\mathrm{mmol} . \mathrm{L}^{-1}\right)$ no rio Betari no período de 21/07/00 a 25/07/00.

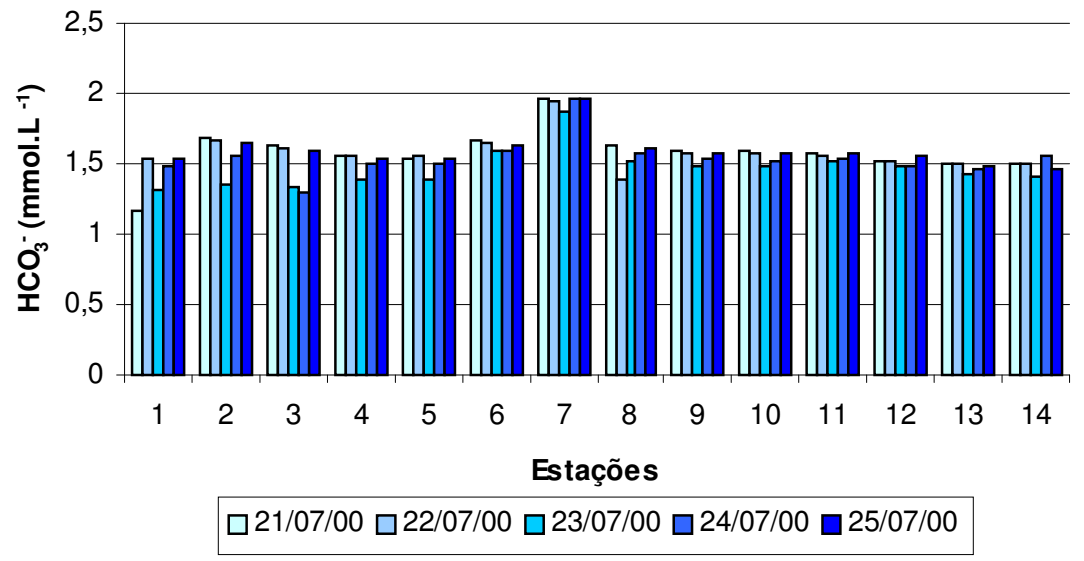

FIGURA 2.3.3.2.1.6 - Variação das concentrações de $\left(\mathrm{HCO}_{3}{ }^{-}\right)\left(\mathrm{mmol} . \mathrm{L}^{-1}\right)$ no rio Betari, no período de 21/07/00 a 25/07/00. 


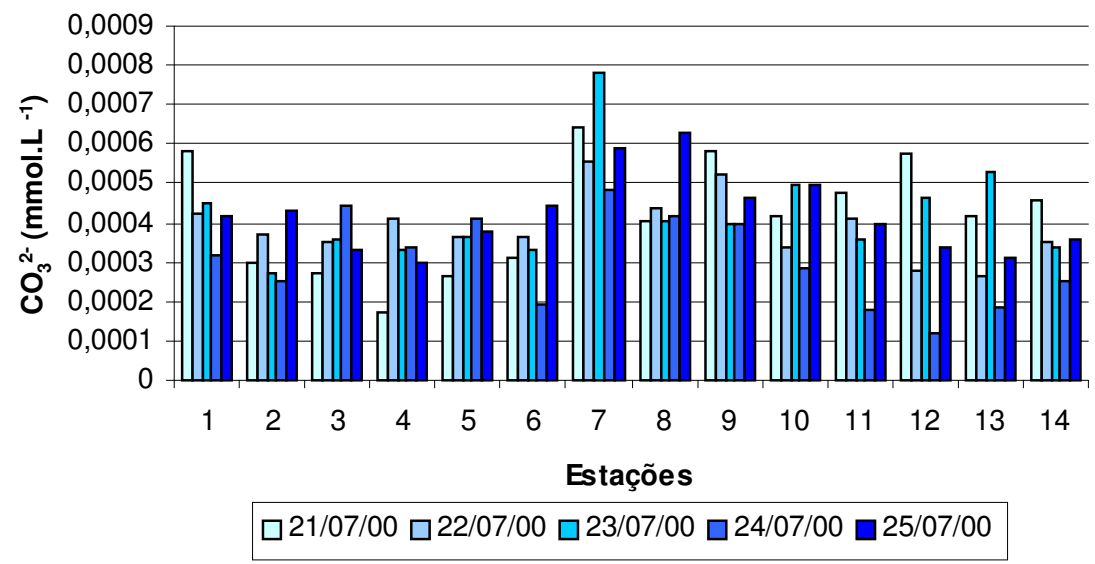

FIGURA 2.3.3.2.1.7 -Variação das concentrações de $\left(\mathrm{CO}_{3}{ }^{2-}\right)\left(\mathrm{mmol}^{-\mathrm{L}^{-1}}\right)$ no rio Betari, no período de 21/07/00 a 25/07/00.

\subsection{Oxigênio dissolvido}

As concentrações de oxigênio dissolvido foram elevadas em todo rio Betari, em julho de 2000; elas oscilaram entre $8,4 \mathrm{mg} \cdot \mathrm{L}^{-1}$ na estação 1 , e $10,3 \mathrm{mg} . \mathrm{L}^{-1}$ na estação 10 (figura2.3.3.2.2). Os maiores valores de oxigênio dissolvido ocorreram no dia 21/07/00, em todas as estações de amostragem.

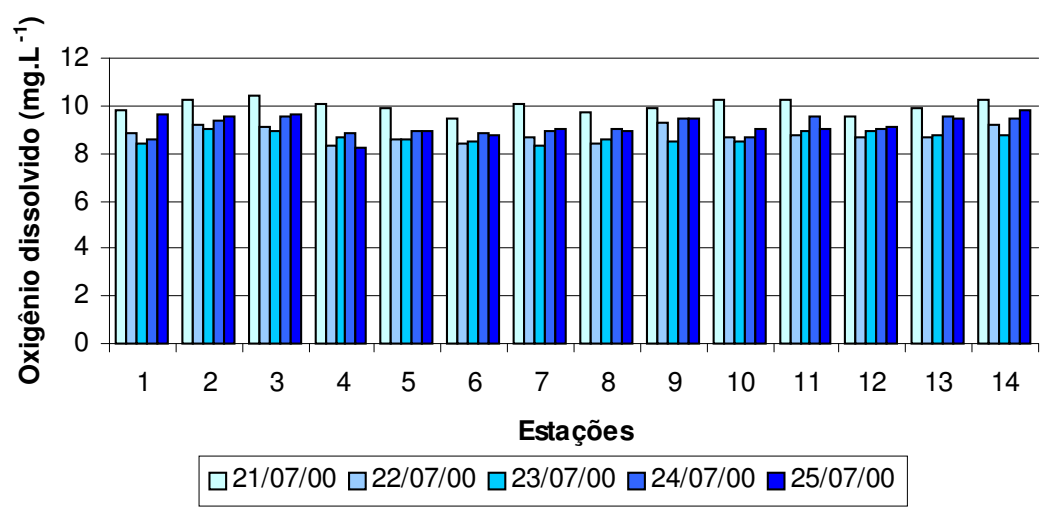

FIGURA 2.3.3.2.2 - Variação das concentrações de oxigênio dissolvido (mg. $\left.\mathrm{L}^{-1}\right)$ no rio Betari, no período de 21/07/00 a 25/07/00. 


\subsection{Turbidez, sólidos em suspensão orgânicos e inorgânicos}

Os valores de turbidez, em julho de 2000, foram inferiores ao limite de detecção. Acompanhando a turbidez, a concentração de sólidos em suspensão foi pequena. Pôde ser observado um aumento no terceiro dia de amostragem, em função de chuvas que incidiram sobre a bacia (figuras 2.3.3.2.3.1 e 2.3.3.2.3.2).

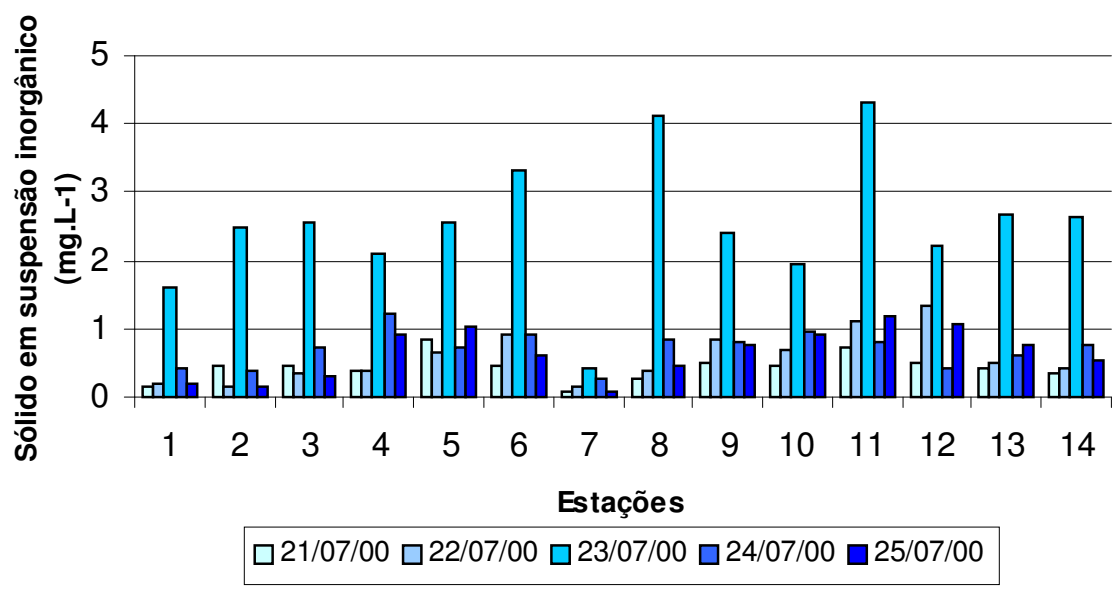

FIGURA 2.3.3.2.3.1 - Variação das concentrações de sólidos em suspensão inorgânicos (mg.L $\mathrm{L}^{-}$ ${ }^{1}$ ) no rio Betari, no período de 21/07/00 a 25/07/00.

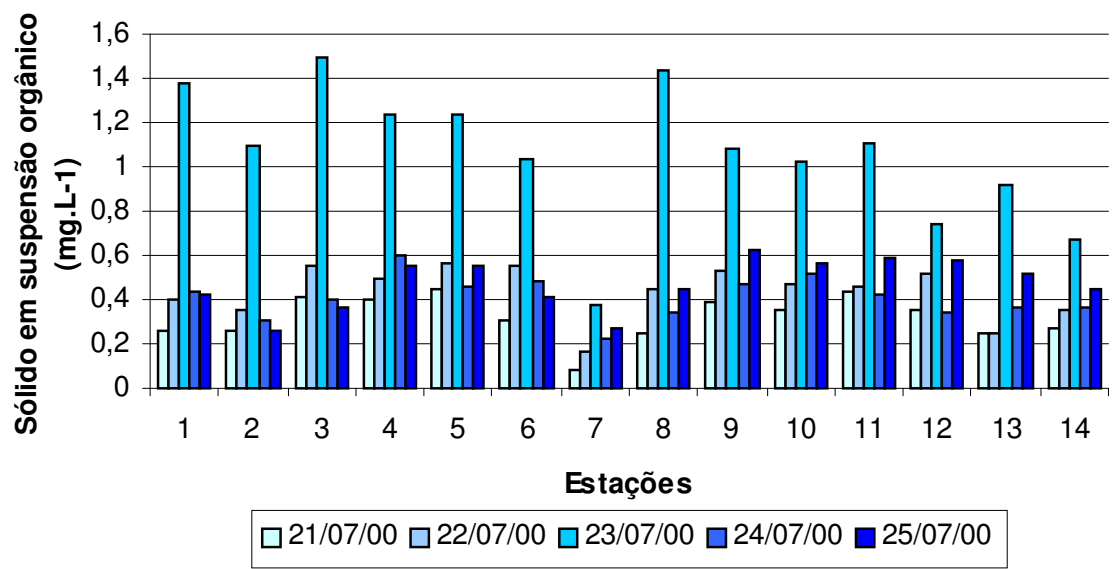


FIGURA 2.3.3.2.3.2 - Variação das concentrações de sólidos em suspensão orgânicos (mg.L $\left.{ }^{-1}\right)$ no rio Betari, no período de 21/07/00 a 25/07/00.

\subsection{Temperatura da Água}

Os valores de temperatura da água no rio Betari ficaram entre $9,4{ }^{\circ} \mathrm{C}$ na estação 1, e $17,0{ }^{\circ} \mathrm{C}$ na estação 12 (figura 2.3.3.2.4). O primeiro dia apresentou os menores valores de temperatura em todo o rio Betari, o que, provavelmente, influenciou as concentrações de oxigênio dissolvido.

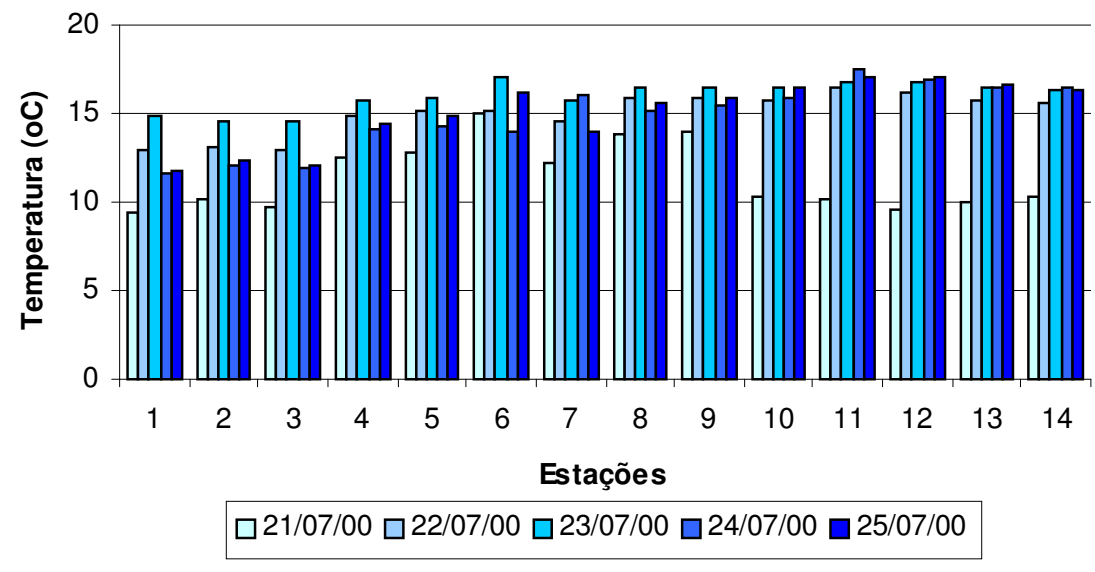

FIGURA 2.3.3.2.4 - Variações dos valores de temperatura $\left({ }^{\circ} \mathrm{C}\right)$ no rio Betari, no período de 21/07/00 a 25/07/00.

\subsection{Demanda Bioquímica de Oxigênio}

A demanda bioquímica de oxigênio no rio Betari, em de julho de 2000, oscilou entre $0,07 \mathrm{mg} . \mathrm{L}^{-1}$ na estação 6 , e $1,83 \mathrm{mg} . \mathrm{L}^{-1}$ na estação 8 , distribuindo-se diferentemente ao longo do rio (figura 2.3.3.2.5). 


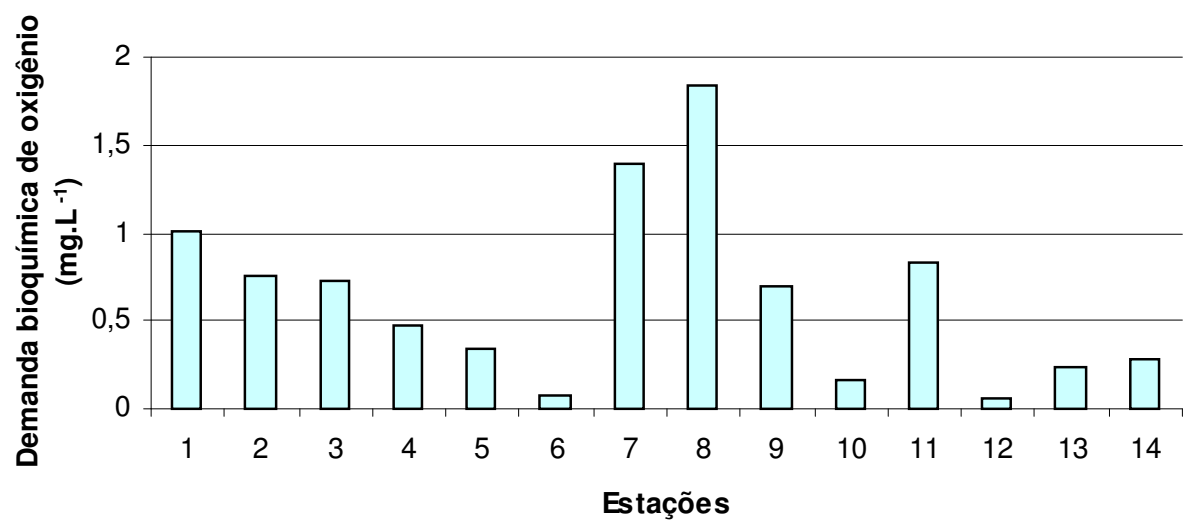

FIGURA 2.3.3.2.5- Variação da demanda bioquímica de oxigênio (mg. $\mathrm{L}^{-1}$ ) no rio Betari $(25 / 07 / 00)$.

\subsection{Nutrientes dissolvidos e totais na água}

As concentrações das formas nitrogenadas estão apresentadas nas figuras 2.3.3.2.6.1 (nitrogênio amoniacal), 2.3.3.2.6.2 (nitrato), 2.3.3.2.6.3 (nitrito) e 2.3.3.2.6.4 (nitrogênio orgânico total). As chuvas que ocorreram na bacia no terceiro dia de amostragem provocaram aumento nas concentrações de todas as formas de nitrogênio, predominando o nitrogênio orgânico total.

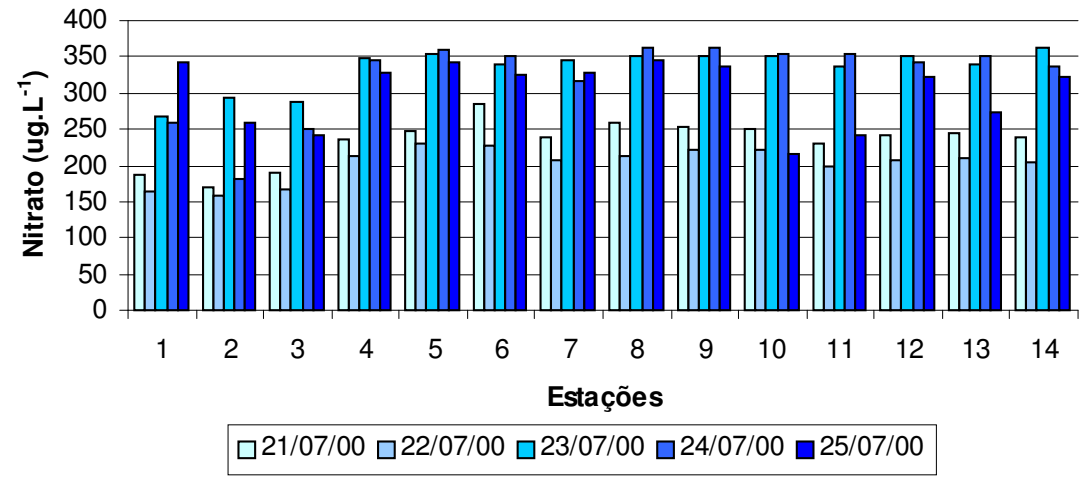




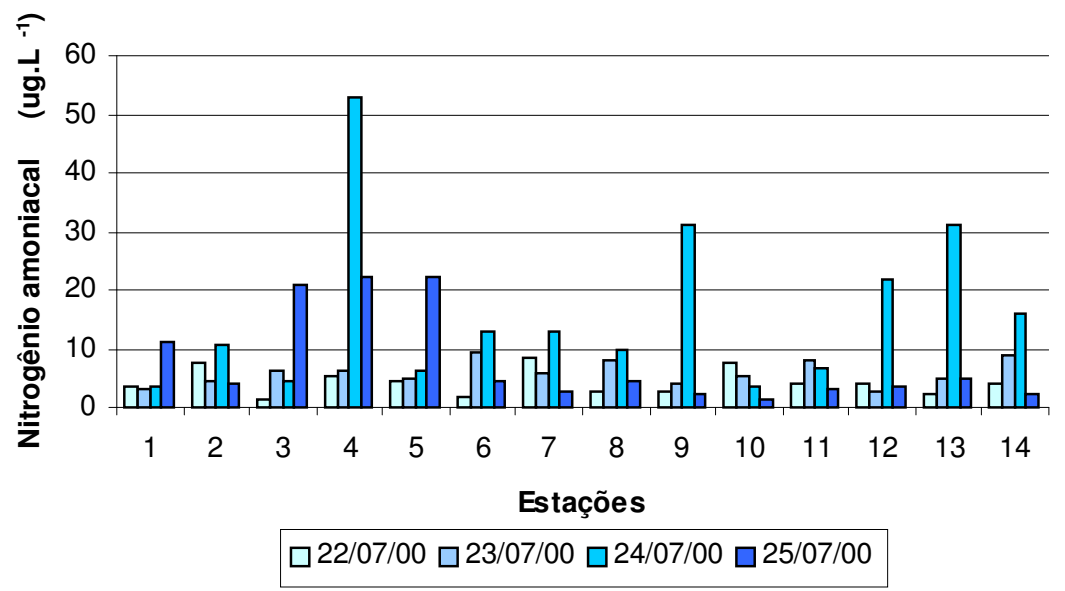

FIGURA 2.3.3.2.6.1 - Variação das concentrações de nitrogênio amoniacal (ug.L $\mathrm{L}^{-1}$ ) no rio Betari, no período de 22/07/00 a 25/07/00.

FIGURA 2.3.3.2.6.2 - Variação das concentrações de nitrato $\left(\mathrm{ug} . \mathrm{L}^{-1}\right)$ no rio Betari, no período de 21/07/00 a 25/07/00.

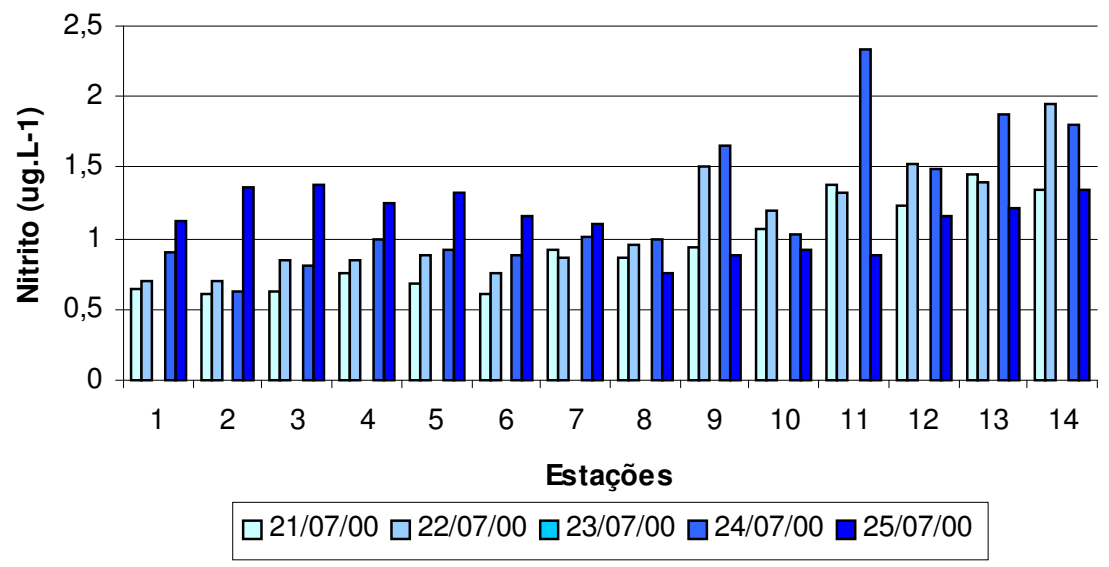

FIGURA 2.3.3.2.6.3 - Variação das concentrações de nitrito (ug. $\left.L^{-1}\right)$ no rio Betari, no período de 21/07/00 a 25/07/00. 


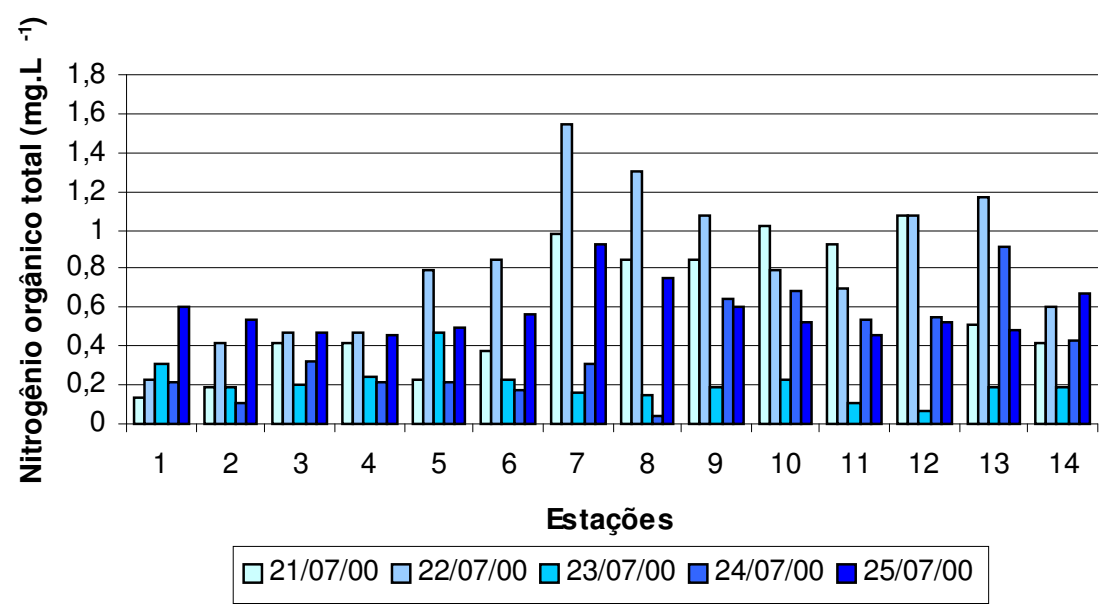

FIGURA 2.3.3.2.6.4 - Concentrações de nitrogênio orgânico total $\left(\mathrm{mg} . \mathrm{L}^{-1}\right)$ no rio Betari, no período de 21/07/00 a 25/07/00.

As formas de fósforo (figuras 2.3.3.2.6.5, 2.3.3.2.6.6 e 2.3.3.2.6.7) distribuíram-se diferentemente no eixo longitudinal do rio Betari e, assim como as de nitrogênio, essas concentrações foram influenciadas pelas chuvas que incidiram sobre a bacia. Para o fosfato inorgânico, que apresentou grande oscilação nesse período de estudo, 0,68 ug. $\mathrm{L}^{-1}$ a $20,24 \mathrm{ug} \cdot \mathrm{L}^{-1}$, ocorreu uma diminuição das concentrações no terceiro dia de amostragem, enquanto que as concentrações de fosfato total dissolvido e o fósforo total aumentaram no mesmo período.

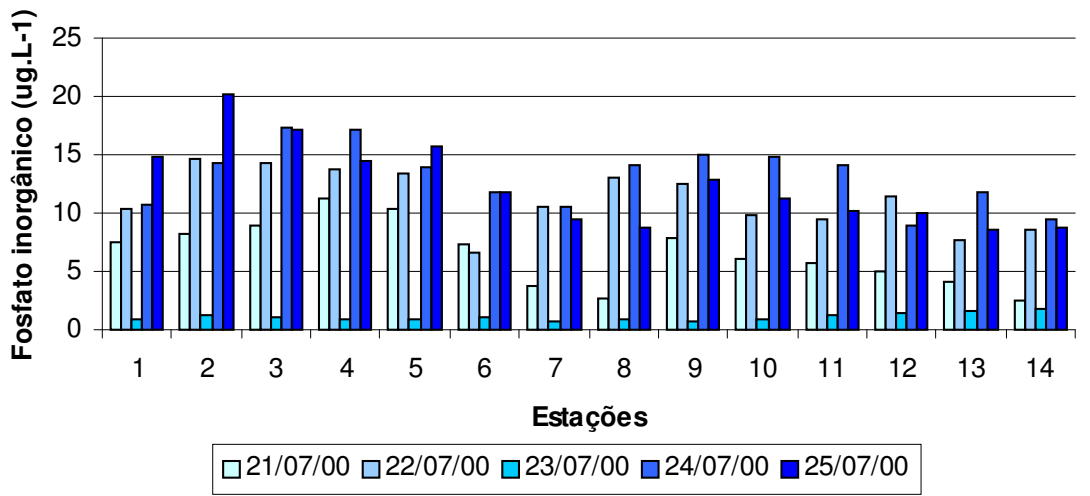

FIGURA 2.3.3.2.6.5 - Variação das concentrações de fosfato inorgânico (ug. $\mathrm{L}^{-1}$ ) no rio Betari, no período de 21/07/00 a 25/07/00. 


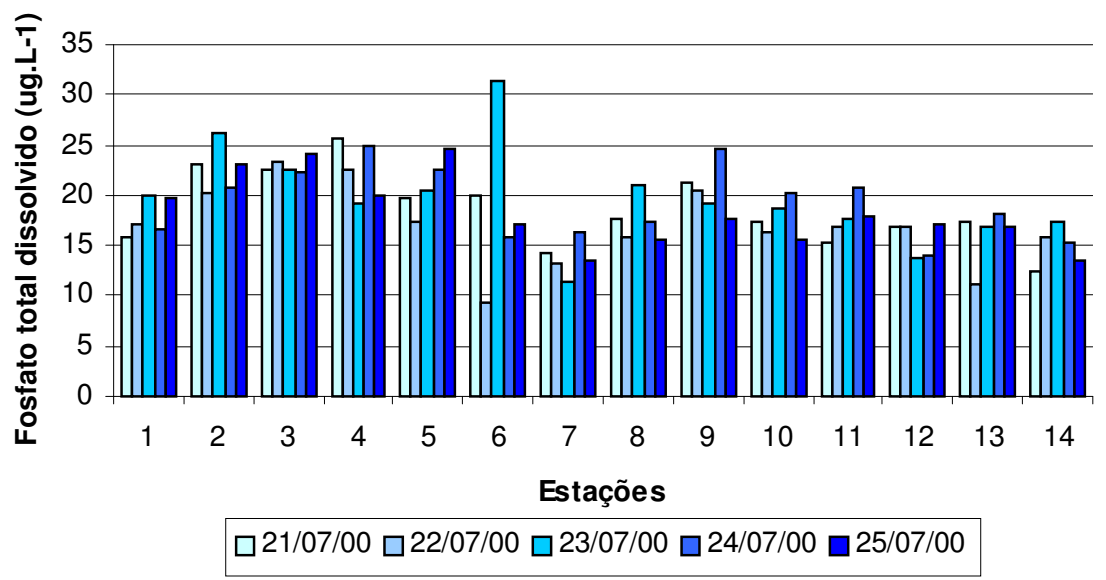

FIGURA 2.3.3.2.6.6 - Variação das concentrações de fosfato total dissolvido(ug. $\mathrm{L}^{-1}$ ) no rio Betari, no período de 21/07/00 a 25/07/00. 


\subsubsection{QUARTA CAMPANHA DE AMOSTRAGEM (OUTUBRO DE 2000)}

\subsubsection{Velocidade de escoamento e vazão}

No período de amostragem, outubro de 2000, a velocidade da corrente foi mais elevada nas estações 9, 10 e 11 do rio Betari. A maior velocidade de escoamento ocorreu na estação 9 no dia 15/10/00 $\left(1,18 \mathrm{~m} \cdot \mathrm{s}^{-1}\right)$, enquanto a menor ocorreu na estação 1 , em 18/10/00 $\left(0,14 \mathrm{~m} \cdot \mathrm{s}^{-1}\right)$ - figura 2.3.4.1.1. As vazões (figura 2.3.4.1.2) aumentaram progressivamente em direção à foz do rio Betari e variaram de $3,4 \mathrm{~m}^{3} . \mathrm{s}^{-1}$ na estação 14 , a $0,3 \mathrm{~m}^{3} \cdot \mathrm{s}^{1}$ na estação 2. A estação 7 correspondeu ao córrego Furnas (afluente do rio Betari).

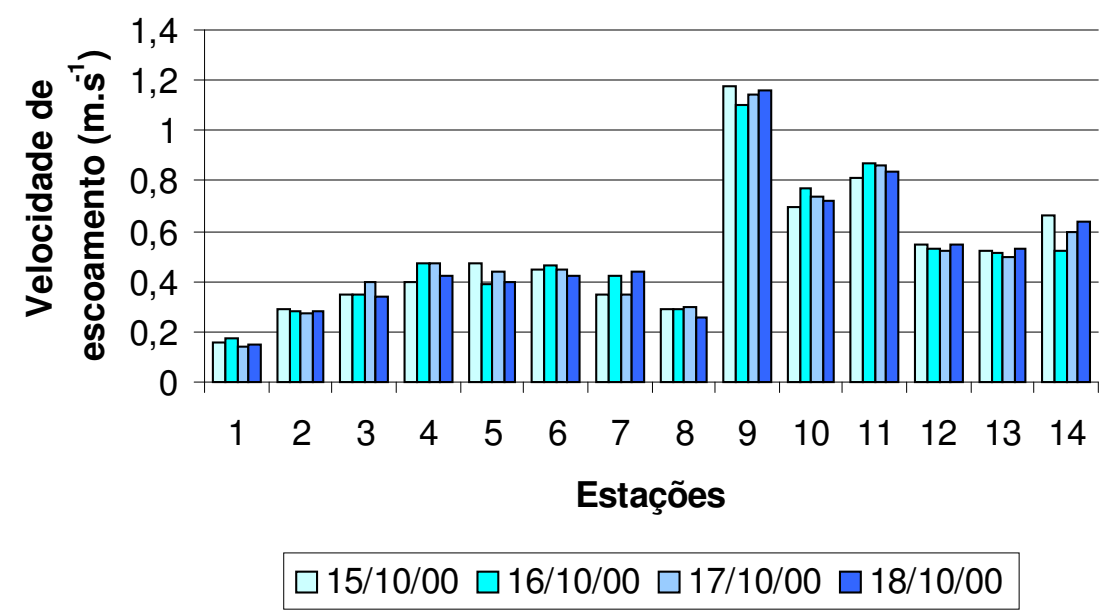

FIGURA 2.3.4.1.1- Variação da velocidade da corrente $\left(\mathrm{m} . \mathrm{s}^{-1}\right)$ no eixo longitudinal do rio Betari, no período de 15/10/00 a 18/10/00. 


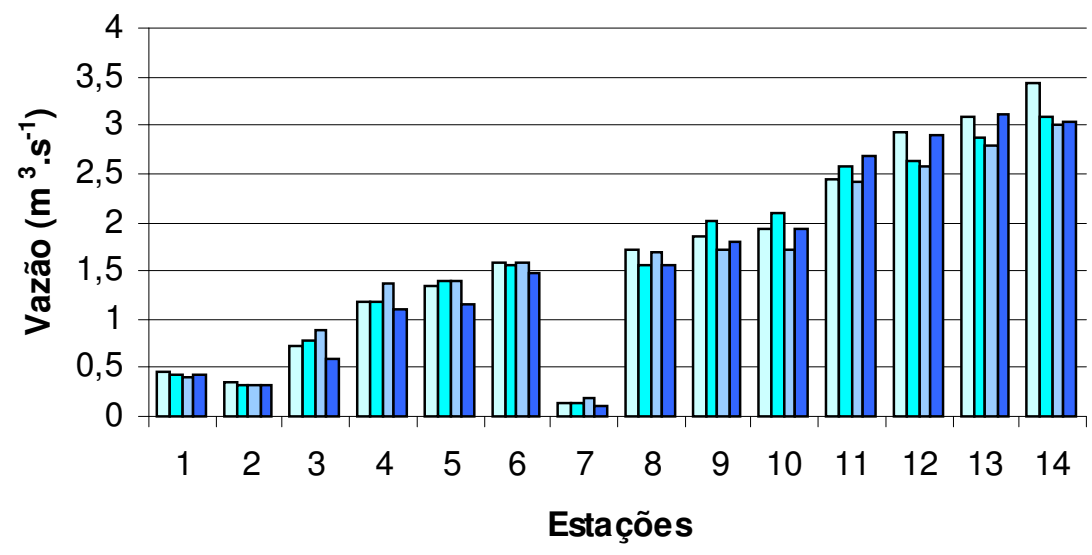

$\square 15 / 10 / 00 \square 16 / 10 / 00 \square 17 / 10 / 00 \square 18 / 10 / 00$

FIGURA 2.3.4.1.2 - Variação da vazão $\left(\mathrm{m}^{3} . \mathrm{s}^{-1}\right)$ no eixo longitudinal do rio Betari, no período de $15 / 10 / 00$ a $18 / 10 / 00$.

\subsubsection{Variáveis físicas e químicas da água.}

\subsubsection{1. $\mathrm{pH}$, condutividade, alcalinidade e formas de carbono.}

Os valores de $\mathrm{pH}$ do rio Betari foram alcalinos em outubro de 2000 (figura 2.3.4.2.1.1), variando de 6,65 na estação 1 , a 8,4 na estação 14 . Os valores de $\mathrm{pH}$ foram acompanhados pelos valores de condutividade elevados (figura 2.3.4.2.1.2), em torno de 215 uS.cm ${ }^{-1}$ na estação 7 e 140 uS.cm ${ }^{-1}$ nas demais estações.

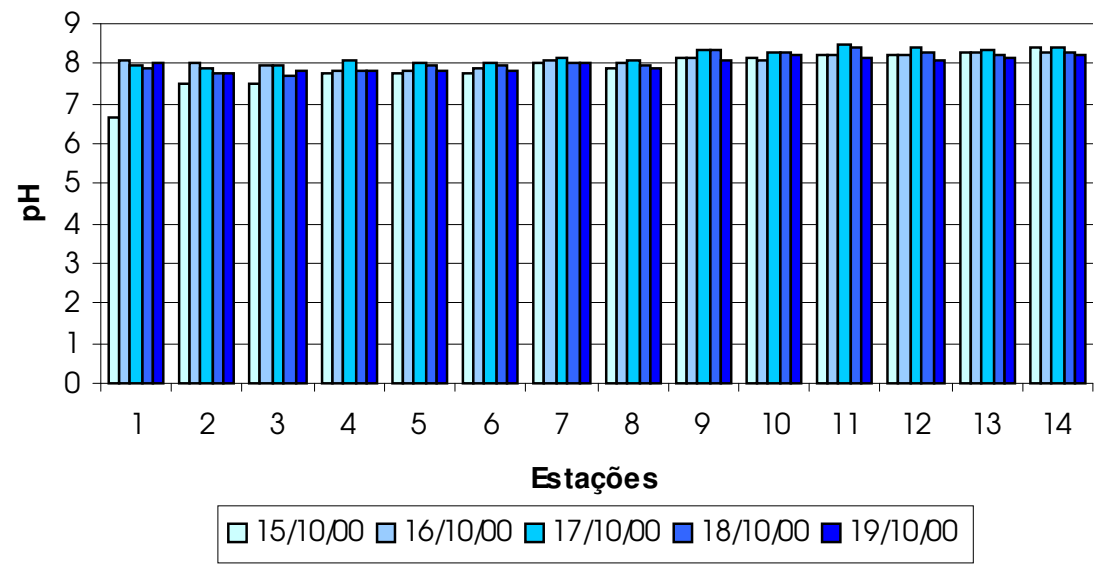

FIGURA 2.3.4.2.1.1 - Variação dos valores de pH no rio Betari, no período de 15/10/00 
a $19 / 10 / 00$.

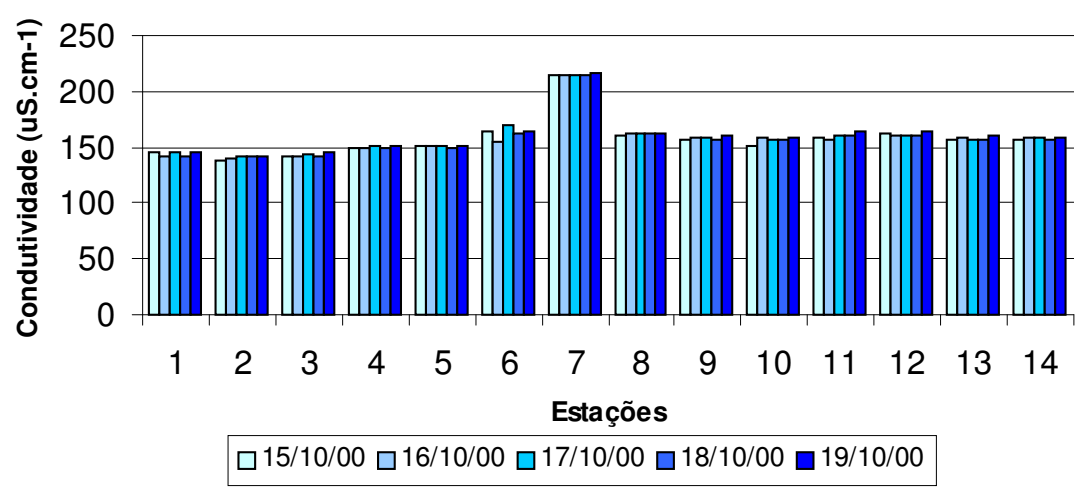

FIGURA 2.3.4.2.1.2 - Variação dos valores de condutividade $\left(\mathrm{uS} . \mathrm{cm}^{-1}\right)$ no rio Betari, no período entre $15 / 10 / 00$ e $19 / 10 / 00$.

Como se pode observar, os valores de $\mathrm{pH}$ alcalinos e altas condutividades das águas do rio Betari, que ocorreram em outubro de 2000, repetiu o comportamento das demais épocas amostradas. A alcalinidade variou de 1,18 meq.L $L^{-1}$ na estação 2 , a 1,42 meq. $\mathrm{L}^{-1}$ na 6; a estação 7 destacou-se das demais pelos valores mais elevados (figura 2.3.4.2.1.3). As concentrações de carbono apresentadas nas figuras 2.3.4.2.1.4 até 2.3.4.2.1.7 estão representadas predominantemente pela forma $\mathrm{HCO}_{3}{ }^{-}$. A alcalinidade $\mathrm{e}$ $\mathrm{o}_{\mathrm{HCO}}{ }^{-}$foram inferiores nas estações do alto curso. 


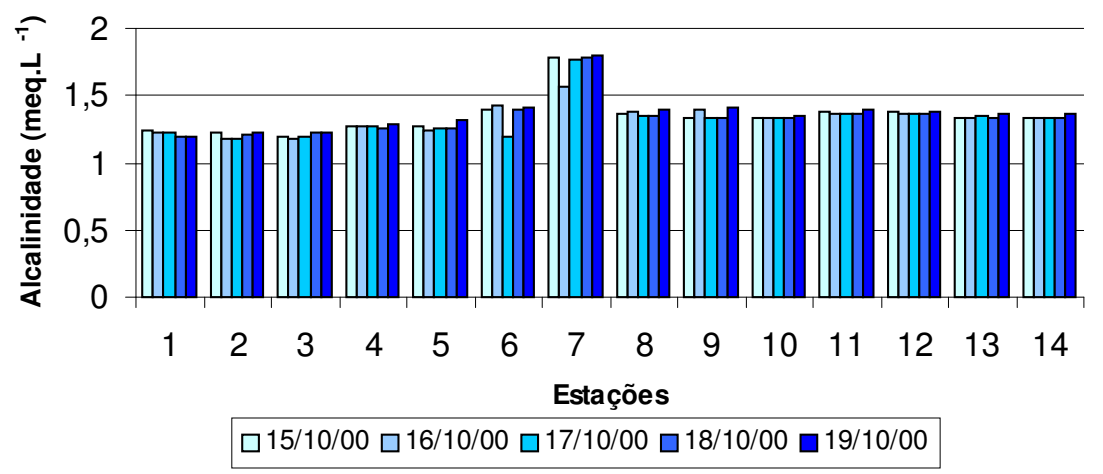

FIGURA 2.3.4.2.1.3 - Variação da alcalinidade (meq.L $L^{-1}$ ) no rio Betari, no período de 15/10/00 a 19/10/00.

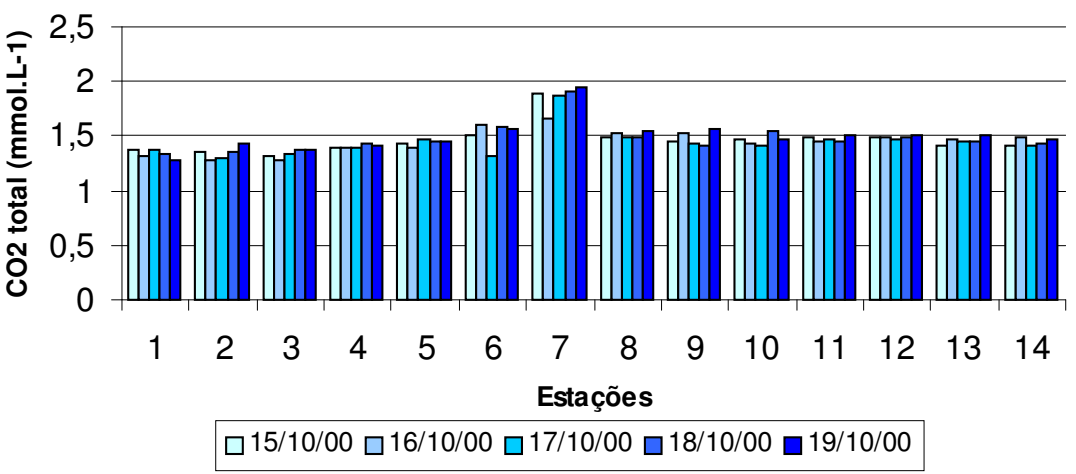

FIGURA 2.3.4.2.1.4 - Variação das concentrações de $\left(\mathrm{CO}_{2}\right)$ total $\left(\mathrm{mmol} . \mathrm{L}^{-1}\right)$ no rio Betari no período de 15/10/00 a 19/10/00. 


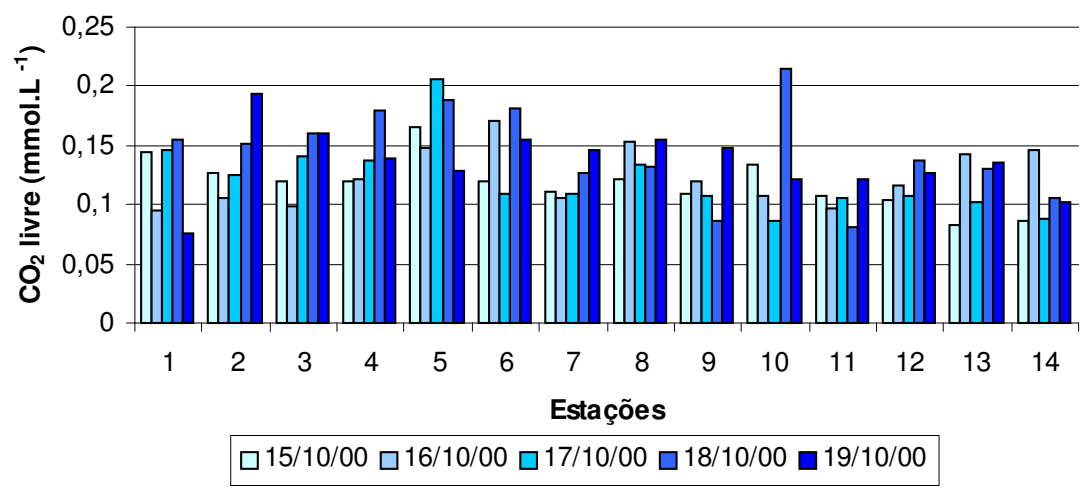

FIGURA 2.3.4.2.1.5 - Variação das concentrações de $\left(\mathrm{CO}_{2}\right)$ livre $\left(m m o l . L^{-1}\right)$ no rio Betari, no período de 15/10/00 a 19/10/00.

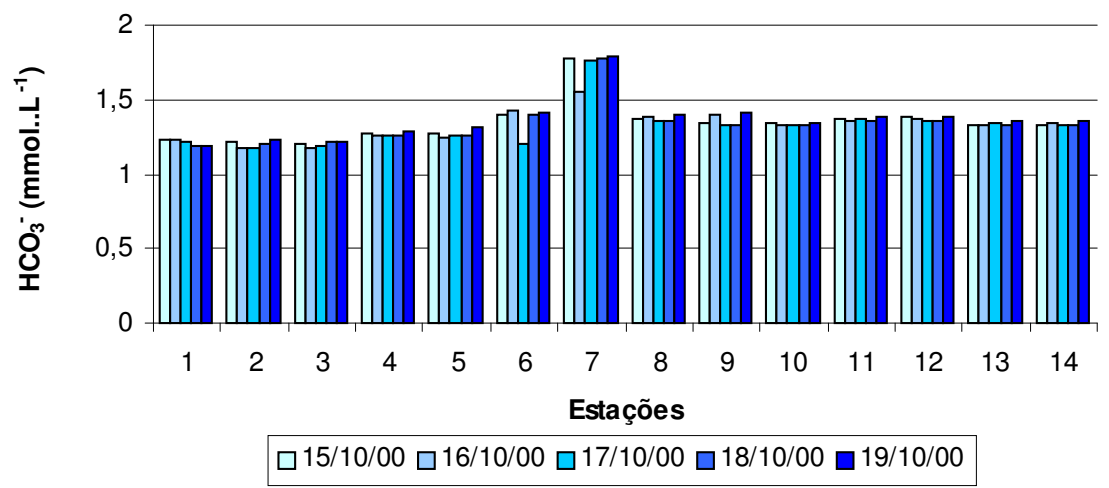

FIGURA 2.3.4.2.1.6 - Variação das concentrações de $\left(\mathrm{HCO}_{3}^{-}\right)\left(\mathrm{mmol} . \mathrm{L}^{-1}\right)$ no rio Betari, no período de 15/10/00 a 19/10/00.

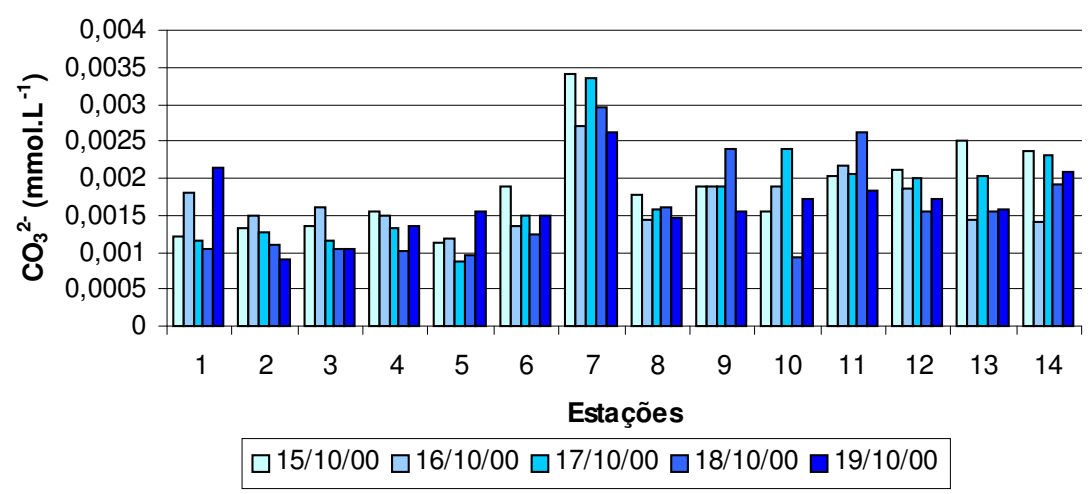

FIGURA 2.3.4.2.1.7 - Variação das concentrações de $\left(\mathrm{CO}_{3}^{--}\right)\left(\mathrm{mmol} . \mathrm{L}^{-1}\right)$ no rio Betari, no período de 15/10/00 a 19/10/00. 


\subsection{Oxigênio Dissolvido}

As concentrações de oxigênio dissolvido no rio Betari estiveram acima de 8,22 mg. $L^{-1}$ (figura 2.3.4.2.2).

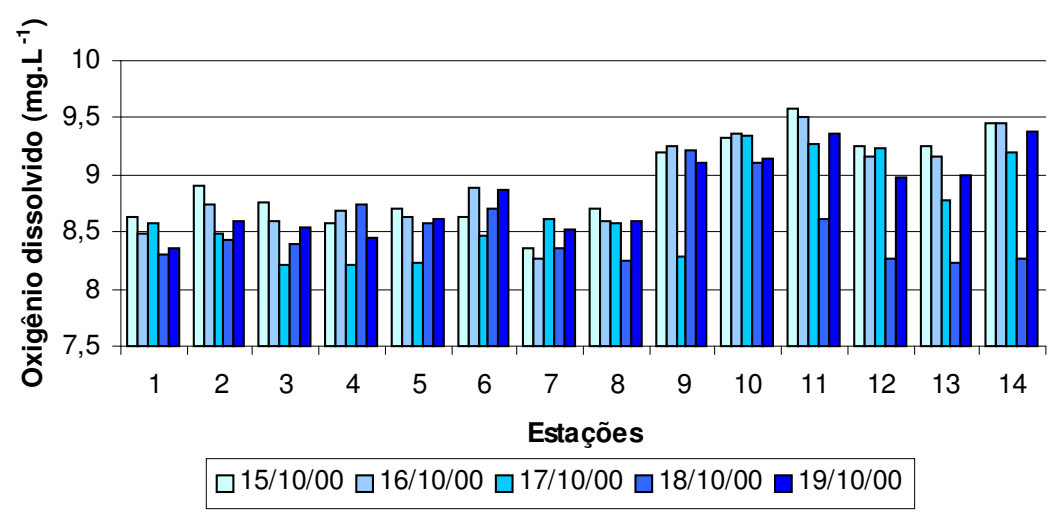

FIGURA 2.3.4.2.2 - Variação das concentrações de oxigênio dissolvido (mg. $\mathrm{L}^{-1}$ ) no rio Betari, no período de 15/10/00 a 19/10/00.

\subsection{Turbidez, sólidos em suspensão orgânicos e inorgânicos.}

Os valores de turbidez, em outubro de 2000, ficaram abaixo dos limites de detecção, como aconteceu nos outros períodos de amostragem. A maior concentração de sólidos em suspensão inorgânicos ocorreu na estação 7 (3,08 mg. $\left.\mathrm{L}^{-1}\right)$ e a menor, na estação $1\left(0,48 \mathrm{mg} \cdot \mathrm{L}^{-1}\right)$ - figura 2.3.4.2.3.1. De maneira geral, as concentrações de sólidos em suspensão orgânicos foram menores do que a fração inorgânica, com exceção feita às estações 1 e 2 (figura 2.3.4.2.3.2). As concentrações de sólidos em suspensão observadas podem ser consideradas baixas. 


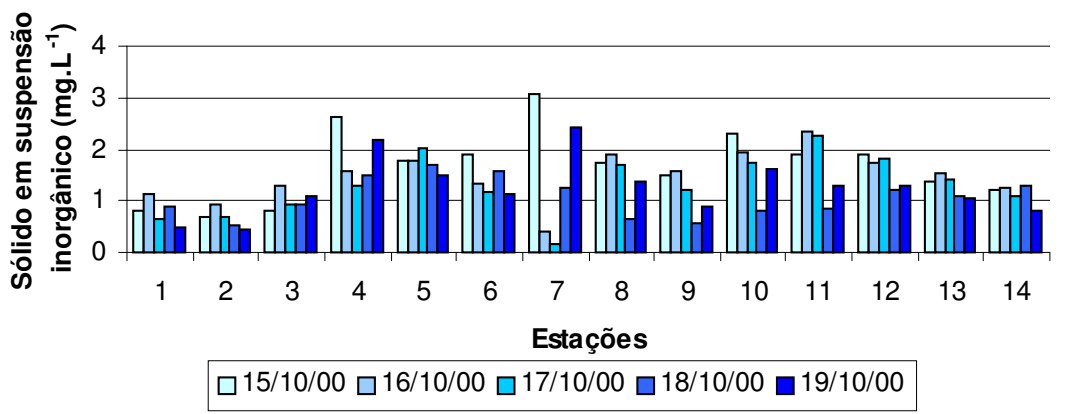

FIGURA 2.3.4.2.3.1- Variação das concentrações de sólidos em suspensão inorgânicos $\left(\mathrm{mg} \cdot \mathrm{L}^{-1}\right)$ no rio Betari, no período de 15/10/00 a 19/10/00.

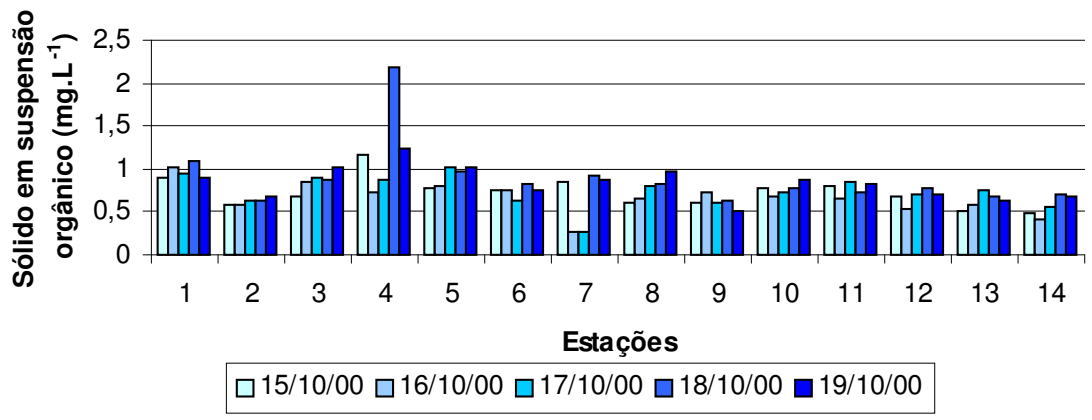

FIGURA 2.3.4.2.3.2 - Variação das concentrações de sólidos em suspensão orgânicos $\left(\mathrm{mg}^{-1} \mathrm{~L}^{-1}\right)$ no rio Betari, no período de 15/10/00 a 19/10/00.

\subsection{Temperatura da água}

Os valores de temperatura da água no rio Betari, entre 15/10/00 e 19/10/00, ficaram ficarão próximo aos de $19^{\circ} \mathrm{C}$ nas estações de 1 a 8 , e na próximo aos $20^{\circ} \mathrm{C}$ nas estações de 9 a 14 (figura 2.3.4.2.4). Os valores mais elevados de temperatura ocorreram nas estações de 11 a 14 . 


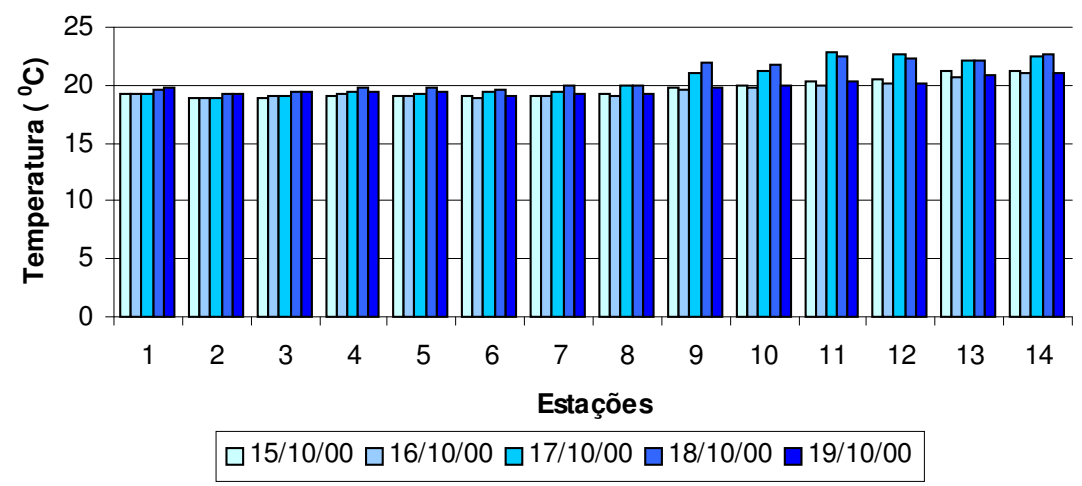

FIGURA 2.3.4.2.4 - Variação dos valores de temperatura da água $\left({ }^{\circ} \mathrm{C}\right)$ no rio Betari, no período de 15/10/00 a 19/10/00.

\subsection{Demanda Bioquímica de Oxigênio}

A demanda bioquímica de oxigênio foi baixa em todas as estações ao longo do rio Betari, em outubro de 2000. A estação 8 apresentou a maior DBO $\left(0,68 \mathrm{mg} \cdot \mathrm{L}^{-1}\right)$, e a menor foi observada na estação 10 (figura 2.3.4.2.5).

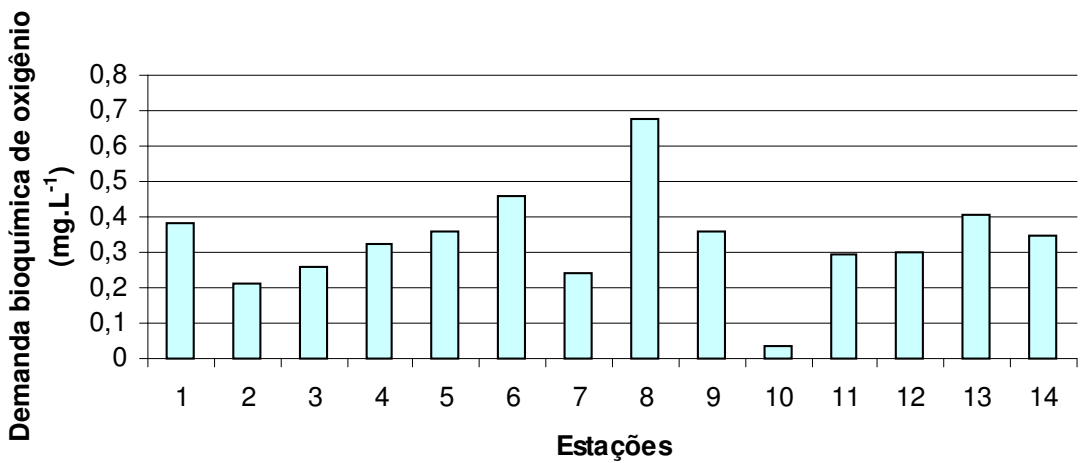

FIGURA 2.3.4.2.5. - Variação da demanda bioquímica de oxigênio ( $m g \cdot \mathrm{L}^{-1}$ ) no rio Betari no dia 19/10/00.

\subsection{Nutrientes dissolvidos e totais na água}

As figuras 2.3.4.2.6.1 até 2.3.4.2.6.4 apresentam as concentrações das 
formas de nitrogênio (nitrogênio amoniacal, nitrato, nitrito, nitrogênio orgânico total), em de outubro de 2000, quando o nitrogênio orgânico foi predominante, seguido do nitrito. A distribuição das formas de nitrogênio no eixo longitudinal do rio Betari não apresentaram um padrão definido.

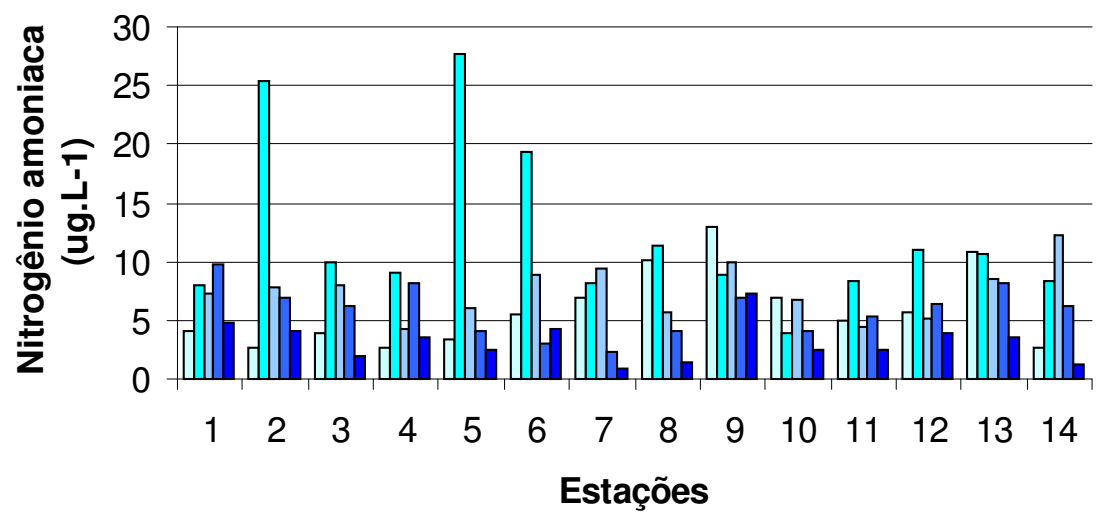

$\square$ 15/10/00 $\square$ 16/10/00 $\square$ 17/10/00 $\square$ 18/10/00 $\square$ 19/10/00

FIGURA 2.3.4.2.6.1 - Variação das concentrações de nitrogênio amoniacal (ug. $\mathrm{L}^{-1}$ ) no rio Betari, no período de 15/10/00 a 19/10/00.

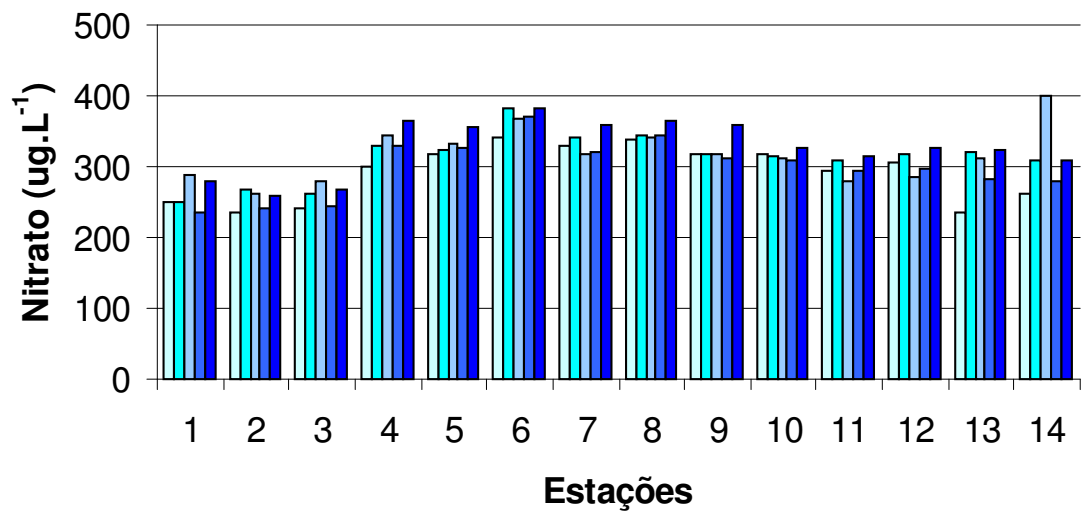

$\square$ 15/10/00 $\square$ 16/10/00 $\square$ 17/10/00 $\square$ 18/10/00 $\square$ 19/10/00

FIGURA 2.3.4.2.6.2 - Variação das concentrações de nitrato (ug. $\mathrm{L}^{-1}$ ) no rio Betari, no período de 15/10/00 a 19/10/00. 


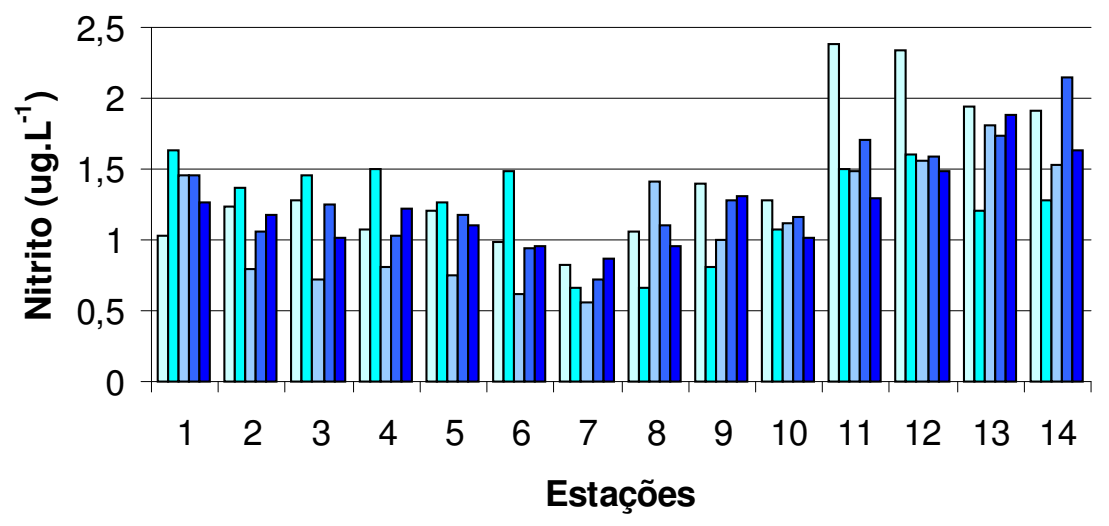

\section{$\square$ 15/10/00 $\square$ 16/10/00 $\square$ 17/10/00 $\square$ 18/10/00 19/10/00}

FIGURA 2.3.4.2.6.3 - Variação das concentrações de nitrito (ug. $\mathrm{L}^{-1}$ ) no rio Betari, no período de15/10/00 a 19/10/00.

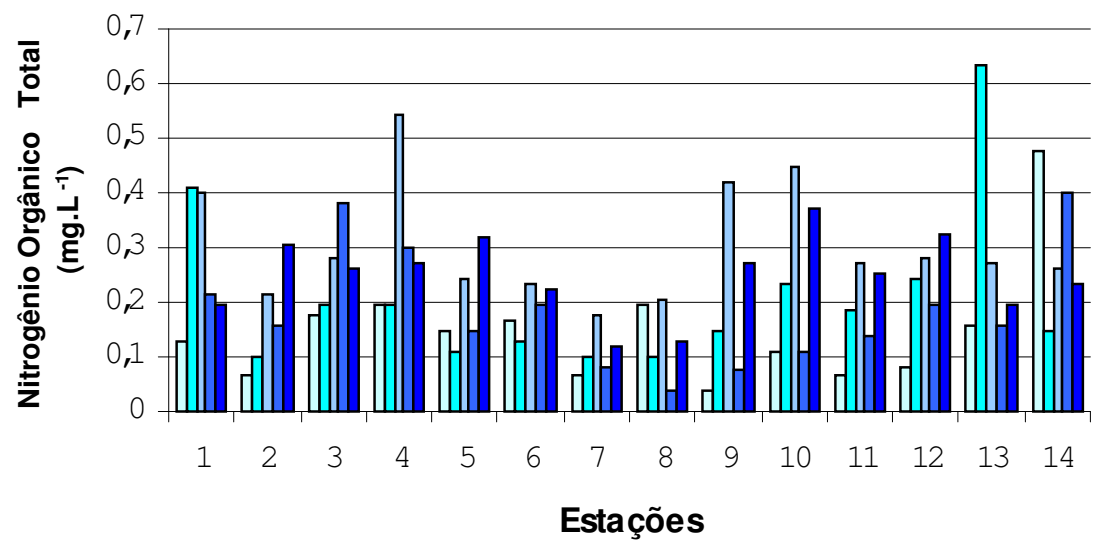

$\square^{15 / 10 / 00} \square^{16 / 10 / 00} \square^{17 / 10 / 00} \square^{18 / 10 / 00} \square^{19 / 10 / 00}$

FIGURA 2.3.4.2.6.4 - Variação das concentrações de nitrogênio orgânico total $\left(\mathrm{mg}^{\mathrm{L}} \mathrm{L}^{-1}\right)$ no rio Betari, no período de 15/10/00 a 19/10/00. 
As concentrações das formas de fósforo dissolvidas (fosfato inorgânico e fosfato total dissolvido) foram mais elevadas nas estações do alto curso do rio Betari em outubro de 2000, e variaram de 3,68 ug. $\mathrm{L}^{-1}$ a 19,20 ug. $\mathrm{L}^{-1}$, e 8,56 ug. $\mathrm{L}^{-1}$ a $32,90 \mathrm{ug} \cdot \mathrm{L}^{-1}$, respectivamente. As concentrações de fósforo total distribuíram-se irregularmente no eixo longitudinal do rio (figuras 2.3.4.2.6.5 até 2.3.4.2.6.7).

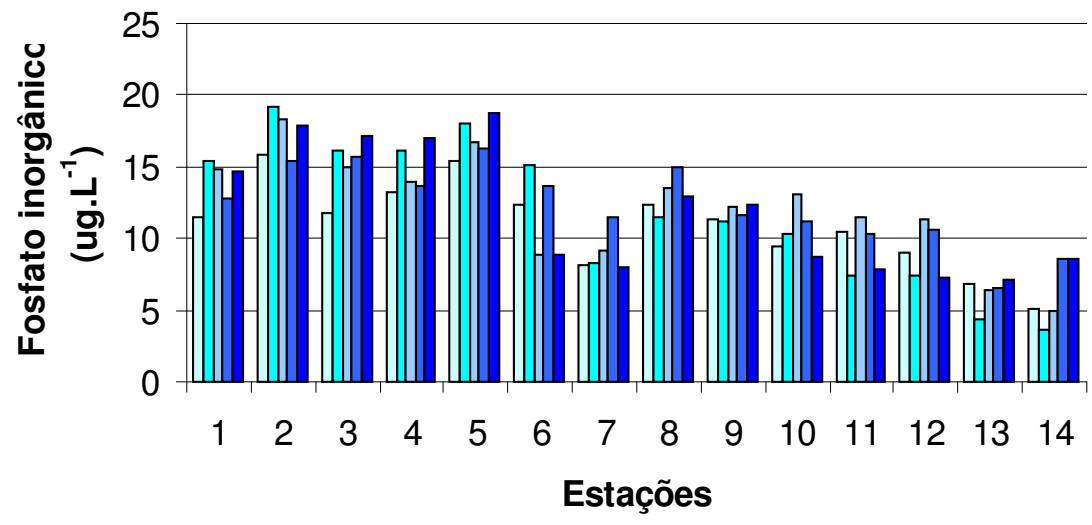

\section{$\square$ 15/10/00 $\square$ 16/10/00 $\square$ 17/10/00 $\square$ 18/10/00 $\square$ 19/10/00}

FIGURA 2.3.4.2.6.5 - Variação das concentrações de fosfato inorgânico (ug. $\mathrm{L}^{-1}$ ) no rio Betari, no período de 15/10/00 a 19/10/00.

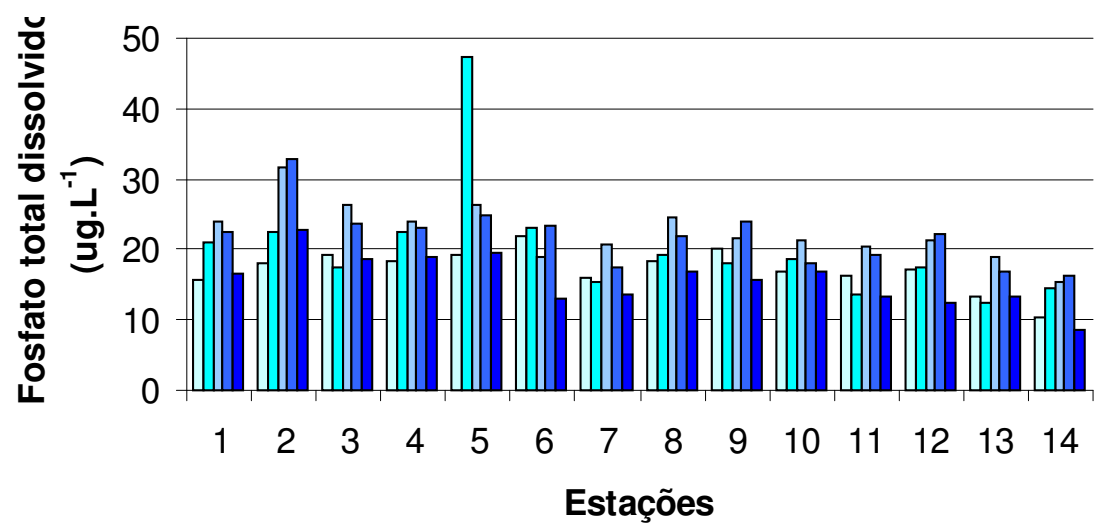

$\square$ 15/10/00 $\square$ 16/10/00 $\square$ 17/10/00 $\square$ 18/10/00 $\square$ 19/10/00

FIGURA 2.3.4.2.6.6 - Variação das concentrações de fosfato total dissolvido (ug. $\mathrm{L}^{-1}$ ) no rio Betari, no período de 15/10/00 a 19/10/00. 


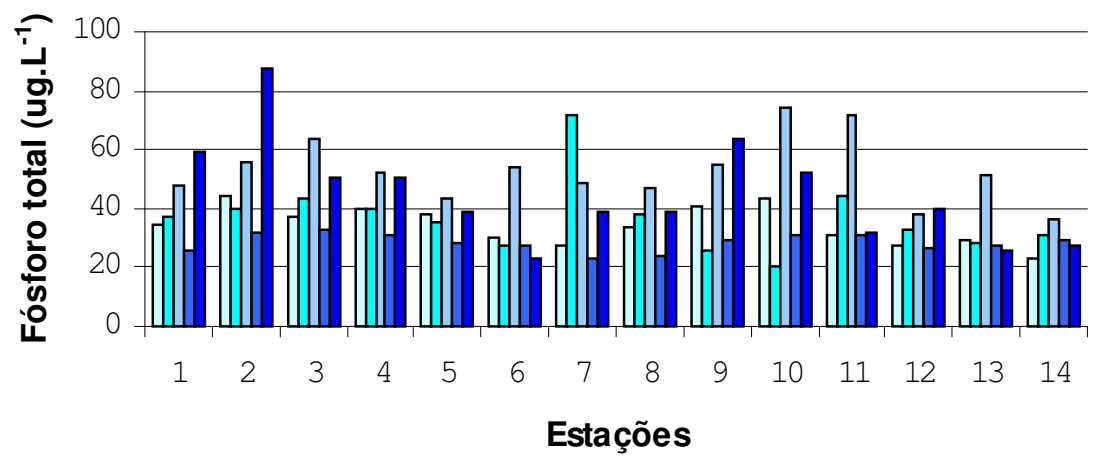

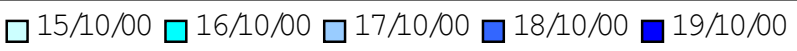

FIGURA 2.3.4.2.6.7 - Variação das concentrações de fósforo total (ug. $\left.\mathrm{L}^{-1}\right)$ no rio Betari, no período de 15/10/00 a 19/10/00.

As concentrações de silicato reativo mostraram-se elevadas ao longo de todo o rio Betari, durante os cinco dias de amostragem, variando de $5,00 \mathrm{mg} \cdot \mathrm{L}^{-1}$ a $10,28 \mathrm{mg} \cdot \mathrm{L}^{-1}$, com ligeira diminuição em direção à foz (figura 2.3.4.2.5.8).

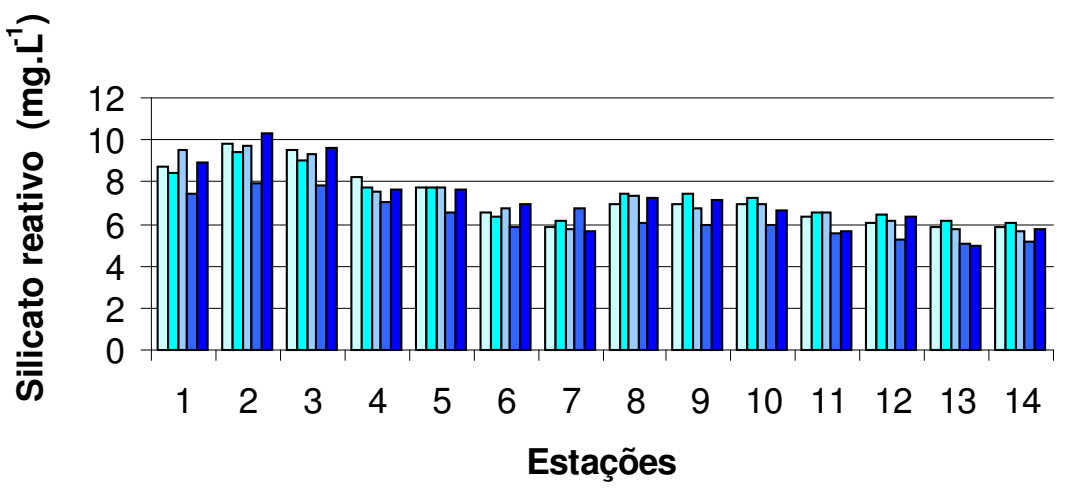

$\square$ 15/10/00 $\square$ 16/10/00 $\square$ 17/10/00 $\square$ 18/10/00 $\square$ 19/10/00

FIGURA 2.3.4.2.6.8 - Variação das concentrações de silicato reativo $\left(\mathrm{mg} \cdot \mathrm{L}^{-1}\right)$ no rio Betari, no período de 15/10/00 a 19/10/00. 


\subsubsection{7. Íons Dissolvidos na Água}

Como aconteceu nos demais meses de amostragem, as concentrações de cálcio, sódio e magnésio apresentaram-se acima do limite de detecção dos métodos utilizados e o chumbo não foi detectado. As concentrações de zinco (tabela 2.3.4.2.7) ficaram entre $0,15 \mathrm{mg}^{-\mathrm{L}^{-1}}$, na estação 7 , e um valor próximo a 0 na estação 5 .

TABELA 2.3.4.2.7 - Variação das concentrações de íons totais na água no rio Betari na amostragem de outubro de 2000.

\begin{tabular}{lcccccccccccccc}
\hline Estações & 1 & 2 & 3 & 4 & 5 & 6 & 7 & 8 & 9 & 10 & 11 & 12 & 13 & 14 \\
\hline $\mathrm{Zn}\left(\mathrm{mg} \cdot \mathrm{L}^{-1}\right)$ & 0,02 & 0,01 & 0,01 & 0,00 & 0,00 & 0,00 & 0,15 & 0,03 & 0,02 & 0,02 & 0,02 & 0,01 & 0,03 & 0,01 \\
$\mathrm{~Pb}\left(\mathrm{mg} \cdot \mathrm{L}^{-1}\right)$ & $*$ & $*$ & $*$ & $*$ & $*$ & $*$ & $*$ & $*$ & $*$ & $*$ & $*$ & $*$ & $*$ & $*$ \\
$\mathrm{Ca}\left(\mathrm{mg} \cdot \mathrm{L}^{-1}\right)$ & $>15$ & $>15$ & $>15$ & $>15$ & $>15$ & $>15$ & $>15$ & $>15$ & $>15$ & $>15$ & $>15$ & $>15$ & $>15$ & $>15$ \\
$\mathrm{Na}\left(\mathrm{mg} \cdot \mathrm{L}^{-1}\right)$ & $>2$ & $>2$ & $>2$ & $>2$ & $>2$ & $>2$ & $>2$ & $>2$ & $>2$ & $>2$ & $>2$ & $>2$ & $>2$ & $>2$ \\
$\mathrm{Mg}\left(\mathrm{mg} \cdot \mathrm{L}^{-1}\right)$ & $>2$ & $>2$ & $>2$ & $>2$ & $>2$ & $>2$ & $>2$ & $>2$ & $>2$ & $>2$ & $>2$ & $>2$ & $>2$ & $>2$ \\
\hline * abaixo do limite de detecção
\end{tabular}

\subsubsection{Análise numérica}

A análise de agrupamento realizada com a média do conjunto de dados físicos e químicos da água obtidos na coleta de outubro de 2000 , reuniu as estações de amostragem em quatro grupos no perfil longitudinal: estações 1 a 5 (grupo 1); estações 8 a 10 (grupo 2); estações 11 a 14 (grupo 3); e estação 7 (grupo 4) - figura 2.3.4.3. Porém, a análise discriminante realizada (utilizando os grupos formados) evidenciou a inexistência de diferenças estatisticamente significativas (intervalo de confiança de $95 \%$ ) entre os grupos formados pela análise de cluster. 


\section{Dendrogram}

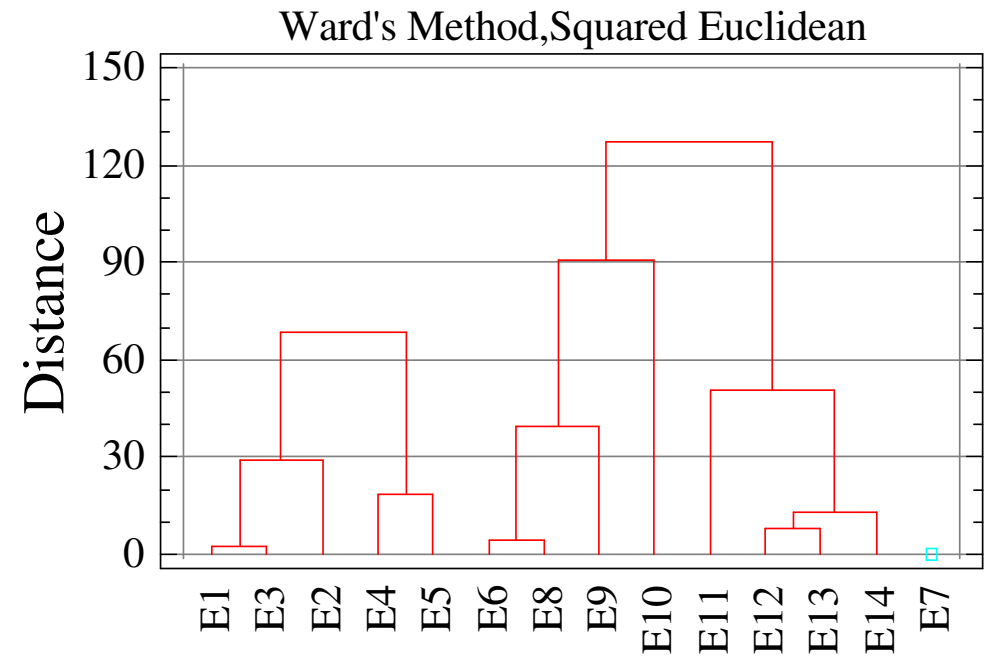

Figura 2.3.4.4 - Dendograma da análise de agrupamento das médias das variáveis físicas e químicas da água nas estações do rio Betari em outubro de 2000. 


\section{Dendrogram}

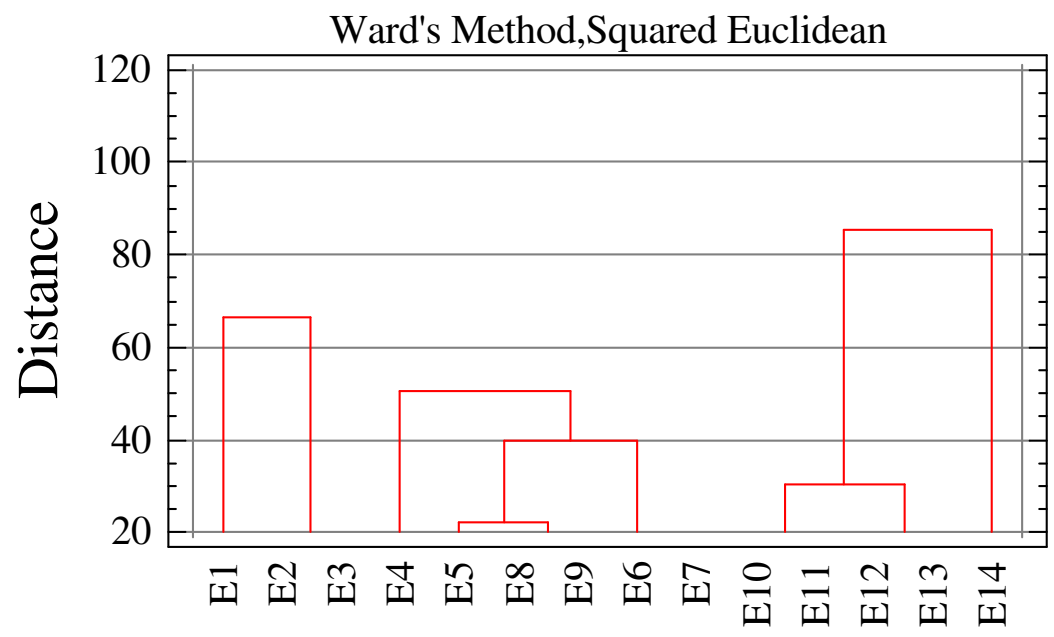

FIGURA 2.3.2.3 - Dendograma da análise de agrupamento das médias das variáveis físicas e químicas da água nas estações do rio Betari, em abril de 2000. 


\subsubsection{ANÁLISE SAZONAL DAS VARIÁVEIS LIMNOLÓGICAS}

O cálculo das médias dos cinco dias de campanha para cada ponto permitiu melhor visualização das variações sazonais das variáveis hidrológicas.

\subsubsection{1. $\mathrm{pH}$, condutividade, alcalinidade e $\mathrm{CO}_{2}$ total}

As estações do alto curso do rio Betari (estações 1, 2 e 3) apresentaram valores de $\mathrm{pH}$ maiores em julho e outubro, e as demais apresentaram maiores médias, principalmente, em janeiro, com exceção da estação 12, onde a média de outubro foi ligeiramente maior (figura 2.3.5.1.1).

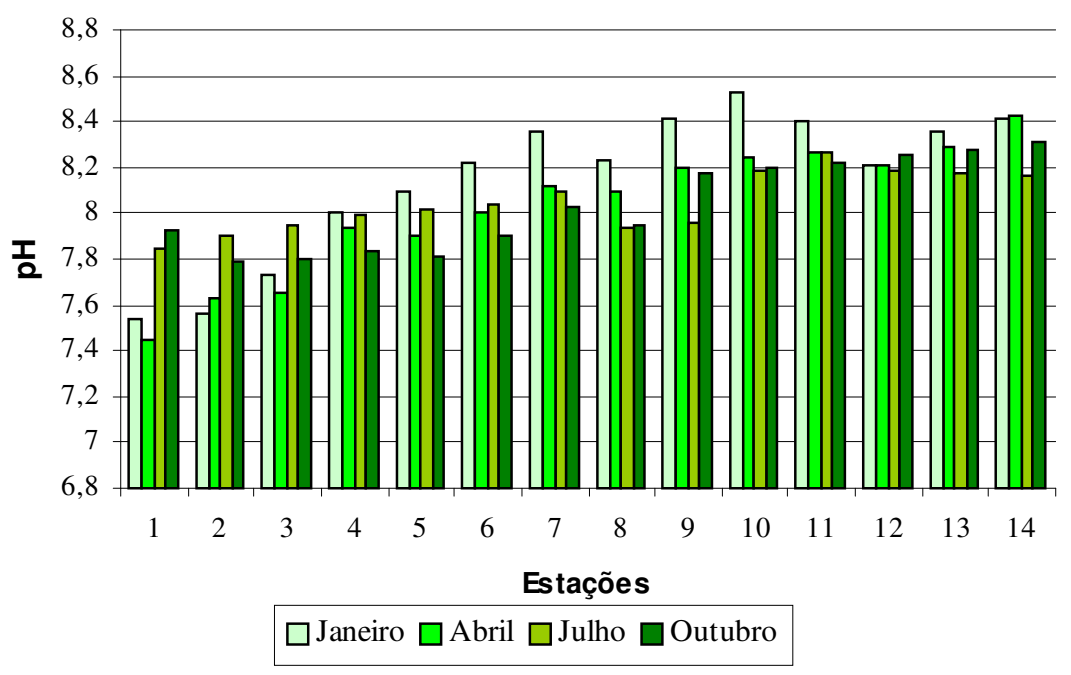

FIGURA 2.3.5.1.1.- Valores médios de pH dos cinco dias de coleta intensiva, nos quatro períodos de estudo no rio Betari.

As médias de condutividade elétrica apresentaram aumento durante as estações do ano (figura 2.3.5.1.2). Pode-se observar que os menores valores ocorreram em janeiro. Nas estações 
1 a 6, o aumento ocorreu até julho, caindo em outubro. Nas demais estações, o aumento acorreu até as coletas de outubro.

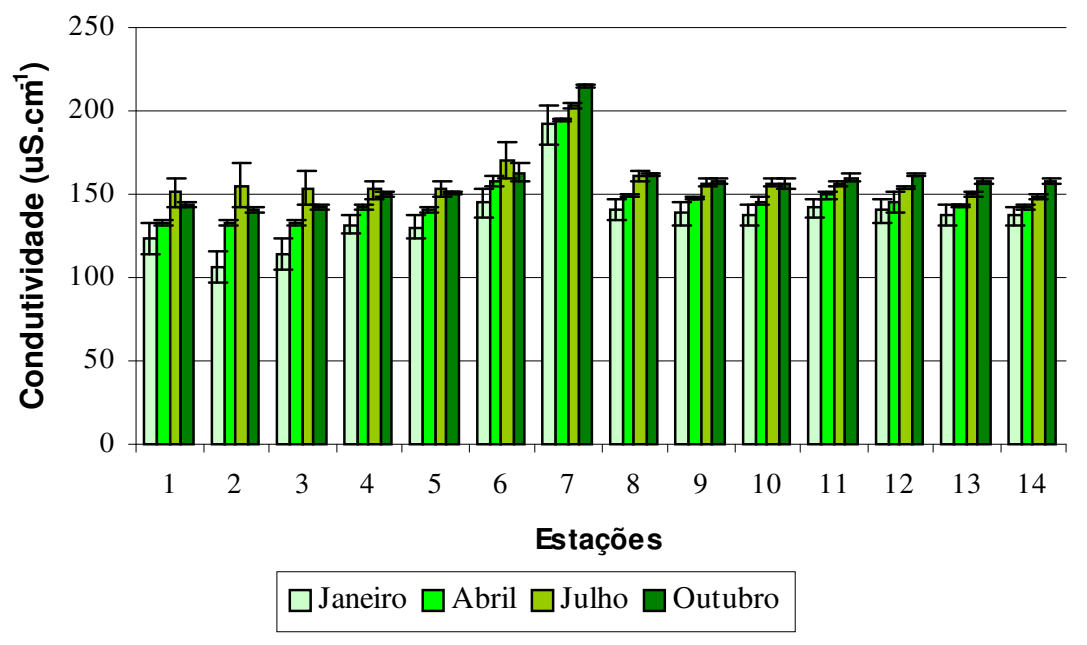

FIGURA 2.3.5.1.2 - Valores médios de condutividade elétrica dos cinco dias de coleta intensiva, nos quatro períodos de estudo no rio Betari.

$\mathrm{Na}$ figura 2.3.5.1.3 podem ser observados os valores médios da alcalinidade, assim como os desvios-padrão de cada período de amostragem. Os maiores valores foram observados nas coletas de julho, seguidos por abril, outubro e janeiro. Já as concentrações de $\mathrm{CO}_{2}$, total foram maiores em julho, decrescendo em abril, janeiro e outubro, respectivamente, como mostra a figura 2.3.5.1.4. 


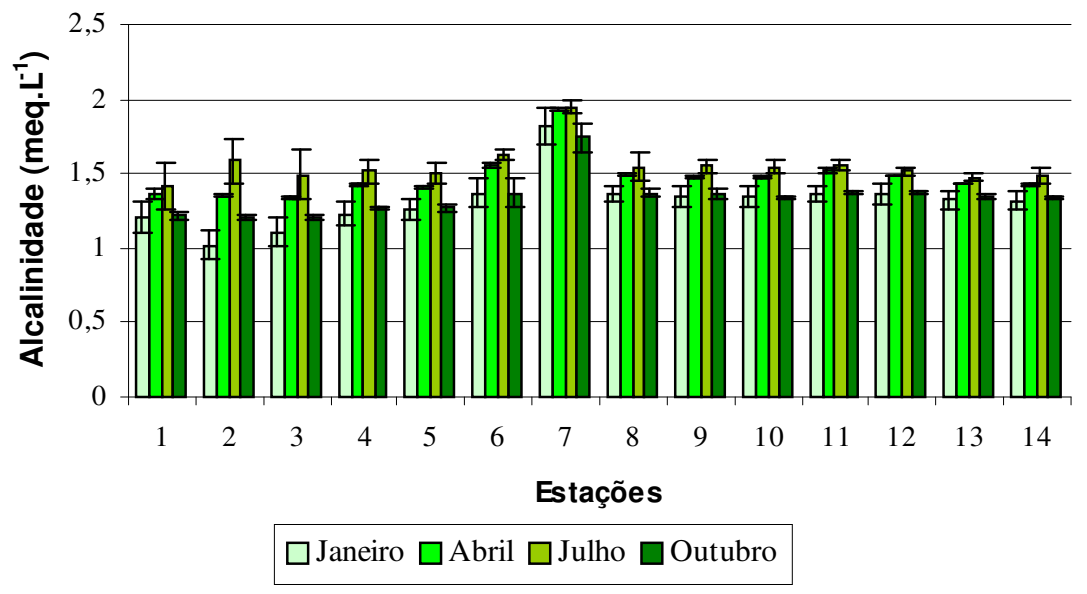

FIGURA 2.3.5.1.3- Valores médios de alcalinidade dos cinco dias de coleta intensiva, nos quatro períodos de estudo no rio Betari.

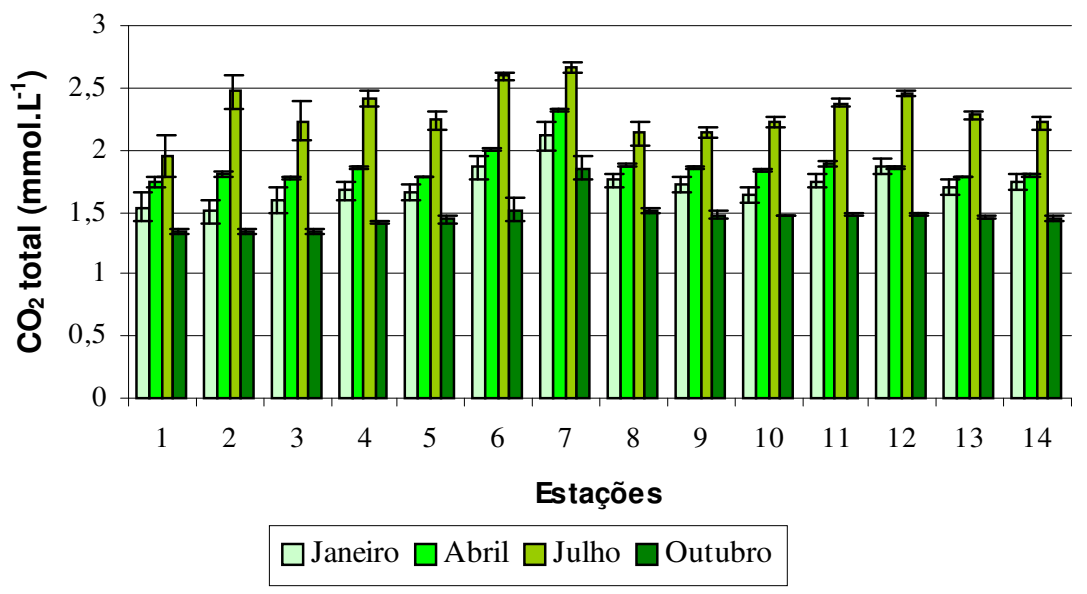

FIGURA 2.3.5.1.4 - Valores médios de $\left(\mathrm{CO}_{2}\right)$ total dos cinco dias de coleta intensiva, nos quatro períodos de estudo no rio Betari.

\subsubsection{Oxigênio dissolvido}


Com exceção da estação 10, que apresentou uma concentração média de oxigênio dissolvido maior em outubro, as demais apresentaram maiores valores em julho (figura 2.3.5.2.1).

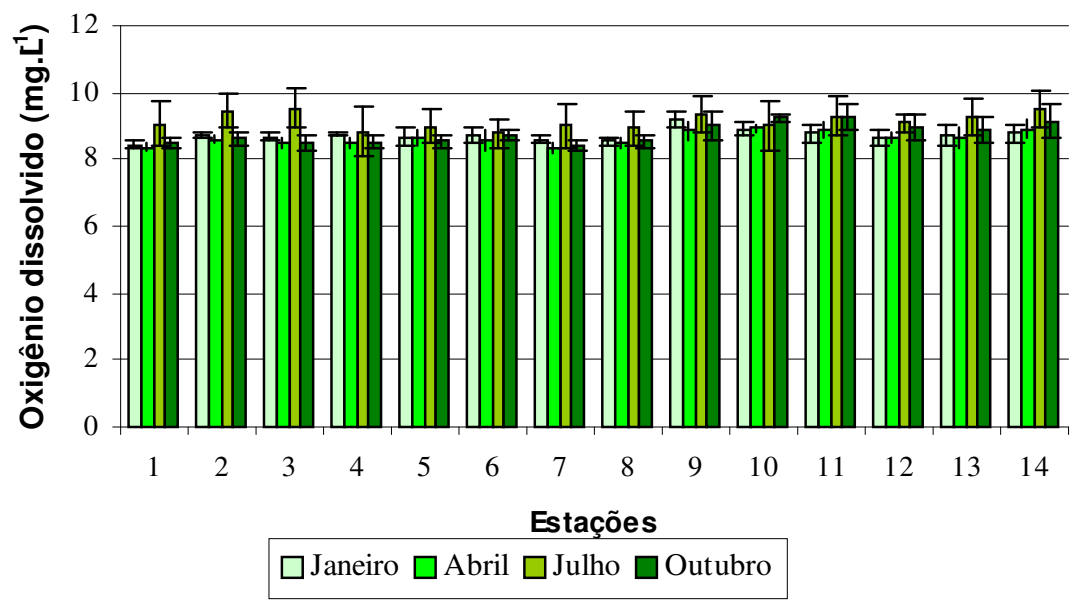

FIGURA 2.3.5.2.1- Valores médios de $\mathrm{O}_{2}$ dissolvido dos cinco dias de coleta intensiva, nos quatro períodos de estudo no rio Betari.

\subsubsection{Sólidos em suspensão orgânicos e inorgânicos}

Nas figuras 2.3.5.3.1 e 2.3.5.3.2 podem ser observados os valores médios das concentrações de sólidos orgânicos e inorgânicos em suspensão, respectivamente. As maiores médias, tanto para orgânicos quanto para inorgânicos, ocorreram nas coletas de janeiro, decrescendo em abril e julho, voltando a aumentar em outubro. Ocorreu predomínio de material inorgânico. Também pode-se observar que em janeiro ocorreu uma tendência de aumento de montante para jusante da fração inorgânica em suspensão. 


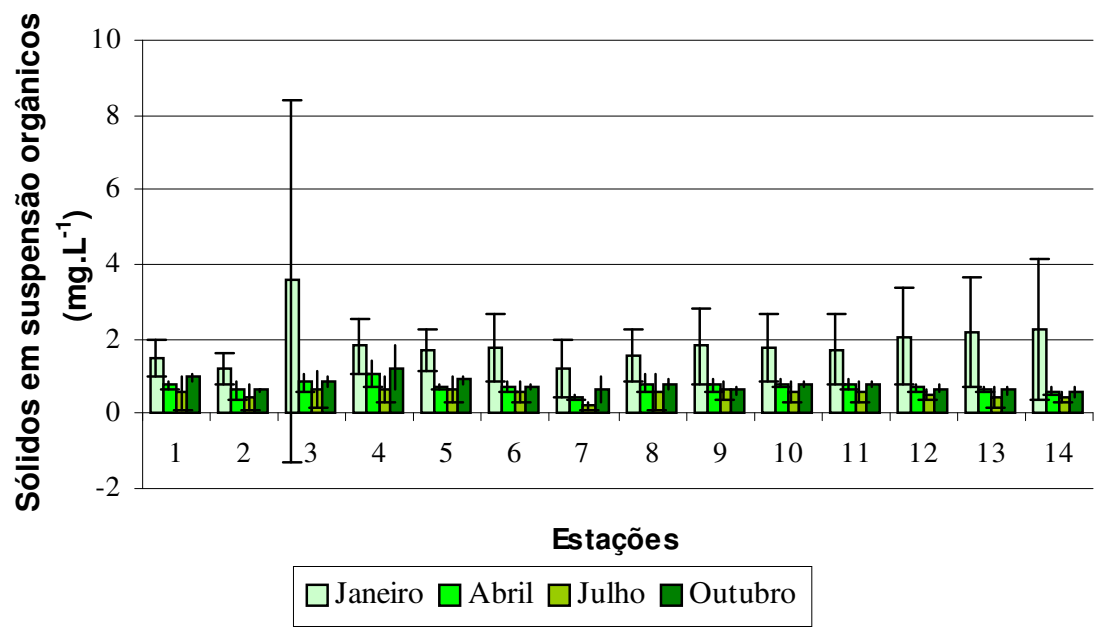

FIGURA 2.3.5.3.1- Valores médios de sólidos orgânicos em suspensão dos cinco dias de coleta intensiva, nos quatro períodos de estudo no rio Betari.

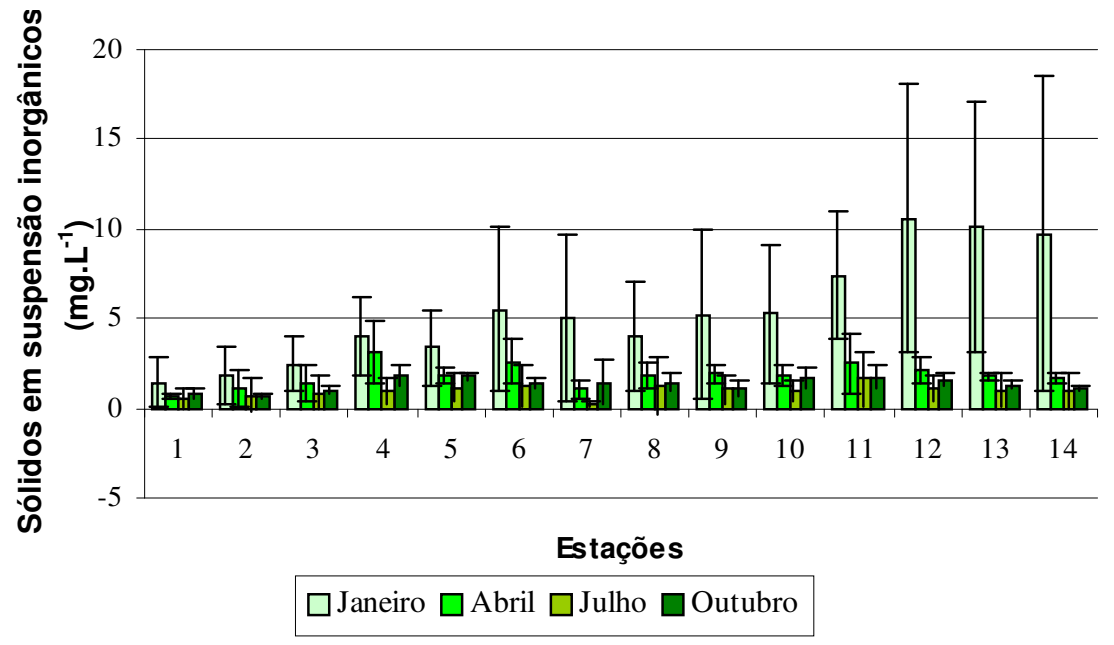

FIGURA 2.3.5.3.2 - Valores médios de sólidos inorgânicos em suspensão dos cinco dias de coleta intensiva, nos quatro períodos de estudo no rio Betari. 


\subsubsection{Temperatura da água}

Os valores médios de temperatura da água podem ser observados na figura 2.3.5.4. As médias acompanharam os valores da temperatura do ar, que diminui de janeiro para julho e aumentou em outubro. Deve-se notar também um ligeiro aumento da temperatura de montante para jusante.

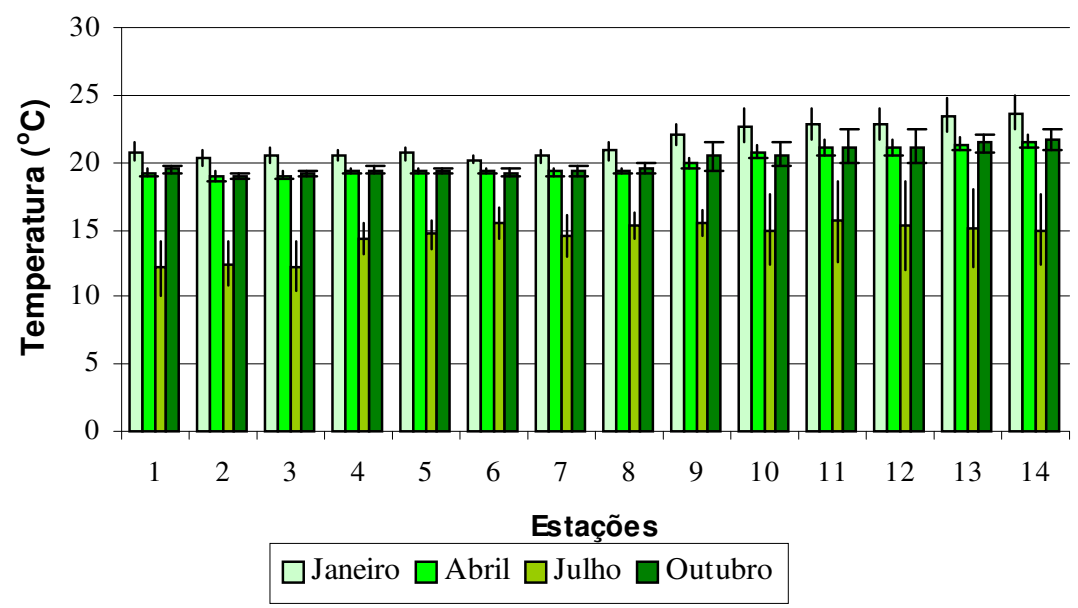

FIGURA 2.3.5.4 - Valores médios de temperatura dos cinco dias de coleta intensiva, nos quatro períodos de estudo no rio Betari.

\subsubsection{Demanda Bioquímica de Oxigênio}

A DBO do rio Betari não apresentou um padrão, mostrando variações temporais e espaciais, aparentemente aleatórias. Em oito das 14 estações, os maiores valores de DBO foram observados em janeiro, e isso ocorreu, principalmente, no médio e baixo curso do rio (figura 2.3.5.5). Nas estações 1, 
3, 7, 8 e 11, os maiores valores ocorreram em julho. Somente na estação 9 o valor de abril foi maior.

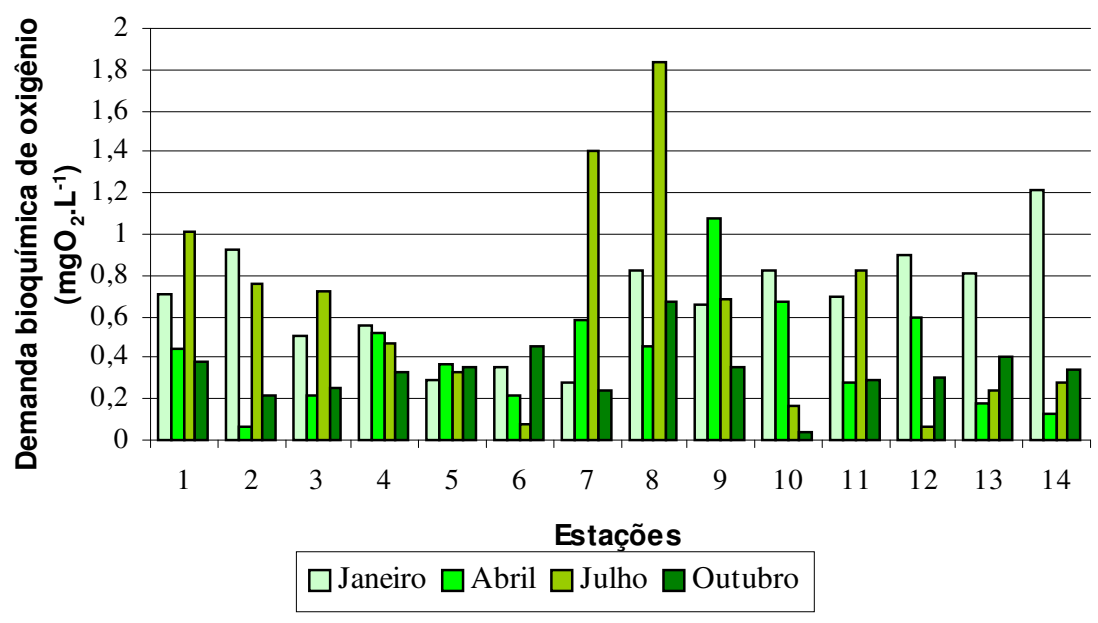

FIGURA 2.3.5.5 - Valores da DBO dos cinco dias de coleta intensiva, nos quatro períodos de estudo no rio Betari.

\subsubsection{Nutrientes dissolvidos e totais na água}

As figuras 2.3.5.6.1, 2.3.5.6.2, 2.3.5.6.3 e 2.3.5.6.4 apresentam as concentrações médias de nitrogênio amoniacal, nitrito, nitrato e nitrogênio orgânico total. As concentrações de amônia foram menores em janeiro e tenderam a ser maiores em abril. Já as médias das concentrações de nitrito, apresentaram valores maiores em janeiro e outubro, com julho apresentando os menores. As estações do trecho baixo do rio Betari apresentaram valores maiores em janeiro, enquanto que as estações dos trechos alto e médio apresentaram valores ligeiramente maiores em outubro. 
As maiores concentrações de nitrogênio total ocorreram em julho, principalmente nos trechos médio e baixo do rio Betari. As concentrações médias de abril apresentaram grandes variações, exceto na estação 14.

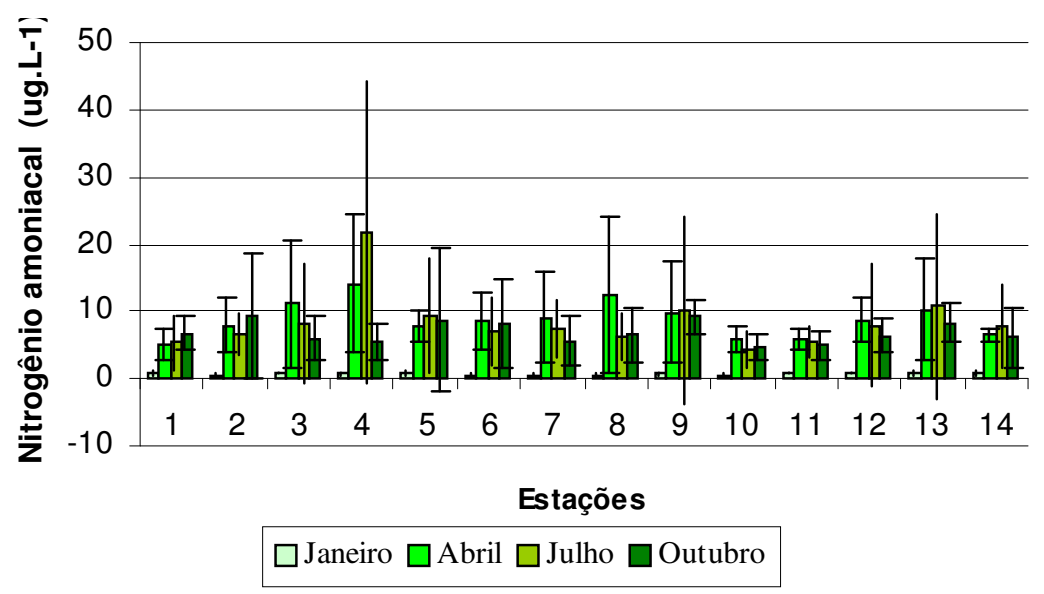

FIGURA 2.3.5.6.1- Valores médios da concentração de nitrogênio amoniacal dos cinco dias de coleta intensiva, nos quatro períodos de estudo no rio Betari.

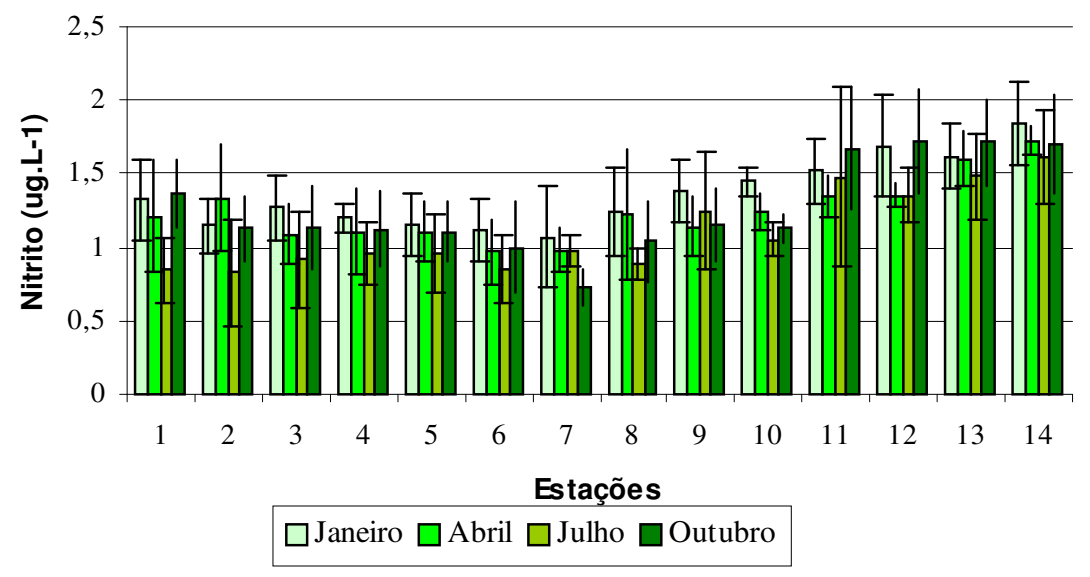


FIGURA 2.3.5.6.2 - Valores médios da concentração de nitrito dos cinco dias de coleta intensiva, nos quatro períodos de estudo no rio Betari.

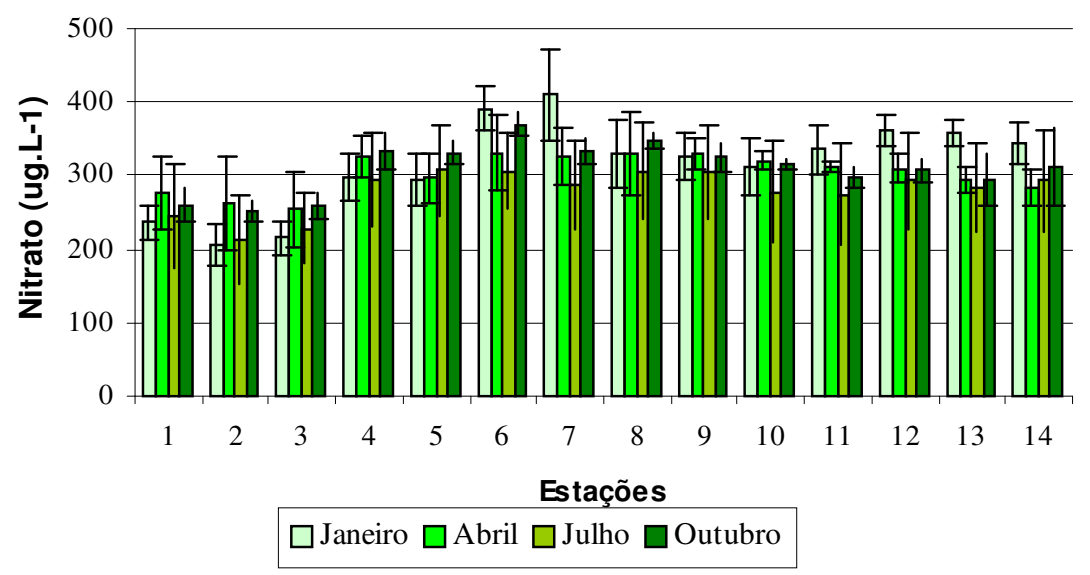

FIGURA 2.3.5.6.3 - Valores médios da concentração de nitrato dos cinco dias de coleta intensiva, nos quatro períodos de estudo no rio Betari.

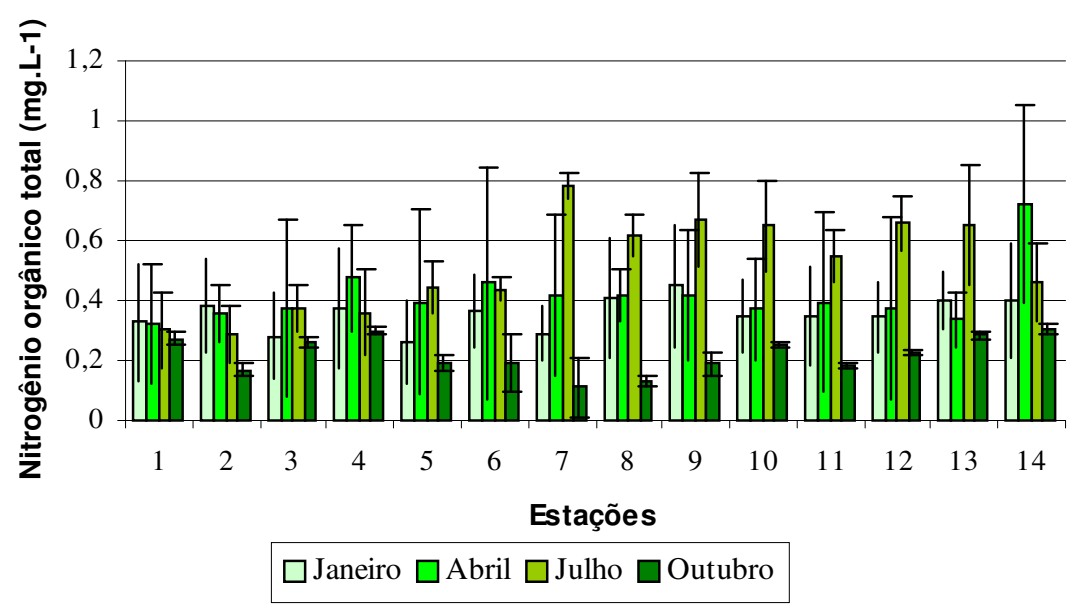

FIGURA 2.3.5.6.4- Valores médios da concentração de nitrogênio orgânico total dos cinco dias de coleta intensiva, nos quatro períodos de estudo no rio Betari.

O fosfato inorgânico apresentou, de forma geral, uma diminuição de montante para jusante, como pode ser observado na figura 2.3.5.6.5. Em praticamente todas as estação, os 
maiores valores ocorreram em outubro e os menores em julho, seguido de janeiro e abril. $\mathrm{O}$ fosfato total dissolvido também apresentou maiores valores em outubro, mas mostrou uma tendência de aumento em abril e julho. Nas estações dos trechos médio e inferior, em janeiro, os valores de fosfato total dissolvido foram maiores que em abril e julho (Figura 2.3.5.6.6).

A figura 2.3.5.6.7 mostra os valores médios das concentrações de fósforo total. A tendência que pode ser verificada é de valores maiores em outubro, seguido de janeiro, julho e abril.

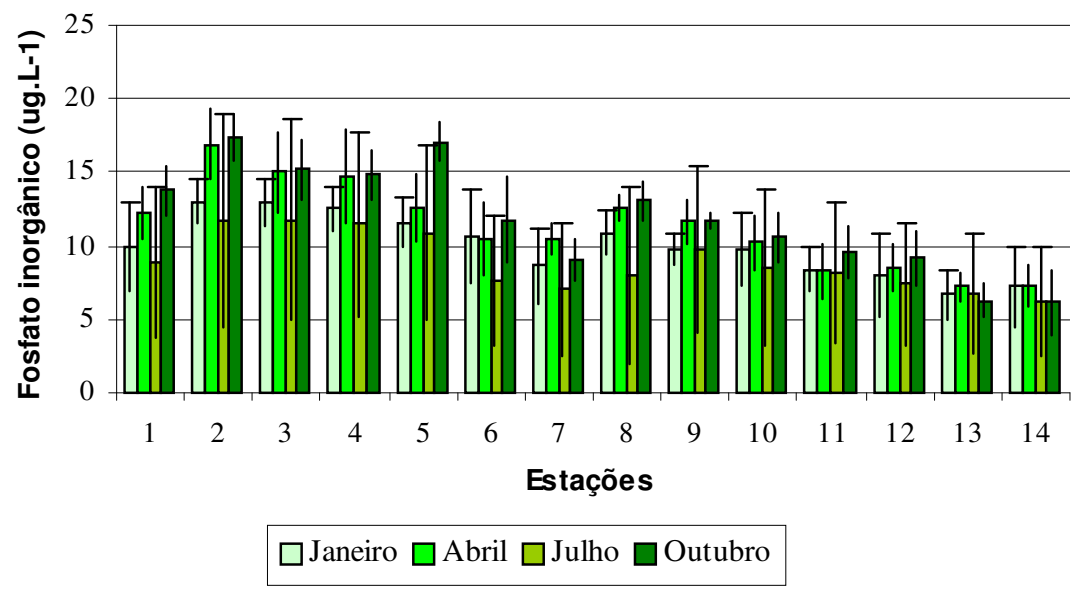

FIGURA 2.3.5.6.5 - Valores médios da concentração de fosfato inorgânico dos cinco dias de coleta intensiva, nos quatro períodos de estudo no rio Betari.

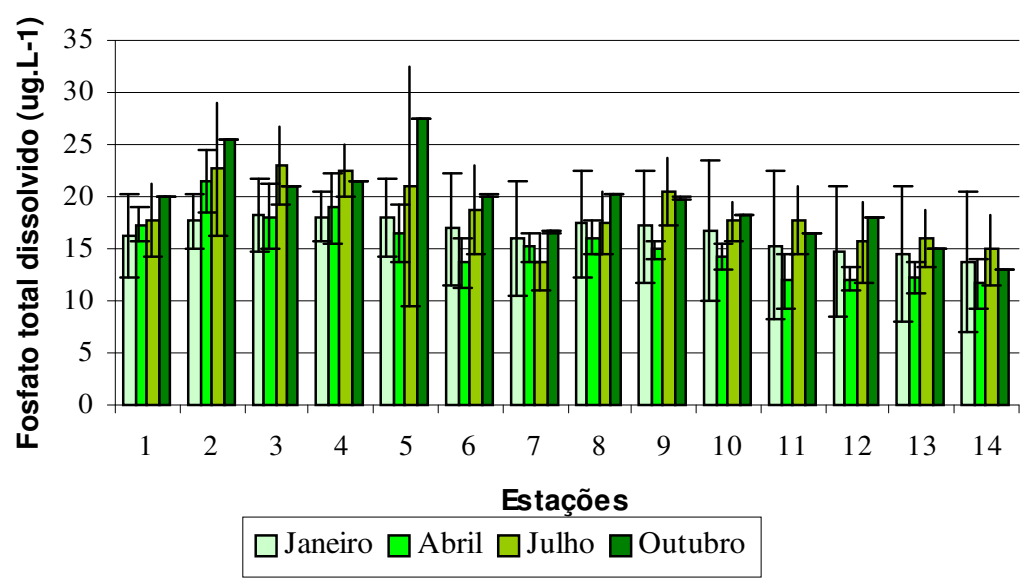


FIGURA 2.3.5.6.6 - Valores médios da concentração de fosfato total dissolvido dos cinco dias de coleta intensiva, nos quatro períodos de estudo no rio Betari.

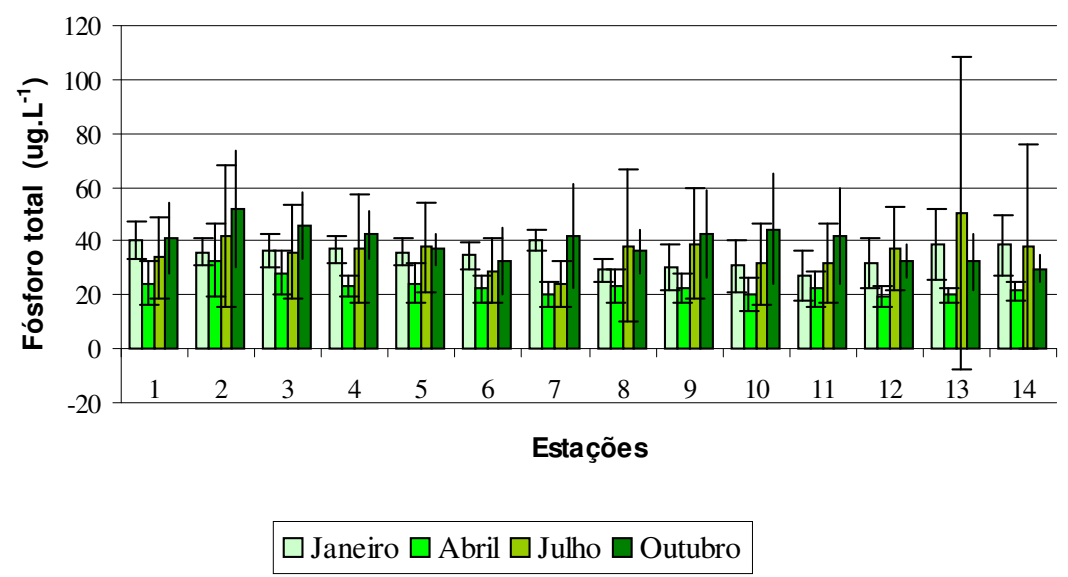

FIGURA 2.3.5.6.7 - Valores médios da concentração de fósforo total dos cinco dias de coleta intensiva, nos quatro períodos de estudo no rio Betari.

Os valores médios das concentrações de silicatos reativos estão apresentadas na figura 2.3.5.6.8. A tendência observada é de aumento com a diminuição das chuvas, assim, os maiores valores ocorreram em julho, e os menores em janeiro. 


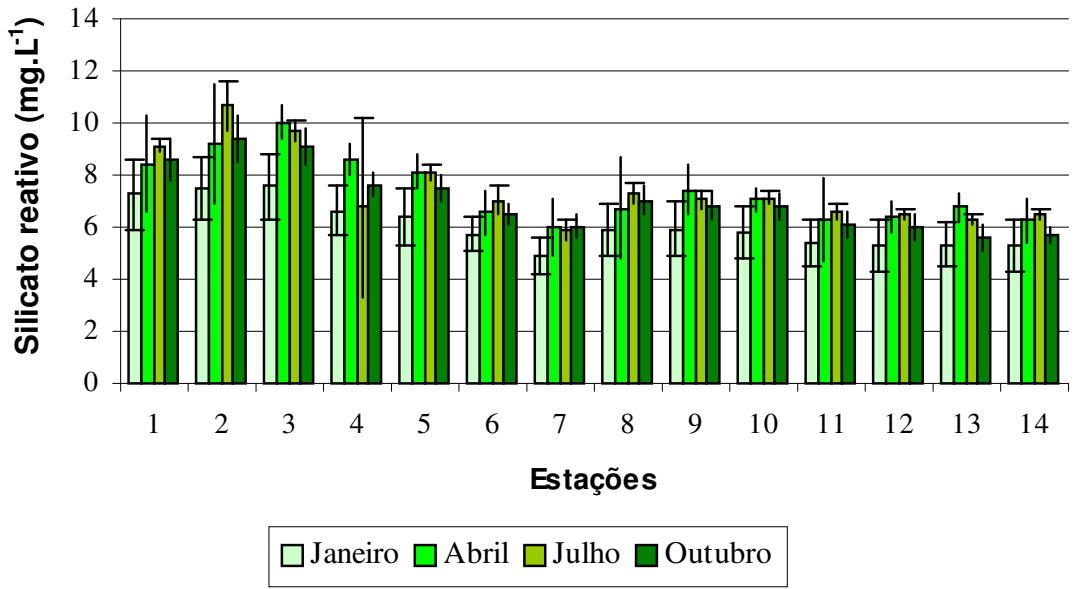

FIGURA 2.3.5.6.8 - Valores médios da concentração de silicato reativo dos cinco dias de coleta intensiva, nos quatro períodos de estudo no rio Betari. 


\subsubsection{VARIÁVEIS QUÍMICAS DO SEDIMENTO}

\subsubsection{Nitrogênio e fósforo do sedimento}

As porcentagens de nitrogênio do sedimento estão apresentadas na tabela 2.3.6.1.1, onde é possível observar que os valores variaram espacial e temporalmente. A maior concentração de nitrogênio no sedimento ocorreu na estação $14(0,683 \mathrm{mg} / \mathrm{g})$, enquanto que a menor ocorreu na estação $3(0,006$ $\mathrm{mg} / \mathrm{g}$ ), ambas em outubro.

TABELA 2.3.6.1.1 - Variação das concentrações de nitrogênio no sedimento $(\mathrm{mg} / \mathrm{g})$ do rio Betari em janeiro, abril, julho e outubro de 2000.

\begin{tabular}{ccccc}
\hline Estações & JAN & ABR & JUL & OUT \\
\hline 1 & 0,014 & 0,300 & 0,008 & 0,193 \\
2 & 0,168 & 0,325 & 0,053 & 0,109 \\
3 & 0,224 & 0,294 & 0,213 & 0,011 \\
4 & 0,213 & 0,148 & 0,199 & 0,056 \\
5 & 0,084 & 0,123 & 0,062 & 0,067 \\
6 & 0,174 & 0,610 & 0,188 & 0,109 \\
7 & 0,179 & 0,216 & 0,154 & 0,305 \\
8 & 0,252 & 0,210 & 0,168 & 0,109 \\
9 & 0,126 & 0,025 & 0,636 & 0,006 \\
10 & 0,266 & 0,193 & 0,104 & 0,221 \\
11 & 0,277 & 0,095 & 0,179 & 0,258 \\
12 & 0,056 & 0,294 & 0,109 & 0,403 \\
13 & 0,190 & 0,199 & 0,062 & 0,389 \\
14 & 0,171 & 0,157 & 0,011 & 0,683 \\
\hline
\end{tabular}

$\mathrm{Na}$ tabela 2.3.6.1.2 estão apresentadas concentrações de fósforo no sedimento. Pode-se observar que variaram de $0,890 \mathrm{mg} / \mathrm{g}$ na estação 13 , em outubro, a valores não detectáveis. Os percentuais do mês de abril tenderam a valores menores, na maioria dos pontos de amostragem. 
TABELA 2.3.6.1.2 - Variação das concentrações de fósforo no sedimento $(\mathrm{mg} / \mathrm{g})$ do rio Betari em janeiro, abril, julho e outubro de 2000.

\begin{tabular}{ccccc}
\hline Estações & JAN & ABR & JUL & OUT \\
\hline 1 & 0,420 & 0,128 & 0,224 & 0,361 \\
2 & 0,526 & 0,254 & 0,539 & 0,590 \\
3 & 0,003 & 0,191 & 0,651 & 0,329 \\
4 & 0,174 & 0,521 & 0,589 & - \\
5 & 0,180 & 0,254 & 0,315 & 0,331 \\
6 & 0,475 & 0,458 & 0,498 & 0,067 \\
7 & 0,352 & 0,334 & 0,326 & 0,318 \\
8 & 0,515 & 0,249 & 0,615 & 0,411 \\
9 & 0,358 & 0,517 & - & 0,782 \\
10 & 0,580 & 0,333 & 0,417 & 0,238 \\
11 & 0,785 & 0,256 & 0,328 & 0,314 \\
12 & 0,237 & 0,194 & 0,551 & 0,890 \\
13 & 0,544 & 0,229 & 0,163 & 0,431 \\
14 & 0,761 & 0,472 & 0,208 & - \\
\hline
\end{tabular}

- ausência de dado

\subsubsection{2. Íons do sedimento}

A maior porcentagem de cálcio $(0,178 \%)$ não foi encontrada no rio Betari, e sim no córrego Furnas (estação 7), em janeiro de 2000. No rio Betari, a estação 8 apresentou a maior porcentagem de cálcio $(0,063 \%)$, em julho de 2000, e a menor (0,004\%) ocorreu na estação 1 (tabela 2.3.6.2.1).

As maiores quantidades de magnésio foram encontradas nas estações do médio curso do rio Betari (máximo 0,021\%, estação 6 - julho). A menor porcentagem de magnésio ocorreu na estação 12 (0,007\% - outubro) - tabela 2.3.6.2.2.

As porcentagens de zinco no sedimento (tabela 2.3.6.2.3) mostraram um aumento a partir da estação 7 (córrego Furnas), que apresentou o maior valor $(0,107 \%$ em outubro).

Quanto às quantidades de chumbo, mais uma vez observou-se maiores concentrações no córrego Furnas $(0,095 \%$ em abril de 2000$)$ e na estação 8 $(0,030 \%$ em julho de 2000$)$, que se localiza a jusante do córrego Furnas. As 
estações a montante desse rio apresentaram porcentagens baixas de chumbo no sedimento. Esse comportamento foi semelhante ao do zinco (tabela 2.3.6.2.4).

TABELA 2.3.6.2.1 - Porcentagens de cálcio no sedimento do rio Betari em janeiro, abril, julho e outubro de 2000.

\begin{tabular}{ccccc}
\hline Ca & JAN & ABR & JUL & OUT \\
\hline 1 & 0,026 & 0,008 & 0,004 & 0,004 \\
2 & 0,020 & 0,011 & 0,009 & 0,008 \\
3 & 0,018 & 0,014 & 0,017 & 0,007 \\
4 & 0,016 & 0,021 & 0,010 & 0,013 \\
5 & 0,014 & 0,009 & 0,005 & 0,004 \\
6 & 0,019 & 0,011 & 0,005 & 0,009 \\
7 & 0,178 & 0,084 & 0,132 & 0,086 \\
8 & 0,058 & 0,041 & 0,063 & 0,062 \\
9 & 0,015 & 0,022 & 0,032 & 0,018 \\
10 & 0,015 & 0,016 & 0,009 & 0,012 \\
11 & 0,020 & 0,013 & 0,014 & 0,012 \\
12 & 0,018 & 0,018 & 0,017 & 0,015 \\
13 & 0,015 & 0,011 & 0,010 & 0,010 \\
14 & 0,017 & 0,016 & 0,015 & 0,019 \\
\hline
\end{tabular}

TABELA 2.3.6.2.2 - Porcentagens de magnésio no sedimento do rio Betari em janeiro, abril, julho e outubro de 2000.

\begin{tabular}{ccccc}
\hline $\mathrm{Mg}$ & JAN & ABR & JUL & OUT \\
\hline 1 & 0,011 & 0,008 & 0,008 & 0,010 \\
2 & 0,012 & 0,013 & 0,012 & 0,012 \\
3 & 0,010 & 0,013 & 0,013 & 0,014 \\
4 & 0,009 & 0,017 & 0,014 & 0,016 \\
5 & 0,009 & 0,013 & 0,013 & 0,013 \\
6 & 0,013 & 0,011 & 0,021 & 0,012 \\
7 & 0,016 & 0,015 & 0,015 & 0,013 \\
8 & 0,015 & 0,015 & 0,013 & 0,013 \\
9 & 0,008 & 0,012 & 0,017 & 0,012 \\
10 & 0,009 & 0,010 & 0,010 & 0,010 \\
11 & 0,012 & 0,009 & 0,009 & 0,012 \\
12 & 0,010 & 0,010 & 0,008 & 0,007 \\
13 & 0,009 & 0,009 & 0,008 & 0,008 \\
14 & 0,007 & 0,009 & 0,016 & 0,007 \\
\hline
\end{tabular}


TABELA 2.3.6.2.3 - Porcentagens de zinco no sedimento do rio Betari em janeiro, abril, julho e outubro de 2000 .

\begin{tabular}{ccccc}
\hline Zn & JAN & ABR & JUL & OUT \\
\hline 1 & 0,001 & $*$ & $*$ & 0,001 \\
2 & $*$ & $*$ & 0,003 & 0,001 \\
3 & $*$ & $*$ & 0,001 & $*$ \\
4 & $*$ & $*$ & $*$ & $*$ \\
5 & $*$ & $*$ & $*$ & $*$ \\
6 & $*$ & $*$ & 0,001 & $*$ \\
7 & 0,060 & 0,083 & 0,100 & 0,107 \\
8 & 0,037 & 0,021 & 0,027 & 0,028 \\
9 & 0,011 & 0,011 & 0,008 & 0,015 \\
10 & 0,005 & 0,030 & 0,008 & 0,011 \\
11 & $*$ & 0,012 & 0,014 & 0,014 \\
12 & 0,011 & 0,012 & 0,009 & 0,007 \\
13 & 0,011 & 0,006 & 0,005 & 0,005 \\
14 & 0,007 & 0,008 & 0,010 & 0,008 \\
\hline
\end{tabular}

* Concentrações inferiores a 0,0005\%

TABELA 2.3.6.2.4 - Porcentagens de chumbo no sedimento no rio Betari nas amostragens de janeiro, abril, julho e outubro de 2000.

\begin{tabular}{ccccc}
\hline $\mathrm{Pb}$ & JAN & ABR & JUL & OUT \\
\hline 1 & $*$ & $*$ & 0,001 & 0,001 \\
2 & $*$ & $*$ & 0,001 & 0,001 \\
3 & $*$ & $*$ & $*$ & $*$ \\
4 & $*$ & $*$ & 0,001 & $*$ \\
5 & 0,001 & $*$ & $*$ & 0,001 \\
6 & $*$ & 0,001 & $*$ & 0,001 \\
7 & 0,033 & 0,095 & 0,075 & 0,038 \\
8 & 0,015 & 0,021 & 0,030 & 0,021 \\
9 & 0,007 & 0,008 & 0,006 & 0,008 \\
10 & 0,010 & 0,023 & 0,008 & 0,010 \\
11 & 0,013 & 0,012 & 0,013 & 0,011 \\
12 & 0,016 & 0,011 & 0,008 & 0,007 \\
13 & 0,015 & 0,012 & 0,012 & 0,012 \\
14 & 0,009 & 0,008 & 0,011 & 0,008 \\
\hline
\end{tabular}

* Concentrações inferiores a 0,0005\%

\subsubsection{VARIÁVEIS BIÓTICAS}




\subsubsection{Colimetria}

As concentrações de coliformes fecais foram maiores nos trechos alto e médio do rio Betari, em janeiro, e em abril no seu baixo curso, como mostra a figura 2.3.7.1. Outra tendência que pode ser observada é a diminuição da concentração de coliformes num mesmo ponto de amostragem, nos meses mais secos.

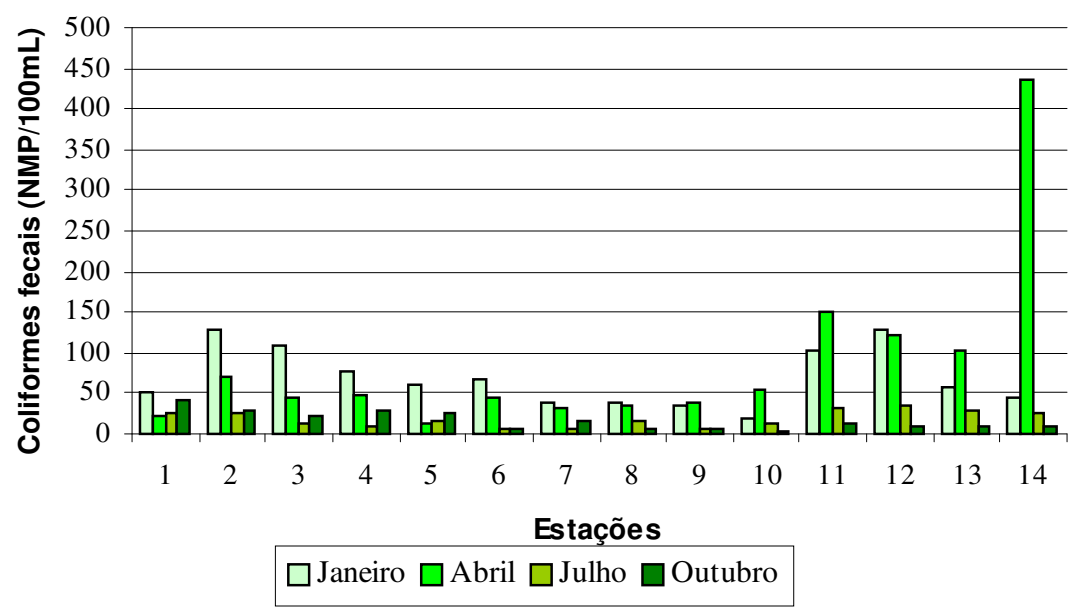

FIGURA 2.3.7.1 - Valores da concentração de coliformes fecais dos cinco dias de coleta intensiva, nos quatro períodos de estudo no rio Betari.

\subsubsection{Comunidade bentônica}

Durante o estudo, foram identificados 53 taxa, conforme tabela 2.3.7.2.1. $\mathrm{Na}$ ordem Coleoptera ocorreram 11 famílias, seguida de Diptera com 10 e Trichoptera com 9 famílias, Ephemeroptera com 6, Odonata com 5 e as demais contribuíram com 1 ou 2 taxa cada. 


\subsection{Organização Temporal da Comunidade Bentônica}

Considerando o número total de espécimes coletados, o maior valor foi encontrado em julho (2962 organismos), seguido das coletas realizadas em outubro (2169 organismos), abril (1735 organismos) e janeiro (565 organismos), que apresentou a menor densidade.

As densidades totais de organismos (número absoluto de organismos coletados) nos pontos de coleta, por unidade taxonômica, estão apresentadas nas tabelas 2.3.7.2.2, 2.3.7.2.3, 2.3.7.2.4 e 2.3.7.2.5, correspondendo às coletas de janeiro (verão), abril (outono), julho (inverno) e outubro (primavera), respectivamente. Nas tabelas 2.3.7.2.6, 2.3.7.2.7, 2.3.7.2.8 e 2.3.7.2.9, são apresentadas as abundâncias relativas, também para os quatro períodos de coleta.

No verão, Coleoptera foi o grupo mais abundante, principalmente, devido à presença de Psephenidae (19,8\%), seguido de Diptera (família Chironomidae contribuiu com 17\%) e

Trichoptera (16,6\%); depois Ephemeroptera e Plecoptera $(11,8 \%$ e 9,5\%, respectivamente, como mostra a tabela 2.3.7.2.6). Ainda nesse período, Elmidae (Coleoptera), Leptophlebidae (Ephemeroptera), Perlidae (Plecoptera), Hydropsychidae (Trichoptera) e Gastropoda foram contribuintes numericamente importantes.

A ordem Trichoptera foi a mais abundante no outono, devido ao grande número de organismos pertencentes às famílias Hydropsychidae, Xiphocentronidae e Odontoceridae encontrados. Diptera, principalmente em função do número de Chironomidae, que apresentou uma abundância relativa de 10,3\%, Coleoptera, graças às famílias Psephenidade e Elmidae, com 4,3\% e 3,4\%, respectivamente, e Ephemeroptera, com a família Ephemerellidae (6,8\%), também se destacaram entre os insetos aquáticos. Nesse período, foi registrada elevada abundância de Gastropoda, com 17,2\% (tabela 2.3.7.2.7).

Gastropoda voltou a se destacar no inverno, com 7,6\% e Trichoptera apresentou a maior abundância (15,8\%), com Hydropsychidae (12,3\%) e Xiphocentronidae (21\%), como mostra a tabela 2.3.7.2.8. Nesta época, Ephemeroptera apareceu em segundo lugar, 
principalmente com as contribuições de Leptohyphidae $(7,8 \%)$ e Ephemerellidae $(6,4 \%)$, seguidas de Diptera (Chironomidae, com 11,9\%) e Coleoptera, novamente com Psephenidae e Elmidae.

A tabela 2.3.7.2.9 apresenta as abundâncias relativas observadas na primavera. Diptera predominou, graças à família Chironomidae $(22,6 \%)$, seguida de Trichoptera, grupo no qual Xiphocentronidae foi importante, contribuindo com 15,5\% dos organismos, Ephemeroptera com Ephemerellidae (6\%) e Leptohyphidae (3\%), e Coleoptera. Gastropoda também ocorreu em grande número.

Quanto à ocorrência, as famílias Elmidae e Psephenidae (Coleoptera), e Chironomidae, foram consideradas freqüentes em todos os períodos de estudo. Limnichidae (Coleoptera), Ephemerellidae (Ephemeroptera), Perlidae (Plecoptera) e Hydropsichidae (Trichoptera) foram freqüentes no outono, inverno e primavera. Pyralidae (Lepidoptera), Odontoceridae (Trichoptera), Aegla sp e Gastropoda foram considerados comuns durante todo estudo, como pode ser observado na tabela 2.3.7.2.14. 
TABELA 2.3.7.2.1 - Taxa identificados no estudo do rio Betari

\begin{tabular}{|c|c|c|c|c|}
\hline FILO & CLASSE & ORDEM & FAMÍLIA & GÊNERO \\
\hline \multirow[t]{51}{*}{ ARTHROPODA } & INSECTA & COLEOPTERA & Curculionidae & \\
\hline & & & Crysomelidae & \\
\hline & & & Dytiscidae & \\
\hline & & & Elmidae & \\
\hline & & & Haliplidae & \\
\hline & & & Scirtidae & \\
\hline & & & Hydrophilidae & \\
\hline & & & Limnichidae & \\
\hline & & & Noteridae & \\
\hline & & & Psephenidae & \\
\hline & & & Ptilodactylidae & \\
\hline & & DIPTERA & Tipulidae & \\
\hline & & & Blephariceridae & \\
\hline & & & Ceropotamidae & \\
\hline & & & Chironomidae & \\
\hline & & & Culicidae & \\
\hline & & & Ephydridae & \\
\hline & & & Tabanidae & \\
\hline & & & Simuliidae & \\
\hline & & & Sciomyzidae & \\
\hline & & & Stratiomyidae & \\
\hline & & EPHEMEROPTERA & Caenidae & \\
\hline & & & Ephemerellidae & \\
\hline & & & Leptophlebiidae & \\
\hline & & & Leptohyphidae & \\
\hline & & & Oniscigastridae & \\
\hline & & & Tricorythidae & \\
\hline & & HEMIPTERA & Belostomatidae & \\
\hline & & & Naucoridae & \\
\hline & & LEPIDOPTERA & Pyralidae & \\
\hline & & MEGALOPTERA & Corydalidae & \\
\hline & & ODONATA & & \\
\hline & & & Calopterygidae & \\
\hline & & & Lestidae & \\
\hline & & & Libelluloidae & \\
\hline & & & Megapodagrionidae & \\
\hline & & ORTHOPTERA & & \\
\hline & & PLECOPTERA & Grypopterygidae & \\
\hline & & & Perlidae & \\
\hline & & TRICHOPTERA & & \\
\hline & & & Helycopsychidae & \\
\hline & & & Hydropsychidae & \\
\hline & & & Hydroptilidae & \\
\hline & & & Leptoceridae & \\
\hline & & & Odontoceridae & \\
\hline & & & Philopotamidae & \\
\hline & & & Polycentropodidae & \\
\hline & & & Rhyacophilidae & \\
\hline & & & Xiphocentronidae & \\
\hline & CRUSTACEA & DECAPODA & & Aegla sp \\
\hline & & AMPHIPODA & & \\
\hline ANNELIDA & OLIGOCHAETA & & Tubificidae & \\
\hline MOLLUSCA & GASTROPODA & & & \\
\hline
\end{tabular}




\subsection{Organização Espacial da Comunidade Bentônica}

\section{Verão}

A maior densidade durante a coleta de verão (tabela 2.3.7.2.2) ocorreu no ponto 14 (115 organismos), onde Riacophilidae (Trichoptera) e Gastropoda foram considerados abundantes (tabela 2.3.7.2.10), correspondendo a 45,9\% e $36 \%$ dos organismos coletados, com densidades de 53 e 42 organismos, respectivamente. Deve-se observar que Gastropoda só ocorreu nos pontos $13 \mathrm{e}$ 14. Em seguida veio o ponto 1, com 107 organismos, sendo que Chironomidae foi abundante e dominante, com 82 organismos e $77,6 \%$ de abundância relativa. No ponto 9, a densidade foi de 85 organismos, onde Leptophebiidae (Ephemeroptera) apresentou o valor de 25 organismos. Já os pontos 2, 10, $11 \mathrm{e}$ 12 apresentaram densidades muito baixas. No ponto 11 só foram encontrados dois taxa: Hydrophilidae (4 organismos) e Caenidade (2 organismos).

Plecoptera e Crustacea (Aegla sp) ocorreram principalmente nos pontos de amostragem localizados a montante do bairro da Serra (tabela 2.3.7.2.2).

O taxa Coleoptera foi considerado abundante do ponto 2 ao ponto 12, só não dominando nos pontos 2, 7 e 9. Psephenidae foi o principal contribuinte para dominância deste grupo. Hidrophilidae foi dominante no ponto 11 . Trichoptera foi dominante nos pontos 13 e 14, com Hydropsichidae e Rhyacophilidae. No ponto 1 , Chironomidae foi considerado dominante e Perlidae (Plecoptera), no ponto 2.

Elmidae (Coleoptera) foi um taxon freqüente, ocorrendo em metade dos pontos de coleta, principalmente nos localizados a montante do bairro da Serra. Psephenidae só não ocorreu nos pontos 2, 7 e 11, sendo também considerado freqüente, da mesma forma que Chironomidae e Leptophebiidae, como mostra a tabela 2.3.7.2.14. 


\section{Outono}

No outono, as maiores densidades de organismos ocorreram nos pontos 14, 9 e 11, com 453 organismos, 438 organismos e 209 organimos, respectivamente. Neste período, os pontos 8 e 12 apresentaram valores superiores aos de janeiro, ambos com 138 organismos coletados, , como pode ser observado na tabela 2.3.7.2.3.

No ponto 14, 63,2\% dos organismos corresponderam a Gastropoda, com 287 organismos (tabela 2.3.7.2.7), sendo, portanto, o grupo dominante, seguido de Trichoptera, com 90 organismos. No ponto 9, Trichoptera dominou com 268 organismos, graças à presença de Hydropsychidae, Xiphocentronidae e Odontoceridae, todos abundantes, como pode ser observado na tabela 2.3.7.2.11. No ponto 11, Trichoptera também dominou com 143 orgnismos, devido aos mesmos grupos, mas na seguinte ordem: Odontoceridae, Xiphocentronidae e Hydropsychidae.

Os pontos 8, 10 e 12 também apresentaram densidades elevadas. Já o ponto 5, apresentou o menor valor desse período, com 15 organismos.

Ainda no período em questão, foram freqüentes e abundantes em várias estações Elmidae (pontos 4, 5 e 6), Psephenidae (dos pontos 2 a 6 e ponto 8), Chironomidae (3, 7, 9, 10 e 13), Ephemerellidae (pontos 2, 3, 5, 8 e 11), Perlidae (pontos 2, 3, 4, 6, de 8 11), Hydropsychidae (dos pontos 8 a 14) e Xiphocentronidae (pontos 4, 5, 9, 11, 12 e 14). Hydropsychidae e Hydroptilidae só ocorreram nos pontos localizados a jusante do ponto 7. Perlidae e Ephemerellidae ocorreram em 12 dos 14 pontos de amostragem, enquanto que Psephenidae e Chironomidae ocorreram em 10.

\section{Inverno}

Novamente, no inverno, o ponto 14 apresentou maior densidade de organismos, 632 organismos, sendo esta a maior de todo o estudo. Gastropoda foi o principal contribuinte para o valor encontrado, com 222 organismos, grupo dominante junto de Xiphocentronidae e de Elmidae, com 150 e 90 organismos, respectivamente. No ponto 11, Trichoptera foi mais abundante com 296 
organismos, devido à grande densidade de Hydripsychidae (209 organismos), grupo dominante deste ponto, junto de Xiphocentronidae e Leptohyphidae. No ponto 12, Trichoptera e Ephemeroptera também ocorreram em grande densidade, mas Chironomidae se destacou, com 85 organismos, sendo também considerado um grupo abundante. No ponto 10, Chironomidae foi o mais abundante, com 39\%, seguido de Xiphocentronidae, com 18,4\%. Deve-se observar que no ponto 13 Xiphocentronidae foi o único dominante, com $63,1 \%$ de abundância relativa (tabela 2.3.7.2.12). Xiphocentronidae, Hydropsychidade, Perlidae e Chironomidae foram considerados dominantes no ponto 9, que apresentou uma densidade total de 291 organismos.

Neste período, Psephenidae, Limnichidae, Ephemerellidae e Leptohiphidae ocorreram em 12 pontos de coleta, já Elmidae, Chironomidae e Perlidae em 11 pontos, e Hydrosychidae em 10. Todos esses grupos foram considerados freqüentes. Outros grupos com ocorrência menor também foram considerados freqüentes, como Noteridade e Leptophlebiidae.

\section{Primavera}

Na primavera, o ponto 14 apresentou a maior densidade de organismos, 341 organismos, devido à grande densidade de Gastropoda, com uma abundância relativa de $80,2 \%$ (tabela 2.3.7.2.9). O ponto 12 apresentou a segunda maior densidade, 324 organismos, onde Trichoptera foi mais abundante, com 43,8\%, graças à grande densidade de Xiphocentronidae (215 organismos). No ponto 9, Diptera e Trichoptera foram os mais abundantes, com Chironomidae apresentando 149 organismos. Chironomidae também apresentou elevada abundância relativa no ponto 10 (63,9\%). Este grupo ocorreu em todos os pontos de coleta, sendo considerado dominante nos pontos 1, 3, 5, 7 8, 9 e 10, e foi abundante nos pontos 6 e 12 (tabela 2.3.7.2.13).

Psephenidae também foi um grupo freqüente, ocorrendo em 11 pontos, e foi considerado dominante nos pontos 4, 5 e 8, e abundante nos pontos 1, 3 e 6 . Ephemrellidae 
apresentou resultados semelhantes, sendo também um grupo freqüente, ocorrendo em 12 pontos de amostragem. Este dominou nos pontos 1, 3, 6 e 11 e foi considerado abundante nos pontos 4,5 e 13 .

$\mathrm{Na}$ ordem Plecoptera, Perlidae também foi freqüente e considerado abundante nos pontos 2, 3, 5, 6, 9 e 10. Entre Trichoptera, Hydropsychidae foi considerado abundante nos pontos 7, 9, 10 e 13, e dominante no ponto 11. Já Xiphocentronidae foi freqüente, ocorrendo em 10 pontos de amostragem, sendo considerado abundante nos pontos 2,6 , e do ponto 8 ao 14. Foi dominante nos pontos 8, 12 e 13. Gastropoda, mais uma vez, foi considerado dominante no ponto 14 .

\subsection{Riqueza de Taxa}

No verão, a riqueza variou de 2 (pontos 4 e 11) até 11 (ponto 9), como pode ser observado na tabela 2.3.7.2.15. No outono, o ponto 9 apresentou 0 maior número de unidades taxonômicas deste estudo (24 unidades), seguido do ponto 10 (17 unidades), do ponto 14 (16 unidades) e dos pontos 8, 11 e 13 (15 unidades taxonômicas). No inverno, foram observados valores entre 6 e 19 unidade taxonômicas, sendo que os pontos a jusante do bairro da Serra mostraram maiores valores. Na primavera, ocorreram valores extremos: no ponto 7 foi encontrado o menor valor (5 unidades taxonômicas), enquanto que 0 maior ocorreu no ponto 2 (20 unidades).

Existiu uma tendência de aumento das riquezas nos pontos localizados a jusante do bairro da Serra, exceto na primavera quando maiores riquezas foram observadas no trecho superior do rio Betari 
TABELA 2.3.7.2.2 - DENSIDADE DE ORGANISMOS POR UNIDADE TAXONÔMICA E TOTAL DA COLETA

DE VERÃO (JAN/00)

\begin{tabular}{|c|c|c|c|c|c|c|c|c|c|c|c|c|c|c|c|c|}
\hline & & 1 & 2 & 3 & 4 & 5 & 6 & 7 & 8 & 9 & 10 & 11 & 12 & 13 & 14 & Total \\
\hline \multirow[t]{8}{*}{ COLEOPTERA } & Crysomelidae & & & & & & & & & 2 & & & & & & 2 \\
\hline & Curculionidae & & & & & & & & & & & & 2 & & & 2 \\
\hline & Dytiscidae & & & & & & & & & & & & & 1 & & 1 \\
\hline & Elmidae & & 3 & 8 & 2 & 5 & 10 & 7 & & & & & & & 7 & 42 \\
\hline & Scirtidae & & & & & & & & & & & & 1 & & & 1 \\
\hline & Hydrophilidae & & & & & & & & & & & 4 & & & & 4 \\
\hline & Limnichidae & & 1 & & & & & & 6 & 6 & 4 & & & & & 17 \\
\hline & $\begin{array}{c}\text { Psephenidae } \\
\text { Noteridae }\end{array}$ & 5 & & 3 & 16 & 17 & 30 & & 19 & $\begin{array}{c}12 \\
2\end{array}$ & 7 & & 4 & 2 & 1 & $\begin{array}{r}116 \\
2\end{array}$ \\
\hline DIPTERA & Chironomidae & 82 & & 3 & & 1 & & 2 & & & & & 3 & 1 & 2 & 94 \\
\hline \multirow[t]{4}{*}{ EPHEMEROPTERA } & Caenidae & 1 & & & & & & & & & & 2 & & & & 3 \\
\hline & Ephemerellidae & & & & & & & & & & & & 2 & & 2 & 4 \\
\hline & Leptophlebidae & 6 & 1 & & & 1 & 13 & & 2 & 26 & 1 & & & & & 50 \\
\hline & Tricorythidae & & & & & & & & 8 & & & & & & & 8 \\
\hline HETEROPTERA & Naucoridae & & & & & & & & & & & & & & 1 & 1 \\
\hline LEPIDOPTERA & Pyralidae & & & & & & 2 & & & 2 & & & & & & 4 \\
\hline MEGALOPTERA & Corydalidae & & & & & & & & 1 & & & & & & & 1 \\
\hline ODONATA & Libelluloidae & & & & & & & & & & & & 1 & & & 1 \\
\hline ORTHOPTERA & & & 1 & & & 1 & & & & & & & & & & 2 \\
\hline \multirow[t]{2}{*}{ PLECOPTERA } & Grypopterygidae & 5 & & & & 1 & & 3 & 5 & 4 & 1 & & & & & 19 \\
\hline & Perlidae & & 10 & 2 & & & 6 & 6 & & 13 & & & & & & 37 \\
\hline \multirow[t]{5}{*}{ TRICHOPTERA } & Hydropsychidae & & & & & & & 2 & & 13 & & & & 13 & 6 & 34 \\
\hline & Odontoceridae & 1 & & & & & & 1 & & & & & & & & 2 \\
\hline & Polycentropodidae & & & & & & & & & & & & & 1 & & 1 \\
\hline & Rhyacophilidae & & & & & & & & & & & & & & 53 & 53 \\
\hline & Xiphocentronidae & & & & & & & & 4 & & & & & & & 4 \\
\hline \multirow[t]{2}{*}{ CRUSTACEA } & Aegla sp & 6 & & & & 2 & 2 & & 1 & 2 & & & & & & 13 \\
\hline & Amphipoda & 1 & & & & & & & & & & & & & & 1 \\
\hline MOLLUSCA & Gastropoda & & & & & & & & & & & & & 1 & 42 & 43 \\
\hline OLIGOCHAETA & & & & & & 1 & & & & 4 & & & & & 1 & 6 \\
\hline DENSIDADE TOTAL & & 107 & 16 & 16 & 18 & 29 & 63 & 21 & 46 & 86 & 13 & 6 & 13 & 19 & 115 & 568 \\
\hline
\end{tabular}


TABELA 2.3.7.2.3 - DENSIDADE DE ORGANISMOS POR UNIDADE TAXONÖMICA E TOTAL DA COLETA DE OUTONO

\begin{tabular}{|c|c|c|c|c|c|c|c|c|c|c|c|c|c|c|c|c|}
\hline \multicolumn{17}{|c|}{$\mathrm{BR} / 00)$} \\
\hline & & 1 & 2 & 3 & 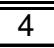 & $\overline{5}$ & 6 & 7 & 8 & 9 & 10 & 11 & 12 & 13 & 14 & Total \\
\hline \multirow[t]{7}{*}{ COLEOPTERA } & Curculionidae & & & & & & & & & 1 & & & & & & 1 \\
\hline & Dytiscidae & & & & & & & & & 4 & 1 & 1 & & & & 6 \\
\hline & Elmidae & & 1 & 2 & 6 & 2 & & 9 & 3 & 5 & & 1 & & 2 & 25 & 56 \\
\hline & Hydrophilidae & & 1 & & & & & & & & & & & & & 1 \\
\hline & Limnichidae & 3 & 1 & & & & 1 & & 9 & 12 & 2 & 1 & 3 & & & 32 \\
\hline & Psephenidae & & 4 & 9 & 8 & 2 & 4 & 1 & 29 & 9 & 4 & & & & 1 & 71 \\
\hline & Noteridae & & & 2 & & & & & 3 & 2 & & & & & 2 & 9 \\
\hline \multirow[t]{7}{*}{ DIPTERA } & Chironomidae & & & 4 & & 1 & & 7 & 5 & 81 & 43 & 13 & 6 & 7 & 5 & 172 \\
\hline & Ephydridae & 2 & & 1 & 6 & & & & & & & & & & & 9 \\
\hline & Pupa Brachycera & 2 & & & & & & & 1 & 5 & 4 & 1 & & 5 & & 18 \\
\hline & Pupa Nematocera & & & & & & & & & 1 & & & & & & 1 \\
\hline & Tabanidae & & & & & 1 & & & & & & & & & & 1 \\
\hline & Blephariceridae & & & & & 1 & & & & & & & 17 & & & 18 \\
\hline & Stratiomyidae & & & & 6 & & & & & & & & & & & 6 \\
\hline \multirow[t]{5}{*}{ 三PHEMEROPTER, } & Caenidae & & & & & & & & & 2 & & & & 6 & 7 & 15 \\
\hline & Ephemerellidae & 4 & 5 & 6 & 3 & 4 & & 1 & 16 & 9 & 2 & 37 & 3 & & 25 & 115 \\
\hline & Leptophlebidae & & & & & & & & 5 & 3 & 5 & & 6 & 3 & 2 & 24 \\
\hline & Leptohyphiidae & & & & & & 4 & & & 1 & & 1 & & & & 6 \\
\hline & Tricorythidae & & & & & & 3 & & 1 & & & & & & & 4 \\
\hline HETEROPTERA & Naucoridae & & & & & & & & & & & & & & 3 & 3 \\
\hline LEPIDOPTERA & Pyralidae & & & & & & & 2 & & 2 & 4 & & & 3 & 3 & 14 \\
\hline MEGALOPTERA & Corydalidae & & & & & & & & & & & 2 & & 1 & & 3 \\
\hline \multirow[t]{2}{*}{ ODONATA } & Calopterygidae & & & & & & & & & & 1 & 1 & & & & 2 \\
\hline & Megapodagrionidae & & & & & & & & & 1 & & & & 2 & & 3 \\
\hline ORTHOPTERA & & & 3 & & & & & & & 1 & & & & & & 4 \\
\hline \multirow[t]{2}{*}{ PLECOPTERA } & Grypopterygidae & 16 & & 2 & & & 5 & & 17 & & 2 & & & & & 42 \\
\hline & Perlidae & & 6 & 4 & 6 & 1 & 11 & & 17 & 31 & 15 & 5 & 6 & 1 & 3 & 106 \\
\hline \multirow[t]{8}{*}{ TRICHOPTERA } & Hydropsychidae & & & & & & & & 16 & 57 & 20 & 23 & 41 & 6 & 37 & 200 \\
\hline & Odontoceridae & & & & & & 1 & & & 55 & 15 & 68 & 21 & 2 & & 162 \\
\hline & Philopotamidae & & & 1 & & & & & 14 & 1 & & & 1 & & & 17 \\
\hline & Helycopsychidae & & & & & & & & & 3 & & & & & & 3 \\
\hline & Leptoceridae & 1 & & & & & & & & & & & & & & 1 \\
\hline & Hydroptilidae & & & & & & & & 2 & 96 & 3 & & & & 1 & 102 \\
\hline & Xiphocentronidae & & & & 6 & 2 & & 2 & & 56 & & 52 & 26 & & 49 & 193 \\
\hline & Pupa & & & & & & & & & & & & & 1 & 3 & 4 \\
\hline CRUSTACEA & Aegla sp & & & 3 & & & & & & & 1 & & & & & 4 \\
\hline MOLLUSCA & Gastropoda & & & & & & & & & & & & & 5 & 287 & 292 \\
\hline OLIGOCHAETA & Tuficidae & & & & & 1 & & & & & 1 & 3 & 8 & 2 & & 15 \\
\hline IENSIDADE TOTAL & & 28 & 21 & 34 & 41 & 15 & 29 & 22 & 138 & 438 & 123 & 209 & 138 & 46 & 453 & 1735 \\
\hline
\end{tabular}




\begin{tabular}{|c|c|c|c|c|c|c|c|c|c|c|c|c|c|c|c|c|}
\hline & & 1 & 2 & 3 & 4 & 5 & 6 & 7 & 8 & 9 & 10 & 11 & 12 & 13 & 14 & Total \\
\hline \multirow[t]{7}{*}{ COLEOPTERA } & Dytiscidae & & & & & & & & 1 & 1 & & & & 1 & & 3 \\
\hline & Elmidae & 1 & 1 & & 8 & 3 & & & 5 & 4 & 3 & 3 & 14 & 12 & 90 & 144 \\
\hline & Noteridae & & 1 & & & 4 & 14 & 2 & 1 & 5 & & 6 & & & 4 & 37 \\
\hline & Haliplidae & & & & & & & & & 2 & 2 & & & & 8 & 12 \\
\hline & Hydrophilidae & & & & & & & & & & & & & & 1 & 1 \\
\hline & Limnichidae & 4 & & 5 & 5 & 1 & 3 & 2 & 2 & 4 & 2 & 14 & 1 & 1 & & 44 \\
\hline & Psephenidae & 41 & 2 & 25 & 13 & 24 & 12 & 4 & 15 & 3 & 16 & & 1 & 1 & & 157 \\
\hline \multirow[t]{9}{*}{ DIPTERA } & Tipulidae & & & 1 & & & & & & & & & & & & 1 \\
\hline & Blephariceridae & & & & 1 & & & & & & & & & & & 1 \\
\hline & Chironimidae & & & & 2 & 3 & 3 & 62 & 8 & 36 & 139 & 6 & 85 & 4 & 8 & 356 \\
\hline & Culicidae & & & & & & & & & & 22 & 2 & 12 & & & 36 \\
\hline & Pupa Brachicera & & & 1 & & & & 6 & & & 7 & 7 & & 1 & 3 & 25 \\
\hline & Pupa Nematocera & & & & & 1 & & & & & 2 & & 8 & 2 & & 13 \\
\hline & Sciomyzidae & & & & & & & 1 & & & & & & & & 1 \\
\hline & Stratiomyidae & & & 2 & & & & & & & & & & & 1 & 3 \\
\hline & Tabadinae & & & & & & & & & 1 & & & & & & 1 \\
\hline \multirow[t]{5}{*}{ :PHEMEROPTERA } & & & 2 & & & & & & & & & & & & & 2 \\
\hline & Ephemerellidae & 1 & & 5 & 4 & 7 & 8 & & 8 & 17 & 20 & 30 & 58 & 12 & 19 & 189 \\
\hline & Leptophlebidae & & & & & & 8 & 19 & 13 & 18 & 3 & 15 & 19 & 1 & 21 & 117 \\
\hline & Leptohyphidae & 1 & & 1 & 5 & 7 & 7 & 1 & 14 & & 18 & 67 & 69 & 17 & 27 & 234 \\
\hline & Tricorythidae & & & & & & 3 & & & & & 53 & 6 & & & 62 \\
\hline HETEROPTERA & Belostomatidae & & & & & & & 2 & & & & & & & & 2 \\
\hline \multirow[t]{2}{*}{ LEPIDOPTERA } & pupa & 1 & & & & & & & & & & & & & & 1 \\
\hline & Pyralidade & & & & 1 & & & & & 6 & 27 & & 9 & 5 & 7 & 55 \\
\hline MEGALOPTERA & Corydalidae & & & & 1 & & & & & 1 & & & 1 & & & 3 \\
\hline \multirow[t]{3}{*}{ ODONATA } & & & & 5 & 1 & 6 & & & 2 & & 2 & & & & 2 & 18 \\
\hline & Megapodagrionidae & & & & & & 3 & & & & & & & & & 3 \\
\hline & Lestidae & & & & & & & & & & & & & 1 & & 1 \\
\hline ORTHOPTERA & & & & & 1 & 1 & & & & & & & & & & 2 \\
\hline \multirow[t]{2}{*}{ PLECOPTERA } & Grypopterigidae & 8 & & 6 & 6 & 8 & 4 & & 16 & & & & & & & 48 \\
\hline & Perlidae & & 2 & 3 & 4 & 8 & 12 & & 7 & 40 & 6 & 6 & 3 & & 2 & 93 \\
\hline \multirow{10}{*}{ TRICHOPTERA } & & & 3 & & & & & & & & & & & & & 3 \\
\hline & Adulto & & & & & & & & & & 1 & 4 & & & & 5 \\
\hline & Helycopsychidae & & & & & 3 & & & & & 2 & 3 & & & & 8 \\
\hline & Hydropsychidae & 1 & & & & & 2 & 22 & 5 & 50 & 17 & 209 & 22 & 3 & 37 & 368 \\
\hline & Hydroptilidae & & & & & 1 & & & 2 & & & & & & & 3 \\
\hline & Leptoceridae & & & & & & & & 2 & & & & & & & 2 \\
\hline & Odontoceridae & & & & & & & & & & & 2 & 3 & 1 & 25 & 31 \\
\hline & Philopotamidade & & & & 2 & & 3 & & 1 & 2 & & & 6 & & 2 & 16 \\
\hline & Pupa & & & & & & & & & & & & 2 & & & 2 \\
\hline & Xiphocentronidae & & & & & & & & & 100 & 66 & 78 & 124 & 111 & 150 & 629 \\
\hline CRUSTACEA & Aegla sp & 1 & & 4 & 3 & 1 & & & & 1 & 1 & & & & & 11 \\
\hline MOLLUSCA & Gastropoda & & & & & & 1 & & & & & & & & 222 & 223 \\
\hline OLIGOCHAETA & Tubuficidae & & & & & & & & & & & & & & 3 & 3 \\
\hline DENSID & ADE TOTAL & 59 & 11 & 58 & 57 & 78 & 83 & 121 & 102 & 291 & 356 & 505 & 443 & 173 & 632 & 2969 \\
\hline
\end{tabular}


TABELA 2.3.7.2.5 - DENSIDADE DE ORGANISMOS POR UNIDADE TAXONÔMICA E TOTAL DA COLETA DE PRIMAVERA (OUT

\begin{tabular}{|c|c|c|c|c|c|c|c|c|c|c|c|c|c|c|c|c|}
\hline & & 1 & 2 & 3 & 4 & 5 & 6 & 7 & 8 & 9 & 10 & 11 & 12 & 13 & 14 & Total \\
\hline \multirow[t]{8}{*}{ COLEOPTERA } & Curculionidae & & & & & & & & & & & & 1 & & & 1 \\
\hline & Dytiscidade & & 2 & 1 & & & & & & & & & & & & 3 \\
\hline & Elmidae & 6 & 1 & 8 & & 2 & & & 5 & 4 & & & 5 & 8 & 21 & 60 \\
\hline & Noteridae & & 2 & & & 2 & 5 & & & 7 & & 3 & & 2 & 7 & 28 \\
\hline & Haliplidae & & & & & & & & & & & & 1 & & 1 & 2 \\
\hline & Limnichidae & 2 & 1 & & & 1 & 5 & 13 & & 6 & 2 & 5 & 1 & & & 36 \\
\hline & Psephenidae & 6 & & 12 & 9 & 16 & 14 & & 14 & 5 & 1 & 1 & 2 & 1 & & 81 \\
\hline & Ptilodactylidae & & & & & 4 & & & & & & & & & & 4 \\
\hline \multirow[t]{8}{*}{ DIPTERA } & Cerapotamidae & 1 & & & & & & & 1 & & & & & & & 2 \\
\hline & Blephariceridae & & & & 4 & 2 & 9 & & 1 & 1 & & 16 & & & & 33 \\
\hline & Chironomidae & 22 & 1 & 30 & 5 & 26 & 8 & 16 & 20 & 149 & 170 & 14 & 33 & 2 & 1 & 497 \\
\hline & Culicidae & 1 & 1 & & & & & 2 & & 9 & 12 & & 1 & & & 26 \\
\hline & Pupa Brachycera & 3 & 4 & 9 & 2 & 3 & 4 & & & 6 & & 4 & 3 & & & 38 \\
\hline & Pupa Nematocera & & & & & & 2 & 2 & 3 & 12 & 18 & 2 & & & & 39 \\
\hline & Simuliidae & & 1 & & 1 & & 2 & & 1 & 1 & & 16 & & & 1 & 23 \\
\hline & Tabanidae & 2 & & & & 2 & & & & & & & & & & 4 \\
\hline \multirow[t]{6}{*}{ EPHEMEROPTERA } & Caenidae & 1 & & & & & & & & & & & & & & 1 \\
\hline & Ephemerellidae & 20 & 1 & 25 & 3 & 5 & 15 & & 4 & 2 & 2 & 33 & 11 & 6 & 7 & 134 \\
\hline & Leptophlebidae & 1 & 2 & & & & 15 & & 2 & 12 & 3 & 23 & 1 & 1 & 2 & 62 \\
\hline & Leptohyphidae & 3 & 1 & 30 & 12 & 4 & 9 & & & & & 9 & & & & 68 \\
\hline & Oniscigastridae & 1 & 2 & & & 3 & & & & & & & & & & 6 \\
\hline & Tricorythidae & & & & & 3 & & & & & & 5 & & & & 8 \\
\hline \multirow[t]{2}{*}{ LEPIDOPTERA } & Pupa & & & & & 4 & & & & & & & & & & 4 \\
\hline & Pyralidae & & & & & & & & & 4 & 4 & & 5 & 5 & 1 & 19 \\
\hline MEGALOPTERA & Corydalidae & & & & & & & & 1 & & & & & & & 1 \\
\hline \multirow[t]{2}{*}{ ODONATA } & & & & 4 & & & & & 1 & & & & & & & 5 \\
\hline & Lestidae & 1 & & 2 & 1 & & 1 & & & & & & & & & 5 \\
\hline \multirow[t]{2}{*}{ PLECOPTERA } & Grypopterigidae & 7 & & 7 & 3 & 2 & 3 & & 12 & & 1 & 1 & & & & 36 \\
\hline & Perlidae & 1 & 2 & 14 & & 7 & 14 & & 5 & 25 & 4 & & & & & 72 \\
\hline \multirow[t]{6}{*}{ TRICHOPTERA } & Hydropsychidae & 2 & & 4 & & 3 & 9 & 1 & 3 & 31 & 18 & 41 & 5 & 5 & 8 & 130 \\
\hline & Hydroptilidae & & & & 2 & & & & & 12 & & 12 & 31 & 2 & & 59 \\
\hline & Odontoceridae & & & & 4 & & & & & & & & 2 & 1 & & 7 \\
\hline & Philopotamidae & 1 & & 2 & & & 1 & & & & 1 & & & 1 & & 6 \\
\hline & Pupa & & & & & & & & & & & & 3 & & & 3 \\
\hline & Xiphocentronidae & & 2 & 7 & & & 8 & & 17 & 25 & 26 & 11 & 215 & 14 & 17 & 342 \\
\hline CRUSTACEA & Aegla sp & 1 & & 4 & 5 & & 1 & & 1 & & & & & & & 12 \\
\hline MOLLUSCA & Gastropoda & & & 2 & 1 & & & & & & & 1 & 2 & 3 & 274 & 283 \\
\hline OLIGOCHAETA & & 4 & & 1 & 1 & 2 & & & 12 & & 4 & 2 & 2 & & 1 & 29 \\
\hline DENSIDADE TOTAL & & 86 & 23 & 162 & 53 & 91 & 125 & 34 & 103 & 311 & 266 & 199 & 324 & 51 & 341 & 2169 \\
\hline
\end{tabular}


TABELA 2.3.7.2.6 - Abundância relativa por unidade taxonômica na coleta de verão (jan/00)

\begin{tabular}{|c|c|c|c|c|c|c|c|c|c|c|c|c|c|c|c|c|}
\hline & & 1 & 2 & 3 & 4 & 5 & 6 & 7 & 8 & 9 & 10 & 11 & 12 & 13 & 14 & Total \\
\hline \multirow[t]{9}{*}{ COLEOPTERA } & Crysomelidae & & & & & & & & & $2.5 \%$ & & & & & & $0.4 \%$ \\
\hline & Curculionidae & & & & & & & & & & & & $15.9 \%$ & & & $0.4 \%$ \\
\hline & Dytiscidae & & & & & & & & & & & & & $5.7 \%$ & & $0.2 \%$ \\
\hline & Elmidae & & $20.6 \%$ & $49.5 \%$ & $11.3 \%$ & $17.8 \%$ & $16.4 \%$ & $33.1 \%$ & & & & & & & $6.3 \%$ & $7.5 \%$ \\
\hline & Scirtidae & & & & & & & & & & & & $7.3 \%$ & & & $0.2 \%$ \\
\hline & Hydrophilidae & & & & & & & & & & & $65.8 \%$ & & & & $0.7 \%$ \\
\hline & Limnichidae & & $6.3 \%$ & & & & & & $13.5 \%$ & $7.4 \%$ & $30.9 \%$ & & & & & $3.1 \%$ \\
\hline & Psephenidae & $4.9 \%$ & & $18.8 \%$ & $88.7 \%$ & $57.5 \%$ & $47.3 \%$ & & $40.1 \%$ & $13.4 \%$ & $54.3 \%$ & & $30.5 \%$ & $12.3 \%$ & $0.9 \%$ & $19.8 \%$ \\
\hline & Noteridae & & & & & & & & & $2.5 \%$ & & & & & & $0.4 \%$ \\
\hline DIPTERA & Chironomidae & $77.6 \%$ & & $18.8 \%$ & & $3.4 \%$ & & $9.8 \%$ & & & & & $23.2 \%$ & $5.7 \%$ & $1.9 \%$ & $17.0 \%$ \\
\hline \multirow[t]{4}{*}{ EPHEMEROPTERA } & Caenidae & $0.9 \%$ & & & & & & & & & & $34.2 \%$ & & & & $0.6 \%$ \\
\hline & Ephemerellidae & & & & & & & & & & & & $15.9 \%$ & & $1.9 \%$ & $0.8 \%$ \\
\hline & Leptophlebiidae & $6.0 \%$ & $6.3 \%$ & & & $3.4 \%$ & $19.6 \%$ & & $4.6 \%$ & $30.3 \%$ & $7.4 \%$ & & & & & $8.9 \%$ \\
\hline & Tricorythidae & & & & & & & & $17.7 \%$ & & & & & & & $1.5 \%$ \\
\hline HETEROPTERA & Naucoridae & & & & & & & & & & & & & & $0.9 \%$ & $0.2 \%$ \\
\hline LEPIDOPTERA & Pyralidae & & & & & & $3.4 \%$ & & & $2.5 \%$ & & & & & & $0.8 \%$ \\
\hline MEGALOPTERA & Corydalidae & & & & & & & & $2.1 \%$ & & & & & & & $0.2 \%$ \\
\hline ODONATA & Libelluloidae & & & & & & & & & & & & $7.3 \%$ & & & $0.2 \%$ \\
\hline ORTHOPTERA & & & $6.3 \%$ & & & $3.4 \%$ & & & & & & & & & & $0.3 \%$ \\
\hline \multirow[t]{2}{*}{ PLECOPTERA } & Grypopterygidae & $4.9 \%$ & & & & $3.4 \%$ & & $14.3 \%$ & $11.0 \%$ & $4.9 \%$ & $7.4 \%$ & & & & & $3.5 \%$ \\
\hline & Perlidae & & $60.3 \%$ & $12.9 \%$ & & & $9.9 \%$ & $28.6 \%$ & & $14.6 \%$ & & & & & & $6.0 \%$ \\
\hline \multirow[t]{5}{*}{ TRICHOPTERA } & Hydropsychidae & & & & & & & $9.8 \%$ & & $14.6 \%$ & & & & $65.1 \%$ & $5.5 \%$ & $5.8 \%$ \\
\hline & Odontoceridae & $0.9 \%$ & & & & & & $4.5 \%$ & & & & & & & & $0.4 \%$ \\
\hline & Polycentropodidae & & & & & & & & & & & & & $5.7 \%$ & & $0.2 \%$ \\
\hline & Rhyacophilidae & & & & & & & & & & & & & & $45.9 \%$ & $9.5 \%$ \\
\hline & Xiphocentronidae & & & & & & & & $8.9 \%$ & & & & & & & $0.7 \%$ \\
\hline \multirow[t]{2}{*}{ CRUSTACEA } & Aegla sp & $3.9 \%$ & & & & $7.5 \%$ & $3.4 \%$ & & $2.1 \%$ & $2.5 \%$ & & & & & & $2.1 \%$ \\
\hline & Amphipoda & $0.9 \%$ & & & & & & & & & & & & & & $0.2 \%$ \\
\hline MOLLUSCA & Gastropoda & & & & & & & & & & & & & $5.7 \%$ & $36.0 \%$ & $7.6 \%$ \\
\hline OLIGOCHAETA & Tubuficidae & & & & & $3.4 \%$ & & & & $4.9 \%$ & & & & & $0.9 \%$ & $1.1 \%$ \\
\hline
\end{tabular}




\begin{tabular}{|c|c|c|c|c|c|c|c|c|c|c|c|c|c|c|c|c|}
\hline & ELA 2.3.7.2.7 & $\begin{array}{r}\text { Abun } \\
1\end{array}$ & $\frac{\text { ancla }}{2}$ & 3 & 4 & 5 & $\frac{\tan }{6}$ & 7 & $\frac{\mathbf{a} \mathbf{n a}}{8}$ & :0leta & $\begin{array}{c}\text { de ou } \\
10\end{array}$ & ono ( & $\frac{10 / 11 / 0}{12}$ & $\overline{c 13}$ & $\bar{~} 14$ & Total \\
\hline \multirow[t]{7}{*}{ COLEOPTERA } & Curculionidae & & & & & & & & & $0.3 \%$ & & & & & & $0.1 \%$ \\
\hline & Dytiscidae & & & & & & & & & $1.1 \%$ & $0.8 \%$ & $0.5 \%$ & & & & $0.4 \%$ \\
\hline & Elmidae & & $5.1 \%$ & $6.1 \%$ & $14.7 \%$ & $13.8 \%$ & & $40.6 \%$ & $2.3 \%$ & $1.3 \%$ & & $0.5 \%$ & & $4.5 \%$ & $5.5 \%$ & $3.4 \%$ \\
\hline & Hydrophilidae & & $5.1 \%$ & & & & & & & & & & & & & $0.1 \%$ \\
\hline & Limnichidae & $11.2 \%$ & $5.1 \%$ & & & & $3.4 \%$ & & $6.6 \%$ & $2.9 \%$ & $1.7 \%$ & $0.5 \%$ & $2.4 \%$ & & & $1.9 \%$ \\
\hline & Psephenidae & & $21.2 \%$ & $26.2 \%$ & $19.3 \%$ & $13.8 \%$ & $14.3 \%$ & $4.3 \%$ & $20.8 \%$ & $2.4 \%$ & $3.3 \%$ & & & & $0.2 \%$ & $4.3 \%$ \\
\hline & Noteridae & & & $6.1 \%$ & & & & & $2.3 \%$ & $0.6 \%$ & & & & & $0.5 \%$ & $0.6 \%$ \\
\hline \multirow[t]{7}{*}{ DIPTERA } & Chironomidae & & & $11.7 \%$ & & $6.4 \%$ & & $31.9 \%$ & $3.7 \%$ & $20.6 \%$ & $34.2 \%$ & $6.5 \%$ & $4.9 \%$ & $15.2 \%$ & $1.1 \%$ & $10.3 \%$ \\
\hline & Ephydridae & $7.6 \%$ & & $2.8 \%$ & $14.7 \%$ & & & & & & & & & & & $0.6 \%$ \\
\hline & Pupa Brachycera & $7.6 \%$ & & & & & & & $0.7 \%$ & $1.3 \%$ & $3.3 \%$ & $0.5 \%$ & & $10.7 \%$ & & $1.1 \%$ \\
\hline & Pupa Nematocera & & & & & & & & & $0.3 \%$ & & & & & & $0.1 \%$ \\
\hline & Tabanidae & & & & & $6.4 \%$ & & & & & & & & & & $0.1 \%$ \\
\hline & Blephariceridae & & & & & $6.4 \%$ & & & & & & & $6.4 \%$ & & & $0.6 \%$ \\
\hline & Stratiomyidae & & & & $14.7 \%$ & & & & & & & & & & & $0.4 \%$ \\
\hline \multirow[t]{5}{*}{ EPHEMEROPTERA } & Caenidae & & & & & & & & & $0.6 \%$ & & & & $13.1 \%$ & $1.6 \%$ & $0.9 \%$ \\
\hline & Ephemerellidae & $14.7 \%$ & $26.3 \%$ & $17.8 \%$ & $7.3 \%$ & $26.6 \%$ & & $4.3 \%$ & $11.2 \%$ & $2.4 \%$ & $1.7 \%$ & $17.4 \%$ & $2.4 \%$ & & $5.5 \%$ & $6.8 \%$ \\
\hline & Leptophlebiidae & & & & & & & & $3.7 \%$ & $0.8 \%$ & $4.1 \%$ & & $4.9 \%$ & $6.6 \%$ & $0.5 \%$ & $1.5 \%$ \\
\hline & Leptohyphidae & & & & & & $14.3 \%$ & & & $0.3 \%$ & & $0.5 \%$ & & & & $0.4 \%$ \\
\hline & Tricorythidae & & & & & & $10.9 \%$ & & $0.7 \%$ & & & & & & & $0.2 \%$ \\
\hline HETEROPTERA & Naucoridae & & & & & & & & & & & & & & $0.7 \%$ & $0.2 \%$ \\
\hline LEPIDOPTEA & Pyralidae & & & & & & & $9.4 \%$ & & $0.6 \%$ & $3.3 \%$ & & & $6.6 \%$ & $0.7 \%$ & $0.9 \%$ \\
\hline MEGALOPTERA & Corydalidae & & & & & & & & & & & $1.0 \%$ & & $2.1 \%$ & & $0.2 \%$ \\
\hline \multirow{2}{*}{ ODONATA } & Calopterygidae & & & & & & & & & & $0.8 \%$ & $0.5 \%$ & & & & $0.1 \%$ \\
\hline & Megapodagrionidae & & & & & & & & & $0.3 \%$ & & & & $4.5 \%$ & & $0.2 \%$ \\
\hline ORTHOPTERA & & & $16.1 \%$ & & & & & & & $0.3 \%$ & & & & & & $0.2 \%$ \\
\hline \multirow[t]{2}{*}{ PLECOPTERA } & Grypopterygidae & $55.3 \%$ & & $6.1 \%$ & & & $17.7 \%$ & & $12.6 \%$ & & $1.7 \%$ & & & & & $2.5 \%$ \\
\hline & Perlidae & & $21.2 \%$ & $11.7 \%$ & $14.7 \%$ & $6.4 \%$ & $36.0 \%$ & & $12.6 \%$ & $8.0 \%$ & $12.5 \%$ & $2.5 \%$ & $4.9 \%$ & $2.1 \%$ & $0.7 \%$ & $6.3 \%$ \\
\hline \multirow[t]{8}{*}{ TRICHOPTERA } & Hydropsychidae & & & & & & & & $11.9 \%$ & $14.6 \%$ & $15.8 \%$ & $11.0 \%$ & $31.2 \%$ & $13.1 \%$ & $8.0 \%$ & $11.8 \%$ \\
\hline & Odontoceridae & & & & & & $3.4 \%$ & & & $14.0 \%$ & $12.5 \%$ & $32.3 \%$ & $16.0 \%$ & $4.5 \%$ & & $9.6 \%$ \\
\hline & Philopotamidae & & & $2.8 \%$ & & & & & $9.6 \%$ & $0.3 \%$ & & & $0.8 \%$ & & & $1.0 \%$ \\
\hline & Helycopsychidae & & & & & & & & & $0.8 \%$ & & & & & & $0.2 \%$ \\
\hline & Leptoceridae & $3.5 \%$ & & & & & & & & & & & & & & $0.1 \%$ \\
\hline & Hydroptilidae & & & & & & & & $1.5 \%$ & $12.2 \%$ & $2.5 \%$ & & & & $0.2 \%$ & $3.2 \%$ \\
\hline & Xiphocentronidae & & & & $14.7 \%$ & $13.8 \%$ & & $9.4 \%$ & & $14.3 \%$ & & $24.9 \%$ & $19.9 \%$ & & $10.8 \%$ & $11.5 \%$ \\
\hline & Pupa & & & & & & & & & & & & & $2.1 \%$ & $0.7 \%$ & $0.2 \%$ \\
\hline CRUSTACEA & Aegla sp & & & $8.9 \%$ & & & & & & & $0.8 \%$ & & & & & $0.2 \%$ \\
\hline MOLLUSCA & Gastropoda & & & & & & & & & & & & & $10.7 \%$ & $63.2 \%$ & $17.2 \%$ \\
\hline OLIGOCHAETA & Tuficidae & & & & & $6.4 \%$ & & & & & $0.8 \%$ & $1.5 \%$ & $6.4 \%$ & $4.5 \%$ & & $0.9 \%$ \\
\hline
\end{tabular}


TABELA 2.3.7.2.8 - Abundância relativa por unidade taxonômica na coleta de inverno (julho/00)

\begin{tabular}{|c|c|c|c|c|c|c|c|c|c|c|c|c|c|c|c|c|}
\hline \multicolumn{17}{|c|}{ TABELA 2.3.7.2.8 - Abundância relativa por unidade taxonômica na coleta de inverno (julho/00) } \\
\hline & & $\begin{array}{ll}1 \\
1\end{array}$ & 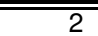 & 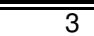 & $\begin{array}{ll}4 \\
\end{array}$ & 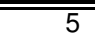 & $\begin{array}{l}6 \\
\end{array}$ & $\begin{array}{ll}7 \\
\end{array}$ & 8 & 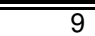 & ב 10 & 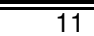 & 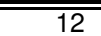 & $\overline{13}$ & 14 & $\overline{\text { Total }}$ \\
\hline \multirow[t]{7}{*}{ COLEOPTERA } & Dytiscidae & & & & & & & & $1.0 \%$ & $0.3 \%$ & & & & $0.6 \%$ & & $0.1 \%$ \\
\hline & Elmidae & $1.7 \%$ & $8.6 \%$ & & $14.3 \%$ & $3.9 \%$ & & & $5.0 \%$ & $1.4 \%$ & $0.9 \%$ & $0.6 \%$ & $3.0 \%$ & $6.6 \%$ & $14.2 \%$ & $4.8 \%$ \\
\hline & Noteridae & & $8.6 \%$ & & & $5.1 \%$ & $16.1 \%$ & $1.8 \%$ & $1.0 \%$ & $1.8 \%$ & & $1.2 \%$ & & & $0.7 \%$ & $1.3 \%$ \\
\hline & Haliplidae & & & & & & & & & $0.7 \%$ & $0.6 \%$ & & & & $1.3 \%$ & $0.4 \%$ \\
\hline & Hydrophilidae & & & & & & & & & & & & & & $0.2 \%$ & $0.0 \%$ \\
\hline & Limnichidae & $6.9 \%$ & & $8.7 \%$ & $8.9 \%$ & $1.2 \%$ & $3.8 \%$ & $1.8 \%$ & $2.1 \%$ & $1.4 \%$ & $0.6 \%$ & $2.7 \%$ & $0.2 \%$ & $0.6 \%$ & & $1.5 \%$ \\
\hline & Psephenidae & $67.6 \%$ & $18.6 \%$ & $42.1 \%$ & $21.4 \%$ & $29.5 \%$ & $13.7 \%$ & $3.4 \%$ & $14.3 \%$ & $1.1 \%$ & $4.4 \%$ & & $0.2 \%$ & $0.6 \%$ & & $5.2 \%$ \\
\hline \multirow[t]{9}{*}{ DIPTERA } & Tipulidae & & & $1.7 \%$ & & & & & & & & & & & & $0.0 \%$ \\
\hline & Blephariceridae & & & & $1.7 \%$ & & & & & & & & & & & $0.0 \%$ \\
\hline & Chironimidae & & & & $3.7 \%$ & $3.9 \%$ & $3.8 \%$ & $50.8 \%$ & $8.1 \%$ & $12.2 \%$ & $39.0 \%$ & $1.2 \%$ & $19.1 \%$ & $2.4 \%$ & $1.3 \%$ & $11.9 \%$ \\
\hline & Culicidae & & & & & & & & & & $6.1 \%$ & $0.4 \%$ & $2.6 \%$ & & & $1.2 \%$ \\
\hline & Pupa Brachicera & & & $1.7 \%$ & & & & $5.2 \%$ & & & $2.1 \%$ & $1.4 \%$ & & $0.6 \%$ & $0.5 \%$ & $0.9 \%$ \\
\hline & Pupa Nematocera & & & & & $1.2 \%$ & & & & & $0.6 \%$ & & $1.9 \%$ & $1.2 \%$ & & $0.5 \%$ \\
\hline & Sciomyzidae & & & & & & & $0.8 \%$ & & & & & & & & $0.0 \%$ \\
\hline & Stratiomyidae & & & $3.7 \%$ & & & & & & & & & & & $0.2 \%$ & $0.1 \%$ \\
\hline & Tabadinae & & & & & & & & & $0.3 \%$ & & & & & & $0.0 \%$ \\
\hline \multirow[t]{5}{*}{ EPHEMEROPTERA } & & & $18.6 \%$ & & & & & & & & & & & & & $0.1 \%$ \\
\hline & Ephemerellidae & $1.7 \%$ & & $8.7 \%$ & $7.1 \%$ & $9.0 \%$ & $10.0 \%$ & & $8.1 \%$ & $5.7 \%$ & $5.6 \%$ & $6.0 \%$ & $13.2 \%$ & $6.6 \%$ & $3.0 \%$ & $6.4 \%$ \\
\hline & Leptophlebiidae & & & & & & $10.0 \%$ & $15.5 \%$ & $12.2 \%$ & $6.1 \%$ & $0.9 \%$ & $2.9 \%$ & $4.2 \%$ & $0.6 \%$ & $3.3 \%$ & $3.9 \%$ \\
\hline & Leptohyphidae & $1.7 \%$ & & $1.7 \%$ & $8.9 \%$ & $9.0 \%$ & $8.8 \%$ & $0.8 \%$ & $13.2 \%$ & & $5.0 \%$ & $13.2 \%$ & $15.5 \%$ & $9.5 \%$ & $4.3 \%$ & $7.8 \%$ \\
\hline & Tricorythidae & & & & & & $3.8 \%$ & & & & & $10.5 \%$ & $1.4 \%$ & & & $2.1 \%$ \\
\hline HETEROPTERA & Belostomatidae & & & & & & & $1.8 \%$ & & & & & & & & $0.1 \%$ \\
\hline \multirow[t]{2}{*}{ LEPIDOPTERA } & pupa & $1.7 \%$ & & & & & & & & & & & & & & $0.0 \%$ \\
\hline & Pyralidae & & & & $1.7 \%$ & & & & & $2.2 \%$ & $7.6 \%$ & & $2.1 \%$ & $3.0 \%$ & $1.2 \%$ & $1.9 \%$ \\
\hline MEGALOPTERA & Corydalidae & & & & $1.7 \%$ & & & & & $0.3 \%$ & & & $0.2 \%$ & & & $0.1 \%$ \\
\hline \multirow[t]{3}{*}{ ODONATA } & & & & $8.7 \%$ & $1.7 \%$ & $7.8 \%$ & & & $2.1 \%$ & & $0.6 \%$ & & & & $0.3 \%$ & $0.6 \%$ \\
\hline & Megapodagrionidae & & & & & & $3.8 \%$ & & & & & & & & & $0.1 \%$ \\
\hline & Lestidae & & & & & & & & & & & & & $0.6 \%$ & & $0.0 \%$ \\
\hline ORTHOPTERA & & & & & $1.7 \%$ & $1.2 \%$ & & & & & & & & & & $0.1 \%$ \\
\hline \multirow[t]{2}{*}{ PLECOPTERA } & Grypopterigidae & $13.9 \%$ & & $10.7 \%$ & $10.9 \%$ & $10.2 \%$ & $5.0 \%$ & & $15.3 \%$ & & & & & & & $1.6 \%$ \\
\hline & Perlidae & & $18.6 \%$ & $5.3 \%$ & $7.1 \%$ & $10.2 \%$ & $13.7 \%$ & & $7.2 \%$ & $13.6 \%$ & $1.8 \%$ & $1.2 \%$ & $0.7 \%$ & & $0.3 \%$ & $3.2 \%$ \\
\hline \multirow[t]{10}{*}{ TRICHOPTERA } & & & $27.1 \%$ & & & & & & & & & & & & & $0.1 \%$ \\
\hline & Adulto & & & & & & & & & & $0.3 \%$ & $0.8 \%$ & & & & $0.2 \%$ \\
\hline & Helycopsychidae & & & & & $3.9 \%$ & & & & & $0.6 \%$ & $0.6 \%$ & & & & $0.3 \%$ \\
\hline & Hydropsychidae & $1.7 \%$ & & & & & $2.6 \%$ & $18.0 \%$ & $5.0 \%$ & $17.2 \%$ & $4.7 \%$ & $41.3 \%$ & $4.9 \%$ & $1.8 \%$ & $5.8 \%$ & $12.3 \%$ \\
\hline & Hydroptilidae & & & & & $1.2 \%$ & & & $2.1 \%$ & & & & & & & $0.1 \%$ \\
\hline & Leptoceridae & & & & & & & & $2.1 \%$ & & & & & & & $0.1 \%$ \\
\hline & Odontoceridae & & & & & & & & & & & $0.4 \%$ & $0.7 \%$ & $0.6 \%$ & $4.0 \%$ & $1.1 \%$ \\
\hline & Philopotamidae & & & & $3.7 \%$ & $1.2 \%$ & $3.8 \%$ & & $1.0 \%$ & $0.7 \%$ & & & $1.4 \%$ & & $0.3 \%$ & $0.6 \%$ \\
\hline & Pupa & & & & & & & & & & & & $0.5 \%$ & & & $0.1 \%$ \\
\hline & Xiphocentronidae & & & & & & & & & $34.4 \%$ & $18.4 \%$ & $15.4 \%$ & $28.0 \%$ & $63.1 \%$ & $23.7 \%$ & $21.1 \%$ \\
\hline CRUSTACEA & Aegla sp & $1.7 \%$ & & $7.0 \%$ & $5.4 \%$ & $1.2 \%$ & & & & $0.3 \%$ & $0.3 \%$ & & & & & $0.4 \%$ \\
\hline MOLLUSCA & Gastropoda & & & & & & $1.2 \%$ & & & & & & & $1.8 \%$ & $35.1 \%$ & $7.6 \%$ \\
\hline OLIGOCHAETA & Tubificidae & & & & & & & & & & & & & & $0.5 \%$ & $0.1 \%$ \\
\hline
\end{tabular}


TABELA 2.3.7.2.9 - Abundância relativa por unidade taxonômica na coleta da primavera (out/00)

\begin{tabular}{|c|c|c|c|c|c|c|c|c|c|c|c|c|c|c|c|c|c|c|}
\hline & & & 1 & 2 & 3 & 4 & 5 & 6 & 7 & 7 & 8 & 9 & 10 & 11 & 12 & 13 & & Total \\
\hline \multirow[t]{8}{*}{ COLEOPTERA } & Curculionidae & & & & & & & & & & & & & & $0.3 \%$ & & & $0.0 \%$ \\
\hline & Dytiscidae & & & $9.0 \%$ & $0.6 \%$ & & & & & & & & & & & & & $0.1 \%$ \\
\hline & Elmidae & & $7.3 \%$ & $4.1 \%$ & $5.1 \%$ & & $2.3 \%$ & & & & $5.1 \%$ & $1.3 \%$ & & & $1.6 \%$ & $16.0 \%$ & $6.1 \%$ & $2.8 \%$ \\
\hline & Noteridae & & & $9.0 \%$ & & & $2.3 \%$ & $4.1 \%$ & & & & $2.4 \%$ & & $1.6 \%$ & & $4.2 \%$ & $2.1 \%$ & $1.3 \%$ \\
\hline & Haliplidae & & & & & & & & & & & & & & $0.3 \%$ & & $0.3 \%$ & $0.1 \%$ \\
\hline & Limnichidae & & $2.5 \%$ & $4.1 \%$ & & & $1.1 \%$ & $4.1 \%$ & $70.1 \%$ & $37.3 \%$ & & $2.0 \%$ & $0.8 \%$ & $2.6 \%$ & $0.3 \%$ & & & $2.2 \%$ \\
\hline & Psephenidae & & $7.3 \%$ & & $7.0 \%$ & $17.2 \%$ & $16.8 \%$ & $10.7 \%$ & & & $13.3 \%$ & $1.7 \%$ & $0.4 \%$ & $0.5 \%$ & $0.7 \%$ & $1.9 \%$ & & $3.6 \%$ \\
\hline & Ptilodactylidae & & & & & & $4.5 \%$ & & & & & & & & & & & $0.2 \%$ \\
\hline \multirow[t]{8}{*}{ DIPTERA } & Ceratopogonidae & & $1.2 \%$ & & & & & & & & $1.0 \%$ & & & & & & & $0.1 \%$ \\
\hline & Blephariceridae & & & & & $7.7 \%$ & $2.3 \%$ & $7.4 \%$ & & & $1.0 \%$ & $0.3 \%$ & & $7.9 \%$ & & & & $1.5 \%$ \\
\hline & Chironomidae & & $24.0 \%$ & $4.1 \%$ & $18.4 \%$ & $9.8 \%$ & $28.0 \%$ & $6.6 \%$ & & $46.8 \%$ & $19.3 \%$ & $47.8 \%$ & $63.9 \%$ & $6.8 \%$ & $10.2 \%$ & $4.2 \%$ & $0.3 \%$ & $22.6 \%$ \\
\hline & Culicidae & & $1.2 \%$ & $4.1 \%$ & & & & & $12.1 \%$ & $6.5 \%$ & & $3.0 \%$ & $4.3 \%$ & & $0.3 \%$ & & & $1.3 \%$ \\
\hline & Pupa Brachycera & & $3.7 \%$ & $17.2 \%$ & $5.7 \%$ & $4.0 \%$ & $3.4 \%$ & $3.3 \%$ & & & & $2.0 \%$ & & $2.1 \%$ & $1.0 \%$ & & & $1.8 \%$ \\
\hline & Pupa Nematocera & & & & & & & $1.7 \%$ & $12.1 \%$ & $6.5 \%$ & $3.1 \%$ & $3.7 \%$ & $6.6 \%$ & $1.1 \%$ & & & & $1.9 \%$ \\
\hline & Simuliidae & & & $4.1 \%$ & & $1.8 \%$ & & $1.7 \%$ & & & $1.0 \%$ & $0.3 \%$ & & $7.9 \%$ & & & $0.3 \%$ & $1.0 \%$ \\
\hline & Tabadinae & & $2.5 \%$ & & & & $2.3 \%$ & & & & & & & & & & & $0.2 \%$ \\
\hline \multirow[t]{6}{*}{ EPHEMEROPTERA } & Caenidae & & $1.2 \%$ & & & & & & & & & & & & & & & $0.0 \%$ \\
\hline & Ephemerellidae & & $22.9 \%$ & $4.1 \%$ & $15.3 \%$ & & $5.5 \%$ & $11.6 \%$ & & & $4.1 \%$ & $0.7 \%$ & $0.8 \%$ & $16.8 \%$ & $3.2 \%$ & $12.1 \%$ & $2.1 \%$ & $6.0 \%$ \\
\hline & Leptophlebiidae & & $1.2 \%$ & $9.0 \%$ & & $5.8 \%$ & & $11.6 \%$ & & & $2.1 \%$ & $3.7 \%$ & $1.2 \%$ & $11.6 \%$ & $0.3 \%$ & $1.9 \%$ & $0.6 \%$ & $3.0 \%$ \\
\hline & Leptohyphidae & & $3.7 \%$ & $4.1 \%$ & $18.4 \%$ & $21.2 \%$ & $4.5 \%$ & $7.4 \%$ & & & & & & $4.7 \%$ & & & & $3.1 \%$ \\
\hline & Oniscigastridae & & $1.2 \%$ & $9.0 \%$ & & & $3.4 \%$ & & & & & & & & & & & $0.3 \%$ \\
\hline & Tricorythidae & & & & & & $3.4 \%$ & & & & & & & $2.6 \%$ & & & & $0.4 \%$ \\
\hline \multirow[t]{2}{*}{ LEPIDOPTERA } & Pupa & & & & & & $4.5 \%$ & & & & & & & & & & & $0.2 \%$ \\
\hline & Pyralidade & & & & & & & & & & & $1.3 \%$ & $1.6 \%$ & & $2.2 \%$ & $9.9 \%$ & $0.3 \%$ & $1.0 \%$ \\
\hline MEGALOPTERA & Corydalidae & & & & & & & & & & $1.0 \%$ & & & & & & & $0.0 \%$ \\
\hline \multirow[t]{2}{*}{ ODONATA } & & 0 & $1.2 \%$ & & $2.5 \%$ & $1.8 \%$ & & $0.8 \%$ & & & $1.0 \%$ & & & & & & & $0.4 \%$ \\
\hline & Lestidae & & & & $1.3 \%$ & & & & & & & & & & & & & $0.1 \%$ \\
\hline \multirow[t]{2}{*}{ PLECOPTERA } & Grypopterigidae & & $8.5 \%$ & & $4.5 \%$ & $5.8 \%$ & $2.3 \%$ & $2.5 \%$ & & & $11.3 \%$ & & $0.4 \%$ & $0.5 \%$ & & & & $1.7 \%$ \\
\hline & Perlidae & & $1.2 \%$ & $9.0 \%$ & $8.2 \%$ & & $7.8 \%$ & $10.7 \%$ & & & $5.1 \%$ & $8.0 \%$ & $1.6 \%$ & & & & & $3.3 \%$ \\
\hline \multirow[t]{6}{*}{ TRICHOPTERA } & Hydropsychidae & & $2.5 \%$ & & $2.5 \%$ & & $3.4 \%$ & $7.4 \%$ & $5.6 \%$ & $3.0 \%$ & $3.1 \%$ & $10.0 \%$ & $6.6 \%$ & $20.5 \%$ & $1.6 \%$ & $9.9 \%$ & $2.4 \%$ & $6.0 \%$ \\
\hline & Hydroptilidae & & & & & $4.0 \%$ & & & & & & $3.7 \%$ & & $5.8 \%$ & $9.6 \%$ & $4.2 \%$ & & $2.7 \%$ \\
\hline & Odontoceridae & & & & & $7.7 \%$ & & & & & & & & & $0.7 \%$ & $1.9 \%$ & & $0.3 \%$ \\
\hline & Philopotamidae & & $1.2 \%$ & & $1.3 \%$ & & & $0.8 \%$ & & & & & $0.4 \%$ & & & $1.9 \%$ & & $0.3 \%$ \\
\hline & Pupa & & & & & & & & & & & & & & $1.0 \%$ & & & $0.1 \%$ \\
\hline & Xiphocentoridae & & & $9.0 \%$ & $4.5 \%$ & & & $6.6 \%$ & & & $16.4 \%$ & $8.0 \%$ & $9.8 \%$ & $5.3 \%$ & $65.5 \%$ & $25.9 \%$ & $4.9 \%$ & $15.5 \%$ \\
\hline CRUSTACEA & Aegla sp & & $1.2 \%$ & & $2.5 \%$ & $9.5 \%$ & & $0.8 \%$ & & & $1.0 \%$ & & & & & & & $0.6 \%$ \\
\hline MOLLUSCA & Gastropoda & & & & $1.3 \%$ & $1.8 \%$ & & & & & & & & $0.5 \%$ & $0.7 \%$ & $6.1 \%$ & $80.2 \%$ & $12.9 \%$ \\
\hline OLIGOCHAETA & Tubificidae & & $4.8 \%$ & & $0.6 \%$ & $1.8 \%$ & $2.3 \%$ & & & & $11.3 \%$ & & $1.6 \%$ & $1.1 \%$ & $0.7 \%$ & & $0.3 \%$ & $1.3 \%$ \\
\hline
\end{tabular}


TABELA 2.3.7.2.10 - ABUNDÂNCIA E DOMINÂNCIA POR UNIDADE TAXONÔMICA NA DE VERÃO (JAN/00)

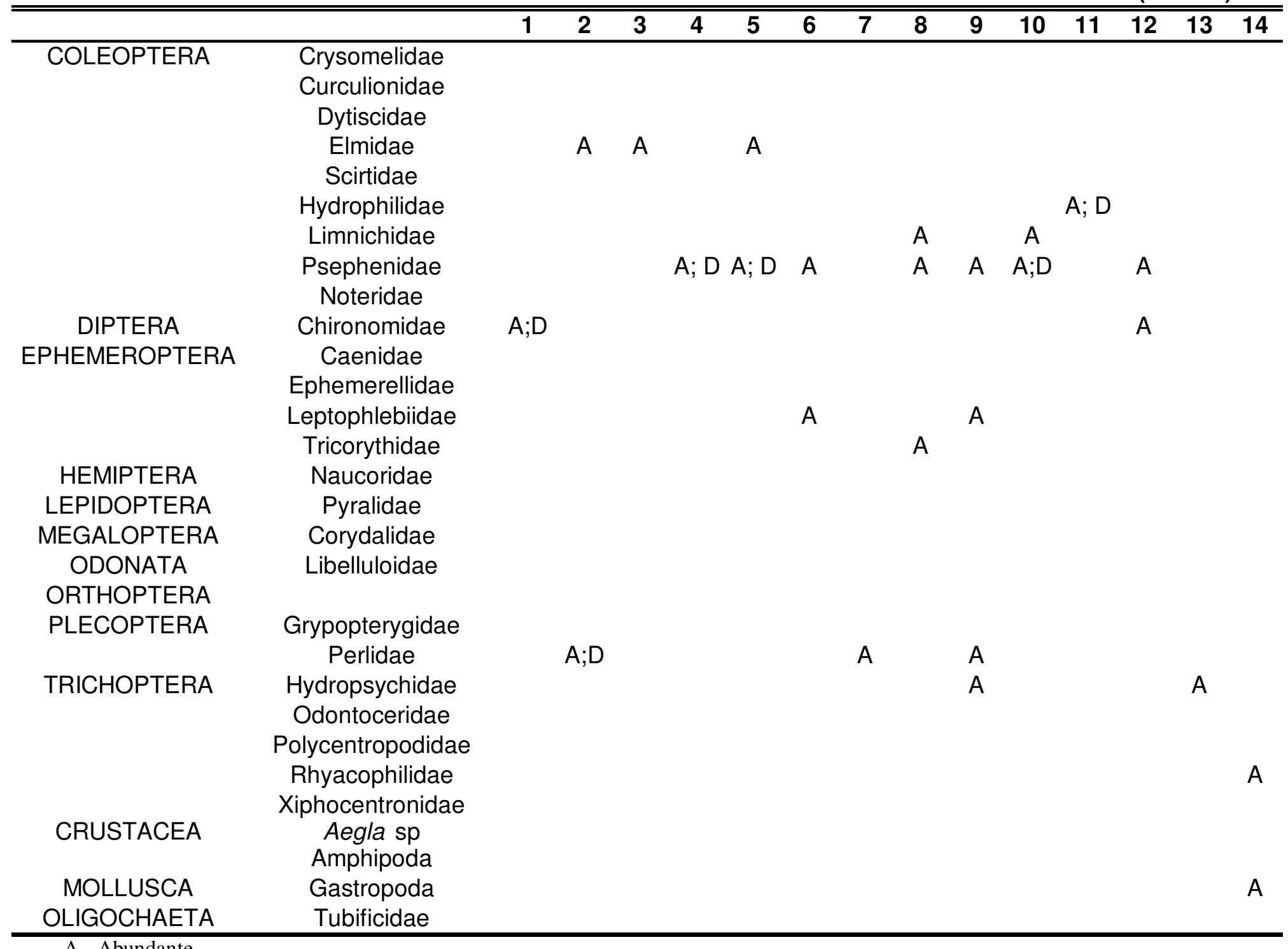

A - Abundante

D - Dominante 
TABELA 2.3.7.2.11 - ABUNDÂNCIA E DOMINÂNCIA POR UNIDADE TAXONÔMICA NA DE OUTONO (ABR/00)

\begin{tabular}{|c|c|c|c|c|c|c|c|c|c|c|c|c|c|c|c|}
\hline & & 1 & 2 & 3 & 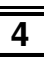 & 5 & 6 & 7 & 8 & 9 & 10 & 11 & $\overline{12}$ & 13 & 14 \\
\hline \multirow[t]{5}{*}{ COLEOPTERA } & $\begin{array}{l}\text { Curculionidae } \\
\text { Dvtiscidae }\end{array}$ & & & & & & & & & & & & & & \\
\hline & Elmidae & & & & A & A & & A & & & & & & & \\
\hline & Hydrophilidae & & & & & & & & & & & & & & \\
\hline & Limnichidae & & & & & & & & A & & & & & & \\
\hline & $\begin{array}{l}\text { Psephenidae } \\
\text { Noteridae }\end{array}$ & & A & $A$ & $A$ & A & $A$ & & A & & & & & & \\
\hline \multirow[t]{6}{*}{ DIPTERA } & Chironomidae & & & $A$ & & & & A & & A & $A$ & & & A & \\
\hline & Ephydridae & & & & A & & & & & & & & & & \\
\hline & Pupa Brachycera & & & & & & & & & & & & & A & \\
\hline & Pupa Nematocera & & & & & & & & & & & & & & \\
\hline & Tabanidae & & & & & & & & & & & & & & \\
\hline & Blephariceridae & & & & A & & & & & & & & & & \\
\hline \multirow{5}{*}{ EPHEMEROPTERA } & Caenidae & & & & & & & & & & & & & A & \\
\hline & Ephemerellidae & & A & A & & A & & & A & & & A & & & \\
\hline & Leptophlebildae & & & & & & & & & & & & & & \\
\hline & Leptohyphidae & & & & & & A & & & & & & & & \\
\hline & Tricorythidae & & & & & & & & & & & & & & \\
\hline HEMIPTERA & Naucoridae & & & & & & & & & & & & & & \\
\hline LEPIDOPTERA & Pyralidae & & & & & & & & & & & & & & \\
\hline MEGALOPTERA & Corydalidae & & & & & & & & & & & & & & \\
\hline ODONATA & Calopterygidae & & & & & & & & & & & & & & \\
\hline & Megapodagrionidae & & & & & & & & & & & & & & \\
\hline ORTHOPTERA & & & A & & & & & & & & & & & & \\
\hline \multirow{2}{*}{ PLECOPTERA } & Grypopterygidae & $A ; D$ & & & & & A & & A & & & & & & \\
\hline & Perlidae & & A & A & A & & A & & A & A & A & A & & & \\
\hline \multirow[t]{7}{*}{ TRICHOPTERA } & Hydropsychidae & & & & & & & & A & A & A & A & A & A & A \\
\hline & Odontoceridae & & & & & & & & & $A$ & A & A & $A$ & & \\
\hline & Philopotamidae & & & & & & & & & & & & & & \\
\hline & Helycopsychidae & & & & & & & & & & & & & & \\
\hline & Leptoceridae & & & & & & & & & & & & & & \\
\hline & Hydroptilidae & & & & & & & & & A & & & & & \\
\hline & $\begin{array}{c}\text { Xiphocentronidae } \\
\text { Pupa }\end{array}$ & & & & $A$ & A & & & & A & & A & A & & $A$ \\
\hline CRUSTACEA & Aegla sp & & & & & & & & & & & & & & \\
\hline MOLLUSCA & Gastropoda & & & & & & & & & & & & & A & $A ; D$ \\
\hline OLIGOCHAETA & Tubificidae & & & & & & & & & & & & & & \\
\hline
\end{tabular}




\begin{tabular}{|c|c|c|c|c|c|c|c|c|c|c|c|c|c|c|c|}
\hline & & 1 & 2 & 3 & 4 & 5 & 6 & 7 & 8 & 9 & 10 & 11 & 12 & 13 & 14 \\
\hline \multirow[t]{7}{*}{ COLEOPTERA } & Dytiscidae & & & & & & & & & & & & & & \\
\hline & Elmidae & & & & $A ; D$ & & & & & & & & & $A$ & $A ; D$ \\
\hline & Noteridae & & & & & & $A ; D$ & & & & & & & & \\
\hline & Haliplidae & & & & & & & & & & & & & & \\
\hline & Hydrophilidae & & & & & & & & & & & & & & \\
\hline & Limnichidae & & & & $A$ & & & & & & & & & & \\
\hline & Psephenidae & $A ; D$ & $A$ & $A ; D$ & $A ; D$ & $A ; D$ & $A$ & & $A ; D$ & & & & & & \\
\hline \multirow[t]{9}{*}{ DIPTERA } & Tipulidae & & & & & & & & & & & & & & \\
\hline & Blephariceridae & & & & & & & & & & & & & & \\
\hline & Chironomidae & & & & & & & $A ; D$ & & $A ; D$ & $A ; D$ & & $A ; D$ & & \\
\hline & Culicidae & & & & & & & & & & $A$ & & & & \\
\hline & Pupa Brachicera & & & & & & & & & & & & & & \\
\hline & Pupa Nematocera & & & & & & & & & & & & & & \\
\hline & Sciomyzidae & & & & & & & & & & & & & & \\
\hline & Stratiomyidae & & & & & & & & & & & & & & \\
\hline & Tabadinae & & & & & & & & & & & & & & \\
\hline \multirow[t]{5}{*}{ EPHEMEROPTERA } & & & $A$ & & & & & & & & & & & & \\
\hline & Ephemerellidade & & & & $A$ & $A$ & $A$ & & A & & $A$ & $A$ & $A ; D$ & $A$ & \\
\hline & Leptophlebildae & & & & & & $A$ & $A$ & $A ; D$ & $A$ & & & & & \\
\hline & Leptohyphidae & & & & $A$ & $A$ & $A$ & & $A ; D$ & & $A$ & $A ; D$ & $A ; D$ & $A$ & \\
\hline & Tricorythidae & & & & & & & & & & & $A$ & & & \\
\hline \multirow{3}{*}{$\begin{array}{l}\text { HETEROPTERA } \\
\text { LEPIDOPTERA }\end{array}$} & Belostomatidae & & & & & & & & & & & & & & \\
\hline & pupa & & & & & & & & & & & & & & \\
\hline & Pyralidade & & & & & & & & & & $A$ & & & & \\
\hline MEGALOPTERA & Corydalidae & & & & & & & & & & & & & & \\
\hline \multirow[t]{3}{*}{ ODONATA } & & & & & & $A$ & & & & & & & & & \\
\hline & Megapodagrionidae & & & & & & & & & & & & & & \\
\hline & Lestidae & & & & & & & & & & & & & & \\
\hline \multicolumn{16}{|l|}{ ORTHOPTERA } \\
\hline \multirow[t]{2}{*}{ PLECOPTERA } & Grypopterigidae & $A$ & & $A$ & $A$ & $A$ & & & $A ; D$ & & & & & & \\
\hline & Perlidae & & $A$ & & $A$ & $A$ & $A$ & & $A$ & $A ; D$ & & & & & \\
\hline \multirow[t]{10}{*}{ TRICHOPTERA } & & & $A$ & & & & & & & & & & & & \\
\hline & Adulto & & & & & & & & & & & & & & \\
\hline & Helycopsychidae & & & & & & & & & & & & & & \\
\hline & Hydropsychidae & & & & & & & $A$ & & $A ; D$ & & $A ; D$ & & & $A$ \\
\hline & Hydroptilidae & & & & & & & & & & & & & & \\
\hline & Leptoceridae & & & & & & & & & & & & & & \\
\hline & Odontoceridae & & & & & & & & & & & & & & \\
\hline & Philopotamidae & & & & & & & & & & & & & & \\
\hline & Pupa & & & & & & & & & & & & & & \\
\hline & Xiphocentroridae & & & & & & & & & $A ; D$ & $A ; D$ & $A ; D$ & $A ; D$ & $A ; D$ & $A ; D$ \\
\hline CRUSTACEA & Aegla sp & & & & & & & & & & & & & & \\
\hline MOLLUSCA & Gastropoda & & & & & & & & & & & & & & $A ; D$ \\
\hline OLIGOCHAETA & Tubificidae & & & & & & & & & & & & & & \\
\hline
\end{tabular}

D - Dominante 
TABELA 2.3.7.2.13 - ABUNDÂNCIA E DOMINÂNCIA POR UNIDADE TAXONÔMICA NA DE PRIMAVERA (0UT/00)

\begin{tabular}{|c|c|c|c|c|c|c|c|c|c|c|c|c|c|c|c|}
\hline & & 1 & 2 & 3 & 4 & 5 & 6 & 7 & 8 & 9 & 10 & 11 & 12 & 13 & 14 \\
\hline \multirow[t]{8}{*}{ COLEOPTERA } & Curculionidae & & & & & & & & & & & & & & \\
\hline & Dytiscidae & & $A$ & & & & & & & & & & & & \\
\hline & Elmidae & $A$ & & & & & & & $A$ & & & & & $A ; D$ & \\
\hline & Noteridae & & $A$ & & & & & & & & & & & & \\
\hline & Haliplidae & & & & & & & & & & & & & & \\
\hline & Limnichidae & & & & & & & A & & & & & & & \\
\hline & Psephenidae & $A$ & & $A$ & $A ; D$ & $A ; D$ & $A$ & & $A ; D$ & & & & & & \\
\hline & Ptilodactylidae & & & & & $A$ & & & & & & & & & \\
\hline \multirow[t]{7}{*}{ DIPTERA } & Cerapotamidae & & & & & & & & & & & & & & \\
\hline & Blephariceridae & & & & A & & A & & & & & $A$ & & & \\
\hline & Chironomidae & $A ; D$ & & $A ; D$ & & $A ; D$ & A & $A ; D$ & $A ; D$ & $A ; D$ & $A ; D$ & & A & & \\
\hline & & & ח. & A & & & & & & & & & & & \\
\hline & $\begin{array}{l}\text { Pupa Brachycera } \\
\text { Pupa Nematocera }\end{array}$ & & $A, D$ & $A$ & & & & & & & A & & & & \\
\hline & Simuliidae & & & & & & & & & & & $A$ & & & \\
\hline & Tabadinae & & & & & & & & & & & & & & \\
\hline \multirow[t]{6}{*}{ EPHEMEROPTERA } & Caenidae & & & & & & & & & & & & & & \\
\hline & Ephemerellidade & $A ; D$ & & $A ; D$ & $A$ & $A$ & $A ; D$ & & & & & $A ; D$ & & $A$ & \\
\hline & Leptophlebildae & & $A$ & & & & $A ; D$ & & & & & $A ; D$ & & & \\
\hline & Leptohyphidae & & & $A ; D$ & $A ; D$ & $A$ & $A$ & & & & & & & & \\
\hline & Oniscigastridae & & $A$ & & & & & & & & & & & & \\
\hline & Tricorythidae & & & & & & & & & & & & & & \\
\hline \multirow[t]{2}{*}{ LEPIDOPTERA } & Pupa & & & & & A & & & & & & & & & \\
\hline & Pyralidae & & & & & & & & & & & & & $A$ & \\
\hline \multirow{3}{*}{$\begin{array}{c}\text { MEGALOPTERA } \\
\text { ODONATA }\end{array}$} & Corydalidae & & & & & & & & & & & & & & \\
\hline & & & & & & & & & & & & & & & \\
\hline & Lestidae & & & & & & & & & & & & & & \\
\hline \multirow[t]{2}{*}{ PLECOPTERA } & Grypopterigidae & $A$ & & & A & & & & $A ; D$ & & & & & & \\
\hline & Perlidae & & $A$ & A & & $A$ & $A$ & & $A$ & $A$ & & & & & \\
\hline \multirow[t]{5}{*}{ TRICHOPTERA } & Hydropsychidae & & & & & & $A$ & & & $A$ & $A$ & $A ; D$ & & $A$ & \\
\hline & Hydroptilidae & & & & & & & & & & & $A$ & $A$ & & \\
\hline & Odontoceridae & & & & A & & & & & & & & & & \\
\hline & Philopotamidade & & & & & & & & & & & & & & \\
\hline & Xiphocentronidae & & A & & & & A & & $A ; D$ & A & A & $A$ & $A ; D$ & $A ; D$ & \\
\hline CRUSTACEA & Aegla sp & & & & $A$ & & & & & & & & & & \\
\hline MOLLUSCA & Gastropoda & & & & & & & & & & & & & & $A ; D$ \\
\hline OLIGOCHAETA & Tubificidae & A & & & & & & & $A ; D$ & & & & & & \\
\hline
\end{tabular}

A - Abundante

D - Dominante 
TABELA 2.3.7.2.14 - FREQÜÊNCIA DE OCORRÊNCIA TOTAL DAS UNIDADES TAXONOMICAS EM TODAS AS COLETAS

\begin{tabular}{|c|c|c|c|c|c|}
\hline & & Verão & Outono & Inverno & Primavera \\
\hline \multirow[t]{11}{*}{ COLEOPTERA } & Curculionidae & Comum & Raro & Ausente & Raro \\
\hline & Crysomelidae & Raro & Ausente & Ausente & Ausente \\
\hline & Dytiscidae & Raro & Comum & Comum & Comum \\
\hline & Elmidae & Freqüente & Freqüente & Freqüente & Freqüente \\
\hline & Haliplidae & Ausente & Ausente & Comum & Comum \\
\hline & Scirtidae & Raro & Ausente & Ausente & Ausente \\
\hline & Hydrophilidae & Raro & Raro & Raro & Ausente \\
\hline & Limnichidae & Comum & Freqüente & Freqüente & Freqüente \\
\hline & Noteridae & Raro & Comum & Freqüente & Freqüente \\
\hline & Psephenidae & Freqüente & Freqüente & Freqüente & Freqüente \\
\hline & Ptilodactylidae & Ausente & Ausente & Ausente & Raro \\
\hline \multirow[t]{12}{*}{ DIPTERA } & Tipulidae & Ausente & Ausente & Raro & Ausente \\
\hline & Blephariceridae & Ausente & Comum & Raro & Comum \\
\hline & Ceropotamidae & Ausente & Ausente & Ausente & Comum \\
\hline & Chironomidae & Freqüente & Freqüente & Freqüente & Freqüente \\
\hline & Culicidae & Ausente & Ausente & Comum & Comum \\
\hline & Ephydridae & Ausente & Comum & Ausente & Ausente \\
\hline & Pupa Brachycera & Ausente & Comum & Comum & Freqüente \\
\hline & Pupa Nematocera & Ausente & Raro & Comum & Comum \\
\hline & Tabanidae & Ausente & Raro & Raro & Comum \\
\hline & Simuliidae & Ausente & Ausente & Ausente & Freqüente \\
\hline & Sciomyzidae & Ausente & Ausente & Raro & Ausente \\
\hline & Stratiomyidae & Ausente & Raro & Comum & Ausente \\
\hline \multirow[t]{6}{*}{ EPHEMEROPTERA } & Caenidae & Comum & Comum & Raro & Raro \\
\hline & Ephemerellidae & Comum & Freqüente & Freqüente & Freqüente \\
\hline & Leptophlebiidae & Freqüente & Comum & Freqüente & Freqüente \\
\hline & Leptohyphidae & Ausente & Comum & Freqüente & Freqüente \\
\hline & Oniscigastridae & Ausente & Ausente & Ausente & Comum \\
\hline & Tricorythidae & Raro & Comum & Comum & Comum \\
\hline \multirow[t]{2}{*}{ HEMIPTERA } & Belostomatidae & Ausente & Ausente & Raro & Ausente \\
\hline & Naucoridae & Raro & Ausente & Ausente & Ausente \\
\hline \multirow[t]{2}{*}{ LEPIDOPTERA } & Pupa & Ausente & Ausente & Raro & Raro \\
\hline & Pyralidae & Comum & Comum & Comum & Comum \\
\hline MEGALOPTERA & Corydalidae & Raro & Comum & Comum & Raro \\
\hline \multirow[t]{5}{*}{ ODONATA } & & Ausente & Ausente & Comum & Comum \\
\hline & Calopterygidae & Ausente & Comum & Ausente & Ausente \\
\hline & Lestidae & Ausente & Ausente & Raro & Comum \\
\hline & Libelluloidae & Raro & Ausente & Ausente & Ausente \\
\hline & Megapodagrionidae & Ausente & Comum & Raro & Ausente \\
\hline ORTHOPTERA & & Comum & Comum & Comum & Ausente \\
\hline \multirow[t]{2}{*}{ PLECOPTERA } & Grypopterygidae & Comum & Comum & Comum & Freqüente \\
\hline & Perlidae & Comum & Freqüente & Freqüente & Freqüente \\
\hline \multirow[t]{12}{*}{ TRICHOPTERA } & & Ausente & Ausente & Raro & Ausente \\
\hline & Adulto & Ausente & Ausente & Comum & Ausente \\
\hline & Helycopsychidae & Ausente & Raro & Comum & Ausente \\
\hline & Hydropsychidae & Comum & Freqüente & Freqüente & Freqüente \\
\hline & Hydroptilidae & Ausente & Comum & Comum & Comum \\
\hline & Leptoceridae & Ausente & Raro & Raro & Ausente \\
\hline & Odontoceridae & Comum & Comum & Comum & Comum \\
\hline & Philopotamidae & Ausente & Comum & Comum & Comum \\
\hline & Polycentropodidae & Raro & Ausente & Ausente & Ausente \\
\hline & Rhyacophilidae & Raro & Ausente & Ausente & Ausente \\
\hline & Xiphocentronidae & Raro & Freqüente & Comum & Freqüente \\
\hline & Pupa & Ausente & Comum & Raro & Raro \\
\hline \multirow[t]{2}{*}{ CRUSTACEA } & Aegla sp & Comum & Comum & Comum & Comum \\
\hline & Amphipoda & Raro & Ausente & Ausente & Ausente \\
\hline MOLLUSCA & Gastropoda & Comum & Comum & Comum & Comum \\
\hline OLIGOCHAETA & Tubificidae & Comum & Comum & Raro & Freqüente \\
\hline
\end{tabular}


TABELA 2.3.7.2.15 - NÚMERO DE UNIDADES TAXONÖMICAS POR PONTO DE COLETA DURANTE O ESTUDO

\begin{tabular}{cccccccccccccccc}
\hline \hline & $\mathbf{1}$ & $\mathbf{2}$ & $\mathbf{3}$ & $\mathbf{4}$ & $\mathbf{5}$ & $\mathbf{6}$ & $\mathbf{7}$ & $\mathbf{8}$ & $\mathbf{9}$ & $\mathbf{1 0}$ & $\mathbf{1 1}$ & $\mathbf{1 2}$ & $\mathbf{1 3}$ & $\mathbf{1 4}$ & Total \\
\hline Verão & 8 & 5 & 4 & 2 & 8 & 6 & 6 & 8 & 11 & 4 & 2 & 6 & 6 & 9 & 30 \\
Outono & 6 & 7 & 10 & 7 & 9 & 7 & 6 & 15 & 24 & 17 & 15 & 12 & 15 & 16 & 39 \\
Inverno & 9 & 6 & 11 & 15 & 16 & 14 & 10 & 16 & 17 & 19 & 16 & 18 & 16 & 19 & 44 \\
Primavera & 20 & 14 & 17 & 14 & 18 & 18 & 5 & 17 & 17 & 14 & 18 & 18 & 13 & 12 & 38 \\
\hline
\end{tabular}




\subsection{DISCUSSÃO}

\subsubsection{VARIÁVEIS HIDRÁULICAS}

A análise da velocidade de corrente é especialmente importante para 0 estudo da fauna bentônica, uma vez que a colonização e retirada de organismos dependem, em parte, da velocidade de escoamento, assim como do transporte de alimentos, além de selecionar organismos adaptados à ação mecânica da água. A velocidade de corrente também está relacionada ao ciclo e à espiral de nutrientes, dentre outros processos (ALLAN, 1995).

A velocidade da corrente e a vazão do rio Betari mostraram relação com a precipitação e as características geomorfológicas da bacia, como era esperado. A variação da precipitação na bacia hidrográfica determinou períodos com escoamentos diferentes, que geraram modificações nas velocidades de corrente, nas vazões e no transporte de materiais. As vazões do rio Betari mostraram sua relação direta com a precipitação na bacia, aumentando nos meses chuvosos, e nos dias de coleta que coincidiram com chuvas. Também o esperado aumento da vazão de montante para jusante, graças à contribuição de afluentes, foi observado. Esse fato poderia não ocorrer, uma vez que o rio Betari drena terrenos cársticos, que são favoráveis ao desenvolvimento de sumidouros.

BEAUMONT (1975) citou que os maiores inputs em bacias hidrográficas se devem à precipitação e à energia solar, já o escoamento, transporte de sedimentos, evapotranspiração e re-radiação, são os outputs mais significativos.

Além do aspecto climático, agindo temporalmente, outro fator determinante da velocidade de corrente e da vazão são as características geomorfológicas da bacia, nesse caso, originando variações espaciais. Por estar encaixado em um vale profundo no seu alto curso e se abrir em um vale, 
ainda encaixado, no médio e baixo curso, as vazões e velocidades de corrente do rio Betari responderam rapidamente às chuvas.

Em função dessas características geomorfológicas, as águas do rio Betari também ficam confinadas na calha principal do rio que, dependendo da época do ano, pode se apresentar com maior ou menor volume de água. Outra característica que deve ser observada, em relação às rápidas respostas às precipitações, é a elevada densidade de drenagem da bacia, que favorece o rápido escoamento para o curso principal, o rio Betari.

Numa escala espacial menor, a velocidade de corrente também é determinada pelas características do canal. CHURCH (1996) comentou que o volume e o tempo de distribuição das águas das cabeceiras, a quantidade e tipo de sedimento que são transportados e depositados, a natureza do material através do qual o rio atravessa e a história geológica da região, são fatores primários na determinação da morfologia do canal. Já o clima, o tipo de vegetação marginal e o uso da terra na bacia de drenagem são fatores secundários. Desta forma, o rio pode percorrer regiões ao longo da bacia hidrográfica com diferentes características e, assim, apresentar canal com diferentes morfologias, onde se alternam poços, corredeiras, depósitos de seixos e trechos com fluxo menos turbulento. Isso explica as variações espaciais da velocidade, observadas no rio Betari. Em alguns trechos ocorreu fluxo mais turbulento com menores velocidades, mesmo com declividade significativa. Nesses pontos, o fundo é composto de lajes ou grandes rochas com partes emersas, correspondendo ao trecho entre as estações 2 e 5, como pode ser observado nas figuras 2.2.5 a 2.2.7; as declividades nessa região são superiores a $50 \%$. A estação 1 , que está localizada no final de um pequeno poço, inclusive com depósitos de areia e detritos vegetais, apresentou as menores velocidades. Na estação 8 , foram observadas velocidades menores e isto se deve a sua localização, no final de um poço do rio. Nos trechos em que a água escoa sobre um fundo de seixos, a velocidade é maior, já que o fluxo tende a ser mais laminar; este é o caso das estações 9, 11, 12, 13 e 14. Na 
estação 10, o rio apresentava um canal, artificialmente construído, mais profundo e com maiores velocidades.

Um aspecto importante a ser considerado na bacia hidrográfica do rio Betari, quando se estuda vazão, são suas características geológicas. A rocha calcária e o sistema cárstico formado vão proporcionar características particulares de retenção e escoamento de água subterrâneos, dependentes das fraturas e fissuras no calcário, com implicações no ciclo hidrológico regional.

No solo, a infiltração da água da chuva depende de fatores edáficos como umidade, permeabilidade, temperatura do solo e profundidade em que se localiza a camada impermeável. A permeabilidade é o fator preponderante e depende da cobertura vegetal, compactação, infiltração de materiais finos, dentre outros fatores (VILLELA e MATTOS, 1975). Quando saturado, o solo permite o escoamento superficial (BURT, 1996). Na rocha calcária, a presença de poros, fissuras e cavidades geram processos hidrológicos particulares, com diferentes tempos de retenção no maciço rochoso. Segundo SMITH (1993), nas rochas calcárias, as fissuras originadas pela dissolução da rocha armazenam água que pode suprir nascentes em períodos secos.

BURT (1996) comparou duas bacias hidrográficas na Inglaterra que apresentaram a mesma altura de chuva, e observou que as características físicas da bacia foram mais importantes que as climáticas, na determinação das vazões. Uma bacia apresentava solos argilosos permeáveis, mas compactados pela agricultura, com drenagem desenvolvida e topografia suave, outra com solos calcários, com elevada capacidade de infiltração e o escoamento principal subterrâneo. A primeira respondia rapidamente às chuvas com fluxos superficiais (runoff) e que não abasteciam o curso d'água no período seco; já na outra bacia, o fluxo sub-superficial prevalecia, com abastecimento contínuo do corpo d'água durante o ano.

As características morfométricas da bacia hidrográfica do rio Betari indicam que ela não deve ser suscetível a enchentes, e as características morfológicas sugerem que a água das chuvas atingem rapidamente o rio Betari, 
porém a rocha calcária pode reter água, retardando sua chegada ao rio. Isso mostra a complexidade de fatores que determinam o ciclo hidrológico nesse sistema.

\subsubsection{VARIÁVEIS ABIÓTICAS}

A variação da temperatura da água está relacionada à temperatura do meio aéreo circundante. Assim, uma variação sazonal é esperada (HYNES, 1970), com maiores valores nos meses mais quentes e menores valores nos meses frios. As águas do rio Betari se comportaram dessa forma, e as maiores temperaturas foram observadas no verão. Segundo HYNES (op. cit.), outra variação temporal esperada é a nictimeral, quando ocorre aquecimento diurno e perda de calor à noite; desta forma, temperaturas maiores devem ocorrer à tarde e menores no início da manhã.

Em uma escala de tempo intermediária à sazonal e à nictimeral, estão as variações diárias na temperatura, que podem ocorrer devido a diferentes coberturas de nuvens ou modificações na temperatura do ar, por exemplo, devido ao avanço de frentes frias, muito comuns na região estudada. Nesses casos, são observadas variações de temperatura de um dia para o outro, no mesmo ponto de amostragem.

As maiores variações de temperatura da água num mesmo período de estudo ocorreram na coleta de inverno, tanto longitudinal, quando temporalmente. Nesse período, o volume de água é menor e as respostas podem ser mais rápidas; desta forma, o sistema pode ganhar ou perder calor mais facilmente, e as entradas passam a ser mais significativas. As entradas subterrâneas podem ter influenciado as temperaturas observadas, assim como chuvas, que ocorreram no terceiro dia de coleta, quando a temperatura subiu. Nesse período, fica também evidente a relação com a temperatura do meio aéreo, pois no primeiro dia de amostragem (21/07/00), apesar de não existirem registros, foram feitas coletas depois de uma noite com geadas, portanto a 
temperatura do ar esteve abaixo de $0^{\circ} \mathrm{C}$. Na coleta do outono, também com amplitudes térmicas maiores, provavelmente, a temperatura do ar e a insolação devem ter influenciado as variações observadas, já que foi um período que alternou dias ensolarados e nublados.

As variações longitudinais da temperatura observadas durante o estudo se devem a dois efeitos principais. Nos pontos próximos à cabeceira, a incidência de radiação solar, que aqueceria o sistema, é menor devido à presença da vegetação ciliar e ao fato de o rio ser bastante encaixado num canyon, gerando sombras em algumas horas do dia. Na porção média do rio, o vale se abre e a vegetação ciliar foi suprimida pela ocupação humana, a insolação é maior, propiciando maior aquecimento.

Também as diferenças de altitude podem gerar diferenças longitudinais na temperatura. A estação de coleta 1 está localizada a uma altitude aproximada de $350 \mathrm{~m}$ e a estação 14 , a $80 \mathrm{~m}$. As nascentes do rio Betari e de muitos afluentes estão em altitudes próximas aos $900 \mathrm{~m}$.

Deve-se considerar, porém, o fato de as medidas de temperatura dos pontos nas regiões média e baixa do rio Betari terem sido feitas à tarde, permitindo que ocorresse ganho de calor pelo sistema hídrico. RIOS (1993) considerou que os dois fatores, horário de amostragem e, principalmente a cobertura vegetal, influenciaram os resultados de temperatura encontrados no ribeirão do Feijão, em São Carlos (SP). NECCHI et al. (1996) estudaram variação nictimeral da temperatura no córrego da Barra Funda, noroeste do estado de São Paulo, e verificaram que as menores temperaturas ocorreram às $06 \mathrm{~h} 00$ no outono e inverno, e às $08 \mathrm{~h} 00$ na primavera e verão. As máximas ocorreram às $14 \mathrm{~h} 00$ no verão, e às $16 \mathrm{~h} 00$ nas demais estações do ano.

O outro fator que pode ter influenciado a temperatura no rio Betari são as drenagens sub-superficiais. No inverno, ao percorrerem alguns quilômetros no interior de condutos subterrâneos, podem receber e transportar energia que foi absorvida pelas rochas e solo, para o rio, contribuindo para elevação da temperatura em alguns pontos. No verão, pode ocorrer o processo inverso, com 
o aporte no rio, de águas com temperaturas menores, provenientes dos sistemas sub-superficiais.

Portanto, a temperatura do rio Betari pode ter sido influenciada longitudinalmente pelas características geomorfológicas (altitude, relevo e carste) e ocupação da bacia (supressão da vegetação ciliar), e temporalmente pelas características climáticas (temperatura do ar, insolação e frentes frias).

Segundo ALLAN (1995), as características químicas das águas de rios são altamente variáveis, especialmente em riachos e pequenos rios, como o Betari. A composição química e a quantidade de materiais dissolvidos nesses corpos d' água variam grandemente com a sua localização, devido à geologia local, e com as estações do ano, devido à precipitação, à posição no continuum fluvial e à extensão da influência antrópica.

A geologia da bacia hidrográfica é um fator que influencia as variáveis limnológicas dos sistemas lóticos. CAMARGO et al. (1997) determinaram essas influências em rios na bacia hidrográfica do rio Itanhaém, São Paulo, correlacionando vários parâmetros limnológicos entre rios (de águas claras, pretas e brancas) que drenam áreas com características geológicas distintas.

Áreas cársticas, como a bacia hidrográfica do rio Betari, apresentam características geológicas particularmente importantes na determinação de várias características químicas dos corpos d'água, influenciando $\mathrm{pH}$, alcalinidade, concentração de carbonatos, bicarbonatos, íons cálcio e magnésio, precipitação de diversos metais e também condutividade elétrica.

$\mathrm{O} \mathrm{pH}$ e a condutividade elétrica estão entre os parâmetros que são influenciados pelas características geológicas da área drenada. HYNES (1970) citou que $\mathrm{o} \mathrm{pH}$ e as formas de carbono, cálcio e magnésio, apresentam uma relação complexa entre si e suas concentrações variam com a estrutura geológica da bacia hidrográfica. Segundo GOLTERMAM (1975), em rios e lagos com baixa interferência humana, a concentração de bicarbonato de cálcio nas águas é o principal regulador do $\mathrm{pH}$. 
A dissolução da rocha calcária é o principal agente determinante do relevo cárstico. Nesse processo, os ácidos presentes nas águas, principalmente o ácido carbônico, que passam por fissuras, reagem com carbonato de cálcio (insolúvel), liberando bicarbonato (solúvel) e cálcio. O bicarbonato é convertido em carbonato quando a solução entra em contato com a atmosfera ou água com maiores concentrações de $\mathrm{CO}_{2}$.

A solução bicarbonatada originada da dissolução da rocha, ao atingir o meio aéreo subterrâneo, apresenta elevadas concentrações de carbonatos e bicarbonatos. WHITE (1988) encontrou concentrações superiores a $400 \mathrm{mg} / \mathrm{L}$ de carbonato de cálcio na água que percola espeleotemas. Os rios subterrâneos são enriquecidos com a solução de carbonatos e bicarbonatos, originada da dissolução da rocha calcária. Ao mesmo tempo, ocorre uma neutralização dos ácidos, elevando o pH. Esses processos podem variar com o regime pluviométrico da região e o fraturamento das rochas, que permitem a passagem da solução com diferentes velocidades.

Diversos rios subterrâneos deságuam no Betari (rio Água Suja, rio Roncador, córrego Ouro Grosso, córrego Seco, rio Alambari, rio Areias, dentre outros), ou são afluentes que recebem descargas de rios subterrâneos, como 0 córrego Grande. Vale ressaltar que outros rios drenam áreas com características geológicas diferenciadas (filitos), como o córrego do Sem Fim. Essas diferentes contribuições podem gerar variações nas características físicas e químicas da água.

WISSMAR et al. (1997), estudando rios que drenam uma bacia hidrográfica com características geológicas distintas na ilhas Prince of Wales, no Alasca, observaram que a dissolução da rocha calcária era responsável pelas elevadas alcalinidades, maiores que 1254 i eql, e pH maior que 7, como observado na bacia hidrográfica do rio Betari neste estudo. Os autores também encontraram elevadas concentrações de cálcio e magnésio, e associaram à dissolução da rocha calcária. Em rochas ígneas $\mathrm{o} \mathrm{pH}$, alcalinidade $\mathrm{e}$ concentração de carbonatos foram menores. 
No rio Betari, os valores de $\mathrm{pH}$ oscilaram dentro de um mesmo período de estudo, e entre os períodos, demonstrando que esta variável sofre influência de diversos fatores, o que dificulta sua explicação. Nas estações localizadas no trecho médio do rio, os valores médios do $\mathrm{pH}$ mostram-se maiores no período chuvoso; já nas estações de coleta do trecho do alto curso, foram maiores no período seco.

No curso superior, região com maior cobertura vegetal intacta, possivelmente 0 aporte de ácidos, originados pela decomposição de material orgânico da vegetação, conduzidos para o corpo d' água no período de chuvas, fez com que o pH diminuísse, além da diluição dos bicarbonatos e carbonatos. Nessa região da bacia, as respostas devem ser rápidas devido à declividade da área; assim, a água ao atingir o solo, que pode estar saturado nesse período, tende a escoar superficialmente e sub-superficialmente, carreando os ácidos. As maiores oscilações de $\mathrm{pH}$ ocorreram no período chuvoso, e oscilações em outros períodos coincidiram com chuvas durante a coleta. Na coleta de janeiro, pôde-se observar que o pH se elevou com a diminuição das chuvas durante o estudo. Também em outubro, a chuva durante a coleta parece ter diminuído os valores de $\mathrm{pH}$. No período mais seco do ano, os valores foram maiores e menos oscilantes.

No médio curso do rio, as declividades são menores, permitindo maior infiltração, e muitos tributários drenam cavernas, e as concentrações de carbonatos e bicarbonatos e a alcalinidade tendem a aumentar nessas regiões. Isso explica as variações longitudinais observadas. Os valores de $\mathrm{pH}$ parecem ter aumentado de montante para jusante. Nos médio e baixo curso, o rio Betari drena áreas onde predominam calcários, enquanto que nas cabeceiras ocorrem quartzitos e metassedimentos síltico-argilosos (figura 1.4.2).

Fatores pontuais que poderiam gerar essas diferenças seriam: entrada de efluentes orgânicos, fato que parece não ter gerado grandes modificações nesse sistema; o desmatamento da bacia, que permitiria o escoamento de substâncias que modificariam o pH, através do escoamento superficial e pelos 
afluentes; e supressão da vegetação ciliar, que permitiria a retirada de $\mathrm{CO}_{2}$ da água pelo processo fotossintético, colaborando para o aumento do $\mathrm{pH}$. Esta ultima hipótese não parece interferir nesse sistema, não pela integridade da vegetação ciliar, mas porque em águas ricas em carbonatos e bicarbonatos, o $\mathrm{CO}_{2}$ é rapidamente reposto, graças à dissociação desses íons (ESTEVES, 1988).

Os valores de alcalinidade observados no rio Betari foram elevados, se comparados aos de outros rios brasileiros (LAGE FILHO, 1996; NECCHI et al., 2000; OLIVEIRA e CALHEIROS, 1998; PRIMAVESI, et al 2000; RIOS, 1993), porém esses rios não drenavam áreas cársticas e, como observa NECCHI et al. (2000) e PRIMAVESI et al. (2000), a alcalinidade está intimamente relacionada ao $\mathrm{pH}$.

A alcalinidade variou da mesma forma que as concentrações de carbonato; longitudinalmente, ocorreu uma tendência de aumento de jusante para montante, e temporalmente variou com as chuvas, aumentando no período seco. Novamente pode-se relacionar essas observações à maior densidade de tributários drenando o carste no médio e baixo curso do rio, à presença de outro tipo de litologia no alto curso e aos efeitos de diluição provocados pela chuva. A condutividade elétrica também parece ter sido influenciada dessa forma.

Segundo BAKALOWICZ (1994), o tempo de residência nas fissuras ou o tempo de contato com a rocha calcária é determinante da concentração de solutos na água. Desta forma, em períodos chuvosos, a velocidade de escoamento é maior, diminuindo o tempo de contato e a concentração de solutos.

Os valores de condutividade elétrica observados no rio Betari foram relativamente elevados. Foram aproximadamente 3 vezes maiores que os observados por NECCHI et al (1996) no córrego da Barra Funda, em São José do Rio Preto, e por NECCHI et al. (2000) na bacia hidrográfica do rio São Francisco, no Parque Nacional da Serra da Canastra, sistemas ainda preservados. Também foram superiores aos dos rios Borá, Preto e São José 
dos Dourados, em diferentes bacias hidrográficas, pertencentes à Grande Bacia do Paraná, estudados por BRANCO e NECCHI (1997).

A dissolução da rocha calcária também é uma possível explicação para esses valores de condutividade no rio Betari. Como foi citado por BACK \& ARENAS (1989), a quantidade de sais dissolvidos (carbonatos e bicarbonatos) pode provocar a formação de cálculos em pessoas que consomem esse tipo de água, o que demonstra ser significativo esse efeito. Em algumas regiões, a água acumulada na rocha calcária é salobra. As elevadas concentrações de carbonatos e bicarbonatos também apóiam essa hipótese, e devem ser somados a outros íons que se mostraram em concentrações elevadas (cálcio, magnésio e sódio) e os demais nutrientes.

Em outubro, porém, nos pontos localizados a montante do bairro da Serra, pode-se observar que a condutividade aumentou. Nesse período iniciaram as chuvas e o efeito da diluição de íons não ocorreu, ao contrário, como se tratava das primeiras chuvas e da região com maior ocupação e uso da bacia, o carreamento de íons deve ter contribuído para o aumento da condutividade.

A concentração de íons cálcio, sódio e magnésio, na água do rio Betari, sempre esteve acima dos limites de detecção dos métodos utilizados (15 mg/L, $2 \mathrm{mg} / \mathrm{L}$ e $2 \mathrm{mg} / \mathrm{L}$, respectivamente). As concentrações elevadas de cálcio e magnésio devem estar associadas à dissolução da rocha calcária, que apresenta esses elementos químicos em sua constituição.

Outro fator que pode elevar as concentrações de cálcio é a supressão da vegetação, que pode provocar, além de erosão, aumento da taxa de troca iônica, liberando mais cálcio do solo, como observaram OCHIAl et al. (2000).

Segundo ALLAN (1995), o cálcio é o cátion mais abundante nos rios e, juntamente com magnésio, se originam do intemperismo das rochas. $\mathrm{O}$ sódio, além da origem geológica, pode ocorrer devido a aerossóis de origem marinha e esgoto doméstico. 
As elevadas concentrações de cálcio e magnésio podem estar relacionadas às concentrações de sódio. Segundo BAKALOWICZ (1994), cálcio e magnésio são os principais cátions trocados com sódio em argilas (troca catiônica).

Segundo ESTEVES (1988), a origem desses íons em ambientes continentais está relacionada às condições geológicas da região e se devem ao intemperismo de rochas e solos, que posteriormente é escoado aos corpos d' água. CASSIANO (2001) observou que pilhas de rejeito de mineração semelhante às da mina de Furnas, podem liberar cálcio e magnésio nos períodos chuvosos. Nesse caso, o rio Furnas transportaria esses íons para o rio Betari.

$\mathrm{NECCHI}$ et al. (2000) encontraram concentrações baixas de cálcio em rios que drenam rochas pré-cambrianas, onde predominam quartzitos e micaxistos, no Parque Nacional Serra da Canastra, em Minas Gerais. Já WISSMAR et al. (1997), relacionaram as elevadas concentrações de cálcio, principalmente, e de magnésio aos processos de dissolução da rocha calcária em rios no Alaska. OMETO et al. (2000) também encontraram forte correlação entre as concentrações de cálcio e magnésio e a alcalinidade nos rios Pisca e das Cabras (São Paulo) e associaram ao uso de calcário para correção do pH do solo, na região de Piracicaba. Os autores consideraram, ainda, que o esgoto doméstico e áreas agrícolas são fontes de sódio para os rios.

Outros íons analisados neste estudo no rio Betari foram os considerados nutrientes e os metais pesados. Estes últimos podem gerar modificações nos ecossistemas, interferindo, principalmente, na comunidade biológica. WHITTON e SAY (1975) citaram que os organismos que sobreviveram aos efeitos dos metais pesados, mostraram a contaminação através da diminuição da taxa de crescimento, redução da capacidade de completar alguns estágios do ciclo de vida, acúmulo das substâncias no organismo, que são transferidas pela cadeia alimentar. 
GOLTERMAN (1975) e ESTEVES (1988) citaram que as principais fontes naturais desses elementos são a dissolução e o intemperismo que as rochas sofrem. Exposição de solo e atividades de mineração são processos, provocados pelo ser humano, que aceleram a ciclagem desses elementos e, conseqüentemente, seu aporte aos sistemas hídricos. Outras fontes geradas por processos antrópicos são os efluentes industriais, domésticos e áreas onde são utilizados defensivos agrícolas (ESTEVES, 1988).

Considerado um elemento traço, o zinco ocorreu em todos os períodos de estudo e não foi detectado somente em 3 estações de coleta no mês de outubro. Deve-se ressaltar que suas concentrações estiveram acima dos limites estabelecidos pela Resolução CONAMA 020/86 (0,18 mg/L) no ponto 7, exceto na coleta de outubro, quando a concentração observada foi de $0,15 \mathrm{mg} / \mathrm{L}$.

EYSINK et al. (1988) encontraram concentrações de zinco da ordem de 0,001 a $0,1 \mathrm{mg} / \mathrm{L}$ na água do rio Betari e CASSIANO (2001) observou que as concentrações de zinco estiveram, em grande parte de suas análises, acima dos valores limites, tanto na água, quanto no sedimento deste rio. A autora citou que a mina de Furnas apresenta um minério com maiores teores de zinco que outras minas do mesmo tipo.

Além do intemperismo na bacia do rio Betari, a exposição de rejeitos de mineração é uma fonte de metais pesados para o rio. Comprovadamente, a mina do Furnas, como é chamada, é uma fonte de zinco e outros metais (CASSIANO, 2001). Porém, existem outras minas abandonadas (chumbo e calcário) na bacia (CPRM, 1974a), como pode ser observado na figura 1.4.1, sem comprovação da presença de rejeitos. O zinco encontra-se, freqüentemente, associado a outros minerais.

Segundo OSSANI (1979), o zinco, muitas vezes, encontra-se associado a sulfetos de outros metais, principalmente chumbo, cobre e ferro.

JENSEN et al. (1998) encontraram concentrações de até $10 \mathrm{mg}$ de zinco/L no rio Orkla (Noruega), um sistema que apresenta em sua bacia hidrográfica intensa atividade minerária de pirita (minério de cobre). Esses 
valores são bem superiores às concentrações de zinco encontradas no rio Betari, que apresentou valores próximos aos encontrados em rios amazônicos (ESTEVES, 1988). JENSEN et al. (1998) observaram que maiores concentrações de zinco ocorreram no período seco, em que as concentrações também foram maiores no rio Betari. Dois fatores podem estar ligados a isso: a diluição no período chuvoso e a associação desse elemento com substâncias orgânicas ou inorgânicas. A quantidade de sólidos orgânicos em suspensão foi maior no período chuvoso e, provavelmente, os compostos orgânicos dissolvidos devem ter aumentado nesse período, graças ao runoff. DUDGEON \& BRETSCHKO (1996) citaram que a entrada de material orgânico pode ocorrer pela queda direta no sistema aquático (aerial drift), runoff e através de importações sub-superficiais. Compostos húmicos e fúlvicos são os principais ligantes orgânicos, e os íons bicarbonatos, carbonatos, hidróxidos, sulfatos e fosfatos são os principais ligantes inorgânicos dos elementos traços.

Segundo CASSIANO (2001), o Distrito Mineral de chumbo, zinco e prata do Vale do Ribeira foi um dos maiores produtores de chumbo do Brasil, operando de 1920 a 1995. As principais minas produtoras foram: Furnas, Panelas, Barrinha, Rocha, Perau e Canoas. A mina de Furnas encerrou suas atividades em 1993, mas existem 9 pilhas de resíduos estéreis com predominância de material calcário $(6093,5$ t) e 3 pilhas de minério piritoso (2081,87 t) que são possíveis focos de contaminação (CORSI, 1998). CASSIANO (op cit.) considerou essas pilhas de rejeitos e sedimentos contaminados, além de outras localizadas na região do Alto Ribeira, como as duas principais fontes de elementos traços para o rio Ribeira de Iguape e seu estuário. O rio Betari faz parte do sistema de transporte e armazenamento desses elementos para o rio Ribeira de Iguape.

EYSINK et al. (1988) analisaram a presença de metais pesados nas águas do rio Betari e encontraram cobre $(0,004 \mathrm{mg} / \mathrm{L})$, traços de cádmio e chumbo (até $0,1 \mathrm{mg} / \mathrm{L}$ ), além de zinco. No sedimento, as concentrações encontradas pelos autores foram bastante elevadas. Essas análises foram 
realizadas quando a mineradora CAF - Argentífera Furnas (mina de Furnas) ainda estava em operação.

$\mathrm{Na}$ bacia do rio Stillwater, em Montana (Estados Unidos), GURRIERI (1998) estudou os efeitos de minerações na concentração de metais. O zinco foi rapidamente removido da coluna d'água por adsorção a óxidos de ferro e deposição no sedimento.

Longitudinalmente, o zinco apresentou aumento no ponto 7, o tributário que drena a antiga mineração, mas decaiu e, abaixo do ponto 9 , os valores encontrados foram semelhantes aos dos pontos localizados a montante do ponto 7 , fato que pode estar associado à diluição, devido à entrada de outros tributários a jusante do rio Furnas, e à complexação desse metal com compostos orgânicos e inorgânicos, provocando sua precipitação. Ao contrário do zinco, nesse estudo o chumbo só foi detectado na coleta de janeiro, nas estações 7,8 e 9 . A estação 7, como citado acima, está localizada no rio Furnas, que drena a região da antiga mineradora.

As concentrações de chumbo encontradas na água não atingiram os limites estabelecidos pela Resolução CONAMA 020/86, de 0,03 mg de chumbo/L. EYSINK et al. (1988) encontraram concentrações de chumbo, no rio Betari, superiores aos limites determinados para abastecimento e para preservação da vida aquática (Resolução CONAMA 020/86), quando a mina ainda estava em atividade.

Os estudos de CASSIANO (op cit.), simulando lixiviação em pilhas de rejeitos, demonstraram que, após chuvas, ocorre a dissolução de sulfatos, principalmente de cálcio e magnésio e, com isso, pode ocorrer a oxidação de sulfetos associados ao chumbo na base das pilhas. Os sulfetos migram para a superfície na forma de sulfatos epiflorescentes, nos períodos secos. Nesse caso, o transporte mecânico prevaleceria sobre o químico. Testes ecotoxicológicos demonstraram que os rejeitos apresentam risco para os ecossistemas aquáticos. 
As concentrações das formas nitrogenadas não apresentaram um padrão definido ao longo do estudo. Os valores das formas nitrogenadas observados foram baixos, quando comparados a outros rios do Estado de São Paulo, com bacias hidrográficas antropizadas. Em rios da bacia do rio Sorocaba, SMITH e PETRERE JR (2000) encontraram concentrações de nitrogênio amoniacal e nitrito, variando de 0,06 a $0,11 \mathrm{mg} / \mathrm{L}$ e 0,01 a $0,9 \mathrm{mg} / \mathrm{L}$, respectivamente. SILVA et al. (1998) também encontraram valores superiores de nitrogênio total no rio Pardo, em Botucatu, e aos de nitrito obtidos por PRIMAVESI et al. (2000) no ribeirão Canchim, em São Carlos. Em comparação aos rios Pisco e das Cabras, ambos pertencentes à bacia do rio Piracicaba, com diversas influências antrópicas, os valores de amônia e nitrato do rio Betari foram inferiores (OMETO et al., 2000). CAMARGO et al. (1996) encontraram valores próximos aos do rio Betari de nitrogênio total e amoniacal, em rios da costa sul de São Paulo, que drenam a Mata Atlântica, em bacias com maior grau de preservação.

A origem do nitrogênio nos rios pode estar relacionada a processos internos e externos. A entrada de material orgânico alóctone é uma fonte importante em alguns sistemas, como deve ser o caso do rio Betari, que drena uma bacia com cobertura vegetal significativa e com vegetação ciliar intacta em grande parte de seu curso. Também devem ser consideradas as entradas de nutrientes dissolvidos, provocadas pela precipitação na bacia e possíveis contaminações por esgotos domésticos. ALLAN (1995) citou que a fixação de nitrogênio gasoso por bactérias e cianobactérias é uma importante fonte autóctone em ambientes onde o nitrogênio é limitante. As baixas concentrações das frações do nitrogênio sugerem que as entradas alóctones, promovidas pela vegetação ciliar, devem ser o principal contribuinte.

Nitrato foi a forma de nitrogênio inorgânica predominante no rio Betari, provavelmente graças às elevadas concentrações de oxigênio dissolvido que favorecem a oxidação biológica da amônia e do nitrito. ALLAN (op cit.) comentou que, em sedimentos de grande granulometria e oxigenados, como na 
maioria dos pontos de coleta do rio Betari, a nitrificação pode ser elevada. Já a desnitrificação, que poderia diminuir as concentrações das frações de nitrogênio, é pouco significativa nesses ambientes. STEINHART et al. (2000) demonstraram que, em rios norte-americanos, a desnitrificação é elevada em depósitos de detritos orgânicos, e que em sedimentos arenosos, a perda de nitrato da água pela desnitrificação não foi significativa. Os depósitos de detritos vegetais no rio Betari não são grandes e se limitam a poços mais profundos. Pelo contrário, detritos retidos entre seixos podem ser colonizados por microrganismos, que assimilam formas nitrogenadas ou intensificam a nitrificação. Isto foi observado por WEBSTER et al. (2000) na Carolina do Norte, em rios com vegetação ciliar, que fornece grande quantidade de detritos.

Existiu uma tendência de aumento dos valores médios de nitrato a partir da estação de coleta 3. Até esse ponto, o rio é encachoeirado, com grandes pedras e poços que podem reter volumes maiores de detritos. A partir do ponto 4 , ocorrem seixos menores, e menor volume de detrito é retido entre eles, o que pode permitir a colonização por bactérias nitrificantes, que têm disponível oxigênio suficiente para realizar seu metabolismo.

$\mathrm{Na}$ coleta de julho, período seco, ocorreu um aumento da concentração das formas de nitrogênio (amônia, nitrito e nitrato), que coincidiu com uma intensa precipitação. Ocorreu uma chuva depois de quase um mês sem precipitação e, nesse caso, os nutrientes podem ter suas concentrações elevadas, graças ao carreamento de materiais pelo escoamento superficial.

WOLLHEIM, et al. (2001) consideraram que os processos controladores das concentrações de amônia, em rios de regiões árticas, estavam relacionados às suas características físicas (profundidade e velocidade da corrente) e que em pequenos rios, com rápidas mudanças nessas características, a amônia é mais rapidamente metabolizada.

As concentrações de nitrito, nitrato e nitrogênio orgânico, no período seco somente, apresentaram tendência de aumento nos pontos localizados a jusante do bairro da Serra e na área com maior ocupação da bacia, como 
mostram os valores médios. Não se podem descartar entradas pontuais de esgotos domésticos e da criação de animais, assim como o uso de fertilizantes em algumas regiões da bacia e seu aporte para o corpo d' água.

PERONA et al. (1999) observaram que ocorria aumento das frações inorgânicas do nitrogênio e de fosfatos no rio Alberche, Espanha, no verão, período que coincidia com o aumento da população flutuante em férias. Os autores dividiram o rio em duas porções: a região superior, com pequena ocupação humana e substrato silicoso, apresentava águas mais pobres em nutrientes e de baixa composição iônica; e a inferior, com construções e efluentes domésticos, que geraram eutrofizações sazonais.

As variações observadas nas frações de nitrogênio e também em outros nutrientes e íons, como fósforo, podem estar relacionadas à entrada de tributários. SULLIVAN e DREVER (2001) observaram que nas Montanhas Rochosas, no riacho Peru, que apresenta diversas minas abandonadas na bacia, os tributários provocaram diluição ou concentração de íons (dependendo do íon analisado, como nitrato) e, ainda, a precipitação de metais.

Os valores de nitrato e nitrito no rio Betari, assim como o de fosfato total observados, estiveram abaixo dos limites determinados pela Resolução CONAMA 020/86, para rios da classe I.

As frações do fosfato também apresentaram oscilações diárias, sazonais e espaciais, que podem estar relacionadas a entradas por tributários ou pelo escoamento superficial, tanto de formas orgânicas quanto inorgânicas, entrada de detritos orgânicos que são decompostos, liberando fósforo, e até devido a efluentes, mesmo que diluídos, e possivelmente, fertilizantes.

HENRY e GOUVEIA (1993) encontraram valores para fosfatos inorgânicos e totais dissolvidos, em um rio da bacia do Alto Paranapanema, semelhantes aos encontrados no rio Betari, porém, deve-se ressaltar que se tratavam de áreas com diferentes usos, com predomínio de pastagens. ALLAN (1995) citou que as águas naturais apresentam concentrações de fosfato inorgânico e fosfato total dissolvido baixas, da ordem de 0,01 mg/L e 0,025 
$\mathrm{mg} / \mathrm{L}$, respectivamente, valores semelhantes aos observados no rio Betari. Concentrações maiores podem estar relacionadas a esgotos domésticos, como foi observado por CAMARGO et al. (1996) e RIOS (1993).

Maiores concentrações de fosfatos inorgânicos nas estações localizadas na região superior da bacia podem estar relacionadas à maior taxa de mineralização da serapilheira e liberação de fosfatos, que são conduzidos para o corpo d'água, como observou AFONSO (1993) no córrego Itaúnas, em Itatinga, São Paulo.

Outra possível causa para variações longitudinais da concentração de fosfato pode estar relacionada com a absorção desse nutriente por microrganismos heterotróficos, que ocorrem associados a detritos. Isto pode ter contribuído para a diminuição do fosfato nos trechos médio e baixo do rio que, como comentado anteriormente, parecem reter mais detritos entre os seixos. Este processo foi observado por WEBSTER et al. (2000) em rios de primeira ordem, ainda não perturbados, na Carolina do Norte. Desta forma, a região superior do rio pode ser fornecedora de fósforo, que é metabolizado nos trechos inferiores pelos microrganismos.

KRONVANG et al. (1999) também verificaram que, dependendo da concentração de nutrientes e da morfologia do sistema, ocorre retenção de fósforo particulado em bancos de sedimento.

As concentrações de fosfatos podem ser influenciadas pelas concentrações de cálcio e carbonatos, como citado por ESTEVES (1988), pois ocorre a formação de fosfato de cálcio ou a adsorção em cristais de carbonato de cálcio. A diminuição de concentração de fosfatos ao longo do rio Betari também pode estar relacionada à disponibilidade de cálcio e carbonatos no sistema.

Em julho ocorreu uma queda nas concentrações de fosfato inorgânico em todos os pontos de coleta, no terceiro dia de amostragem, fato que coincidiu com uma precipitação com altura de chuva significativa para o período $(20,50 \mathrm{~mm})$, depois de longo tempo de estiagem. Isto sugere que o fósforo pode 
estar no corpo d' água, em equilíbrio com o fósforo do sedimento e, por efeito d diluição e arraste, diminuiu.

A dinâmica das concentrações de fosfato foi observada por HOUSE e DENISON (1997) no rio Great Ouse, na Inglaterra. Os autores analisaram a capacidade de absorção, as propriedades físicas e químicas do sedimento e estimaram possíveis trocas com o corpo d' água e o sedimento. No período chuvoso, ocorreu diluição e, no verão, a precipitação dos fosfatos, quando a vazão foi menor.

Os silicatos ocorreram em maior concentração nos pontos localizados no alto curso do rio Betari, na região da bacia com maiores áreas de quatzitos e epiquartzitos, como pode ser observado na figura 1.4.2. Esta região também apresentou menores valores de $\mathrm{pH}$, que favorecem a solubilização. Temporalmente, no período mais seco, quando a vazão é menor, as concentrações de silicatos foram maiores, possivelmente causada pela menor diluição. Os menores valores observados nos dias que coincidiram com chuvas, nas coletas de janeiro e outubro, parecem corroborar essa hipótese. Porém, a chuva ocorrida no período seco parece não ter afetado as concentrações de silicato. Talvez o carreamento tenha compensado a diluição.

HOUSE e DENISON (1997) verificaram que a solubilidade do quartzo foi maior no verão, o que justifica os maiores valores observados pelos autores nesse período. Os autores também sugeriram que o decréscimo de silicatos de montante para jusante pode estar relacionado à assimilação por diatomáceas bentônicas. Deve-se ressaltar que o sistema estudado recebe efluentes de estações de tratamento e drena depósitos calcários.

Segundo GOLTERMAN (1975), os silicatos que ocorrem em águas alcalinas estão na forma de $\mathrm{Si}(\mathrm{OH})_{4}$ ou $\mathrm{SiO}_{2}$, e sua origem nos sistemas lóticos se deve ao intemperismo químico e à erosão, sendo que esta pode liberar partículas maiores. GOLTERMAN (op. cit.) citou que a solubilidade pode ser maior em menores valores de pH e ALLAN (1995) mostrou que, nos trópicos, a dissolução é maior, devido à temperatura. 
Os valores médios de $\mathrm{pH}$ e de silicatos variaram inversamente, segundo o coeficiente de correlação de Pearson $(-0,88,-0,72,-070$ e $-0,84$ para janeiro, abril, julho e outubro, respectivamente). Nos pontos em que o $\mathrm{pH}$ foi maior, em diferentes períodos de coleta, a concentração de silicatos reativos foi menor.

As concentrações de oxigênio dissolvido sempre estiveram elevadas durante o estudo. Isto se deve à grande turbulência do sistema, provocada pela declividade e morfologia do substrato, que promove a oxigenação. Maiores valores no inverno e nos pontos de coleta localizados abaixo do ponto 9 foram observados. No inverno, devido às menores temperaturas, podem-se esperar maiores concentrações, pois a dissolução dos gases é maior. Isto também foi observado por RIOS (1993) nos ribeirões do Feijão, Laranja Azeda e nos córregos São José e Monjolinho, em São Carlos, e é o comportamento esperado para este fator em condições naturais, sem interferência humana.

As águas de um rio em condições normais, com extensões e volumes consideráveis e sem contaminações orgânicas, apresentam uma taxa de oxigênio dissolvido próxima à saturação, ou seja, próximo ao equilíbrio com a pressão parcial do gás no ar (PENNAK, 1971).

A segunda tendência em relação às concentrações de oxigênio dissolvido, maiores valores a partir do ponto 9 , podem estar relacionadas à produção primária pelo perifíton, já que a partir desse ponto, parte da vegetação ciliar foi suprimida, permitindo maior insolação no sistema.

As águas do rio Betari sempre se apresentaram bastante transparentes, tanto que a turbidez só foi detectada no verão e, mesmo assim, apresentou valor elevado somente no ponto de coleta 11 , no segundo dia de amostragem, permanecendo baixo nos demais.

Também as concentrações de sólidos em suspensão mostraram duas tendências. Temporalmente, foram observadas maiores concentrações nos períodos chuvosos e menores nos secos. O transporte de partículas pelo escoamento superficial da água da chuva pode ser responsável por esse aumento, assim como a ressuspensão de partículas pode ter colaborado com 
esses valores. A turbidez só pôde ser medida no período de maior precipitação, mesmo assim, apresentou valores baixos. NECCHI et al. (1996) também relacionaram maiores valores de sólidos em suspensão com períodos chuvosos.

A ação da precipitação no transporte de partículas foi bastante evidenciada nas coletas de janeiro e julho, quando precipitações, durante as coletas, elevaram as concentrações de sólidos em suspensão. Os sólidos orgânicos e inorgânicos em suspensão aumentaram no período chuvoso, mas os sólidos inorgânicos mostraram aumentos maiores, portanto, ocorreu maior aporte de material inorgânico.

RIOS (1993) relacionou os maiores valores de material orgânico em suspensão, encontrados no ribeirão do Feijão, com a integridade da bacia, já que ela apresentava maior porcentagem de cobertura vegetal. Apesar de a cobertura vegetal da bacia hidrográfica do rio Betari se manter, em sua maior parte, íntegra, os valores de material orgânico não superaram os de inorgânico. RIOS (1993) citou que na cabeceira do rio estudado, as maiores declividades favoreciam o transporte de material orgânico da vegetação ciliar para o sistema. Já as concentrações maiores de sólidos inorgânicos, foram associadas pelo autor ao uso e ocupação desordenada da bacia. A grande declividade nas cabeceiras do rio Betari também favoreceu o transporte do material orgânico, produzido pela vegetação, para o corpo d' água; na região do médio e baixo curso do rio Betari, a ocupação humana pode ter influenciado a concentração de sólidos inorgânicos observados nesse estudo.

A ação antrópica, intensificada na porção média e inferior do rio Betari, justificaram a variação espacial observada na concentração de sólidos totais, quanto aos sólidos inorgânicos, já que valores bem maiores ocorreram nas regiões médias e baixas do curso.

Os valores de DBO encontrados no rio Betari durante o estudo nunca estiveram próximos do limite estabelecido pela Resolução CONAMA 020/86 de $3,0 \mathrm{mgO}_{2} / \mathrm{L}$, para águas da classe 1 . A DBO observada deve estar relacionada 
à decomposição das pequenas concentrações de substâncias orgânicas presentes na água. PRIMAVESI et al. (2000) observaram um valor médio de 0,3 $\mathrm{mgO}_{2} / \mathrm{L}$ no rio Canchim, São Carlos, mas encontraram valores quase dez vezes maiores em pontos com despejos pontuais de esgoto (fossas). SILVA et al. (1998) encontraram $\mathrm{DBO}$ de $1,05 \mathrm{mgO}_{2} / \mathrm{L}$ próximo às nascentes do rio Pardo em Botucatu, mas os valores se elevavam, devido ao despejo de efluentes orgânicos.

Os valores de DBO variaram bastante, tanto sazonal quanto longitudinalmente, no rio Betari, não apresentando tendências de variação; porém, podem ser feitas algumas inferências. No período chuvoso, os valores do baixo curso podem ter se elevado pelo transporte de material alóctone para o rio, principalmente, aquele proveniente da criação de animais em determinados trechos. Na estação 8 , os valores tenderam a ser maiores, talvez por se localizar no final de um grande poço que pode acumular material orgânico, que é liberado para o curso do rio. Por outro lado, nos pontos onde a velocidade foi maior, como os pontos 4, 5, 9, 10 e 11, não ocorreu acúmulo de substâncias orgânicas.

Uma melhor análise da demanda bioquímica de oxigênio poderia ser feita se no estudo tivessem sido determinadas as concentrações de carbono orgânico dissolvido, que podem consumir oxigênio na sua degradação.

\subsubsection{AGRUPAMENTOS}

Os agrupamentos, formados com a média do conjunto das variáveis abióticas da água do rio Betari, demonstraram a existência de 4 grupos de estações amostrais, apesar das diferenças não serem estatisticamente significantes entre os grupos, o que mostra a homogeneidade do sistema em relação a essas variáveis ambientais. Os parâmetros que puderam diferenciar esses grupos foram: $\mathrm{pH}$, temperatura, nitrogênio total, nitrato, nitrito, sólidos em 
suspensão inorgânicos, vazão e velocidade de corrente (que apresentaram aumento dos valores de montante para jusante); condutividade e alcalinidade (que também apresentaram aumento dos valores de montante para jusante, mas com diferenças menores ao longo do rio); silicato reativo, fosfato total dissolvido e fosfato inorgânico (que tiveram seus valores diminuídos de montante para jusante).

Ocorreram variações temporais entre os grupos. O primeiro envolveu as estações 1, 2, 3, 4 e 5, em janeiro e outubro, e somente as estações 1, 2 e 3 em abril e julho. O segundo, formado pelas estações 6, 8, 9 e 10 em janeiro e outubro, e 4, 5, 8, 9 e 6 em abril e julho, também mostrou variação. O terceiro grupo foi formado pelas estações 11, 12, 13 e 14 em janeiro e outubro, e acrescido da estação 10 nos outros dois períodos de estudo. Aparentemente, nos períodos com maiores precipitações (janeiro e outubro), ocorreu um alongamento da região do alto Betari ou da cabeceira, devido ao aumento do volume de água que alterou as características ambientais, provavelmente diluindo alguns solutos. Da mesma forma, a região do médio Betari se estendeu até a estação 10, nos períodos de maior precipitação. O quarto grupo foi formado exclusivamente pela estação 7 e correspondeu ao ponto de coleta no rio Furnas. O rio Furnas apresenta morfologia diferente do rio Betari. A vazão é bem menor e ele é totalmente envolvido pela vegetação ciliar, recebendo, provavelmente, grande quantidade de material alóctone. Possíveis fatores que distinguiram esta estação das demais são: valores mais elevados de condutividade, alcalinidade e concentração de nitratos, e menores concentrações de silicato reativo e nitrito. Essa estação também apresentou as maiores concentrações de chumbo e zinco. As prováveis causas são os rejeitos da mineração presentes a montante do ponto de amostragem que, como discutido anteriormente, causam profundas modificações no sistema aquático. 


\subsubsection{VARIÁVEIS BIOLÓGICAS}

A concentração de coliformes fecais é um parâmetro importante na avaliação da qualidade da água para o uso humano. A origem dos coliformes está associada a fezes de animais de sangue quente, dentre eles o ser humano, sendo que esses microrganismos estão associados ao trato digestivo desses organismos.

Além do esgoto doméstico, atividades pecuárias podem ser fonte de coliformes fecais, mas não se pode descartar origens naturais, provenientes de animais selvagens. PRIMAVESI et al. (2000) encontraram valores da ordem de 11 e 611 NMP/100mL nas nascentes do rio Canchim, São Carlos, e observaram que esses valores aumentaram muito em pontos com despejos de fossa. CARVALHO et al. (1998) encontraram valores para coliformes fecais acima dos limites da classe 1 da Resolução CONAMA 020/86, quando estudaram áreas com atividades agropastoris, mas não conseguiram correlacionar os valores com a pecuária. Por outro lado, os autores observaram maiores valores no período de maior precipitação, apesar da potabilidade também estar comprometida no período seco. Os autores alegaram que a lavagem do solo e o carreamento das bactérias foram os fatores que elevaram os valores no período chuvoso.

Alguns pontos de coleta, localizados no trecho superior do rio Betari, apresentaram maiores valores no período chuvoso, e uma possível explicação seria a presença de grande densidade de aves nos paredões de calcário, na cachoeira das Andorinhas, há poucos metros a montante do ponto 2. A chuva pode lavar a rocha e transportar para o rio os coliformes. A partir desse ponto, ocorreu um decaimento no número de coliformes até o ponto 11, a jusante do bairro da Serra, quando o número voltou a aumentar, nesse momento devido à presença de porcos criados às margens do rio Alambari, afluente do rio Betari, pouco antes do ponto 11. Ocorrem criações de aves (patos) e bovinos às 
margens do rio, no ponto 13. Não se pode desprezar a existência de lançamentos de esgoto doméstico no bairro da Serra.

A Resolução CONAMA, 020/86 admite 0 (zero) NMP/100mL para 0 consumo, menos de $200 \mathrm{NMP} / 100 \mathrm{~mL}$ para irrigação, e até $1000 \mathrm{NMP} / 100 \mathrm{~mL}$ para balneabilidade satisfatória. A mesma resolução classifica como "muito boa" para balneabilidade, as águas com até 500 coliformes fecais por $100 \mathrm{~mL}$. Em nenhum momento do estudo esse valor foi ultrapassado e deve-se considerar que o uso para banho e bóia-cross pelos turistas é intenso.

Os invertebrados bentônicos compõem um grupo ecologicamente muito importante. São o elo de ligação entre produtores primários, dos quais se alimentam, e de elos superiores da teia trófica, como os peixes e outros vertebrados. Também são importantes nos processos de ciclagem de nutrientes, por apresentarem maior reposição de nutrientes que os microrganismos, e menor que os peixes (CUMMINS, 1996).

Atualmente, os organismos bentônicos, principalmente os macroinvertebrados, têm recebido atenção por serem utilizados como bioindicadores. Segundo BARBOUR et al. (1999), os macroinvertebrados apresentam as seguintes vantagens como bioindicadores:

$v$ são bons indicadores das condições ambientais, devido à pequena capacidade de migração, sofrendo, portanto, os impactos;

$v$ muitas espécies têm ciclo de vida complexo, com estágios que respondem prontamente ao estresse, indicando variações de curto prazo;

$v$ podem ser identificados até "família" com certa facilidade e muitas delas são intolerantes a mudanças ambientais;

$v$ este grupo é composto por várias espécies que ocupam diferentes níveis tróficos, e são tolerantes à poluição, provendo informações sobre efeitos cumulativos;

$v$ a amostragem é relativamente fácil e barata;

$v$ são abundantes e apresentam grande diversidade; 
$v$ muitas agências (americanas) possuem dados e utilizam rotineiramente os macroinvertebrados em estudos.

Segundo CUMMINS (1996), os estudos envolvendo esses organismos não são recentes. Além dos estudos taxonômicos, abordando principalmente os insetos aquáticos, as pesquisas têm enfocado os padrões de distribuição e abundância, e os fatores ambientais controladores desse grupo, como os fatores físico-químicos e biológicos. No rio Betari foram observados variações espaço-temporais na organização da comunidade de macroinvertebrados bentônicos.

Fatores determinantes da organização temporal são os dependentes do clima (como temperatura da água e precipitação, que determina a vazão e velocidade da corrente), da disponibilidade de nutrientes, da quantidade de material orgânico drenado da bacia hidrográfica, e do ciclo de vida dos organismos, uma vez que muitos dos bentônicos correspondem a estágios larvais de insetos.

BISPO e OLIVEIRA (1998), estudando córregos de cerrado em Goiânia, e KIKUCHI e UIEDA (1998), abordando um córrego da Bacia do Paranapanema, no município de Itatinga -SP, encontraram maiores densidades de organismos no período seco, fato que foi observado no estudo do rio Betari. Os autores relacionaram as menores densidades do período chuvoso ao aumento da vazão e da velocidade da corrente que carreiam sedimentos, detritos vegetais e os organismos (drift). CUMMINS (1996) citou que o drift é um processo importante na dispersão desses organismos, o que, na verdade, não fica muito claro, uma vez que uns organismos são carreados e outros são trazidos para recolonização.

No rio Macaé, Rio de Janeiro, BAPTISTA et al. (2001a) também observaram menores densidades no período chuvoso, mas a composição de macroinvertebrados não apresentou variação significativa, indicando que o sistema apresentava elevado grau de resistência e recuperação nesse período. 
HABDIJA et al. (1998) verificaram diminuição da densidade e diversidade de organismos bentônicos no período chuvoso, quando foram eliminados por drift acidental os organismos coletores, filtradores e trituradores, e quando a disponibilidade de detritos orgânicos foi menor. Já predadores e raspadores, parecem não ter sido afetados pelas maiores vazões, por utilizarem recursos alimentares que, até certo ponto, não são influenciados pela vazão. Isso mostrou que, além do efeito físico do carreamento, organismos são selecionados no período de maior vazão pela categoria trófica a que pertencem, fator muito importante na organização espacial da comunidade bentônica.

BISPO e OLIVEIRA (1998) relacionaram a forma do corpo e a construção de abrigos e redes para "captura" de alimentos, que necessitam de certo fluxo de água, comum nos Trichoptera, com a maior suscetibilidade ao carreamento. Coleoptera foi um grupo importante no rio Betari no verão, principalmente a família Psephenidae, fato que pode estar relacionado à forma achatada de seu corpo, permitindo ao organismo ficar na superfície das rochas sem ser carreado quando a vazão é maior.

Chironomidae foi a família mais freqüente e muitas vezes dominante durante o estudo. Foi o grupo com a segunda maior densidade em janeiro e abril, caindo para terceira em julho, e subindo para primeira em outubro, mostrando uma tendência de diminuição no período seco. Talvez a maior disponibilidade de partículas orgânicas drenadas da bacia tenha favorecido seu desenvolvimento. Por outro lado, existem outros fatores controladores, como verificaram BRENNAN et al. (1978), no rio Northern Tyne, na Inglaterra. Os autores observaram que nos períodos chuvosos, ocorreu a lavagem da superfície dos seixos e rochas, diminuindo a quantidade de material epilítico, que este grupo utiliza para alimentação e para construção de tubos, e com isso ocorreu a diminuição de sua densidade.

HENRIQUES-OLIVEIRA et al. (1999) associaram as variações sazonais de larvas de Chironomidae, em riachos de montanhas no Rio de Janeiro, às variações de velocidade da corrente, lavagem do substrato e variação do 
tamanho das áreas de depósito. Os períodos secos favoreceram a fixação das larvas. Os autores citaram que rios com cobertura florestal preservada sofrem menos influência das estações do ano, pois filtram os raios solares e a chuva, que poderiam modificar algumas características da água, proporcionando, assim, maior estabilidade e uma fauna mais estruturada, com grupos menos tolerantes a perturbações ambientais, e permitindo maior eqüidade entre os grupos.

Segundo HUAMANTICO e NESSIMIAN (1999), a estabilidade ambiental, qualidade e disponibilidade de alimento, fatores determinados pelas precipitações, estão ligadas à maior densidade de larvas de Trichoptera em riachos da região serrana do Rio de Janeiro no inverno, corroborando os resultados observados no rio Betari.

Outro aspecto a ser considerado em relação à organização temporal é o ciclo de vida dos insetos. FROEHLICH (2000) estudou o ciclo de vida do Plecoptera: Glipopterygidae, Tupiperla illiesi e verificou que, na serra costeira do sudeste do Brasil, adultos são encontrados em maior número no período quente e chuvoso, e em Campos do Jordão - SP, aparentemente, eles não voam nos meses mais frios. HUAMANTINCO e NESSIMIAN (2000), em estudo com larvas de Trichoptera realizado em rios de primeira ordem em Teresópolis, região serrana do Rio de Janeiro, mencionaram que a emergência e ovoposição devem ocorrer na primavera, período em que predominam os últimos estágios larvais. Os organismos emergiram nos períodos mais quentes, que coincidiram com a época das chuvas, diminuindo o número dos estágios aquáticos. No outono e inverno ocorreu o crescimento, graças à disponibilidade de detritos trazidos pela correnteza, que foi menor nessa época, e aos depósitos em poças. Aparentemente, o início do período chuvoso desencadeou o processo de emergência. No presente estudo, provavelmente, ocorreu o mesmo processo. Trichoptera foi o grupo observado em maior número no outono e inverno, passando para o segundo maior na primavera, e terceiro no verão. 
Este processo biológico também pode ocorrer com outros grupos, em diferentes estações do ano.

Fatores que simulam condições de épocas específicas do ano, como trechos com diferentes velocidades de corrente, gerados por variações de declividade e não por aumento da vazão, são também determinantes da organização espacial dessa comunidade. As características do leito, como qualidade do sedimento, a presença de vegetação ciliar, a ocupação da bacia e suas características geomorfológicas, e entrada de tributários, são igualmente determinantes da organização espacial.

No rio Betari, características do substrato, a velocidade da corrente e a cobertura florestal, ou parâmetros relacionados a estes, são os fatores que podem ter determinado a distribuição longitudinal da fauna bentônica.

A maioria dos pontos de coleta deste estudo apresentaram cascalho e rochas e elevada velocidade de corrente. Em poucos locais ocorreu acúmulo de folhiço e areia. No rio Betari, ocorrem trechos onde alternam corredeiras sobre lajes e rochas, com regiões turbulentas sobre cascalho grosso e grandes seixos com poços não muito profundos. Os pontos de coleta dentro do bairro da Serra não apresentaram vegetação ciliar e alguns podem receber carga orgânica, ainda que estas pareçam não alterar as características da água. Os pontos 1, 2 e 3 apresentavam seixos menores que os demais pontos. Devido às características geomorfológicas da bacia hidrográfica, o rio Betari não apresenta uma zona significativa de deposição, apesar do trecho inferior apresentar menor declividade. $O$ rio Betari pode ser caracterizado, em todo seu curso, como um rio de cabeceira, que corresponde àqueles de até terceira ordem, baseado no trabalho de VANNOTE et al. (1980).

Plecoptera e, principalmente, os grupos Trichoptera e Ephemeroptera apresentaram maiores densidades nos trechos médio e inferior do rio Betari, com seixos que permitem maior retenção de detritos, entre eles e de correnteza. BATISTA et al. (2001 a), verificaram que nos rios de encostas da Serra do Mar, no Rio de Janeiro, Plecoptera e Trichoptera foram mais 
abundantes no trecho superior. O primeiro tipo de organismo foi associado a detritos de substrato arenoso ou pedregoso e o segundo, a substrato arenoso. Ephemeroptera foi mais abundante no trecho inferior, em áreas com depósitos de seixos. Diptera e Coleoptera não mostraram preferência, ocorrendo em todos os substratos, e no rio Betari essa característica também foi observada. Os autores apontaram, ainda, que Odonata preferiu áreas com baixo fluxo, e Hemíptera, áreas de deposição. Talvez por isso, a contribuição desses grupos tenha sido pequena no rio Betari, com poucas áreas de deposição e de menor fluxo.

HUAMANTINCO e NESSIMIAN (1999) verificaram que larvas de Trichoptera preferiram as áreas onde se acumula folhiço retido entre rochas, que fornecem abrigo e alimentação. Observaram que a velocidade da corrente e a disponibilidade de alimento foram os fatores determinantes de sua distribuição. As espécies que constróem rede de captura preferem trechos de maior velocidade, assim como os raspadores. BISPO e OLIVEIRA (1998) observaram que Hydropsychidae e Philopotamidae preferem trechos com maior correnteza para filtrar seu alimento. KIKUCHI e UIEDA (1998) mostraram que Simulidae, Corydalidae, Gripopterigydae Perlidae, Trichotythidae, Elmidae Hydropsychidae e Oligochaeta preferiam trechos de corredeira. Deve-se notar que esses grupos foram importantes no presente estudo, principalmente a jusante do ponto 8 , onde as densidades foram maiores.

Psephenidae apresenta organismos com formato do corpo achatado, portanto, adaptados a maiores velocidades de corrente, e os adultos vivem na vegetação marginal (HILSENHOFF, 1991). Provavelmente, isso deve ter favorecido a maior abundância desses organismos nos pontos localizados no trecho superior do rio Betari.

Leptophlebidae e, principalmente, Ephemerellidae foram consideradas famílias abundantes e dominantes entre os Ephemeroptera, em várias estações de coleta do rio Betari. Segundo HILSENHOFF (1991), muitas espécies de Ephemerellidae habitam águas claras de rios, preferindo depósitos de folhas, em regiões turbulentas ou próximo a bancos de sedimentos, sendo muito sensíveis ao enriquecimento orgânico. Leptophlebidae prefere águas correntes, entre rochas, seixos e madeiras. 
HILSENHOFF (op cit.) citou que Hidropsychidae, outra família abundante e dominante no rio Betari, é freqüente e numericamente importante em rios de vários tipos, com diferentes tamanhos, correntezas e temperaturas.

No presente estudo, as maiores densidades de organismos ocorreram nos pontos médios do rio (pontos $9,10,11$ e 12), de onde a vegetação ciliar foi retirada e também onde ocorre a entrada de vários afluentes, que contribuem com material particulado. Nos pontos próximos à cabeceira, apesar da presença da vegetação ciliar, o tipo de substrato, gerado pela presença de maiores velocidades de corrente, deve influenciar mais a organização da comunidade.

A importância da vegetação ciliar tem sido muito avaliada. A influência dessa vegetação se dá através do sombreamento (limitando a produção primária e diminuindo o aquecimento), como fornecedora de material orgânico alóctone (que, além de alimento, serve de substrato para colonização) e, ainda, ela é uma fonte de organismos adultos que depositaram seus ovos e larvas, e ocuparam os sistemas aquáticos. Além disso, ela diminui o aporte de material inorgânico da bacia para o sistema hídrico, contribui para recarga do aqüífero e tem papel fundamental na biodiversidade terrestre.

A qualidade e disponibilidade de detritos produzidos pela vegetação ciliar influenciam a dieta alimentar da comunidade bentônica e o fornecimento de abrigo e substrato para ocupação. Porém, sua ausência permite a entrada de radiação solar no sistema e a produção primária autóctone aumenta, disponibilizando outro tipo de alimento. No rio Betari, a vegetação ciliar não filtra totalmente a radiação solar. Por outro lado, ela interage com o sistema aquático, pois o vale é bastante encaixado. Nos pontos onde a vegetação ciliar foi suprimida, essa interação permanece, graças à entrada de tributários e presença de áreas florestadas.

DUDGEON (1988) verificou que a vegetação ciliar foi importante na composição da comunidade bentônica, por determinar a disponibilidade de alimento (detritos), quando comparou rios com diferentes coberturas de 
vegetação ciliar em Hong Kong. ROQUE (2000), estudando córregos no Parque Estadual do Pico do Jaraguá, e VOUGHT e LANNERSTAD (2000), na Suécia, em regiões onde a vegetação ciliar foi suprimida, verificaram diminuição do número de taxa em rios.

Além de alimento, a vegetação ciliar pode fornecer abrigo aos adultos. Os Coleoptera, Elmidae e Psephenidade foram abundantes nas estações de coleta localizadas nos trechos médio e superior do rio Betari, dentro do PETAR, região com vegetação ciliar preservada. Os adultos dessas famílias vivem na vegetação marginal (HILSENHOFF, 1991).

Segundo RICE et al. (2001), a entrada de tributários também pode funcionar como um rompimento no modelo de continuidade proposto por VANNOTE et al. (1980), da mesma forma que a supressão da vegetação ciliar ou o lançamento de esgotos.

RICE et al. (op cit.) salientaram a importância da qualidade do sedimento, que depende das características geológicas da bacia e da velocidade da corrente, na organização da comunidade bentônica. A granulometria e a forma do sedimento podem gerar microhábitats e refúgios e aprisionar detritos, aumentando a heterogeneidade do sistema. O reflexo disso são variações na abundância e diversidade dos organismos bentônicos ao longo do rio. KIKUCHI \& UIEDA (1998) e ROQUE (2000) encontraram diferentes abundâncias em trechos com corredeiras, de substrato rochoso, quando comparados aos trechos com poços, de substrato mais fino.

Apesar de não ter sido evidenciado, possivelmente as comunidades de macroinvertebrados bentônicos respondem à divisão, em trechos, observada no rio Betari. A análise de agrupamento dos parâmetros físicos e químicos dividiu o rio Betari em três grupos, apesar de, estatisticamente, essas diferenças não serem significativas, o que demonstrou certa homogeneidade. O primeiro grupo, com os pontos de coleta 1, 2 e 3 e, dependendo do período de coleta, os pontos 4 e 5 foram incluídos (por exemplo, em janeiro quando a cabeceira é estendida além do ponto 3 , provavelmente, por efeito da precipitação). 0 
segundo grupo englobou os pontos 6, 8, 9 e eventualmente os pontos 7, 4 e 5, área da bacia com certa antropização. O terceiro grupo, formado pelos pontos $10,11,12,13$ e 14, abaixo do bairro da Serra, região da bacia mais ocupada por atividades agropastoris.

A riqueza da macrofauna bentônica do rio Betari variou de acordo com os padrões numéricos, temporais e espaciais, observados na comunidade. A diminuição da densidade de organismos, no verão, foi acompanhada pela diminuição da diversidade, e o aumento da densidade, nos pontos localizados no médio e baixo curso do rio, foi acompanhado do aumento da diversidade.

Considerando que as coletas foram realizadas somente com amostrador de Surber, somente em trechos do rio com cascalho e que a identificação dos organismos foi feita, na grande maioria, até a "família" a riqueza foi grande. Um esforço amostral maior, explorando diferentes substratos (folhiço, areia e vegetação marginal, por exemplo) e pontos com diferentes velocidades de corrente teria contribuído para uma visão melhor da riqueza de macroinvertebrados bentônicos do rio Betari.

Alterações temporais da diversidade de espécies, graças ao aumento da vazão no período chuvoso, devem-se aos mesmos processos controladores da densidade. Assim, os autores que observaram menores densidades no período chuvoso, também encontraram menores diversidades (BISPO e OLIVEIRA, 1998; BRENNAN et al., 1978; HABDIJA et al., 1995, KIKUCHI e UIEDA, 1998). Da mesma forma, as variações espaciais que podem determinar as modificações na estrutura numérica da comunidade bentônica, determinam as variações de diversidade.

ROQUE (2000) relacionou o aumento da riqueza com a presença de vegetação ciliar em riachos do Parque Estadual do Pico do Jaraguá, São Paulo, e DUDGEON (1988), em rios de Hong Kong.

BAPTISTA et al. (2001 a) observaram maiores diversidades na cabeceira do rio Macaé, onde a diversidade das unidades taxonômicas inferiores foi maior no trecho do rio de segunda ordem, e relacionaram à heterogeneidade e 
complexidade de hábitats. CALLISTO et al. (2001) observaram que a vegetação ciliar e as macrófitas aquáticas propiciaram maior riqueza em rios da Serra do Cipó, por oferecerem recursos alimentares e abrigo. MAZURKIEWICS e FLEITUCH (2000) encontraram menor diversidade em poços, e maior em substrato formado por seixos, onde a complexidade de hábtats foi menor.

Os tributários são responsáveis por abruptas mudanças na comunidade bentônica, segundo RICE et al.(2001), devido às diferentes características da água, presença de sedimentos que podem modificar o substrato e aumento do volume de água. A entrada de tributários, de certa forma, apóia as idéias de STATZNER e HIGLER (1986), que acreditam que as características hidráulicas, ou aquelas relacionadas a elas, são as maiores determinantes dos padrões de zonação de invertebrados bentônicos. A heterogeneidade gerada por esses mecanismos colabora para o aumento da diversidade bentônica.

\subsubsection{SEDIMENTO}

O sedimento é constituído de duas frações, orgânica e inorgânica, que podem ter origem autóctone e alóctone. A fração orgânica compreende estruturas biológicas constituídas de restos de organismos do sistema aquático e transportadas para o sistema aquático como detritos, em vários níveis de decomposição. A fração mineral pode ser originária da bacia hidrográfica, com partículas de diferentes tamanhos, ou se formar pela precipitação de substâncias na coluna de água (MARGALEF, 1984).

Segundo ESTEVES (1988), o sedimento é o compartimento que apresenta maior concentração de nutrientes nos ecossistemas aquáticos continentais, e os processos biológicos, físicos e químicos a ele associados influenciam todo metabolismo do sistema.

As concentrações de nitrogênio e fósforo no sedimento do rio Betari apresentaram oscilações espaço-temporais que não permitiram identificar nenhuma tendência. 
CLARKE e WHARTON (2001) também encontraram grande variação de nitrogênio e fósforo no sedimento, tanto em segmentos de $100 \mathrm{~m}$, como entre os 17 rios ingleses estudados, e não conseguindo explicar seus resultados, sugeriram que as características químicas da água, geologia do local, uso da terra e regime hidrológico podem ter gerado variações longitudinais. Os rios apresentavam grau de trofia de moderado a elevado e estavam geograficamente próximos. Os autores encontraram concentrações de fósforo no sedimento que variaram de $0,15 \mathrm{mg} / \mathrm{g}$ a $2,24 \mathrm{mg} / \mathrm{g}$, e de nitrogênio da ordem de $20 \mathrm{mg} / \mathrm{g}$ a $520 \mathrm{mg} / \mathrm{g}$, superiores aos observados no rio Betari. O nitrogênio apresentou grande relação com o carbono do sedimento, indicando que ambos originaram-se da matéria orgânica metabolizada pelos microrganismos.

LAGE FILHO (1996) também determinou valores altos, se comparados aos observados no rio Betari, de nitrogênio (médias entre 1,00 e 8,93 mg/g) e de fósforo (média entre 0,5 e 25,9 mg/g), na bacia hidrográfica do Ribeirão das Antas. Deve-se ressaltar que os maiores valores encontrados por esse autor foram associados a despejos de esgotos domésticos.

Várias hipóteses podem ser levantadas para explicar as variações na concentração de nitrogênio no sedimento. Considerando que o nitrogênio pode ter sido originado da decomposição de detritos orgânicos, como citou CLARKE e WHARTON (2001), a vegetação ciliar pode gerar variações espaço-temporais ao produzir detritos, em diferentes épocas do ano, por não estar homogeneamente distribuída ao longo do rio.

KRONVANG et al. (1999) verificaram que a retenção de fósforo e nitrogênio particulados no sedimento do rio Gjern foi maior nos períodos de menores vazões, ocorrendo ressuspensão no período de tempestades. Esses autores observaram que a retenção aumenta com a diminuição da declividade, e que ela foi maior até a região de $3^{\mathrm{a}}$ ordem do rio.

Outro fator importante, quando se analisa o fósforo do sedimento, é sua capacidade de precipitar, graças a fatores físicos e químicos como $\mathrm{pH}$, condições de óxido-redução, concentrações de íon ferro, alumínio, sulfeto, 
compostos orgânicos e carbonatos (ESTEVES, 1988). As concentrações de fósforo do sedimento podem estar associadas à precipitação por carbonatos, ricos na região, outros íons metálicos e sulfetos. ESTEVES (1988) citou que em $\mathrm{pH}$ elevado e presença de cálcio, o fósforo precipita como fosfato de cálcio ou adsorve a cristais de carbonato de cálcio.

HOUSE e DENISON (1997) observaram acúmulo de cálcio e fosfato, precipitados no sedimento do rio Great Ouse (Inglaterra) durante primavera e verão, mas não detectaram aumento de fósforo no sedimento, nos pontos localizados após despejos de efluentes.

CLARKE e WHARTON (2001) verificaram que ocorria menos fósforo no sedimento quando diminuía a quantidade de argilas. Segundo os autores, quanto menores as partículas, maior a adsorção. Eles também verificaram a precipitação de fósforo associado a cálcio, ferro e alumínio.

Os esgotos domésticos que alcançam as águas do rio Betari parecem não influenciar potencialmente as características ambientais; já as concentrações de metais foram significativas.

WACHS (1998) citou que o sedimento tem importante função na regulação da circulação da matéria, funcionando como receptor de metais pesados. Quanto mais fino o sedimento, maior é a concentração desses metais.

O sedimento parece ser o compartimento que concentra chumbo no rio Betari. $\mathrm{Na}$ água, só foi detectado em três estações (no rio Furnas e nas duas estações a jusante, na coleta de janeiro). Isso demonstra a contribuição desse afluente que drena a área de mineração. Da mesma forma, as concentrações no sedimento foram bem maiores na estação 7 , decaindo a jusante, mas com ocorrência detectável em todas a estações. A montante da estação 7 , o chumbo foi encontrado no sedimento de algumas estações em concentrações menores. Nesse caso, a origem estaria relacionada às características geológicas da bacia e aos processos de intemperismo. O zinco no sedimento se comportou de forma análoga à do chumbo. Novamente o rio Furnas parece ser o principal contribuinte para rio Betari. 
As estações a jusante do ponto 7 parecem receber esses metais através do transporte de sedimentos rio abaixo. Graças à energia do rio Betari, gerada pela declividade da bacia, partículas podem ser transportadas a grandes distâncias, chegando até o rio Ribeira de Iguape e daí até seu baixo curso, próximo ao estuário, como observou CASSIANO (2001).

Outras minas abandonadas na bacia podem apresentar rejeitos expostos, como em Furnas, o que pode justificar as oscilações nas concentrações de íons do sedimento, observadas no baixo curso do rio. A figura 1.4.1 mostra que, na região da bacia que é drenada por afluentes que deságuam na margem direita do rio Betari, junto ao ponto de coleta 11, existem várias minerações de chumbo abandonadas.

CASSIANO (2001) observou que o pH alcalino e o Eh oxidante do rio Ribeira, aliados à provável abundância de óxidos de metais na água, favorecem a formação de complexos insolúveis, aos quais os elementos traços adsorvem ou são co-preciptados. Características semelhantes devem ocorrer no rio Betari, com suas águas alcalinas e oxigenadas. A precipitação de zinco, proveniente da drenagem de mineração, foi observada por GURRIERI (1998) em rios de Montana, associada ao pH alcalino e à adsorção em óxidos de ferro.

LAGE FILHO (1996) observa que em pH ácidos ocorre a solubilização de metais e a conseqüente liberação para o corpo d' água. Em nenhum momento, baixos valores de $\mathrm{pH}$ foram observados no rio Betari, o que favorece a retenção no sedimento.

A presença de cálcio e magnésio já era esperada, devido à grande quantidade desses elementos na litologia da bacia e a sua capacidade de combinação com outros compostos. O rio Furnas parece ser um grande contribuinte em cálcio também para o sedimento do rio Betari, o que enfatiza o efeito dos tributários gerando descontinuidades nos sistemas lóticos, como foi proposto por RICE et al. (2001). 


\subsection{SUMÁRIO}

A velocidade de corrente mostrou que o rio Betari é composto de seguimentos rápidos e lentos, originados pela declividade e características geológicas da bacia. A vazão variou de acordo com o regime pluviométrico regional e, espacialmente, de acordo com a entrada de seus tributários. Temporalmente, a temperatura do sistema variou de acordo com os padrões climáticos locais, e espacialmente, pode ter sido influenciada pela presença de vegetação ciliar. Outro fator que também pode ter influenciado a temperatura do rio Betari são as drenagens sub-superficiais presentes no cárste regional, que podem, no inverno, assimilar calor das rochas e transportá-lo para o rio. Os elevados valores de $\mathrm{pH}$, condutividade, alcalinidade, cálcio, magnésio e carbonatos podem ser uma resposta da dissolução da rocha calcária. No trecho superior do rio, onde ocorrem rochas quartzíticas, os silicatos apresentaram maiores concentrações.

O rio Betari não apresentou elevadas concentrações de nutrientes, talvez como um reflexo das características geológicas e do estado de conservação da bacia. A vegetação parece ser o principal contribuinte nas formas de nitrogênio e fósforo, mas a ação humana pode ter influenciado as concentrações desses componentes no médio e baixo curso do rio, assim como as concentrações de sólidos em suspensão, que foram maiores nestes trechos.

No período chuvoso, $\mathrm{pH}$, alcalinidade, condutividade, silicatos reativos e fosfatos totais diminuíram, provavelmente devido à diluição, e sólidos em suspensão, coliformes e nitrato aumentaram, transportados da bacia para 0 corpo d' água. 
A presença de rejeitos de mineração na sub-bacia do rio Furnas foi responsável pelos valores elevados de zinco e chumbo observados no estudo. Os elevados valores de cálcio, magnésio, condutividade e alcalinidade no rio Furnas também se devem à presença desses rejeitos. Dentre as variáveis analisadas, somente chumbo e zinco, no rio Furnas, se mostraram acima dos valores permitidos pela Resolução CONAMA 020/86 para rios da classe 1. No rio Betari, os valores estiveram abaixo dos limites estabelecidos pela resolução. A concentração de coliformes fecais esteve dentro dos padrões de balneabilidade estabelecido pela mesma resolução.

O macrozoobentos do rio Betari apresentou marcada variação espaçotemporal. O período chuvoso apresentou menor densidade e diversidade, e as estações dos trechos médio e baixo do rio apresentaram maiores densidades de organismos. A velocidade de corrente e vazão foram fatores aparentemente importantes na determinação da comunidade de macroinvertebrados bentônicos. Maiores densidades e riquezas ocorreram no período mais seco ou no início das chuvas, quando os valores dessas duas variáveis foram menores. No período de maiores precipitações, organismos adaptados à correnteza, como Psephenidae, ou aqueles que constróem casulos, predominaram. Trichoptera foi o grupo mais abundante no outono e inverno, Diptera na primavera e Coleoptera no verão. As famílias Elmidae, Psephenidae (Coleoptera) e Chironomidae (Diptera) apresentaram ampla distribuição espaço-temporal. A disponibilidade de material orgânico pode ter favorecido a ocorrência de Chironomidae. Outros fatores que devem ter influenciado a organização da comunidade são vegetação ciliar e tipo de sedimento.

No trecho médio do rio, entre as estações 9 e 12, ocorreram os maiores valores de densidade e riqueza. Trata-se de área onde a vegetação ciliar foi retirada, o que permite maior produção primária, além da entrada de vários afluentes. Nessas condições deve prevalecer grande variedade de alimentos e substratos que permitem a retenção de material orgânico. 
O rio Betari pode ser dividido em alto, médio e baixo cursos, com base nas características morfológicas e de ocupação da bacia. Assim, a região do Alto Betari é delimitada pelas nascentes até o início das instalações do núcleo Santana do PETAR, região com maiores declividades. O médio curso está compreendido desde as áreas de instalação do parque até o limite final do bairro da Serra, área com maior grau de antropização. O baixo curso é limitado pelo bairro da Serra e a foz no rio Ribeira de Iguape.

O sedimento do rio Betari mostrou-se importante compartimento acumulador de fósforo, chumbo e zinco. As condições ambientais favorecem a ocorrência de formas precipitadas associadas ao sedimento. Dessa forma, o rio Betari funciona como transportador de íons para o rio Ribeira de Iguape.

Apesar de indícios de alteração de suas características após passar pelo bairro da Serra, a hipótese do turismo estar contribuindo significativamente para a alteração da qualidade da água do rio Betari não pôde ser confirmada.

\subsection{REFERÊNCIAS BIBLIOGRÁFICAS}

AFONSO, A.A.O., 1993. Aporte, retenção e decomposição da serapilheira de mata galeria e características físicas, químicas e hidrológicas em duas seções do córrego Itaúna (Itatinga - SP), bacia do Alto Paranapanema. Dissertação de Mestrado. Escola de Engenharia de São Carlos - USP. São Carlos. pp. 162.

ALLAN, J.D., 1995. Stream Ecology: structure and function of running waters. London, Chapman \& Hall.

ANDERSEN, J. M., 1976. An ignition method for determination of total phosphorus in lake sediments. Wat. Research. V 10, p 329 - 331.

ANGRISANO, E.B. 1995. Insecta Trichoptera. In Lopretto E.C. \& Tell, G. (eds.). Ecosistemas de aguas continentals. Metodologia para su estudio (Vol. III). Ediciones Sur, p. 1199 - 1237. 
APHA, AWWA, WEF, 1995. Standart Methods: for the examination of water and wastewater. 19 ed. Washington, American Public Health Association, 1134 p.

BACK, W. \& ARENAS, A. D., 1989. Karst terrains: resources and problems. Nature \& Resources, special issue, 19 - 23 p.

BAKALOWICZ, M. 1994. Water geochemistry: water quality and dynamics. In Groundwater Ecology, Gilbert, J., Danielopol, D.L. \& Stanford, J.A., (eds). Academic Press, California, p. 97 - 129.

BAPTISTA, D.F., DORVILLÉ, L.F.M., BUSS, D.F. \& NESSIAMIAN, J.L., 2001a. Spatial and temporal organization of aquatic insects assemblages in the longitudinal gradiente of a tropical river. Rev. Brasil. Biol., vol 61, n 2, p. 295 304.

BAPTISTA, D.F., BUSS, D.F., DORVILLÉ, L.F.M. \& NESSIMIAN, J.L., $2001 \mathrm{~b}$. Diversity and habitat preference of aquatic insects along the longitudinal gradient of the Macaé river basin, Rio de Janeiro, Brazil. Rev. Brasil, Biol., vol 61, no 2, p. $249-258$.

BARBOUR, M. T. , GERRITSEN, J., SNYDER, B. D. \& STRIBLING, J. B., 1999. Rapid bioassessment protocols for use in streams and wadeable rivers: periphyton, benthic macroinvertebrates and fish. Segunda edição, EPA 841-B99-002, U.S. Environmental Protection Agency; Office of Water. Washington, D.C.

BEAUMONT, P., 1975. Hydrology. In River Ecology, Ed. B. A. Whitton, Blackwell Sci. Plub., Oxford, 1 - 38 p.

BISPO, P. C. \& OLIVEIRA, L. G., 1998. Distribuição espacial de insetos aquáticos (Efemeroptera, Plecoptera e Trichoptera) em córregos de cerrado do Parque Ecológico d Goiânia, Estado de Goiás. . In Nessimian J.L. \& A .L. Carvalho (eds). Ecologia de Insetos Aquáticos. Série Oecologia Brasiliensis, vol. V. PPGEUFRJ. Rio de Janeiro, Brasil, pp 175 - 189. 
BRANCO, C. W. C., 1991. A comunidade planctônica e a qualidade da água no Lago Paranoá, DF, Brasil. Dissertação de Mestrado, Universidade de Brasília,. $338 \mathrm{pp}$.

BRANCO, L.H.Z. \& NECCHI Jr., O. 1997. Variação longitudinal de parâmetros físicos e químicos em três rios pertencentes a diferentes bacias de drenagem na região noroeste do estado de São Paulo. Acta Limnol. Brasiliensia, vol. 9, p. 165 - 177.

BRENNAN, A., MCLACHLAN, A. J. \& WOTTON, R.S., 1978. Particulate material and larvae (Chironomidae: Diptera) in an upland river. Hydrobiologia, vol 59, $\mathrm{n}^{\mathbf{o}}$ 1, p. $67-73$.

BURT,T.P., 1996. The hydrology of headwater catchments. In River flows and channel forms. Eds. Petts, G. e Calow, P., Blackwell Science. Oxford, 262p.

CAllistO, M., MORENO, P. \& BARBOSA, F.A .R., 2001. Habitat diversity and benthic functional trophic grouops at Serra do Cipó, southeast Brazil. Rev. Brasil. Biol., vol 61, no 2, p. 259- 266.

CAMARGO, A.F.M.; FERREIRA, R.A.R.; SCHIAVETTI, A. \& BINI, L.M., 1996. Influence of physiography and human activity on limnological characteristics of lotic ecosystems of the south coast of São Paulo, Brasil. Acta Limnologica Brasiliensia. vol. 8, p. 231-243.

CAMARGO, A.F.M., NUCCI, P.R., BINI,L.M. \& SILVA Jr., U.L., 1997. The influence of the geology on the limnological characteristics of some lotic ecosystems of the Itanhaém rive basin, SP-Brazil. Verh. Internat. Verein. Limnol., vol 26, p. 860 864.

CARVALHO A.R., SCHLITTLER, F.H.M. \& TORNISIELO, V.L., 1998. Influência da atividade agropecuária na concentração de coliformes fecais e compostos organoclorados em ambientes lóticos (São Carlos, SP). Acta Limnológica Brasiliensia, vol 10, $\mathrm{n}^{\mathrm{o}}$ 2, p. $115-124$.

CASSIANO, A.M., 2001. Fontes de contaminação por elementos-traço na bacia do rio Ribeira (SP-PR): Estratégias para a remediação de uma área de 
disposição de rejeitos de mineração de Pb-Ag. Tese de Doutorado, Escola de Engenharia de São Carlos - USP, São Carlos, pp. 159.

CHURCH, M. 1996. Channel morphology and typology. In River flows and channel forms. Eds. Petts, G. e Calow, P., Blackwell Science. Oxford, 262p.

CLARKE, S.J. \& WHARTON, G., 2001. Sediment nutrient characteristics and aquatic macrophytes in lowland English rivers. The Science of the Total Environment, vol. 266 , p.103 - 112 .

CONAMA 20, Resolução no 20 de 18/06/86 do Conselho Nacional do Meio Ambiente.

CORSI, A.C., 1998. Estudo da dispersão de metais pesados em água e sedimentos de corrente a partir de mineralizações de Chumbo-Zinco-Prata: o exemplo das jazidas Canoas, Perau e Barrinha (Vale do Ribeira-PR). Dissertação de Mestrado, IGCE - Universidade Estadual Paulista, Rio Claro, pp. 134.

CPRM - COMPANHIA DE PESQUISA DE RECURSOS MINERAIS, 1974(a). Mapa Geológico. Folha SG.22-X-B-V-2-Iporanga. Mapa nº 7. Projeto SUDELPA, vol. II, anexo III, parte I. São Paulo.

CUMMINS, K.W., 1996. Invertebrates. In River Biota: Diversity and dynamics. Eds Petts, G. e Calow, P, Blackwell Science, Oxford, p. 75 - 91.

DOMÍNGUEZ, E., HUBBARD, M.D. \& PETERS, W.L. 1992. Clave para ninfas y adultos de las familias y generos de ephemeroptera (Insecta) sudamericanos. Biologia Acuatica, vol 16, p. 1 - 32.

DUDGEON, D., 1988. The influence of riparian vegetation on macroinvertrebate community struture in fuor Hong Kong streams. J. Zool. Lond., vol. 216, p. 609 627.

DUDGEON,D. \& BRETSCHKO,G., 1996. Allochthonous inputs and land-water interactions in seasonal streams: tropical Asia and temperate Europe. In Perpectives in tropical limnology. Schiemer, F. \& Boland, K.T. (eds.). SPB Academic Publishing, Amsterdã.pp. 161 - 180.

EDMONDSON, W.T., 1959. Freshwater Biology. John Wiley \& Sons Inc. New York, 867 p. 
ESTEVES, F A., 1988. Fundamentos de Limnologia. Editora Interciência/FINEP, Rio de Janeiro, pp. 575.

EYSinK, G. G., PÁduA. H. B., PIVA-BERTOLETTI, S. A. E., MARTinS, M. C., PEREIRA, D. N. \& ROBERTO, S., 1988. Metais pesados no vale do Ribeira e em Iguape-Cananéia. Ambiente. V 2, n 1, p 6 - 13.

FIORENTIN, G.L. \& CORSEUIL, E., 1994. Caracterização das Náiades de plecópteros ocorrentes em três municípios do Rio Grande do Sul, Brasil (Insecta - Plecoptera). Acta Biológica Leopoldensia, vol 16, nº 1, p. 27- 40 .

FONTOURA, A . P., 1985. Manual de vigilância da qualidade das águas superficiais: Avaliação biológica da qualidade da água. Publicações avulsas, Instituto de Zoologia, Faculdade de Ciências, Universidade do Porto, Porto, Portugal.

FROEHLICH, C.G., 1984. Brazilian Plecoptera 4. nymphs of perlid genera from southeastern Brazil. Annls Limnol., vol 20, nº 1-2, p. 43 - 48.

FROEHLICH, C.G., 2000. Biological observations on Tupiperla (Plecoptera: Gripopterygidae). Rev. Brasil. Biol., vol 60, nº 3, p. 447-450.

GOLTERMAN, H.L., 1975. Chemistry. In River Ecology. Whitton, B.A. (ed.), Blackwell Scientific Publications, Oxford, London, p. 39 - 80.

GOLTERMAN , W. L., CLYMO, R. S. \& OHNSTAD, M. A. M., 1978. Methods for chemical and physical analysus of freshwater. IBP Handbook n.8, Blackwell Scientific Publications, Oxford, 213 p.

GORE, J. A., 1996. Responses of aquatic biota to hydrological change. In River biota: Diversity and dynamics. Eds. Petts, G. e Calow, P., Blackwell Science. Oxford, $230 \mathrm{p}$.

GURRIERI, J.T., 1998. Distribution of metals in water and sediment end effects on aquatic biota in upper Stillwater river basin, Montana. Journal of Geochemical Exploration, vol. 64, p. $83-100$. 
HABDIJA,I., RADANOVIC, I. \& PRIMC-HABDIJA, B., 1998. Seasonal changes in the trophic struture of macroinvertebrates on the cobble substrate. Verh. Internat. Verein. Limnol., vol 26, p. 1037 - 1040.

HENRIQUES-OLIVEIRA, A .L., SANSEVERINO, A .M. \& NESSIMIAN, J.L., 1999. Larvas de Chironomidae (Insecta: Diptera) de substrato rochoso em dois rios em diferentes estados de preservação na Mata Atlântica, RJ. Acta Limnologica Brasiliensia, vol 11, no 2, p. 17- 28 .

HENRY, R \& GOUVEIA, L., 1993. Os fluxos de nutrientes e seston em cursos de água do Alto Paranapanema (São Paulo) - sua relação com usos do solo e morfologia das bacias de drenagem. An. Acad. Bras. Ci., vol. 65, no 4, p. 439- 451.

HILSENHOFF, W.L., 1991. Diversity and classification of insects and Collembola. In Ecology and classification of North American freshwater invertebrates, capitulo 17, Thorp, J.H. \& Alan, P.C. (eds). Academic Press, Inc., California, p. $593-663$.

HOUSE, W.A. \& DENISON, F.H., 1997. Nutrient dynamics in a lowland stream impacted by sewage effluent: Great Ouse, England. The Science of the Total Environment, vol 205, p. 25 - 49.

HUAMANTINCO, A . A . \& NESSIMIAN J. L., 1999. Estrutura e distribuição espacial da comunidade de larvas de Trichoptera (Insecta) em um tributário de primeira ordem do Rio Paquequer, Teresópolis, RJ. Acta Limnol. Bras. 11(2), 1 - 16.

HUAMANTINCO, A . A . \& NESSIMIAN J. L., 2000. Variation and life strtegies of the Trichoptera (Insecta) larvae community in a first order tributary of the Paquequer river, Southeastern Brazil. Rev. Brasil. Biol., vol. 60, nº 1, p. $73-82$.

HYNES, H.B.N., 1970. The ecology of running waters. University Press, Liverpoool, $555 \mathrm{p}$.

JENSEN, A.J., GRANDE,M., KORSEN,I. \& HVIDSTEN, N.A., 1998. Reduced heavy metal pollution in the Orkla river, Norway: effects on fish populations. Verh. Internat Verein. Limnol., vol. 26, p. 1235 - 1242. 
JUNK, W. J., BAYLEY, P. B. \& SPARKS, R. E., 1989. The flood pulse concept in river foodplain systems. Can. Spec. Publ.Fish. Aquat. Sci. V 106, p 110 - 127.

KIKUCHI, R. M. \& UIEDA, V. S., 1998. Composição da comunidade de invertebrados de um ambiente lótico tropical e sua variação espacial e temporal. In Nessimian J.L. \& A .L. Carvalho (eds). Ecologia de Insetos Aquáticos. Série Oecologia Brasiliensis, vol. V. PPGE-UFRJ. Rio de Janeiro, Brasil, pp 157 - 173.

KOROLEFF, F., 1976. Determination of nutrients. In Grassnof, K., ed. Methods of seawater analysis. Verlag. Chemie. Weinhein, p. 117-181.

KRONVANG, B., HOFFMANN, C.C., SVENDSEN, L.M., WINDOLF, J.JENSEN, J.P. \& DØRGE, J., 1999. Retention of nutrients in river basins. Aquatic Ecology, vol. 33 , p. $29-40$.

LAGE FILHO, A.L., 1996. Características ecológicas e limnológicas da bacia hidrográficas do Riberirão das Antas, no período de menores preciptações (Poços de Caldas - MG). Dissertação de Mestrado. Escola de Engenharia de São Carlos, USP, São Carlos, 192 p.

LOBO, E. \& LEIGHTON, G., 1986. Estruturas comunitarias de las fitocenosis planctonicas de los sistemas de desembocaduras de rios y esteros de la zona central de Chile. Rev. Biol. Mar. Valparaiso, v 22, n 1, p 1 - 29.

MACCAFFERTY, W.P., 1981. Aquatic entomology. Jones and Barflett Publishers Inc., Boston.

MACKERETH, F. J. H., HERON, J. \& TALLING, J. E., 1978. Water analysis: some revised methods for limnologists. Freshwater Biological Association. Sci. Publ. n. 36. Titus, Wilson and Sons Ltda., Kendall, 117 p.

MARGALEF, R., 1983. Limnologia. Ediciones Omega, Barcelona, 1010 p.

MAZURKIEWICS, G. \& FLEITUCH, T., 2000. Patterns of benthic fauna diversity in a mountain river. Verh. Internat. Verein. Limnol., vol. 27, p. 2529 - 2534.

MERRITT, R.W. \& CUMMINS, K.W., 1996. An introduction to the aquatic insects of North America. 3 rd ed., Kemdall/Humt, Dubuque, 862 p. 
NECCHI Jr., O., BRANCO,L.H.Z. \& BRANCO, C.C.Z., 1996. Análise nictimeral de algumas variáveis limnológicas em um riacho no noroeste do Estado de São Paulo. Acta Limnológica Brasiliensia, vol. 8, p. 169 - 182.

NECCHI Jr, O. ; BRANCO, LHZ \& BRANCO C.C.Z., 2000. Características limnológicas da bacia do Alto Rio São Francisco, Parque Nacional da Serra da Canastra, Minas Gerais. Acta Limnologica Brasiliensia, v 12, n 1, p 11 - 22.

OCHIAI, M., IHARA, M.,HAMABATA,E. \& NAKAJIMA, T., 2000. Effects of forestt cutting on stream water quality. Verh. Internat. Verein. Limnol., vol. 27, p. 1571 -1575 .

OLIVEIRA, M.D. \& CALHEIROS, D.F., 1998. Transporte de nutrientes e sólidos suspensos na bacia do rio Taquari (Mato Grosso do Sul). Acta Limnológica Brasiliensia, 10(2): 35 - 45.

OMETO, J.P.H.B., MARTINELLI, L.A., BALLESTER,V. GESSNER, A., KRUSCHE, A.V., VICTORIA, R.L. \& CENA, W., 2000. Effects of land use on water chemistry and macroinvertebrates in two streams of the Piracicaba river basin, south-east Brazil. Freshwater Biology, vol. 44, p. 327 - 337.

OSSANI, , J., 1979. Efeitos dos metais pesados na saúde. In Seminário sobre poluição por metais pesados, 1 Brasília - DF, SEMA, SACT, pp. 184.

PENNAK, R.W., 1971. Toward a classification of lotic habitat. Hidrobiologia, vol 28, p. $321-334$.

PERONA, E., BONILLA, I. \& MATEO, P., 1999. Spatial And temporal changes in water quality in a Spanish river. The Science of the Total Environment, vol. 241, p. $75-90$.

PETTS, G. E. \& CALLOW, P., 1996. Fluvial hydrosystems: the physical basis. In River flows and channel forms. Eds. Petts, G. e Calow, P., Blackwell Science. Oxford, 262p.

PORTO, M.F.A., 1991. Estabelecimento de parâmetros de controlo da poluição. In Hidrologia Ambiental, Porto, R.L.L. et al. (organizadores), EDUSP/Associação Brasileira de Recursos Hídricos, 375-390 p. 
PRIMAVESI, O.; FREITAS, A.R.; OLIVEIRA, H.T. \& PRIMAVESI, A.C.P.A., 2000. A qualidade da água na microbacia hidrográfica do ribeirão Canchim, São Carlos, SP ocupada por atividade pecuária. Acta Limnologica Brasiliensia. v. 12, n. 1, p. 95-111.

RICE, S.P., GREENWOOD, M.T. \& JOYCE, C.B., 2001. Tributaries, sediment sources, and the longitudinal organization of macroinvertebrate fauna along river systems. Can. J. Fish Aquat. Sci., vol 58, p. 824 - 840.

RIOS, L. 1993. Estudo limnológico e fatores ecológicos em ribeirões e córregos da bacia hidrográfica do ribeirão do Feijão (estado de São Paulo). Dissertação de mestrado, Escola de Engenharia de São Carlos - USP, São Carlos, p.106.

ROQUE, F.O ., 2000. Distribuição espacial dos macroinvertebrados bentônicos nos córregos do Parque Estadual do Jaraguá (SP): Considerações para a conservação ambiental. Dissertação de Mestrado, Universidade Federal de São Carlos, São Carlos, p. 77.

SÃO PAULO (Estado), 1993. Decreto no 8468, de 08 de setembro de 1976. Aprova o regulamento da Lei $n^{\circ}$ 997, de 31 de maio de 1976, que dispõe sobre a prevenção e o controle da poluição do meio ambiente. Legislação Estadual. Controle da Poluição Ambiental do Estado de São Paulo. São Paulo.

SÃO PAULO (Estado), 1993. Decreto $n^{\circ} 10755$, de 22 de novembro de 1977. Dispõe sobre o enquadramento dos corpos de água receptores na classificação prevista no Decreto 8468, de 08 de setembro de 1976. Legislação Estadual. Controle da Poluição Ambiental do Estado de São Paulo. São Paulo.

SABATER, F.; ARMENGOL, J. \& SABATER, S., 1989. Measuring descontinuities in the Ter river. Regulated Rivers Research \& Management, 3: 133 - 142.

SCHUMM, S.A. 1977. The fluvial system. John Wiley \& Sons, New York.

SÉ, J.A.S. (1992). O rio do Monjolinho e sua bacia hidrográfica como integradores de sistemas ecológicos. Dissertação de Mestrado. Escola de Engenharia de São Carlos - USP, São Carlos. 
SILVA, A.M.N., HENRY, R., CARVALHO, L.R. \& SANTINI, J.A.J., 1998. A capacidade de autopurificação de um curso d'água: um estudo de caso no rio Pardo (Botucatu, SP). Acta Limnológica Brasiliensia, vol 10, nº 2, p. 83- 100.

SMITH,D.J., 1993. The nature of karst aquifers and their susceptibility to pollution. In Karst Terrains: Environmental changes and human impact. Williams, P.W. (ed.). Cremlingen-Destedt: Catena-Verl., Supplement 25, p. 41 - 58.

SMITH, W.S. \& PETRERE JR, M., 2000. Caracterização limnológica da bacia de drenagem do rio Sorocaba, São Paulo, Brasil. Acta Limol. Bras., vol 12, p. 15 27.

STATZNER, B. \& HIGLER, B., 1985. Questions and comments on the River Continuun Concept. Can. Jour. Fish. Aquat. Sci., 42: 1038 - 1044.

STATZNER, B. \& HIGLER, B., 1986. Stream hydraulics as a major determinant of benthic invertebrate zonation patterns. Freshwater Biol., 16: 127 - 139.

STEINHART, G.S., LIKENS, G.E. \& GROFFMAN, P.M., 2000. Denitrification in stream sediments in five northeastern (USA) streams. Verh. Internat. Verein. Limnol., vol.27, p. 1331 - 1336.

STRICKLAND, J. D. \& PARSONS, T. R., 1960. A manual of sea water analysis. Bull. Fish. Res. Be. Can., vol. 125, p.1 - 185.

SULLIVAN, A. B. \& DREVER, J.I., 2001. Spatiotemporal variability in stream chemistry in a high-elevation catchment affected by mine drainage. Journal of Hydrology, vol. 252, p. $237-250$.

TEIXEIRA, C., TUNDISI, J. G. \& KUNTER, M. B., 1965. Plankton studies in a mangrove. II standing stock and some ecological factors. Bol. Inst. Oceanogr., 24: $23-41$.

VALENTIN, J.L., 1995. Agrupamento e ordenação. Oecologia brasiliensis. V-2. p 27 55. 
VANnOte, R. L., MinShall, G. W., CUMMINS, K. W. SEDELL, J. R. \& CUSHING, C. E., 1980. The river continuun concept. Can. Jour. Fisch. Aquat. Sci., 37: $130-137$.

VILLELA, S.M. \& MATTOS, A ., 1975. Hidrologia aplicada. McGraw-Hill, Rio de Janeiro, p. 245.

VOUGHT, L.B.M. \& LANNERSTAD, M., 1998. The structure of the riparian ecotone and its implication for stream macroinvertebrate community. Verh. Internat. Verein. Limnol., vol 27, p. 1357 - 1360.

WACHS, B. 1998. A qualitative classification for the evaluation of the heavy metal contamination in river ecosystems. Verh. Internat. Verein.Limnol., vol. 26, p. 1289-1294.

WARD, J.V. \& STANFORD, J.A., 1983. The serial discontinuity concept of lotic ecosystems. In Fontaine, T.D. and Bartell, S.M. (Eds.), Dynamic of lotic ecosystem. Ann. Arbor. Science Publ.. MI, 29 - 42 p.

WARD, J.V. \& STANFORD, J.A., 1995. The serial descontinunity concept: extending the model to floodplain rivers. Regulated Rivers: research and management, vol.11: $000-000$.

WEBSTER, J.R., TANK, J.L., WALLACE, J.B., MEYER, J.L., EGERT, S.L., EHRMAN, T.P., WARD, B.R., BENNETT, B.L., WAGNER, P.F. \& McTAMMANY, M.E., 2000. Effects of litter exclusion and wood removal on phosphorus and nitrogen retention in a forest stream. Verh, Internat. Verein. Lomnol., vol. 27, p. $1337-1340$.

WHITE,W.B., 1988. Geomorphology and hydrology of karst terrains. Oxford University Press, New York, 464 pp.

WHITTON, A. \& SAY, P.J., 1975. Heavy Metals. In River Ecology. Whitton, B.A. (ed.), Blackwell Scientific Publications, Oxford, London, p.287 -311.

WISLER, C.O.\& BARTER, E.F., 1964. Hidrologia. SEDEGRA, Rio de Janeiro. 
WISSMAR, R.C., SWANSTON, D.N., BRYANT, M. \& McGEE, K., 1997. Factors influencing stream chemistry in catchments on Prince of Wales Island, Alaska. Freshwater Biology, vol 38, p. $301-314$.

WOLlHEIN, W.M., PETERSON, B.J., DEEGAN, L.A., HOBBIE, J.E., HOOKER, B., BOWDEN, W.B., EDWARDSON, K.J., ARSCOTT, D.B., HERSHEY, A.E. \& FINLAY,J., 2001. Influence of stream size on ammonium and suspended particulate nitrogen processing. Limnology and Oceanography, vol. 46, $\mathrm{n}^{\circ} 1$, p. 1 $-13$. 


\section{CAPÍTULO III}

\section{O TURISMO NO BAIRRO DA SERRA}

\subsection{TURISMO: IMPACTOS E SUSTENTABILIDADE}

A indústria do turismo é a que mais cresce no mundo. Em 1995, ela movimentou US\$ 3,4 trilhões sendo que, desse total, US\$ 250 bilhões foram gerados pelo chamado turismo ecológico (WWF,1999). Nos últimos 50 anos, a indústria do turismo sofreu grandes mudanças, passando de uma atividade de ricos para um fenômeno de massa, transformando a economia, cultura e meio ambiente (TWINING-WARD, 1999).

A deterioração da qualidade de vida nos grandes centros tem levado a população a buscar, cada vez mais, o contato com a natureza nos momentos de lazer. Cerca de $10 \%$ das pessoas que viajam são ecoturistas, e este segmento cresce $20 \%$ ao ano (MICT/MMA, s/ data).

Como em toda indústria, na do turismo existe um custo sócio-ambiental inserido: os impactos, principalmente devido ao rápido crescimento sem planejamento e à administração inadequada dos locais visitados, preferencialmente em áreas ecológicas e culturalmente frágeis (LINDBERG e HAWKINS, 1995).

Dentre as atividades humanas, o turismo pode ser considerado a que propicia maiores possibilidades de sustentabilidade, por ser uma "indústria" que oferece serviços, e não bens. A própria continuidade do serviço oferecido depende da manutenção de um ambiente sócio-econômico, cultural e natural sadios.

Na década de 60, o reconhecimento dos possíveis impactos da explosão do turismo de massa deu início ao questionamento sobre as conseqüências desta atividade e, nos anos seguintes, ele foi associado ao conceito de desenvolvimento sustentável, levando a um novo conceito: o turismo 
sustentável (SWARBROOKE, 2000). Políticas governamentais, o planejamento e a gestão são os fatores que determinarão e garantirão o desenvolvimento turístico sustentado. SWARBROOK (2000) observou que em diversas regiões como Baltimore (EUA), Liverpool (Reino Unido), áreas rurais da França, Itália, Portugal e Espanha, tem-se utilizado o turismo para alcançar o desenvolvimento sustentável.

Acreditar que o turismo pode ser tratado como uma "indústria limpa" é uma visão simplista. RODRIGUES (1997) assinalou que o turismo "consome" paisagem/espaço/território sem destruí-los aparentemente, mas como todo modo de produção industrial, implica destruição. A atividade turística, como atividade econômica, está inserida num processo de produção e consumo, que pode ser fugaz e intenso. A autora considera que a atividade turística exige um ajustamento das áreas para o consumo, de acordo com os padrões do mundo moderno, transformando a paisagem/espaço/território em algo comercializável, portanto, não compatível com desenvolvimento sustentável.

BENI (2000) apresentou quatro interpretações para a questão da sustentabilidade na atividade turística:

Turismo sustentável: corresponde à meta de viabilidade econômica da atividade turística. Enfatiza o oferecimento de um produto turístico atrativo representado por um processo de comercialização com qualidade e competitividade de preços.

Turismo ecologicamente sustentável: o enfoque é a preservação dos recursos e ecossistemas naturais. São aceitáveis as atividades não perturbadoras do meio.

Desenvolvimento sustentável do turismo: também com perspectiva econômica, porém, visa assegurar a viabilidade da atividade turística a longo prazo, reconhecendo que a qualidade ambiental é um importante fator de competitividade e, desta forma, o meio ambiente deve ser protegido. 
Desenvolvimento econômico ecologicamente sustentável: trata da visão global do desenvolvimento sustentável com enfoque no ser humano e no meio ambiente; busca igualdade econômica e justiça social, melhoria da qualidade de vida e, igualmente, a conservação ambiental, sendo a atividade turística um dos meios para atingi-lo.

Segundo TWINING-WARD (1999), os progressos no desenvolvimento da prática do turismo sustentável, além de esbarrarem na questão semântica apontadas por BENI (2000) e MCCOOL (2001), têm sido limitados, por serem vistos sempre como alternativas para projetos em pequena escala e para países em desenvolvimento; os esforços se aplicam na preservação do meio natural, mais que nos aspectos sociais e culturais, e no erro de pesquisadores em estabelecerem a capacidade de carga, mais que o tipo de desenvolvimento que é apropriado para determinada área. Para se alcançar o desenvolvimento sustentável do turismo, é necessário identificar as necessidades e aspirações da população e governo locais, além dos elementos chaves da cultura, do meio ambiente e da estrutura da indústria turística do destino.

São premissas do desenvolvimento sustentável a maximização dos efeitos positivos e minimização dos negativos. Esses efeitos se traduzem por impactos. Segundo RUSCHMANN (1997), os impactos do turismo "se referem à gama de modificações ou à seqüência de eventos provocados pelo processo de desenvolvimento turístico nas localidades receptoras". Podem-se classificar os impactos do turismo em ambientais, econômicos, sociais e culturais, e eles podem ser positivos ou negativos (Tabela 3.1, Adaptado de ARCHER \& COOPER, 2001; RUSCHMANN, op. cit;; SWARBROOK, 2000.).

A GAFNC (1997) apud SCHLÜTER (1999) ${ }^{1}$, diferenciou cinco categorias de impactos associados à atividade turística:

\footnotetext{
${ }^{1}$-GERMAN FEDERAL AGENCY FOR NATURE CONSERVATION (eds.) (1997) Biodiversity and tourism. Conflicts on the world's sea costs and strategies for their solution. Springer Verlag, Berlin-Heidelber. Apud SCHLÜTER, R.G. (1999) Impactos del turismo em zonas costeras. Rol de los faros em la preservaciónn del ambiente. Estudios y perspectivas em turismo. V. 8 , n. 1., p. 24-56.
} 
- Recreativas: consideradas as que mais causam impactos e que deveriam ser proibidas ou severamente limitadas em áreas protegidas;

- Infra-estrutura para realização de atividades: correspondem às infraestruturas necessárias para o desenvolvimento de práticas de lazer e recreação específicas de uso turístico;

- Infra-estrutura básica: refere-se aos impactos causados pela implantação e operação dos serviços comuns a todos (energia elétrica, abastecimento público, despejo de resíduos);

- Infra-estrutura para a prestação de serviços: trata dos impactos gerados para a instalação dos equipamentos turísticos;

Desenvolvimento induzido: impactos gerados em decorrência do desenvolvimento turístico (urbanização, migração, mudanças sociais).

Segundo RUSCHMANN (1997), atualmente, a discussão e reflexão sobre os impactos nas localidades receptoras tem aumentado, e têm surgido propostas que obtiveram sucesso em minimizar os impactos negativos e otimizar os positivos.

O crescimento e desenvolvimento econômico geram mudanças nos ecossistemas. O planejamento permite a exploração dos recursos dentro de sua capacidade de regeneração, crescimento natural e reorganização, o que reafirma as concepções do desenvolvimento sustentável. Mas deve-se ressaltar que, além das limitações citadas anteriormente, não é apresentada, de forma explícita no conceito, a sustentabilidade social, econômica e cultural. 
TABELA 3.1. -Impactos ambientais, econômicos, sociais e culturais do turismo.

\begin{tabular}{|c|c|c|c|c|c|c|c|}
\hline \multicolumn{2}{|l|}{ Ambientais } & \multicolumn{2}{|l|}{ Econômicos } & \multicolumn{2}{|l|}{ Sociais } & \multicolumn{2}{|l|}{ Culturais } \\
\hline positivos & negativos & positivos & negativos & positivos & negativos & positivos & negativos \\
\hline $\begin{array}{l}\text { Preservação } \\
\text { da fauna e } \\
\text { flora; }\end{array}$ & $\begin{array}{c}\text { Ocupação e } \\
\text { destruição de } \\
\text { áreas naturais; }\end{array}$ & $\begin{array}{l}\text { Aumento de } \\
\text { arrecadação } \\
\text { para o } \\
\text { Estado; }\end{array}$ & $\begin{array}{c}\text { Abandono } \\
\text { de atividades } \\
\text { primárias de } \\
\text { produção; }\end{array}$ & $\begin{array}{l}\text { Promove } \\
\text { melhores } \\
\text { condições de } \\
\text { saúde para } \\
\text { população } \\
\text { local; }\end{array}$ & $\begin{array}{l}\text { Estimular } \\
\text { hábitos de } \\
\text { consumo; }\end{array}$ & $\begin{array}{l}\text { Valorização } \\
\text { do artesanato; }\end{array}$ & $\begin{array}{c}\text { Descaracterização } \\
\text { do artesanato; }\end{array}$ \\
\hline $\begin{array}{l}\text { Investimentos em } \\
\text { medidas } \\
\text { conservacionis- } \\
\text { tas por empresários } \\
\text { do setor turístico e } \\
\text { órgãos públicos; }\end{array}$ & $\begin{array}{l}\text { Poluição e } \\
\text { lixo; }\end{array}$ & $\begin{array}{l}\text { Aumento da } \\
\text { renda da } \\
\text { população; }\end{array}$ & $\begin{array}{l}\text { Evasão de } \\
\text { divisas pela } \\
\text { compra de } \\
\text { importados; }\end{array}$ & $\begin{array}{c}\text { melhoria de } \\
\text { bens e serviços } \\
\text { para } \\
\text { população }\end{array}$ & $\begin{array}{c}\text { Prostituição, } \\
\text { criminalidade e } \\
\text { jogo organizado; }\end{array}$ & $\begin{array}{l}\text { Valorização } \\
\text { da herança } \\
\text { cultural; }\end{array}$ & $\begin{array}{l}\text { Vulgarização } \\
\text { das } \\
\text { manifestações } \\
\text { tradicionais; }\end{array}$ \\
\hline $\begin{array}{c}\text { Descoberta e } \\
\text { acessibilidade de } \\
\text { aspectos naturais } \\
\text { anteriormente não } \\
\text { valorizados; }\end{array}$ & $\begin{array}{c}\text { Destruição da } \\
\text { fauna e flora, } \\
\text { caça e pesca } \\
\text { ilegais; } \\
\text { Alimentação } \\
\text { de animais; }\end{array}$ & $\begin{array}{c}\text { Geração de } \\
\text { empregos diretos } \\
\text {, indiretos e } \\
\text { induzidos; }\end{array}$ & $\begin{array}{c}\text { Economia } \\
\text { dependente do } \\
\text { turismo; }\end{array}$ & $\begin{array}{l}\text { fixação do } \\
\text { homem } \\
\text { no meio } \\
\text { rural; }\end{array}$ & $\begin{array}{l}\text { Neocolonialis- } \\
\text { mo; }\end{array}$ & $\begin{array}{l}\text { Orgulho } \\
\text { étnico; }\end{array}$ & $\begin{array}{l}\text { Arrogância } \\
\text { cultural; }\end{array}$ \\
\hline $\begin{array}{l}\text { Interação cultural e } \\
\text { aumento da } \\
\text { compreensão entre } \\
\text { povos; }\end{array}$ & $\begin{array}{c}\text { Degradação } \\
\text { de sítios } \\
\text { históricos, } \\
\text { arqueológicos } \\
\text { e } \\
\text { monumentos; }\end{array}$ & $\begin{array}{l}\text { Expansão do } \\
\text { setor de } \\
\text { construção; }\end{array}$ & $\begin{array}{c}\text { Inflação e } \\
\text { especulação } \\
\text { imobiliária; }\end{array}$ & & $\begin{array}{c}\text { Conflitos entre } \\
\text { turistas e devotos } \\
\text { nos locais santos; }\end{array}$ & $\begin{array}{c}\text { Valorização e } \\
\text { preservação } \\
\text { do patrimônio } \\
\text { histórico. }\end{array}$ & $\begin{array}{c}\text { Destruição do } \\
\text { patrimônio } \\
\text { histórico. }\end{array}$ \\
\hline $\begin{array}{c}\text { Recuperação } \\
\text { psicofísica dos } \\
\text { indivíduos; }\end{array}$ & $\begin{array}{l}\text { Ruídos e } \\
\text { incêndios }\end{array}$ & $\begin{array}{c}\text { Industrialização } \\
\text { básica na } \\
\text { economia } \\
\text { regional; }\end{array}$ & $\begin{array}{c}\text { Sazonalidade } \\
\text { da demanda } \\
\text { turística. }\end{array}$ & & $\begin{array}{c}\text { Congestionamen- } \\
\text { tos; }\end{array}$ & & \\
\hline $\begin{array}{l}\text { Utilização mais } \\
\text { racional e } \\
\text { valorização dos } \\
\text { espaços naturais. }\end{array}$ & $\begin{array}{c}\text { Alargamento } \\
\text { de trilhas; } \\
\text { Erosão; }\end{array}$ & $\begin{array}{l}\text { Atração de mão- } \\
\text { de-obra de outras } \\
\text { localidades. }\end{array}$ & & & $\begin{array}{l}\text { Divisão } \\
\text { Social; }\end{array}$ & & \\
\hline & $\begin{array}{c}\text { Modificação } \\
\text { do microclima } \\
\text { em } \\
\text { ecossistemas } \\
\text { particulares. }\end{array}$ & & & & $\begin{array}{c}\text { Competitivida- } \\
\text { de. }\end{array}$ & & \\
\hline
\end{tabular}


Não se deve excluir o meio ambiente sócio-cultural. Para SACHS (1994), as dimensões sociais, ecológicas e econômicas devem ser levadas em conta em um modelo de desenvolvimento sustentado, assim como a dimensões espacial e cultural. A sustentabilidade econômica pretende, através de formas racionais e eficazes de gerenciamento, investimentos e financiamentos, atingir um maior equilíbrio na distribuição de renda e de bens gerados na sociedade, tendo como objetivo a sustentabilidade social. A sustentabilidade ecológica e espacial procura melhores técnicas de utilização de recursos naturais e do espaço urbano-rural, distribuição dos assentamentos humanos, além de atividades econômicas mais equilibradas. A sustentabilidade cultural busca a resolução de problemas locais, através das peculiaridades culturais, com 0 envolvimento da população local.

$\mathrm{O}$ ecoturismo tem suas diretrizes norteadas para sustentabilidade dos sistemas ecológicos e sociais. As diretrizes enfatizam a preparação dos viajantes, operadores e guias para minimizar impactos negativos, conservação dos ambientes visitados com baixa geração de resíduos e uso eficiente dos recursos naturais, envolvimento da população local e manutenção da cultura, gerando oportunidades para a comunidade, respeito às leis ambientais e normas locais (EAA, 1998, PATA, 1998; THE ECOTOURISM SOCIETY, 1997). ROSS e WALL (1999) consideraram o ecoturismo uma estratégia potencial para a conservação da natureza e, ao mesmo tempo, para o desenvolvimento sustentável local.

PIRES (2000), estudando os vários conceitos de ecoturismo, verificou que todos são congruentes em 5 aspectos: ênfase na natureza e nas culturas alóctones; preocupação com impactos sócio-econômicos e com a sustentabilidade dos recursos utilizados; compromisso com a geração de benefícios para a comunidade receptora e para economia regional; advento da conscientização ecológica; e apoio a ações conservacionistas nos locais visitados. Para o autor, ecoturismo deve sempre considerar esses aspectos, caso contrário, trata-se de rotulação inadequada, atribuída às diversas 
atividades turísticas convencionais. O mesmo em relação à suposta sustentabilidade do ecoturismo, que não ocorre quando praticado e consumido de forma não coerente com os aspectos citados. Como ROSS e WALL (op cit.) apontaram, a aplicação da teoria não está surtindo os efeitos práticos esperados em relação ao ecoturismo, em parte devido à necessidade de monitoramento, através de indicadores mensuráveis dos impactos,ou seja, das características apontadas por PIRES (op cit.).

Este capítulo tem por objetivo determinar os impactos do turismo no bairro da Serra e sugerir ações para o desenvolvimento sustentável da região.

\subsection{MATERIAL E MÉTODOS}

\subsubsection{IMPACTOS SÓCIO-CULTURAIS E ECONÔMICOS DO TURISMO}

A determinação da percepção popular e dos impactos do turismo foi feita através de entrevista estruturada, com questões abertas e fechadas, na qual um entrevistador fazia perguntas pré-determinadas aos moradores do bairro, um de cada residência. Segundo MATTAR (1996), os questionários estruturados têm por objetivo que os entrevistados respondam sempre a mesma pergunta, já que se uma pergunta for formulada de forma diferente, poderá gerar uma resposta diferente. Também são os de mais simples aplicação e fácil tabulação.

Inicialmente foi realizada uma entrevista preliminar avaliativa (piloto), a partir da qual foi elaborada a definitiva, que foi aplicada nas residências do bairro.

O modelo de entrevista padronizada encontra-se no Anexo I.

As questões de 1 a 6 demonstram a estrutura etária e a origem de cada família ou grupo de moradores, e as questões 7, 8 e 9, a escolaridade e a atividade que exercem. A questão 10 demonstra a freqüência de trabalho dos monitores e a 11, a expectativa criada por esta atividade. A questão 12 tem por 
objetivo verificar se o turismo já foi fonte de renda e não é mais para algum morador. As demais questões, até a 21, tratam do impacto econômico positivo da hospedagem de turistas, e aí se verifica o número de leitos, a demanda e alguns serviços oferecidos. A questão 22 trata da possível expectativa de renda gerada pela hospedagem. As questões 23, 24 e 25 visam identificar os efeitos da especulação imobiliária. As questões sanitárias são identificadas nas de números $26,27,35$ e 36 . As perguntas 28 a 32 têm por objetivo verificar a percepção dos moradores frente à atividade turística e aos turistas. A questão 33 quer demonstrar se o turismo traz algum benefício aos moradores e se existe a integração destes com os turistas. A questão 34 quer determinar a visão dos moradores em relação ao PETAR. A pergunta 37 determina as atividades de lazer e a 38 tem por objetivo determinar se os moradores estão satisfeitos com a situação atual ou têm outras expectativas. A questão 40 visa identificar se os moradores estão engajados em alguma associação ou organização não-governamental. A questão 39 , aliada aos dados de escolaridade, são utilizadas como indicativos do nível sócio-econômico (MATTAR, 1996).

\subsection{RESULTADOS}

\subsubsection{POPULAÇÃO DO BAIRRO DA SERRA}

No ano 2000, constatou-se que existiam 130 casas no bairro da Serra, sendo que destas, 83 são ocupadas por moradores residentes. Das restantes, 38 pertencem a turistas, ocupadas esporadicamente, ou a pessoas que já residiram no Bairro e se mudaram, mantendo a posse das casas. Nove proprietários têm duas casas no bairro. Foram realizadas entrevistas em 98,8\% das casas de moradores residentes (82 casas), sendo que somente em uma das 83 residências ocupadas do bairro, o morador não foi encontrado. 
A maioria das entrevistas foi realizada em residências cujo proprietário era morador. Somente 4 residências não pertenciam aos entrevistados. Também não foi constatada a venda de imóveis por nenhum dos entrevistados no bairro.

A população fixa estimada é de 404 pessoas, e nas entrevistas foram obtidas informações referentes a 401 moradores. A população feminina é de 139 pessoas e a masculina, de 262 pessoas. Destes, 78,6\% nasceram no bairro da Serra, 10\% nasceram em Iporanga, 8,4\% em cidades vizinhas (tabela 3.3.1.1). A maior parte dos moradores ou nasceu no bairro, ou mora lá há mais de 20 anos (86\%), e somente $4 \%$ reside a menos de 05 anos.

O bairro da Serra apresenta uma população jovem. A faixa etária entre 0 e 12 anos é a que apresenta maior número de pessoas, 29\% da população, seguido de 13 a 21 anos com 25\%, 22 a 40 anos com 24\%, 41 a 65 anos com $18 \%$, e acima de 66 anos com $4 \%$.

Da população amostrada, 29,5\% não apresentam nenhum grau de escolaridade, e aí se incluem aqueles que não estudaram $(17,7 \%$ da população) e as crianças em idade pré-escolar (11,8\% da população). 5,1\% da população possuem o nível fundamental concluído, 7,1\% o ensino médio e 1\% nível superior ou pós-graduação. $47 \%$ estão cursando ou não concluíram o nível fundamental e 10,2\% estão cursando ou não concluíram o nível médio.

\subsubsection{MORADIA E SANEAMENTO BÁSICO}

O abastecimento de água da maioria das casas $(80,5 \%)$ é feito pela SABESP, porém $11 \%$ das casas utilizam água captada de cavernas (1 residência da caverna Alambari e 8 residências da caverna Ouro Grosso), e 8,5\% das residências utilizam nascentes para abastecimento de água. Já em relação ao esgoto, $79,3 \%$ das casas possuem fossas negras, $9,8 \%$ fossas sépticas, 9,8\% lançam diretamente em rios e 1,2\% na própria rua. $O$ destino dos resíduos sólidos pode ser observado na tabela 3.3.2.1, e mostra que a 
maioria das casas se utiliza de coleta pública $(79,2 \%), 6,1 \%$ reciclam parte do lixo, mas algumas residências têm seu lixo queimado. Somente em uma residência o lixo é disposto em qualquer local.

TABELA 3.3.1.1 - Local de nascimento dos moradores do bairro da Serra, por Estado ou Município do Vale do Ribeira

\begin{tabular}{|c|c|c|c|c|}
\hline Estado & Município & & NÚMERO & $\%$ \\
\hline \multirow{8}{*}{ São Paulo } & Iporanga & & 10 & 2,5 \\
\hline & & $\begin{array}{c}\text { Bairro da } \\
\text { Serra }\end{array}$ & 315 & 78,6 \\
\hline & Apiaí & & 20 & 5 \\
\hline & Itaóca & & 8 & 2 \\
\hline & Eldorado & & 4 & 1 \\
\hline & Ribeira & & 1 & 0,2 \\
\hline & Iguape & & 1 & 0,2 \\
\hline & Outros & & 26 & 6,5 \\
\hline Paraná & & & 9 & 2,2 \\
\hline Minas Gerais & & & 3 & 0,8 \\
\hline Bahia & & & 1 & 0,2 \\
\hline Paraíba & & & 1 & 0,2 \\
\hline Rio de Janeiro & & & 1 & 0,2 \\
\hline Rio Grande do Sul & & & 1 & 0,2 \\
\hline & & Total & 401 & 100 \\
\hline
\end{tabular}

TABELA 3.3.2.1 - Destino do lixo produzido no bairro da Serra

\begin{tabular}{lll}
\hline & Número & $\%$ \\
\hline Coleta pública & 65 & 79 \\
Coleta pública/separa latinhas & 3 & 3,7 \\
Queimado & 3 & 3,7 \\
Queima o papel/alimentação de animal & 2 & 2,4 \\
Separa como coleta seletiva & 2 & 2,4 \\
Disposto em qualquer lugar & 2 & 2,4 \\
Coleta pública/alimentação de animais & 1 & 1,2 \\
Coleta pública/queima o plástico e papel & 1 & 1,2 \\
Coleta pública/queimado e compostagem & 1 & 1,2 \\
Coleta pública/queimado & 1 & 1,2 \\
Coleta pública/queima o plástico & 1 & 1,2 \\
\hline Total & 82 & 100 \\
\hline
\end{tabular}




\subsubsection{EMPREGOS}

Na tabela 3.3.3.1 são apresentadas as principais ocupações. 50,6\% da população residente entrevistada trabalha. O cultivo de roças ainda é uma atividade bastante praticada, e também pode-se observar que $46,3 \%$ da população economicamente ativa trabalha diretamente com atividades turísticas (guia/monitor, pousadas, camping) ou em empregos gerados indiretamente pelo turismo (pedreiros, comércio).

TABELA 3.3.3.1 - Ocupação principal dos moradores que trabalham no bairro da Serra

\begin{tabular}{lcc}
\hline Ocupação & Número & $\%$ \\
\hline Roça & 31 & 15,3 \\
Guia/monitor & 25 & 12,4 \\
Funcionário de Pousada & 19 & 9,5 \\
Prefeitura & 12 & 5,9 \\
Diarista & 11 & 5,5 \\
Diarista de Pousada & 8 & 3,9 \\
Dono de Pousada & 8 & 3,9 \\
Comércio & 7 & 3,5 \\
Pedreiro & 6 & 3 \\
Funcionário de Camping & 3 & 1,5 \\
Funcionário do Petar & 3 & 1,5 \\
Dono de Camping & 1 & 0,5 \\
Outros serviços & 69 & 34 \\
Total & 203 & 100 \\
\hline
\end{tabular}

Os restantes $49,4 \%$ da população que não trabalha é constituída, em sua grande maioria, por jovens com menos de 18 anos.

$\mathrm{O}$ trabalho em meios de hospedagem gera uma parte significativa dos empregos (18,9\%), sendo que destes postos de trabalho, 23 são ocupados por mulheres e 18 postos por homens. Já o trabalho de monitor é prioritariamente masculino, com somente 3 postos ocupados por mulheres e outros 22 por homens. 
A atividade de monitor ambiental contribui com 12,4\% da ocupação principal dos trabalhadores, sendo que $1,8 \%$ dos trabalhadores têm a atividade de guia como ocupação secundária. Esse tipo de trabalho se concentra nos fins-de-semana, já que somente $10 \%$ dos monitores trabalham diariamente na atividade, e outros $42 \%$ trabalham apenas nos fins-de-semana. Há ainda mais $7 \%$, que trabalham esporadicamente como monitores.

A expectativa em exercer a atividade não é grande, uma vez que $17,1 \%$ dos entrevistados, que não são monitores, gostariam de exercer essa atividade, porém isso pode não exprimir os desejos da população como um todo, somente dos residentes entrevistados (82 moradores).

A hospedagem de turistas é uma expectativa de $50 \%$ dos entrevistados (41 residências). Alguns gostariam de hospedar em casa, outros em camping e um está construindo uma pousada.

\subsubsection{POPULAÇÃO RESIDENTE E TURISMO}

$\mathrm{Na}$ tabela 3.3.4.1 são apresentados os modos de a população residente no bairro da Serra ver o turismo.

De modo geral, a maioria dos residentes entrevistados considera o turismo positivo e acredita que ele traz benefícios. Em relação ao Parque Estadual Turístico do Alto Ribeira, a maioria também considera positiva a sua existência, porém com pequena rejeição, já que $5 \%$ dos entrevistados não gostam, e outros $5 \%$ são indiferentes à existência do PETAR. É curioso o fato de $4 \%$ dos entrevistados não conhecerem o parque. 
TABELA 3.3.4.1 - Modos de ver o turismo pelos 82 residentes entrevistados do bairro da Serra

\begin{tabular}{lc}
\hline Moradores que gostam do turismo & $96 \%$ \\
Moradores que dizem que tanto faz & $4 \%$ \\
\hline Moradores que acreditam que o turismo tráz benefícios & $98 \%$ \\
Moradores que dizem que não tráz benefício & $1 \%$ \\
Moradores que dizem que não muda em nada & $1 \%$ \\
\hline Acreditam que o turismo não mudou o meio ambiente & $58 \%$ \\
Acreditam que o turismo mudou o meio ambiente para pior & $20 \%$ \\
Acreditam que o turismo mudou o meio ambiente para melhor & $12 \%$ \\
Acreditam que o turismo mudou, mas não sabe explicar porque & $10 \%$ \\
\hline Dizem que o turismo não mudou seu modo de vida & $56 \%$ \\
Dizem que mudou para melhor & $32 \%$ \\
Dizem que mudou para pior & $7 \%$ \\
Dizem que mudou um pouco, mas não tão significativamente & $5 \%$ \\
\hline Dizem que o turismo não muda o modo de vida das pessoas & $37 \%$ \\
Dizem que o turismo mudou a vida das pessoas para melhor & $31 \%$ \\
Dizem que o turismo mudou a vida das pessoas para pior & $12 \%$ \\
Não souberam responder & $21 \%$ \\
\hline Gostam do PETAR & $86 \%$ \\
Não conhecem o PETAR & $4 \%$ \\
Não gostam do PETAR & $5 \%$ \\
Gostam mais ou menos & $5 \%$ \\
\hline
\end{tabular}

A percepção dos entrevistados em relação aos impactos ambientais do turismo é variável: $58 \%$ acham que o turismo não modificou o meio ambiente; $20 \%$ acham que modificou para pior; $12 \%$ acreditam que modificou para melhor.

Em relação à interferência no modo de vida das pessoas, a maioria dos moradores considera o turismo um agente positivo, por não interferir no seu modo de vida e no das outras pessoas (56\% e $37 \%$, respectivamente) ou por interferir positivamente (32\% e $31 \%$, respectivamente). Por outro lado, existe por parte de alguns, um certo antagonismo, já que 7\% dos moradores consideram que suas vidas mudaram para pior e $12 \%$, que a vida de outros moradores pioraram em função do turismo.

\subsubsection{NECESSIDADES DA POPULAÇÃO RESIDENTE}

As necessidades para melhoria das condições de vida dos moradores, 
de acordo com a visão deles, estão apresentadas na tabela 3.3.5.1. Emprego, saneamento básico e saúde foram os fatores mais importantes citados: $22 \%$, $19 \%$ e $13 \%$, respectivamente. Deve-se ressaltar que $3 \%$ dos moradores consideram que as condições de vida são boas e $12 \%$ não souberam identificar uma necessidade para melhorar a condição de vida no bairro.

TABELA 3.3.5.1 - Opinião dos entrevistados sobre o que é necessário para a melhoria das condições de vida no bairro da Serra

\begin{tabular}{lcc}
\hline & Freqüência de respostas & $\%$ \\
\hline Emprego & 40 & 22 \\
Saneamento & 35 & 19 \\
Saúde & 27 & 13 \\
Não sabem & 22 & 12 \\
Estradas & 11 & 7 \\
Transporte público & 8 & 5 \\
Ensino & 6 & 4 \\
Roça & 6 & 4 \\
Telefone & 5 & 3 \\
Está bom & 5 & 3 \\
Comércio & 4 & 4 \\
Polícia & 2 & 1 \\
Quadra & 2 & 1 \\
Parque & 2 & 1 \\
Outros & 5 & 3 \\
Total & 180 & 100 \\
\hline
\end{tabular}

O contato da população residente com o turista se dá de várias formas, não somente nas relações de trabalho, mas nos seus momentos de lazer, como é mostrado na tabela 3.3.5.2.

O telefone público é de uso comum entre turistas e população, local mais citado durante as entrevistas (33\%), seguido do "bar do $\mathrm{JJ}$ " e da mercearia $(15,7 \%)$ e do PETAR (12,5\%). Muitos desses encontros ocorrem nos locais destinados a diversão e lazer da comunidade do bairro. 
TABELA 3.3.5.2 - Locais freqüentados pela população residente e pelos turistas

\begin{tabular}{lcc}
\hline & Freqüência de respostas & $\%$ \\
\hline Telefone & 50 & 33 \\
Mercearia & 23 & 15,7 \\
Bar JJ & 23 & 15,7 \\
Parque & 19 & 12,5 \\
Pastelaria & 12 & 7,9 \\
Bar do Saturnino & 8 & 5,3 \\
Pousadas & 7 & 4,6 \\
Beira do rio & 2 & 1,3 \\
Rua & 2 & 1,3 \\
Cavernas & 2 & 0,7 \\
Bar do Pedrinho & 2 & 0,7 \\
Barraca de sorvete & 1 & 0,7 \\
Loja & 1 & 0,7 \\
\hline Total & 152 & 100 \\
\hline
\end{tabular}

Na tabela 3.3.5.3 são mostradas as formas de lazer e diversão da população do bairro da Serra. O PETAR, cavernas e o rio, são locais de lazer da população residente, onde o encontro com turistas é quase certo. A igreja parece ter um papel importante na vida social da comunidade. Alguns se deslocam para outras cidades, como Apiaí, ou vão a Iporanga e mesmo para São Paulo, em busca de divertimento.

A Associação Serrana Ambientalista (ASA) conta com a participação de moradores de $53,7 \%$ das residências. Alguns moradores não têm interesse em participar e somente um respondeu que não foi convidado. Este veio de São Paulo e montou uma pousada no bairro.

Em relação ao nível sócio-econômico da população, alguns indicativos foram coletados. Existem 16 residências com automóveis (1 para cada 25 moradores). Geladeira, banheiro e TV não estão presentes em 7, 6 e 21 residências, respectivamente. Existem 7 residências com aparelho de vídeo cassete e 17 com máquinas de lavar roupas. 
TABELA 3.3.5.3 - Como se divertem os moradores do bairro da Serra

\begin{tabular}{|c|c|c|}
\hline & Frequiência de respostas & $\%$ \\
\hline Petar & 18 & 12,4 \\
\hline Outras cidades & 16 & 11 \\
\hline Iporanga & 15 & 10,3 \\
\hline Igreja & 14 & 10 \\
\hline Não sai & 13 & 9 \\
\hline Rio Betari & 10 & 6,9 \\
\hline Escola & 8 & 5,5 \\
\hline Jogando bola & 8 & 5,5 \\
\hline Cavernas & 6 & 4,1 \\
\hline Passeios na mata & 5 & 3,4 \\
\hline Comércio & 4 & 2,8 \\
\hline TV & 3 & 2,1 \\
\hline Forró & 3 & 2,1 \\
\hline Cachoeira & 3 & 2,1 \\
\hline Quermesse & 3 & 2,1 \\
\hline Festas & 3 & 2,1 \\
\hline Casa dos parentes & 3 & 2,1 \\
\hline São Paulo & 2 & 1,4 \\
\hline Andando pelo Bairro da Serra & 2 & 1,4 \\
\hline Praia & 2 & 1,4 \\
\hline Com crianças & 1 & 0,7 \\
\hline Com turistas & 1 & 0,7 \\
\hline Leva gado para passear & 1 & 0,7 \\
\hline Total & 145 & 100 \\
\hline
\end{tabular}

Existem no bairro 10 pousadas e 5 campings, sendo que desses últimos, somente dois funcionam quando os demais meios de hospedagem estão cheios, e não apresentam nenhuma infra-estrutura para acampamento, somente a área para armação das barracas, e duas residências que alugam quartos. Estão disponibilizados 496 leitos, excluindo a possibilidade de acampamento. O tempo de permanência nos meios de hospedagem é, na maioria das vezes, de 2 a 3 dias, predominantemente, nos fins de semana e 
feriados. Na tabela 3.3.5.4 são apresentados os dados referentes aos meios de hospedagem.

Pode-se observar que não existe um controle do número de hóspedes e que alguns lugares são ocupados somente nos feriados, quando a demanda é muito grande. A maioria recebe grupos de excursões de estudantes. Além dos donos que também trabalham, as pousadas empregam 25 pessoas $(6,2 \%$ da população). Os resíduos sólidos são retirados pela coleta pública, mas o esgoto é descartado em fossas negras (4 pousadas, 2 campings e nas casas que alugam quartos), fossas sépticas (4 pousadas) e no rio (2 pousadas). Todas as pousadas, e os campings do João e Vale das Orquídeas, fornecem refeições para hóspedes. As diárias variam de $R \$ 22,00$ a $R \$ 37,00$ nas pousadas, incluindo café da manhã, uma refeição e a pernoite. Os campings cobram, em média, $R \$ 3,00$ a diária por pessoa. 
TABELA 3.3.5.4 - Caracterização dos meios de hospedagem no bairro da Serra (dados coletados em outubro de 2000)

\begin{tabular}{|c|c|c|c|c|c|c|c|c|c|c|}
\hline Meios de Hospedagem & $\begin{array}{l}\text { Freqüuência de } \\
\text { ocupação }\end{array}$ & $\mathrm{N}^{\circ}$ Leitos & $\begin{array}{c}\text { Demanda } \\
\text { mensal }\end{array}$ & $\begin{array}{l}\text { Tama- } \\
\text { nho do } \\
\text { Grupo }\end{array}$ & $\begin{array}{l}\text { Tempo de } \\
\text { permanên- } \\
\text { cia }\end{array}$ & $\begin{array}{l}\text { Oferece } \\
\text { refeições }\end{array}$ & $\begin{array}{l}\text { Valor da } \\
\text { Diária }\end{array}$ & $\begin{array}{c}\mathrm{N}^{\circ} \text { Funcio- } \\
\text { nários }\end{array}$ & $\begin{array}{l}\text { Destino do } \\
\text { Lixo }\end{array}$ & $\begin{array}{l}\text { Destino do } \\
\text { Esgoto }\end{array}$ \\
\hline Pousa da Fifi & $\mathrm{F}$ & 24 & $?$ & GP & 3 dias & $\operatorname{sim}$ & $\mathrm{R} \$ 20,00$ & $\mathrm{~N}$ & $\mathrm{CP}$ & $\mathrm{R}$ \\
\hline Pousada do Saturnino & $\mathrm{E}$ & 38 & 6 & $\mathrm{GP} / \mathrm{C}$ & 3 dias & $\operatorname{sim}$ & $\mathrm{R} \$ 22,00$ & $\mathrm{~N}$ & $\mathrm{CP}$ & $\mathrm{R}$ \\
\hline Pousada do Quiririm & $\mathrm{F}$ & 39 & 15 & GP & 2 a 4 dias & $\operatorname{sim}$ & $\mathrm{R} \$ 36,00$ & 7 a 9 D & $\mathrm{CP} / \mathrm{CS}$ & FSp \\
\hline Pousada do Abílio & FS & 38 & $?$ & $\mathrm{GP} / \mathrm{C}$ & 2 a 4 dias & $\operatorname{sim}$ & $\mathrm{R} \$ 30,00$ & $\mathrm{~N}$ & $\mathrm{CP} / \mathrm{CS}$ & FN \\
\hline $\begin{array}{l}\text { Pousada da Idati } \\
\end{array}$ & FS & 30 & $?$ & GP/Ex & 2 a 5 dias & $\operatorname{sim}$ & $\mathrm{R} \$ 22,00$ & $1 \mathrm{D}$ & $\mathrm{CP} / \mathrm{CS}$ & FN \\
\hline Pousada do Cidão & $\mathrm{S}$ & 23 & 50 & GP/Ex & 3 dias & $\operatorname{sim}$ & $\mathrm{R} \$ 30,00$ & $1 \mathrm{D}$ & $\mathrm{CP} / \mathrm{CS}$ & FSp \\
\hline Pousada das Cavernas & $\mathrm{S}$ & 80 & 200 & Ex & 3 a 4 dias & $\operatorname{sim}$ & $\mathrm{R} \$ 37,00$ & $3 \mathrm{D}$ e $3 \mathrm{M}$ & $\mathrm{CP} / \mathrm{CS}$ & FSp \\
\hline $\begin{array}{l}\text { Pousada Rancho da } \\
\text { Serra }\end{array}$ & $\mathrm{F}$ & 38 & 40 & GP & 4 dias & $\operatorname{sim}$ & $\mathrm{R} \$ 26,00$ & $2 \mathrm{D}$ e $2 \mathrm{M}$ & $\mathrm{CP}$ & FN \\
\hline Pousada do Didi & $\mathrm{S}$ & 36 & $?$ & GP & 3 dias & $\operatorname{sim}$ & $\mathrm{R} \$ 28,00$ & $\mathrm{~N}$ & $\mathrm{CP}$ & FN \\
\hline Pousada da Diva & FS & 130 & 200 & GP/Ex & 3 dias & $\operatorname{sim}$ & $\mathrm{R} \$ 24,00$ & $4 \mathrm{D}$ & $\mathrm{CP}$ & FSp \\
\hline Camping do João & $\mathrm{F}$ & $?$ & $?$ & $\mathrm{C} / \mathrm{Ex}$ & 3 dias & $\operatorname{sim}$ & $\mathrm{R} \$ 3,00$ & $\mathrm{~N}$ & $\mathrm{CP}$ & FN \\
\hline Camping do Dema & $\mathrm{F}$ & ? & ? & $\mathrm{GP} / \mathrm{C}$ & 3 dias & não & $\mathrm{R} \$ 3,00$ & $\mathrm{~N}$ & $\mathrm{CP}$ & FN \\
\hline
\end{tabular}
E - Eventualmente
R - Rio
F - Feriados
FSp - Fossa séptica
FS - Fins de semana
FN - Fossa negra
S - Sempre
CP - Coleta pública
Ex - Excursões
CS - Coleta seletiva
C - Casais
$\mathrm{N}$ - Nenhum
GP - grupos pequenos de até 15 pessoas
D - Diaristas
? - Não sabe responder
M - Mensalista 


\subsection{DISCUSSÃO}

O município de Iporanga está localizado na região mais carente do Estado de São Paulo. Segundo VEIGA e ROMÃO (1998), no Vale do Ribeira, a renda per capita é menor que a do Nordeste. Com uma área de $1160,21 \mathrm{Km}^{2}$, Iporanga tem $6 \%$ do seu território utilizado para agricultura e outra parte significativa compreende unidades de conservação, o que limita o seu uso e justifica a baixa densidade populacional de 3,93 hab/ $\mathrm{m}^{2}$. Apesar disso, 54,5\% da população (2488 pessoas), segundo censo de 2000, residem em área rural, em condições muitas vezes bastante precárias (IBGE, 2001).

No bairro da Serra residem 16,2\% da população rural do município, com uma qualidade de vida um pouco melhor que o restante da população rural. Isto é proporcionado pelo turismo. O Parque Estadual Turístico do Alto Ribeira recebe anualmente 40.000 turistas (SILVEIRA, 1998), e a maior parte deles se hospeda no bairro da Serra, como observou ROSSI (1996), trazendo benefícios econômicos.

A geração de empregos diretos e indiretos é um dos principais impactos econômicos do turismo. ASCANIO (1994) determinou que cada 55 turistas criaram um emprego direto e outro indireto na llha de Lanzarote, Espanha.

Segundo BONDUKI (1997), existiam no bairro da Serra 10 meios de hospedagem, 5 bares, 4 quituteiras, uma loja de equipamentos para prática de espeleologia e uma barraca de caldo de cana. Em 2000, existiam 5 bares, uma pastelaria, uma barraca de sorvetes, uma loja e 15 meios de hospedagem, o que demonstra o crescimento nesse intervalo de 3 anos.

O turismo gerou e mantém a maior parte dos empregos no bairro, e ainda existe a expectativa de gerar mais empregos e renda, fato que se reflete na aceitação do turismo pela população, até de certa forma mascarando problemas, como a degradação ambiental.

Isso demonstra que os serviços oferecidos tendem a aumentar, já que novos pontos de comércio e prestação de serviços poderão ser abertos, devido 
à expectativa de aumento de renda hospedando turistas, ou pela geração de empregos, como o próprio estudo demonstra. Isso ocorre sem uma avaliação de demanda real, que poderá levar ao fechamento de vários empreendimentos. CAROSO e RODRIGUES (1998) observaram que o crescimento turístico no litoral norte da Bahia criou expectativas não atingidas pelas populações afetadas, gerando conflitos.

BONDUKI (1997) observou que a demanda de monitores no Bairro da Serra era pouco regular e não regulamentada, o que criava incertezas. No presente trabalho, foi observado que a maior demanda por monitores ocorre nos fins-de-semana e é sabido que existe uma competição com monitores de Apiaí e Iporanga, que também tentam se organizar. O mesmo ocorre em relação a pousadas e, como foi observado, algumas têm somente ocupação esporádica.

Um impacto positivo do turismo é o aquecimento da economia. SWARBROOKE (2000) explicou que ocorre o "efeito multiplicador" na economia, sendo o dinheiro gasto pelos turistas, circulado em ondas na economia local. Assim, o dinheiro gasto pelo turista em hospedagem, vestuário, diversão, refeições, guias, etc., gera uma segunda onda de gastos, provocados pelos empreendedores e assalariados, que por sua vez, movimenta todos os setores econômicos. Por outro lado, a fuga do capital gerado pelo turismo é um impacto negativo freqüente em países em desenvolvimento, cuja economia é baseada na produção primária ou na venda do meio ambiente natural. Em menor escala, isso ocorre no bairro da Serra e em Iporanga, locais com poucos recursos. A aquisição de mercadorias para consumo dos turistas é feita em cidades com mais recursos comerciais, onde a oferta de produtos é mais variada e, muitas vezes, o preço é menor. No caso do bairro da Serra, as cidades de Apiaí e Registro são beneficiadas. A fuga de capital diminui o dinheiro gasto pelos turistas que circula na economia local.

Outro impacto econômico negativo decorre da sazonalidade. No bairro da Serra isto pode ser observado nas férias de verão, quando a demanda 
diminui, já que a maioria dos turistas pertence a excursões escolares. Em julho a demanda existe graças à presença de turistas que visitam a região por conta própria. Outro fator importante é o clima que influencia a sazonalidade. Nos períodos chuvosos, além da diminuição do número de turistas, existe o problema do acesso. Em 1997, uma enchente praticamente isolou o bairro e o município de Iporanga, erodindo estradas, provocando desmoronamentos e interditando a ponte que dá acesso para quem vem da Rodovia Régis Bittencourt.

A especulação imobiliária parece ter sido mais intensa em outros períodos. Atualmente, $29,2 \%$ das casas do bairro pertencem a turistas ou a exmoradores, mas não foi encontrado nenhum morador que confirmou ter vendido suas posses e ainda mora no bairro. DE BLASIS (1996) citou que ocorreu adensamento populacional nos pontos iluminados do Bairro e que casas de turistas foram instaladas, permanecendo a maior parte do tempo vazias. CAMPOS (1990) mencionou que inúmeros moradores venderam pequenos lotes. SILVEIRA (1998) cita que alguns lotes foram vendidos para construção de pousadas. Essa opção é menos problemática, uma vez que um bem de produção (a terra) é "trocado" por um de prestação de serviço (hospedagem). O mesmo não ocorreu em Ilha Bela, como observou CALVENTE (1996), onde os pescadores que venderam suas terras tiveram que ocupar áreas críticas, como morros, e alguns ficaram impossibilitados de ter acesso à praia. Cabe ressaltar que a venda de lotes de pequeno tamanho, sem adequação a geomorfologia do terreno, contribui para degradação ambiental, provocando o desmatamento e favorecendo erosão e assoreamento de rios.

A falta de legislação específica para edificação e de estodos de impacto ambiental, levou à ocorrência de vários problemas na costa chilena, como observou MAUREIRA (1998). Segundo o autor, turistas e pescadores reclamaram o livre acesso às praias, além de ter ocorrido degradação ambiental. 
Segundo CAMPOS (1990), no início dos anos 90, era grande o êxodo dos jovens do bairro da Serra para outras regiões em busca de empregos e melhores condições de vida, comportamento que poderia ser alterado com o aumento da oferta de trabalho proporcionado pelo crescimento turístico. Dez anos depois, as previsões parecem ter se concretizado. É grande a população de jovens e pode-se verificar que existe expectativa de trabalho para eles, favorecendo a fixação no local.

O turismo rural tem sido responsabilizado pela fixação do homem no campo. Segundo ZIMMERMANN (2000), uma das funções do turismo rural é a manutenção de atividades agrícolas tradicionais e, conseqüentemente, a manutenção da família rural no campo. Para PRESVELOU (2000), o declínio da produção lucrativa nas áreas rurais promove o êxodo dos jovens, envelhecendo a população rural. Além disso, o descuido com a terra permite a erosão do solo.

Um aspecto importante que deve ser frisado é a geração de empregos para mulheres, principalmente nas pousadas, permitindo uma maior participação feminina na população economicamente ativa. Por outro lado, essa atividade modifica um padrão familiar patriarcal. CAMPOS (1990) citou que as mulheres trabalhavam em casa e na roça, sem fim-de-semana; umas poucas começam a trabalhar fora, em função do turismo.

Em São Carlos de Bariloche, Argentina, o aumento de empregos para mulheres foi considerado um fator importante no desenvolvimento local (SCHLÜTER, 1999), permitindo equilíbrio numérico entre sexos, uma vez que o número de homens era superior ao de mulheres, e muitas delas imigraram para trabalhar em hotéis. Deve-se observar que a maioria da população do bairro da Serra é do sexo masculino, fato que poderia contribuir para a emigração de homens.

Apesar da maioria dos moradores não considerar que o turismo tenha modificado seu modo de vida, ou se mudou foi para melhor, o efeito demonstração deve estimular hábitos de consumo. Isto ocorreu quando foi inaugurada uma loja de artigos para prática de esportes de aventura no bairro, 
para atender turistas, mas que num primeiro momento atendeu aos moradores, principalmente, os mais jovens. O contato com turistas também pode aumentar o consumo de bebidas alcoólicas, principalmente, nos momentos em que eles interagem com turistas nos bares do bairro.

A ascensão social proporcionada pela melhoria das condições econômicas não deve ser descartada como mudança nas condições de vida e gerador de conflitos com os atores que não conseguem essa ascensão. CAMPOS (1990) observou que não existiam diferenças sociais pelo nível de renda no bairro, fato este verificado atualmente.

Por outro lado, pode ocorrer também um efeito contrário, em que o grande fluxo de turistas para o bairro cria interação muito grande com as novidades do mundo urbano, que são trazidas até a população mais jovem, sem causar-lhes a necessidade de sair em busca dessas influências. É como se as atrações da cidade grande viessem até eles. É um tipo de globalização gerada pelo turismo.

Muitas mudanças ocorreram nos últimos 10 anos. CAMPOS (1990) observou que, no final da década de 90 , só existia no bairro um telefone que recebia recados para todos os moradores. Geladeiras eram raras e a televisão passou a ser um atrativo, quando foi instalada no "bar do JJ". Hoje, algumas pousadas possuem telefone e algumas residências têm geladeira.

Como foi observado, muitos atrativos e estabelecimentos comerciais são usados por turistas e moradores. Isto favorece a população local criando novos locais de diversão, porém, cada vez mais, o turismo envolve a população. Todos os entrevistados freqüentam pelo menos um local em comum com turistas. Alguns entrevistados relataram comportamentos dos turistas que os escandalizavam, como banhos nus e o uso de drogas, fato já observado por BONDUKI (1997) anteriormente.

O estudo revelou o baixo grau de instrução da população, o que de certa forma está relacionado ao isolamento do bairro, principalmente, levando em consideração a fração mais velha da população que teve menos oportunidades. 
No bairro só existe uma escola de ensino fundamental, e o ensino médio só é oferecido a $17 \mathrm{Km}$, no centro urbano de Iporanga. CAMPOS (1990) comentou que o ensino era muito fraco no município e BONDUKI (1997) citou que a evasão escolar era grande. Hoje, os jovens têm mais facilidades para freqüentar a escola; uma delas são os meios de transporte. O turismo também contribuiu para a melhoria do grau de instrução dos jovens. Como o trabalho de monitor ambiental é procurado por essa faixa etária, a ASA (Associação Ambientalista Serrana), uma organização não-governamental do bairro, que junto à Secretaria do Meio Ambiente organiza e seleciona os alunos do curso de monitores, exige que eles tenham concluído o ensino médio para serem aceitos, incentivando, desta forma, a freqüência escolar.

Um dos primeiros meios de produção do bairro foi a roça, que ainda contribui com 15,3\% das ocupações, o maior número. BONDUKI (op. cit.) observou que alguns moradores abandonaram as roças para trabalhar como guia. Apesar de ser uma forma de fixar o homem no campo, isso implica modificações de hábitos culturais. Alguns entrevistados consideraram que o turismo melhorou seu modo de vida por permitir o abandono da roça, ao propiciar um trabalho menos desgastante e mais rentável. Por outro lado, 6\% dos entrevistados citaram que a implantação de roças é uma necessidade para melhoria da região.

O impedimento do plantio foi uma das causas do descontentamento dos moradores mais antigos com a implantação do PETAR, uma vez que os limites do Parque se superpunham à área do bairro. Segundo SILVEIRA (1998), quando os limites do parque foram definidos em 1958, ele cortava o bairro da Serra. O parque se tornou vilão, já que muitas pessoas foram impedidas de obter recursos, aumentando ainda mais a pobreza do local. Na década de 90, o turismo modificou este cenário e o período de estagnação pareceu ter terminado (BONDUKI, op. cit.). Os turistas e seus recursos, trazidos pelos atrativos do parque, mudaram essa visão. Mesmo assim, a rejeição em relação ao PETAR ainda existe, como foi observado nesse estudo. 
Os conflitos, gerados pela implantação de unidades de conservação em áreas ocupadas por populações tradicionais, têm sido estudados no Brasil. DIEGUES (1996) apontou que o modelo de preservação americano, adotado no Brasil, em que os espaços preservados são vazios, e não se permite a presença de moradores, está em desacordo com a realidade das florestas tropicais, onde as populações nativas desenvolveram formas de uso e ocupação dos recursos naturais, com sistemas de manejo de fauna e flora, protegendo e até aumentando a biodiversidade.

Exemplos desse descaso com o saber tradicional e com seus criadores foram demonstrados na Reserva Ecológica da Juatinga, no Rio de Janeiro, por DIEGUES e NOGARA (1994). DIEGUES (1998) citou, ainda, estudos realizados pelo NUPAUB (Núcleo de Apoio à Pesquisa sobre Populações Humanas e Áreas Úmidas), enfocando a relação entre áreas protegidas e populações humanas, em Guaraqueçaba (Paraná), Juréia-Itatins (São Paulo), Pantanal Matogrossense, complexo estuarino lagunas de Iguape-Cananéia (São Paulo), dentre outros. Em relação ao turismo, DIEGUES (1997) mencionou a incompreensão dos moradores tradicionais, ao verem turistas nas áreas protegidas de onde foram retirados, e foram os responsáveis pela manutenção da integridade dos ecossistemas.

O PETAR é um lugar de lazer importante para a população local, assim como a igreja. Segundo BONDUKI (1997), a igreja passou a ter o papel de encontro social que anteriormente ocorria no trabalho rural em mutirão. A demanda interna por recursos naturais para o lazer, como foi observado, é um fator importante na valorização e conservação do meio ambiente.

A estagnação criada, quando o parque foi implantado, levou muitos moradores a se tornarem palmiteiros, problema revertido com o aumento da demanda turística. Por outro lado, outros problemas ambientais surgem. $O$ elevado número de turistas leva à produção de grande volume de lixo e esgotos. MAGRO (1999) citou que os efeitos da visitação em parques podem parecer insignificantes, quando comparado a outros problemas ambientais (por 
exemplo, os gerados nos ecossistemas urbanos ou pelas agrícolas). Mas, a crescente demanda por recreação e lazer em áreas naturais têm aumentado a pressão sobre essas áreas.

O lixo é, na maioria dos casos, coletado pela prefeitura e levado para um lixão. Uma pequena parte dos moradores enterra ou queima seu lixo, provocando poluição do solo e do ar. O esgoto da maior parte das pousadas é lançado em fossas negras, que podem contaminar o lençol freático, ou são lançados nos rios. Segundo praticantes de bóia-cross, em alguns locais do rio Betari pode-se sentir "cheiro de peixe", devido ao lançamento de esgotos. Com o aumento da demanda, esse problema pode agravar-se.

Os rios são utilizados para lazer da população e dos turistas, e para dessedentação de animais. Algumas residências são abastecidas com água de cavernas, que podem ter sua qualidade comprometida, devido ao aumento da visitação. Os moradores têm consciência do problema da água. Saneamento básico foi o item mais citado para melhoria do bairro, depois dos empregos.

A aceitação do turismo como algo positivo, que promove 0 desenvolvimento e a melhoria da qualidade de vida, como observado no bairro da Serra, é um fenômeno comum nos locais que estão se desenvolvendo recentemente. A Ilha de Cotijuba, localizada na baía de Marajó, na grande Belém do Pará, passou por situação semelhante. Dados de 1995, obtidos por CRUZ (1996), demonstraram o crescimento do número de empregos e a aceitação do turismo. Novas formas de lazer surgem, como conversas com outras pessoas, porém existe, por parte dos moradores, a consciência dos impactos negativos que o turismo pode trazer. O bairro da Serra parece se encontrar numa fase de euforia em relação ao turismo; o positivismo e as expectativas da comunidade local nos levam a acreditar nisso, o que corresponde ao estágio inicial proposto por DOXEY apud MATHIESON \& WALL $(1988)^{2}$. Segundo esses autores, existe nessa fase um sentimento de satisfação

\footnotetext{
${ }^{2}$ DOXEY apud MATHIESON, A. \& WALL, G., 1988. Tourism. Economic, physical and social impacts. New York, Longman.
} 
mútua, gerada pelo crescimento econômico. Há uma segunda fase, caracterizada por uma apatia, em que a formalidade das relações comerciais predomina. Numa terceira fase, a incapacidade de atender as exigências da demanda e a saturação da atividade provocam irritação. $O$ antagonismo caracteriza a quarta fase, em que os problemas, agora evidentes, são de responsabilidade dos turistas, que passam a ser hostilizados. Finalmente, a quinta fase é a do conformismo, em que a população terá que conviver com o turismo nas proporções em que possa crescer.

PÉREZ (1999) observou uma atitude neutra por $50 \%$ da população local, e positiva por outros $30 \%$ da população da Villa la Angostura (Argentina). Segundo o autor, os impactos econômicos são percebidos como positivos, e geram aceitação do turismo, porém, com o aumento da atividade, os impactos negativos, ambientais e sócio-culturais, começam a ser percebidos, gerando opiniões neutras ou negativas em relação ao turismo, confirmando também a existência de uma faixa de tolerância por parte da população local. As pessoas envolvidas com turismo são as que acham positivo o desenvolvimento da atividade, mesmo sendo as que sofrem maiores impactos.

Existe uma característica importante em relação ao desenvolvimento turístico pelo qual passa o bairro da Serra. Os atrativos naturais da região trazem os turistas, e a comunidade se empenha em aproveitar essa procura. Apesar da falta de investimentos por parte das Instituições Públicas e da falta de uma política governamental de desenvolvimento, ocorre o crescimento econômico e melhorias das condições de vida. As decisões quanto aos investimentos partem exclusivamente da população, assim como em relação à criação de empreendimentos, e até de atrativos que, apesar da falta de planejamento, fazem com que as decisões sejam tomadas pela própria população, dentro de um modelo local. Os empregadores são moradores e os empregados também. Esta situação é diferente de outras áreas onde as decisões são tomadas do topo para a base, sem envolvimento das populações locais, sem observação de suas necessidades, com mão de obra importada. 
Abaixo é apresentado um quadro com o resumo dos impactos do turismo no bairro da Serra (tabela 3.4.1).

TABELA 3.4.1 - Quadro resumo dos impactos do turismo no bairro da Serra.

\begin{tabular}{|c|c|}
\hline Positivos & Negativos \\
\hline \multicolumn{2}{|l|}{ Impactos Econômicos } \\
\hline $\begin{array}{l}\text { Aumento da oferta de empregos diretos e } \\
\text { indiretos }\end{array}$ & Sazonalidade \\
\hline Melhor distribuição de renda & Evasão de divisas \\
\hline Fixação do homem no campo & Especulação imobiliária \\
\hline $\begin{array}{l}\text { Melhoria da infra-estrutura (coleta de lixo, } \\
\text { comércio) }\end{array}$ & $\begin{array}{l}\text { Expectativa de melhoria das condições } \\
\text { econômicas nem sempre atingida }\end{array}$ \\
\hline \multirow[t]{2}{*}{ Maior arrecadação de impostos } & Alteração dos padrões tradicionais de produção \\
\hline & $\begin{array}{l}\text { Atração de mão de obra de outras localidades } \\
\text { (impacto potencial) }\end{array}$ \\
\hline \multicolumn{2}{|l|}{ Impactos Sócio-Culturais } \\
\hline Interação com outras culturas & Alteração de padrões morais (bebida) \\
\hline Ascensão social & Conflitos sociais entre moradores \\
\hline Lazer & $\begin{array}{l}\text { Doenças de veiculação hídrica devido a falta de } \\
\text { saneamento }\end{array}$ \\
\hline Organização comunitária (ASA) & Estimulo à hábitos de consumo \\
\hline Colocação da mulher no mercado de trabalho & Alteração do padrão familiar patriarcal \\
\hline Envolvimento da população local & $\begin{array}{l}\text { Comportamentos considerados ofensivos por } \\
\text { parte dos turistas (uso de drogas e banhos nus) }\end{array}$ \\
\hline \multicolumn{2}{|l|}{ Impactos ambientais } \\
\hline $\begin{array}{l}\text { Valorização e preservação do meio natural } \\
\text { pela população local e turistas }\end{array}$ & Esgoto \\
\hline \multirow[t]{8}{*}{ Aceitação do PETAR } & Lixo \\
\hline & Desmatamento \\
\hline & Barulho \\
\hline & Afugentamento da fauna \\
\hline & Erosão \\
\hline & Assoreamento de rios \\
\hline & Alteração das características geomorfológicas \\
\hline & Ocupação desordenada \\
\hline
\end{tabular}




\subsubsection{PROPOSTAS PARA O DESENVOLVIMENTO SUSTENTÁVEL DO TURISMO NO BAIRRO DA SERRA}

EMBRATUR (1992) salientou que uma das etapas do processo de desenvolvimento turístico é definir, classificar e ordenar instrumentos específicos de planejamento para se executar o processo. Esses instrumentos são divididos em investimentos de ativo fixo, que correspondem à infraestrutura necessária para viabilizar a atividade turística. Outro instrumento são as políticas gerais de gerenciamento, que correspondem às políticas de créditos, salários, tarifas de transportes, entre outras; e o terceiro instrumento corresponde às ações promotoras do desenvolvimento, que envolvem publicidade, promoção, relações públicas, legislação específica setorial, etc. O programa evidencia algumas proposições a serem observadas como infraestrutura urbana, aproveitamento dos espaços, proposições quanto aos equipamentos turísticos, marketing, organização do setor público, sinalização turística, conselho municipal de turismo e comissões comunitárias de turismo.

As Diretrizes para uma Política Nacional de Ecoturismo (MICT/MMA, s/ data), documento elaborado no final do governo do presidente Itamar Franco, tem como objetivo o desenvolvimento sustentável, propõe uma série de ações para que o ecoturismo se desenvolva de forma articulada e organizada. Essas ações envolvem a regulamentação do ecoturismo, interação interinstitucional, formação e capacitação de recursos humanos, controle de qualidade do produto ecoturístico, gerenciamento de informações, incentivos ao desenvolvimento do ecoturismo, implantação e adequação de infra-estrutura, conscientização e informação do turista e participação comunitária. Os dois documentos apresentam proposições que, de certa forma, são correspondentes, porém, não apresentam soluções. Tem-se o que fazer, mas 
falta a viabilização.

A Carta de Goiás - Agenda Única do Turismo Nacional - Ano 2000, documento elaborado no $1^{\circ}$ Congresso Brasileiro da Atividade Turística (1999), cita que a Política Nacional de Turismo estabelecida pela EMBRATUR não surtiu efeito por não ser implementada e coadjuvada pelos órgãos públicos federais, estaduais, municipais e regionais de turismo. Esta carta cita, ainda, que grandes investimentos são feitos pela iniciativa privada, incentivados por órgãos governamentais, que não obedecem à estratégia de desenvolvimento regional, sem contribuir para diminuição do desnível social e econômico da região onde são implementados. Não obedecem a um programa de desenvolvimento sustentável. A Carta de Goiás apresenta ações e medidas prioritárias para o desenvolvimento turístico no Brasil, com problemas apontados e propostas de viabilização. Esses problemas são comuns a todos os municípios e centros emergentes de turismo.

É fundamental a elaboração de um plano de desenvolvimento turístico para o município de Iporanga e bairro da Serra. Novos atrativos devem ser criados e atividades incrementadas, em vez de serem construídas pousadas que passarão a maior parte do tempo desocupadas. Uma opção é estimular, de forma planejada, o turismo no bairro do Betari. Isso diminuirá a pressão em algumas áreas muito visitadas, como as cavernas do parque, e gerará mais empregos.

Estimular a produção agrícola em pequenas roças, por parte dos moradores, para comercialização com as pousadas, ajudará na manutenção das tradições, fixará o homem no campo, propiciará renda a esses produtores e diversificará a produção. Deve-se utilizar áreas antropizadas, com baixa declividade, obedecendo a legislação ambiental, para implantação dessas roças.

É fundamental o treinamento da população para a gestão do turismo e melhoria dos serviços e instalações, contribuindo para maior satisfação do turista e arrecadação dos empreendedores. 
Devem ser feitos investimentos em meios de transporte e estradas, assim como num sistema de saúde mais eficiente e até mais próximo do bairro da Serra. É necessário implantar um sistema de coleta e tratamento de esgoto, antes que os cursos de água estejam comprometidos. Cada residência deve possuir sua fossa séptica, e pousadas com maior número de leitos podem investir em pequenos sistemas de tratamento de esgoto.

A população deve ser ouvida para que suas necessidades sejam atingidas, mesmo porque trata-se de uma comunidade particular, de certa forma fechada, e imposições dificilmente seriam aceitas.

Tudo isso contribuirá para melhoria das condições de vida dos moradores do bairro e preservação ambiental, e garantirá a sustentabilidade da atividade e do ambiente. Segundo HALL (2001), o planejamento turístico não se refere apenas ao desenvolvimento do setor, mas também à promoção de melhoria ou maximização econômica, social e ambiental.

Para que a região se desenvolva de modo sustentável, uma série de ações devem ser implementadas, como sugerido nos quadros que seguem. 


\section{Ações e responsabilidades necessárias para o desenvolvimento sustentável do bairro da Serra}

INFRA-ESTRUTURA

\begin{tabular}{|l|l|l|l|}
\hline Ação & Responsabilidade & Objetivo & Efeito \\
\hline Melhoria dos acessos & $\begin{array}{l}\text { Governos Estadual e } \\
\text { municipal }\end{array}$ & $\begin{array}{l}\text { Facilitar os acessos } \\
\text { para turistas e } \\
\text { população residente }\end{array}$ & $\begin{array}{l}\text { Aumento da demanda, } \\
\text { diminuição da } \\
\text { sazonalidade }\end{array}$ \\
\hline Tratamento de Esgoto & $\begin{array}{l}\text { Governos Estadual e } \\
\text { Municipal e iniciativa } \\
\text { privada }\end{array}$ & $\begin{array}{l}\text { Minimizar impactos } \\
\text { ambientais }\end{array}$ & $\begin{array}{l}\text { Proteção dos corpos } \\
\text { d'água }\end{array}$ \\
\hline $\begin{array}{l}\text { Hospital ou } \\
\text { Ambulatório }\end{array}$ & $\begin{array}{l}\text { Governos Estadual e } \\
\text { Municipal }\end{array}$ & $\begin{array}{l}\text { Atendimento à } \\
\text { população local e } \\
\text { turistas }\end{array}$ & $\begin{array}{l}\text { Melhoria das } \\
\text { condições de vida }\end{array}$ \\
\hline $\begin{array}{l}\text { Programa de coleta } \\
\text { seletiva }\end{array}$ & $\begin{array}{l}\text { Governo Municipal, } \\
\text { iniciativa privada e } \\
\text { comunidade }\end{array}$ & $\begin{array}{l}\text { Minimizar impactos } \\
\text { ambientais }\end{array}$ & $\begin{array}{l}\text { Proteção dos corpos } \\
\text { d'água e do solo }\end{array}$ \\
\hline Área de Lazer & Governo Municipal & Atender população & Fixação da população \\
\hline $\begin{array}{l}\text { Desenvolvimento } \\
\text { turístico de outros } \\
\text { bairros do município }\end{array}$ & $\begin{array}{l}\text { Governo municipal e } \\
\text { iniciativa privada }\end{array}$ & $\begin{array}{l}\text { Dispersar o turista para } \\
\text { novos atrativos }\end{array}$ & $\begin{array}{l}\text { Diminuição dos } \\
\text { impactos no bairro da } \\
\text { Serra e melhoria das } \\
\text { condições de vida de } \\
\text { outras áreas }\end{array}$ \\
\hline $\begin{array}{l}\text { Melhoria das } \\
\text { Telecomunicações }\end{array}$ & Iniciativa privada & $\begin{array}{l}\text { Atender população e } \\
\text { demanda turística }\end{array}$ & $\begin{array}{l}\text { Facilidade de } \\
\text { comunicação }\end{array}$ \\
\hline
\end{tabular}

\section{RECURSOS HUMANOS}

\begin{tabular}{|l|l|l|l|}
\hline Ação & Responsabilidade & Objetivo & Efeitos \\
\hline $\begin{array}{l}\text { Treinamento em } \\
\text { Hospedagem e } \\
\text { Hotelaria }\end{array}$ & $\begin{array}{l}\text { Governo Municipal e } \\
\text { iniciativa privada }\end{array}$ & $\begin{array}{l}\text { Melhorar atendimento } \\
\text { e eficiência }\end{array}$ & Aumento da demanda \\
\hline $\begin{array}{l}\text { Educação para o } \\
\text { turismo (formal e não } \\
\text { formal) }\end{array}$ & $\begin{array}{l}\text { Governo Municipal } \\
\text { (Secretaria da } \\
\text { Educação) e iniciativa } \\
\text { privada }\end{array}$ & $\begin{array}{l}\text { Conscientizar os jovens } \\
\text { sobre a importância e } \\
\text { conseqüiências do } \\
\text { turismo }\end{array}$ & $\begin{array}{l}\text { Melhor entendimento } \\
\text { entre população } \\
\text { residente e turista; } \\
\text { minimizar impactos }\end{array}$ \\
\hline Criar Central de Guias & $\begin{array}{l}\text { ASA (Associação } \\
\text { Serrana Ambientalista) }\end{array}$ & $\begin{array}{l}\text { Melhor distribuição de } \\
\text { trabalho }\end{array}$ & $\begin{array}{l}\text { Melhor distribuição de } \\
\text { renda e geração de } \\
\text { novos empregos }\end{array}$ \\
\hline
\end{tabular}


ASPECTOS LEGAIS

\begin{tabular}{|l|l|l|l|}
\hline Ação & Responsabilidade & Objetivos & Efeitos \\
\hline $\begin{array}{l}\text { Legalização das } \\
\text { empresas }\end{array}$ & Governo Municipal & $\begin{array}{l}\text { Regularizar o } \\
\text { funcionamento dos } \\
\text { equipamentos }\end{array}$ & $\begin{array}{l}\text { Melhorar condições de } \\
\text { atendimento e } \\
\text { arrecadação de recursos }\end{array}$ \\
\hline $\begin{array}{l}\text { Criação das Leis } \\
\text { Municipais de Turismo }\end{array}$ & $\begin{array}{l}\text { Governo Municipal e } \\
\text { comunidade }\end{array}$ & $\begin{array}{l}\text { Regularizar a atividade } \\
\text { turística no município }\end{array}$ & $\begin{array}{l}\text { Normatizar atividade, } \\
\text { a fiscalização e } \\
\text { responsabilidades, de } \\
\text { acordo com a realidade } \\
\text { local }\end{array}$ \\
\hline Vigilância Sanitária & $\begin{array}{l}\text { Governo Municipal e } \\
\text { Estadual }\end{array}$ & $\begin{array}{l}\text { Regularizar o } \\
\text { atendimento para } \\
\text { alimentação }\end{array}$ & $\begin{array}{l}\text { Melhorar condições de } \\
\text { atendimento }\end{array}$ \\
\hline $\begin{array}{l}\text { Fiscalização e controle } \\
\text { de uso e ocupação do } \\
\text { solo }\end{array}$ & $\begin{array}{l}\text { Governos Estadual e } \\
\text { Municipal }\end{array}$ & $\begin{array}{l}\text { Evitar degradação } \\
\text { ambiental e criar } \\
\text { critérios de urbanização }\end{array}$ & $\begin{array}{l}\text { Manutenção das } \\
\text { condições ambientais e } \\
\text { desenvolvimento } \\
\text { urbano planejado }\end{array}$ \\
\hline $\begin{array}{l}\text { Aplicação da Agenda } \\
21 \text { para o Vale do } \\
\text { Ribeira }\end{array}$ & Todos os setores & $\begin{array}{l}\text { Desenvolvimento } \\
\text { sustentável da região }\end{array}$ & $\begin{array}{l}\text { Proteção ambiental, } \\
\text { desenvolvimento social } \\
\text { e econômico }\end{array}$ \\
\hline $\begin{array}{l}\text { Regularização } \\
\text { fundiária }\end{array}$ & Governo Estadual & $\begin{array}{l}\text { Regularizar } \\
\text { propriedades e } \\
\text { demarcação do parque }\end{array}$ & $\begin{array}{l}\text { Legalizar posses e } \\
\text { evitar conflitos de uso } \\
\text { da terra }\end{array}$ \\
\hline
\end{tabular}

\section{TURISMO}

\begin{tabular}{|l|l|l|l|}
\hline Ação & Responsabilidade & Objetivos & Efeitos \\
\hline $\begin{array}{l}\text { Criação de novos } \\
\text { atrativos }\end{array}$ & $\begin{array}{l}\text { Iniciativa privada e } \\
\text { Governo Municipal }\end{array}$ & Diversificar atrativos & $\begin{array}{l}\text { Diminuir pressão de } \\
\text { visitação em alguma } \\
\text { áreas, aumento renda }\end{array}$ \\
\hline $\begin{array}{l}\text { Adequação dos meios } \\
\text { de hospedagem }\end{array}$ & Iniciativa privada & $\begin{array}{l}\text { Melhoria das condições } \\
\text { de hospedagem }\end{array}$ & $\begin{array}{l}\text { Aumento de opções de } \\
\text { hospedagem e } \\
\text { satisfação dos turistas }\end{array}$ \\
\hline $\begin{array}{l}\text { Elaboração de } \\
\text { diretrizes }\end{array}$ & $\begin{array}{l}\text { Iniciativa privada e } \\
\text { Governo Municipal }\end{array}$ & Minimizar impactos & $\begin{array}{l}\text { Auxilia turista e } \\
\text { diminui impactos }\end{array}$ \\
\hline $\begin{array}{l}\text { Recomposição da mata } \\
\text { ciliar }\end{array}$ & Todos os setores & $\begin{array}{l}\text { Restauração das } \\
\text { características } \\
\text { ecológicas }\end{array}$ & $\begin{array}{l}\text { Manutenção da } \\
\text { integridade dos } \\
\text { ecossistemas aquáticos }\end{array}$ \\
\hline
\end{tabular}




\subsection{SUMÁRIO}

A atividade turística gera impacto econômico positivo no bairro da Serra. O número de meios de hospedagem aumentou nos últimos anos, e a maioria dos empregos da população do bairro esta ligada à atividade do turismo. Existe expectativa da geração de mais empregos e renda, e é por isso que a população vê o turismo positivamente. Os empregos, principalmente como guia, favorecem a fixação dos jovens no bairro. As mulheres estão trabalhando nas pousadas, e isso pode gerar conflitos familiares. Modificações na renda de moradores têm gerado divisão social, outro fator gerador de conflitos, uma vez que, a maior parte da população do bairro não tem perspectivas de ascensão social.

O crescimento do turismo propiciou lazer para a população residente, já que equipamentos e serviços (bares) podem ser utilizados pela comunidade local. Por outro lado, novos hábitos de consumo foram inseridos (loja).

Como o turismo é visto positivamente e o PETAR é o principal atrativo, o parque também é aceito hoje, fato que não ocorreu quando de sua implantação. A população pode estar passando por uma fase de euforia em relação ao turismo devido aos impactos econômicos. O crescimento do turismo pode comprometer a qualidade dos sistemas hídricos pela falta de tratamento de esgoto.

O planejamento turístico da área é fundamental para manutenção da qualidade ambiental e melhoria das condições de vida da população local. São necessárias ações em relação à infra-estrutura, recursos humanos, atividade turística e aspectos legais para garantir o desenvolvimento sustentável da região com a atividade turística. 


\subsection{REFERÊNCIAS BIBLIOGRÁFICAS}

ARCHER, B. \& COOPER, C., 2001. Os Impactos positivos e negativos do

Turismo. In Turismo Global, Theobald, W. F., organizador. Editora SENAC, São Paulo, $85-102$ p.

ASCANIO. A, 1994. Impacto del turista no residente en la economia local.

Estudios e Perspectivas en Turismo. V 3, n 2, p115- 125.

BENI, M.C., 2000. Política e estratégia do desenvolvimento regional Planejamento integrado e sustentável do turismo. IN: LAGE, B.H.G. \& MILONE, P.C. (org.) Turismo: Teoria e Prática. São Paulo, Atlas. Parte V-15, p. 165-171.

BONDUKI, M. I., 1997. O turismo como agente transformador do Bairro da Serra - Iporanga - SP. Trabalho de Conclusão de Curso, ECA - USP, p. 77.

CALVENTE, M.C.M.H., 1996. Impactos do turismo sobre comunidades de llha Bela. In Turismo: Impactos sócio-ambientais. Lemos, A ., I. G., org.. Editora Hucitec, São Paulo, 85-92 p.

CAMPOS, A.C.E., 1990. Bairro da Serra - diretrizes para crescimento e participação comunitária. Trabalho de Conclusão de Curso, Faculdade de Arquitetura e Urbanismo, USP, São Paulo. 63 p.

CAROSO, C. \& RODRIGUES, N., 1998. Nativos, veranistas e turistas: Identidades, mudança e deslocamento sociocultural no litoral norte da Bahia. Turismo em análise. $\vee 9, n$ 1, p $61-75$.

CARTA DE GOIÁS - AGENDA ÚNICA DO TURISMO NACIONAL,1999. 1ำ Congresso Brasileiro da Atividade Turística, Goiás, p. 40.

DE BLASIS, P. A. D., 1996. Bairro da Serra em três tempos: arqueologia, uso do espaço regional e continuidade cultural no médio vale do 
Ribeira. Tese de Doutoramento, Universidade de São Paulo, Faculdade de Filosofia, Letras e Ciências Humanas, 166p.

DIEGUES, A. C. S. \& NOGARA, P. J., 1994. O nosso lugar virou parque: estudo sócio-ambiental do Saco do Mamanguá-Parati-Rio de Janeiro., São Paulo, NUPAUB/USP, p. 184.

DIEGUES, A. C., 1998. A questão sociocultural nas áreas protegidas. Os conflitos sociais gerados pelo modelo tradicional de conservação. Debates Sócio Ambientais. V 3, n 9. p 6-8.

DIEGUES, A.C., 1996. O mito moderno da natureza intocada. Editora Hucitec, São Paulo, p. 169.

DIEGUES, A.C., 1997. As áreas naturais protegidas , o turismo e as populações tradicionais. In Viagens à natureza. Serrano, C.M.T. \& Bruhns, H.T. (orgs.). Papirus Editora, Campinas, p. $85-102$.

EAA - ECOTOURISM ASSOCIATION OF AUSTRALIA, 1998. Code of practice for ecotourism operators.

URL:

http://bigvolcano.com.au/ercentre/eaacode.html, 10/03/98.

EMBRATUR - INSTITUTO BRASILEIRO DE TURISMO, 1992. Município: Potencial turístico. $80 \mathrm{p}$.

HALL, C. M., 2001. Planejamento turístico: políticas, processos e relacionamentos. São Paulo, Editora Contexto. p. 296.

IBGE, 2001. Iporanga - $\quad$ SP. $\quad$ CIDADES@,. URL: http://www.censo.gov.br/cidadesat/defoult.php. 19/11/2001

LINDBERG, K. \& HAWKINS, D.E. (eds.), 1995. Ecoturismo: um guia para planejamento e gestão. São Paulo, Editora SENAC.

MAGRO, T.C., 1999. Impactos do uso público em uma trilha no planalto do Parque Nacional de Itatiaia.Tese de Doutorado, Escola de Engenharia de São Carlos - USP, São Carlos, 135 p. 
MATHIESON, A . \& WALL, G., 1988. Tourism - Economic, physical and social impacts. Nova lorque, Longman.

MATTAR, F.N., 1996. Pesquisa de Marketing. Editora Atlas S.A., São Paulo.

MAUREIRA, C. G., 1998. Estúdio Del impacto turístico-inmobiliario en el borde costero de Coquimbo y La Serena, Chile. Turismo em análise. V 9, n 2, p $88-106$.

MCCOOL, S.F., 2001. Linking tourism, the environment and concepts of sustainability: setting the stage. URL: http://www.ecotourism.org/textfiles/mccool.txt. 10/04/2001.

MICT - MINISTÉRIO DA INDÚSTRIA, DO COMÉRCIO E DO TURISMO/MMA MINISTÉRIO DO MEIO AMBIENTE, DOS RECURSOS HÍDRICOS E DA AMAZÔNIA LEGAL, sem data. Diretrizes para uma política nacional de ecoturismo. EMBRATUR/IBAMA, Brasília-DF.

PATA - PACIFIC ASIA TRAVEL ASSOCIATION,1998. The PATA code for environmentally responsible tourism

URL: http://pata.org/greenleaf/code.html, 02/04/98.

PÉREZ, A ., 1999. Impactos turísticos. Su percepción por parte de la población anfitriona. Caso Villa la Angostura (Argentina). Estudios e Perspectiva en Turismo. V 8, p $5-23$.

PIRES, P. S., 2000. O que é ecoturismo: em busca de uma resposta pela via da abordagem conceitual. Turismo e Ação, v 6, p 119 - 128.

PRESVELOU, C., 2000. Ações inovadoras em turismo rural. In Turismo rural e desenvolvimento sustentável. Almeida, J.A ., Froehlich, J.M. \& Riedl, M. (orgs.), Papirus Editora, Campinas, 143 - $162 \mathrm{p}$.

RODRIGUES, A. M., 1997. Desenvolvimento sustentável e atividade turística. In Turismo e desenvolvimento local. Rodrigues, A. B., organizadora. Editora Hucitec, São Paulo, 42 - 54 p. 
ROSS, R. \& WALL, G., 1999. Ecotourism: towards congruence between theory and practice. Tourism Management, v 20: $123-132$.

ROSSI, P.R., 1996. O estudo da demanda real no Núcleo Santana (Parque Estadual Turístico Alto Ribeira. Identificação das possíveis causas para o aparecimento do fluxo do turismo não operacionalizado. Trabalho de Conclusão de Curso. Faculdade Ibero-Americana de Ciências Humanas. São Paulo, 192 p.

RUSCHMANN, D.v.d.M., 1997. Turismo e desenvolvimento sustentável. A proteção do meio ambiente. Papirus Editora, Campinas

SACHS, I., 1994. Estratégias de transição para o século XXI. In: BURSZTYN, Marcel,(org.). Para pensar o desenvolvimento sustentável. São Paulo: Brasiliense, p 29 -56.

SCHLÜTER, R.G. (1999) Impactos del turismo em zonas costeras. Rol de los faros em la preservaciónn del ambiente. Estudios y perspectivas em turismo. V. 8 , n. 1., p. 24-56.

SILVEIRA, P.C.B., 1998. O Bairro da Serra e a questão ambiental: modos de ver e agir no Vale do Ribeira - SP. Relatório Final FAPESP, Processo 97/14513-5. São Paulo, 59 p.

SWARBROOK, J., 2000. Turismo sustentável: conceitos e impacto ambiental. Vol. 1., Editora Aleph, São Paulo, 140 p.

THE ECOTOURISM SOCIETY, 1997. Ecotourism guidelines for nature tours operators. URL: http://www.ecotourism.org/initsfr.html, 02/05/97

TWINING-WARD, L., 1999. Towards sustainable tourism development; observations from a distance. Tourism Management, Vol. 8; p 187 -188.

VEIGA, J. E. R. \& ROMÃO. D. A ., 1998. O Ecoturismo como estratégia de desenvolvimento regional. In Turismo e Meio Ambiente. Vasconcelos, F. P. (org.). Vol 3, Fortaleza, $169-185$ p. 
WWF - WORLD WILDLIFE FOUND. Ecoturismo em Silves. URL: http://www.wwf.org.br/wwfpr16.htm. 14/05/99.

ZIMMERMANN, A ., 2000. Planejamento e organização do turismo rural no Brasil. In Turismo rural e desenvolvimento sustentável. Almeida, J.A ., Froehlich, J.M. \& Riedl, M. (orgs.), Papirus Editora, Campinas, 127 - 142 p. 


\section{CONCLUSÕES}

A bacia hidrográfica do rio Betari está localizada numa das áreas mais pobres do estado de São Paulo e do Brasil. Durante anos a precariedade de acessos e a falta de investimentos na região, fizeram com que ela se mantivesse isolada e, assim, não passou pelos processos desenvolvimentistas que outras regiões sofreram. As roças eram as atividades antrópicas mais impactantes. As características primitivas da região onde está inserida a bacia fizeram-na muito importante para preservação do que restou de Mata Atlântica no estado de São Paulo.

Por outro lado, a vocação minerária da bacia trouxe algum desenvolvimento e também novas interferências nos sistemas ecológicos regionais. O rio Betari tornou-se o canal de transporte de metais pesados, provenientes das minerações, para o rio Ribeira de Iguape, e daí para seu estuário.

A implantação do PETAR, além de interferir no desenvolvimento da atividade minerária, entendido pela população como meio de crescimento econômico para região, também interferiu nos processos produtivos tradicionais, na roça e no uso da terra.

O conflito gerado parece ter amainado recentemente, com a possibilidade de desenvolvimento econômico propiciado pelo turismo. Assim, a conservação do meio natural e a presença do PETAR passaram a ser valorizados, mas novos problemas se instalaram ou podem vir ocorrer, mesmo que ainda não sejam percebidos pela população local.

O grande número de visitantes que se hospedam no bairro da Serra geram impactos econômicos positivos, que estimulam um crescimento sem planejamento. Esse crescimento já se reflete no meio social, como foi evidenciado pelos impactos sócio-culturais observados e ainda pode causar danos aos sistemas ecológicos, como o rio Betari, o que comprometeria um dos principais atrativos da região. 
Por outro lado, o turismo parece ser a vocação da área. As grandes declividades e as áreas protegidas, com os remanescentes da Mata Atlântica, fazem do turismo a atividade mais adequada para o desenvolvimento sustentável regional. Torna-se necessário um plano de desenvolvimento, com estabelecimento das capacidades de cargas para os diversos atrativos e para os sistemas sociais e ecológicos. É necessário implantar um sistema de tratamento adequado de esgotos e orientar a população sobre a importância da manutenção das características ecológicas da bacia hidrográfica do rio Betari.

O meio natural parece não ter sido afetado ainda. A área desmatada nos últimos 14 anos, que abrange o período desse novo agente de desenvolvimento, foi pequena, quando comparada a outras regiões. O rio Betari apresenta, ainda, águas de boa qualidade, que são influenciadas pelo carste regional e pela cobertura vegetal, exceto pelas concentrações de chumbo e zinco herança deixada pelas mineradoras (o rejeito exposto). Mas alguns parâmetros podem ser indicativos de mudanças, como o aumento de sólidos em suspensão e coliformes fecais, observados a jusante do bairro da Serra, reflexo da ocupação humana e do desmatamento de algumas áreas. A divisão do rio em 3 regiões, como os dados sugerem, podem ser respostas a processos naturais (geológicos, geomorfológicos e biológicos) do sistema, mas também pode ser influenciada pela ocupação no trecho médio e baixo do curso do rio.

O planejamento do turismo para a região é fundamental para manter sua atual integridade. É necessário envolver a população local nesse processo, para que eles identifiquem os problemas e partilhem soluções. Só assim os planos e programas para desenvolvimento sustentável serão aceitos. 


\section{ANEXO I}

Questionário utilizado nas entrevistas.

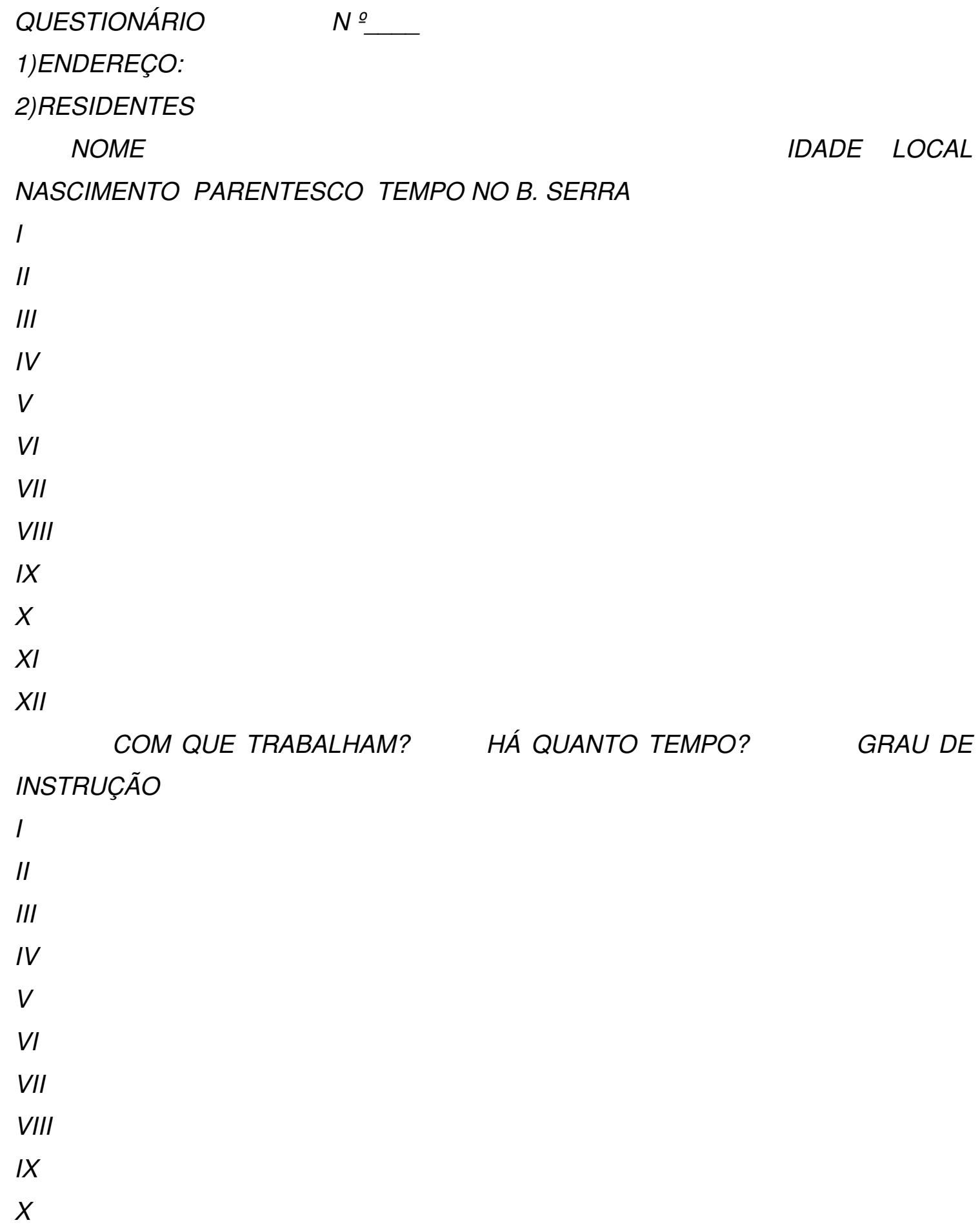


$X I I$

4) SE ALGUÉM É GUIA OU MONITOR, QUAL A FREQÜÊNCIA DE TRABALHO? QUANTOS ?

- TODOS FINS DE SEMANA

- UMA VEZ POR SEMANA

- DUAS VEZES POR SEMANA

- NO MEIO DA SEMANA

- UMA VEZ POR MÊS

- DUAS VEZES POR MÊS

- FÉRIAS

- ESPORADICAMENTE

5)ALGUÉM DA RESIDÊNCIA GOSTARIA DE SER GUIA OU MONITOR? SIM NÃO PORQUE?

6) ANTERIORMENTE ALGUÉM DA RESIDÊNCIA JÁ TRABALHOU COM TURISMO? FUNCIONÁRIO DO PARQUE COMÉRCIO FUNCIONÁRIO DE POUSADA OU CAMPING ALUGUEL DE EQUIPAMENTOS MONITOR OU GUIA DONO DE POUSADA OU CAMPING POR QUE PAROU? 7) HOSPEDA TURISTAS EM QUARTOS, CHALÉS OU CAMPING? SIM NÃO (PULE PARA QUESTÃO 16)

8) SE SIM COM QUE FREQÜÊNCIA?

9) QUANTOS HÓSPEDES PODE RECEBER?

10) QUANTOS HÓSPEDES COSTUMA RECEBER?

11) QUANDO TRABALHA COM CAPACIDADE MÁXIMA?

FINS DE SEMANA

FERIADOS

FÉRIAS DE VERÃO FÉRIAS DE INVERNO 
DURANTE A SEMANA

RARAMENTE FICA CHEIO

12) QUAL O NÚMERO DE HÓSPEDES QUE RECEBE POR MÊS?

13) OS HOSPEDES SÃO NA MAIORIA?

GRUPOS PEQUENOS

CASAIS

UMA PESSOA

EXCURSÕES

14)QUAL TEMPO MÉDIO DE PERMANÊNCIA?

2 DIAS

3 DIAS

4 DIAS

5 DIAS

7 DIAS

10 DIAS

MAIS DE 10 DIAS

15) OFERECE REFEIÇÕES?

CAFÉ DA MANHÃ

ALMOÇO

JANTAR

LANCHE PARA PASSEIO

16) SE NÃO, GOSTARIA DE HOSPEDAR?

SIM NÃO PORQUE?

17) RESIDÊNCIA PRÓPRIA? SIM NÃO

18) SE NÃO, JÁ TEVE CASA PRÓPIA OU TERRENO NO BAIRRO DA SERRA OU

EM IPORANGA? SIM NÃO

19) SE SIM PODE DIZER POR QUE VENDEU?

20) O QUE É FEITO COM LIXO?

ENTERRADO

QUEIMADO

DISPOSTA EM QUALQUER LOCAL 
COLETA PÚBLICA

COLETA SELETIVA

COMPOSTAGEM

ALIMENTAÇÃO ANIMAL

OUTROS OQUE?

21) E O ESGOTO?

FOSSA NEGRA

FOSSA SÉPTICA

COLETA PÚBLICA

LANÇADO EM RIO

OUTROS OQUE?

22) VOCE GOSTA DO TURISMO OU DA PRESENÇA DE TURISTAS?

SIM NÃO PORQUE?

23) NA SUA OPINIÃO O TURISMO TRÁS BENEFÍCIOS PARA REGIÃO SIM NÃO PORQUE?

24) NA SUA OPINIÃO O TURISMO PROVOCOU OU PROVOCA MODIFICAÇÕES NO MEIO AMBIENTE

SIM NÃO QUAIS?

25) A PRESENÇA DE TURISTA MODIFICA SEU MODO DE VIDA OU COMPORTAMENTO?

SIM NÃO PORQUE?

26) E NAS OUTRAS PESSOAS DO BAIRRO?

SIM NÃO PORQUE?

27) QUAIS DAS INFRA-ESTRUTURAS QUE VOCÊ UTILIZA EM COMUM COM TURISTAS?

$B A R J J$

BAR SATURNINO

PASTELARIA

PARQUE

VENDA/MERCEARIA

POSTO TELEFÔNICO 
OUTROS QUAIS?

28) VOCÊ GOSTA DO PETAR?

SIM NÃO PORQUE?

29) QUAL A ORIGEM DA ÁGUA CONSUMIDA PELOS RESIDENTES?

REDE PÚBLICA

$P O C ̧ O$

POÇO ARTEZIANO

CÓRREGO OU RIO

NASCENTE

OUTROS QUAIS?

30) QUAL ORIGEM DA ÁGUA UTILIZADA PARA ANIMAIS/AGRICULTURA?

REDE PÚBLICA

$P O C ̧ O$

POÇO ARTEZIANO

CÓRREGO OU RIO

NASCENTE

OUTROS QUAIS?

31) COMO AS PESSOAS DA RESIDÊNCIA SE DIVERTEM?

FORRÓ

\section{PASSEIOS NA MATA}

PASSEIOS NO PARQUE

APIAÍ

IPORANGA

OUTROS? QUAIS?

32) O QUE É NECESSÁRIO PARA MELHORAR A VIDA DAS PESSOAS NO BAIRRO DO SERRA?

33) QUAIS E QUANTOS ÍTENS ABAIXO POSSUI?

TV

RÁDIO

VÍDEO CASSETES

AUTOMÓVEL
QUANTOS?

QUANTOS?

QUANTOS?

QUANTOS? 
BANHEIRO

GELADEIRA

MÁQUINA DE LAVAR

ASPIRADOR DE PÓ

EMPREGADA MENSALISTA? QUANTAS?

34) PARTICIPA DA ASA OU DE OUTRAS ASSOCIAÇÕES?

$S I M$
QUANTOS?

QUANTOS

QUANTAS? QUANTOS?

POR QUE? 